

\section{Narrating Nonhuman Spaces}

Recent debates about the Anthropocene have prompted a re-negotiation of the relationship between human subjectivity and nonhuman matter within a wide range of disciplines. This collection builds on the assumption that our understanding of the nonhuman world is bound up with the experience of space: thinking about and with nonhuman spaces destabilizes human-scale assumptions. Literary form affords this kind of nonanthropocentric experience; one role of the critic in the Anthropocene is to foreground the function of space and description in challenging the conventional link between narrative and human (inter)subjectivity. Bringing together New Formalism, ecocriticism, and narrative theory, the included essays demonstrate that literature can transgress the strong and long-established boundary of the human frame that literary and narrative scholarship clings to. The focus is firmly on the contemporary but with strategic samplings in earlier cultural texts (the American transcendentalists, modernist fiction) that anticipate present-day anxieties about the nonhuman, while at the same time offering important conceptual tools for working through them.

Marco Caracciolo is Associate Professor of English and Literary Theory at Ghent University in Belgium, where he leads the ERC Starting Grant project "Narrating the Mesh." Marco's work explores the phenomenology of narrative or the structure of the experiences afforded by literary fiction and other narrative media. He is the author of five books, including most recently Narrating the Mesh: Form and Story in the Anthropocene (2021).

Marlene Karlsson Marcussen holds a $\mathrm{PhD}$ in comparative literature from the University of Southern Denmark, where she currently is a scientific assistant. She is the co-editor of How Literature Comes to Matter: Post-Anthropocentric Approaches to Fiction (2021) and has published a number of publications on modernism, materiality, and space such as "The Postapocalyptic Motherhood" (2019) and "The Abundance of Things in the Midst of Writing: A Post-Anthropocentric View on Description and Georges Perec's 'Still Life/Style Leaf'” (2021).

David Rodriguez is a postdoctoral researcher. He holds a PhD in English from Stony Brook University. His dissertation, Spaces of Indeterminacy: Aerial Description and Environmental Imagination in 20th Century American Fiction, studies images of the environment in the novels of Willa Cather, Paul Bowles, and Don DeLillo. He has written further about the phenomenology of reading descriptions of the view from above in Frontiers of Narrative Studies and econarratology in English Studies. 


\section{Routledge Studies in World Literatures and the Environment}

Series Editors: Scott Slovic and Swarnalatha Rangarajan

Titles include:

Packing Death in Australian Literature

Ecocides and Eco-Sides

Iris Ralph

Climate Change, Ecological Catastrophe, and the Contemporary

Postcolonial Novel

Justyna Poray-Wybranowska

\section{Mushroom Clouds}

Ecocritical Approaches to Militarization and the Environment in East Asia Edited by Simon C. Estok, Iping Liang, and Shinji Iwamasa

Dystopias and Utopias on Earth and Beyond

Feminist Ecocriticism of Science Fiction

Edited by Douglas A. Vakoch

Ecofeminist Science Fiction

International Perspectives on Gender, Ecology, and Literature

Edited by Douglas A. Vakoch

Surreal Entanglements

Essays on Jeff VanderMeer's Fiction

Edited by Louise Economides and Laura Shackelford

Narrating Nonhuman Spaces

Form, Story, and Experience Beyond Anthropocentrism

Edited by Marco Caracciolo, Marlene Karlsson Marcussen, and

David Rodriguez

The Tree of Life and Arboreal Aesthetics in Early Modern Literature Victoria Bladen

For more information about this series, please visit: https://www.routledg e.com/Routledge-Studies-in-World-Literatures-and-the-Environment/bookseries/ASHER4038 


\section{Narrating Nonhuman Spaces}

Form, Story, and Experience Beyond Anthropocentrism

Edited byMarco Caracciolo, Marlene Karlsson Marcussen, and David Rodriguez 
First published 2022

by Routledge

605 Third Avenue, New York, NY 10158

and by Routledge

2 Park Square, Milton Park, Abingdon, Oxon, OX14 4RN

Routledge is an imprint of the Taylor \& Francis Group, an informa business

(C) 2022 selection and editorial matter, Marco Caracciolo, Marlene Karlsson Marcussen, and David Rodriguez; individual chapters, the contributors

The right of Marco Caracciolo, Marlene Karlsson Marcussen, and David Rodriguez to be identified as the authors of the editorial material, and of the authors for their individual chapters, has been asserted in accordance with sections 77 and 78 of the Copyright, Designs and Patents Act 1988.

The Open Access version of this book, available at www. taylorfrancis.com, has been made available under a Creative Commons Attribution-Non Commercial-No Derivatives 4.0 license.

Trademark notice: Product or corporate names may be trademarks or registered trademarks and are used only for identification and explanation without intent to infringe.

Library of Congress Cataloging-in-Publication Data

A catalog record for this title has been requested

ISBN: 978-1-032-02101-0 (hbk)

ISBN: 978-1-032-02104-1 (pbk)

ISBN: 978-1-003-18186-6 (ebk)

DOI: $10.4324 / 9781003181866$

Typeset in Sabon

by Deanta Global Publishing Services, Chennai, India 


\section{Contents}

List of Contributors vii

Acknowledgements $\quad \mathrm{x}$

Introduction 1

MARCO CARACCIOLO, MARLENE KARLSSON MARCUSSEN, AND DAVID RODRIGUEZ

\section{PART I}

Objects and the Resources of Description

1 Containment and Empathy in Katherine Mansfield's and Virginia Woolf's Short Stories

LAURA OULANNE

2 Floating Air-Solid Furniture: Vibrant Spaces in Virginia Woolf's “Time Passes”

MARLENE KARLSSON MARCUSSEN

3 The Descriptive Turn in German Nature-Oriented Neue Sachlichkeit (1913-1933): An Essay on Nonhuman Literary Genres

MICHAEL KARLSSON PEDERSEN

PART II

Catastrophic Narrative Environments

4 Nonhuman Presence and Ontological Instability in Twenty-First-Century New York Fiction 
vi Contents

5 Seasonal Feelings: Reading Paolo Bacigalupi's The

Windup Girl During Winter Depression

KAISA KORTEKALLIO

6 Imagining Posthuman Environments in the Anthropocene: The Function of Space in PostApocalyptic Climate Change Fiction CAROLIN GEBAUER

7 "It Wants to Become Real and Can Only Become Prose": Anthropocenic Focalization in 10:04 and The World Without Us

DAVID RODRIGUEZ

PART III

Scales and Limits of Narrative

8 Maarit Verronen's Monomaniacs of the Anthropocene: Scaling the Nonhuman in Contemporary Finnish Fiction SARIANNA KANKKUNEN

9 Plotting the Nonhuman: The Geometry of Desire in Contemporary "Lab Lit" MARCO CARACCIOLO

10 Lithic Space-Time in Lyric: Narrating the Poetic Anthropocene BRIAN J. MCALLISTER

11 Narrating the "Great Outdoors" 201 RIDVAN ASKIN

12 Inside the Great Outdoors: A Complete and Unabridged Guide: With Travelogue, Bestiary, Judgement LINE HENRIKSEN

Index 


\section{Contributors}

Lieven Ameel is senior lecturer in comparative literature at Tampere University, Finland. He holds a PhD in Finnish literature and comparative literature from the University of Helsinki and the Justus Liebig University, Giessen, Germany. He has published widely on literary experiences of the city, narrative planning, and urban futures. His books include Helsinki in Early Twentieth-Century Literature (2014), The Narrative Turn in Urban Planning (2020), and the co-edited volumes Literature and the Peripheral City (2015), Literary Second Cities (2017), The Materiality of Literary Narratives in Urban History (2019), and Literatures of Urban Possibility (2021).

Ridvan Askin is a postdoctoral teaching and research fellow in North American and General Literature at the University of Basel. He is the author of Narrative and Becoming (Edinburgh University Press, 2016), which elaborates a transcendental empiricist concept of narrative arguing for an understanding of narrative as fundamentally nonhuman instead of human, unconscious instead of correlated to consciousness, and expressive instead of representational. He is also the co-editor of several essay collections, including most recently New Directions in Philosophy and Literature (Edinburgh University Press, 2019) and The Aesthetics, Poetics, and Rhetoric of Soccer (Routledge, 2018).

Marco Caracciolo is Associate Professor of English and Literary Theory at Ghent University in Belgium, where he leads the ERC Starting Grant project "Narrating the Mesh." Marco's work explores the phenomenology of narrative, or the structure of the experiences afforded by literary fiction and other narrative media. He is the author of five books, including most recently Narrating the Mesh: Form and Story in the Anthropocene (University of Virginia Press, 2021).

Carolin Gebauer is a postdoctoral researcher at the Department of English and American Studies at the University of Wuppertal, Germany. She is part of the Horizon 2020 project OPPORTUNITIES, which explores narratives on migration in the public sphere. She is currently working 
on a book on the cultural history of the representation of mobility in verbal and audiovisual narrative. Carolin is the author of the monograph Making Time: World Construction in the Present-Tense Novel (De Gruyter, 2021) and a member of the executive team of DIEGESIS, a bilingual interdisciplinary e-journal dedicated to narrative research.

Line Henriksen is a postdoctoral researcher at the IT University of Copenhagen, and affiliated with the Technologies in Practice research group. She holds a PhD in Gender Studies from Linköping University, and an MA in Modern Culture and Cultural Communication from the University of Copenhagen. She is the author of the monograph In the Company of Ghosts: Hauntology, Ethics, Digital Monsters (2016), which explores contemporary digital storytelling practices within the speculative genres. Her research interests include feminist theory and ethics as well as monster theory, hauntology, and creative methods. She is co-founder of the international research network The Monster Network.

Sarianna Kankkunen is a member of the research project "Arctic HysteriaStrange Northern Emotions" led by Riikka Rossi (University of Tampere). Kankkunen is a doctoral researcher at the University of Helsinki and a former member of the European PhDnet for Literary and Cultural Studies (fourth cycle). Her dissertation, Harassing Habitats: Experienced Space in Finnish Contemporary Fiction. A Study of Maarit Verronen, is co-supervised between University of Helsinki and Justus Liebig University, Giessen, Germany. Her research interests and publications involve spatial literary studies and ecocriticism, spaces of dystopian fiction, and literary islands.

Kaisa Kortekallio ( $\mathrm{PhD}$, literary studies) is a postdoctoral researcher at the University of Helsinki. She has published on contemporary ecological speculative fiction, New Weird fiction, more-than-human subjectivity, narrative experientiality, and close reading. Most recently, she has worked on speculative fiction and the "limits of narrative" in the research consortium "Instrumental Narratives: The Limits of Storytelling and New Story-Critical Narrative Theory" (Academy of Finland, 2018-2022).

Marlene Karlsson Marcussen holds a $\mathrm{PhD}$ in comparative literature from the University of Southern Denmark, where she currently is scientific assistant. She is the co-editor of How Literature Comes to Matter: PostAnthropocentric Approaches to Fiction (Edinburgh University Press, 2021) and has published a number of publications on modernism, materiality, and space such as "The Postapocalyptic Motherhood" (Passage, 2019) and "The Abundance of Things in the Midst of Writing: A Post-Anthropocentric View on Description and Georges Perec's 'Still Life/Style Leaf'” (Edinburgh 2021). 
Brian J. McAllister is Assistant Professor of English at the American University of Sharjah in the United Arab Emirates. He has published on the rhetoric of emergence in narrative, visual poetry and narrative theory, disorienting narrative space, and science-fiction poetry. He is the guest editor of a special issue of Narrative on poetry and narrative theory. $\mathrm{He}$ is currently working on a study of art and literature that confront transformations of space and time in the Anthropocene.

Laura Oulanne is a postdoctoral researcher at the University of Helsinki. She holds a $\mathrm{PhD}$ in Comparative Literature from the University of Helsinki and Justus Liebig University, Giessen. Her current project explores the relationship between the mind and the world in modernist fiction by women. She is the author of Materiality in Modernist Short Fiction (Routledge, 2021), as well as a number of publications on materiality and affectivity in modernist literature.

Michael Karlsson Pedersen holds a PhD in Comparative Literature from the University of Southern Denmark. His research focuses on the literary aesthetics of different nonhuman ontologies, especially as found in twentieth-century literature. Publications with nonhuman themes include "Enemy of Stone, Lover of Music: Toward a Material Modernity of Stimmung" (The Germanic Review, vol. 93, no. 4) and "Sylvia Plath's 'Tulips': On the Hostile Nature of Things" (in How Literature Comes to Matter, Edinburgh University Press, 2021).

David Rodriguez is a postdoctoral researcher. He holds a $\mathrm{PhD}$ in English from Stony Brook University. His dissertation, Spaces of Indeterminacy: Aerial Description and Environmental Imagination in 20th Century American Fiction, studies images of the environment in the novels of Willa Cather, Paul Bowles, and Don DeLillo. He has written further about the phenomenology of reading descriptions of the view from above in Frontiers of Narrative Studies and econarratology in English Studies. 


\section{Acknowledgements}

Early drafts of the chapters in this collection were presented at a workshop hosted by Ghent University in December 2017. The setting was the De Krook library, which provided an appropriately captivating space for our discussions. The workshop was funded by the European Research Council under the European Union's Horizon 2020 research and innovation program (grant agreement no. 714166, "Narrating the Mesh: Ecology and the Non-Human in Contemporary Fiction and Oral Storytelling"). ERC funding also made it possible to publish this book in Open Access. We would like to thank the contributors and the workshop participants for the shared thinking that occurred at the Ghent workshop and, later, during the editorial process. Thanks also go to Michelle Salyga and Bryony Reece at Routledge for their assistance and professionalism as the book was going through peer review in the early stages of the COVID-19 pandemic. Finally, we are grateful to Line Henriksen for reading the manuscript and for contributing a creative coda that offers a playful and perceptive counterpoint to the chapters.

The chapter by Lieven Ameel is a republication, in longer and amended form, of the article "Ontological Instability and Nonhuman Presence in Twenty-First-Century New York Fiction” (Style, vol. 55 no. 3, 2021). 


\title{
Introduction
}

\author{
Marco Caracciolo, Marlene Karlsson Marcussen, \\ and David Rodriguez
}

"Soon he is on all fours pushing his pack in front of him. Another hundred yards and he has to crawl on his belly" (Danielewski 447-50). Will Navidson, one of the characters in Mark Danielewski's novel House of Leaves (2000), has discovered a door connecting his house to a series of mysterious underground environments: a staircase, a vast hall, countless corridors. The quoted passage is set deep in the house's recesses, with Navidson exploring a maze-like environment-a deeply layered space that resonates with the classical myth of Theseus and the Minotaur, the Freudian "unheimlich," as well as horror film tropes. But despite these familiar cultural coordinates, this space resists the characters' attempts at representation and appropriation: it is an irreducibly nonhuman environment where human consciousness falters and cognition breaks down. As the disorienting space of the labyrinth becomes foregrounded, Danielewski's novel translates Navidson's experience into the visual language of typography: the passage is stretched over four pages, the layout of the text displaying the shifting corridors and Navidson's bodily contortions as he makes his way through them (see Figure 0.1). Space-meaning both the physical space of the page and the imagined space of the house-destabilizes human understanding and mastery. In this process, spatiality affects the reading experience, confronting readers with how the efficacy of things can spiral out of human control: the titular "house of leaves" takes on an agency of its own, manipulating the characters physically and psychologically, even concretizing typographically into the physical object readers are holding in their hands.

The efficacy of nonhuman spaces, when experienced through narrative form, is at the center of this collection. Recent debates on the Anthropocene have prompted a re-negotiation of the relationship between human subjectivity and nonhuman matter across a wide range of disciplines. "Anthropocene" is a term introduced by chemist Paul Crutzen in the early 2000s to refer to the present geological era and particularly to humanity's lasting impact on the Earth's crust: humanity has become a quasi-geological agent through the burning of fossil fuels and the release of large amounts of near-indestructible plastic into the environment. This term has been discussed by numerous commentators in the humanities as well as social 


\begin{tabular}{|c|c|}
\hline $\begin{array}{l}\text { ch. So } \\
\text { on he i } \\
\text { s on all } \\
\text { fours p }\end{array}$ & $\begin{array}{c}\text { ushing } \\
\text { his pac } \\
\text { k in fro } \\
\text { nt of hi }\end{array}$ \\
& \\
\hline 447 & 448 \\
\hline $\begin{array}{l}\text { m. Another } \\
\text { ds and he } h\end{array}$ & $\begin{array}{l}\text { as to crawl on hi } \\
\text { s belly. As we c }\end{array}$ \\
\hline
\end{tabular}

Figure 0.1 Typography and nonhuman spaces in Danielewski's House of Leaves (447-50). Pages adapted by the authors for readability.

sciences, sometimes critically (see, e.g., Chakrabarty; Crist; Cohen et al.). In broad strokes, the Anthropocene signals a double disruption: humanity is disrupting the geological record, changing the Earth's climate and ecosystems in ways that are already having adverse consequences for a vast range of natural environments and life forms. But, at the same time, the Anthropocene exposes the efficacy of nonhuman processes: how biophysical systems may escape human control and have unintended-and devastating-consequences for human societies themselves (and, certainly, for some human societies more than for others).

The entanglement of human activity and nonhuman processes is inscribed in the physical spaces of our planet, from expanding deserts to melting ice caps and coastal areas threatened by the rise of sea levels. This entanglement can become inscribed in humans' bodily experience of space as well. However, attuning our bodies to the nonhuman is anything but straightforward, because-as many commentators on the ecological crisis point out (Jamieson; Clark) - there is a significant gap between the phenomenology of everyday spaces and wide-ranging changes affecting the planet as a whole. The spatial scale of more-than-human processes, including humanity's 
impact on the planet, eludes everyday experience. Put bluntly: we can experience environmental pollution in our immediate spatial surroundings, but it is easy to ignore an increase of three degrees Celsius in average temperatures around the globe. Human-scale spatiality may be comfortable to inhabit, but it has become (in the West, and increasingly around the globe) bound up with ideologies of human stewardship and mastery over natural resourcesprecisely the ideology that has led to the current ecological crisis.

This collection proposes that spatial forms, and the spatial forms of narrative more specifically, have a pivotal role to play in expanding our imagination beyond this comfort zone. Various contemporary thinkers-from Bruno Latour to Timothy Morton and Jane Bennett-are contending with notions of nonhuman efficacy and materiality in a theoretical vein. Through the evocation of nonhuman environments, narrative can turn this critique of anthropocentrism into the language of imaginative experience. Narrative can hone our sensitivity to nonhuman spaces: for instance, it can explore counterintuitive locations like Danielewski's labyrinthine house, or it can playfully engage with the "Great Outdoors," as Line Henriksen does in the fictional monologue that closes the collection, an ironic meditation on the forms of narrative, typography, and intersubjectivity. Henriksen imagines a "you" who inhabits the nonhuman space of a "reading cosmos" and is reluctant to send postcards from that "weirdly realistic" place. Our inclusion of Henriksen's text is inspired by a special issue of Yale French Studies (1981) devoted to the theory of description, which ends with a piece by French author Georges Perec describing the desk on which he is writing: Henriksen's text offers creative commentary on the ideas outlined in the previous chapters, making sure that the scholarly discussion of nonhuman spaces flows back into imaginative writing. The three parts of this book single out three foci of narrative, and spatial, resistance to anthropocentric assumptions: the first deals with quotidian objects and situations imagined through descriptive strategies that interrupt the human-centered progression of narrative; the second part explores locations affected by disaster and catastrophe, events whose narrativization severely undermines the illusion of human control over space; the third part addresses the epistemological limits of narrative form and how the spatial imagination can attempt to pierce through such limits through various scalar shifts.

The inherently disruptive nature of the Anthropocene has been discussed by many commentators within the field of environmentally conscious literary criticism or "ecocriticism" (e.g., Trexler and Johns-Putra; Rigby). What this collection brings to the table is a sustained engagement with space and form as central sites for confronting the challenges raised by the Anthropocene. Cognitively speaking, the experience of space underlies the modeling of abstract or intangible phenomena such as the "movement" of time or the "overlap" between two concepts (see Rohrer). From a phenomenological perspective, philosopher Peter Woelert writes that "embodied spatial experience ... can ... be broadly regarded as constituting from the very 
beginning an essential condition for the possibility of symbolic domestication of the world" (133). But space is more ambivalent than Woelert admits: just as it is grounded in bodily experience and can serve the ends of "symbolic domestication," it can be used to resist the domestication itself. It can point, allusively but no less powerfully, beyond the conceptual coordinates of everyday reality, as if sending postcards from the "Great Outdoors."

We see space and form as intrinsically bound up: space always presents itself in a particular form (the grid of a North American city, the meandering shape of a river, the undulations of a hilly landscape); conversely, we cannot think about literary and aesthetic form without bringing in spatial relations. Joseph Frank raised this point in an influential 1945 article, but his interest in modernist experimentations led him to see spatial form as a distinctive trait of modern literature. While modernism is well represented in the corpus interrogated by the authors in this collection (Karlsson Pedersen, Oulanne, Marcussen), the other authors turn to nineteenth-century travel writing (Askin) or contemporary fiction (Ameel, Caracciolo, Gebauer, Kankkunen, Kortekallio, Rodriguez) and poetry (McAllister). Indeed, we do not regard spatial form as an exclusively modernist phenomenon, but we see it as inherent in the physical presentation of a text, in strategies for the evocation of imaginative environments as well as in their experienced shape in readers' mental imagery. As Frank rightly suggests, however, the spatiality of this encounter between formal strategies and readers' experience may be foregrounded to different degrees. The narratives we explore employ highly salient spatial forms in ways that resonate, whether presciently or directly, with contemporary debates on the Anthropocene.

An important caveat is that all the literary texts discussed in this collection are by Western writers. We see this focus on Western narrative as a significant constraint on the claims we can make here. Engaging non-Western ways of thinking about space is an important and indeed essential way forward for ecocritically inspired approaches to narrative and a logical next step for our investigation. The work collected in a volume edited by Salma Monani and Joni Adamson, which is positioned at the intersection of ecocriticism and Indigenous studies, is exemplary in this regard. Nevertheless, we believe there is value in examining how Western authors from a variety of geographical contexts (including Scandinavia, Germany, Britain, and the United States) challenge dualistic assumptions about the nonhuman that are at the core of Western modernity. The formalist agenda of this book could also be productively extended to non-Western narrative.

Our approach is inspired by New Formalism, a movement defined by an interest in how form transcends the boundaries of literary or artistic texts and involves the cultural and evaluative formations that shape the life of a given society (see Levinson). Narrative has a central role to play in this project: "The form that best captures the experience of colliding forms is narrative," writes Caroline Levine in a fundamental contribution to New Formalism (Forms 19). This is because narrative, especially 
but not exclusively in the genre of the novel, is capable of absorbing and staging, within its folds, a multitude of conceptual forms. Think about how Danielewski builds on the spatial form of the labyrinth and uses it to generate a deeply perplexing space that, in both the characters' and the readers' experience, questions notions of domesticity and rational control. Narrative is also a pervasive form, structuring our understanding of reality in a broader sense: the Anthropocene itself, with its controversial elevation of "the human" to the role of a geological agent (see Crist), is a "metanarrative" (in Jean-François Lyotard's sense) that circulates in contemporary culture. The malleability of narrative form makes it possible for specific cultural texts to destabilize, through spatial experience, broader metanarratives regarding the human and its position vis-à-vis planetary realities.

We frame this inquiry into nonhuman spaces in the terminology of narrative theory-a field that, even in its poststructuralist incarnations, has retained a deep interest in formal patterns. Over the last two decades, space has become a focus of research at the intersection of narrative theory, literary studies, and the social sciences. While extremely valuable, this work has tended to privilege human-scale spaces and is only beginning to engage with the post-anthropocentric philosophies that Richard Grusin brings together under the rubric of the "nonhuman turn." In turn, post-anthropocentric theories have only partially addressed questions of (narrative) form. In the next two sections of this introduction, our goal is-first-to account for the role of literature vis-à-vis discussions on the Anthropocene and the nonhuman and-second-to review narratological work on space and explain how it can benefit our investigation into nonhuman spatiality.

\section{Literature in the Anthropocene: Theoretical Approaches}

The Anthropocene as a concept is hard to grasp, as it is "no sort of unitary or easily perceived object" (5), as Timothy Clark puts it, or, as Pieter Vermeulen argues, it only "becomes useful if we accept that [it] is inevitably a misnomer" (8). In coming to terms with this diffuse and problematic concept, foregrounding space may prove helpful. We inhabit two spaces at the same time: an abstract planetary space (the Earth) and a concrete embodied space in which we experience the effects of the Anthropocene. A gap thus opens up between the phenomenology of everyday spaces and the wide-ranging changes affecting the planet as a whole. Both spaces disrupt the longstanding dualism that opposes human societies to nonhuman animals and processes (e.g., geological phenomena or the climate). The natural system of the planet is not a stable and self-contained unity but is influenced and challenged by the equally powerful impacts of human expansionism. Likewise, our everyday relationship to natural environments is one of deep entanglement, effectively casting the nonhuman as an active agent resisting mere exploitation. 
Thus, the rise of the Anthropocene has prompted scholars from a wide range of fields to challenge dichotomies between subject and object and to rethink the human-nonhuman binary. Within the nonhuman turn, post-anthropocentric thinkers go against the dominant Western philosophical strand of human exceptionalism and insist on the reciprocal relationship between human societies and nonhuman things and processes. Grusin notes that post-anthropocentric theories are "all engaged in decentering the human in favor of a turn toward and concern for the nonhuman, understood variously in terms of animals, affectivity, bodies, organic and geophysical systems, materiality, or technologies" (vii). The nonhuman turn brings together a wide variety of theoretical approaches such as Actor-Network Theory, Affect Theory, Animal Studies, New Materialism, Speculative Realism, and Object-Oriented-Ontology (OOO). Of particular interest for our volume is the claim, advanced by scholars affiliated with New Materialism and OOO, that literature has a central position in changing our ways of thinking about the nonhuman and challenging preconceived notions about the passivity of spatial environments. These scholars ask us, in Jane Bennett's words, to give up the "habit of parsing the world into dull matter (it, things) and vibrant life (us, beings)" (Vibrant Matter vii). How to do so can be learned from literature. According to Claire Colebrook, literature and the humanities have a crucial role to play in evoking a post-anthropocentric attitude toward the nonhuman, for, "if reason, calculation, practice and day-today thinking have led to a tragic inability to think beyond the expedience of the present, then perhaps it is the task of literature and the humanities to address our sentimental, affective, habitual and non-cognitive comportment toward the world" (115). Literature exposes a vibrantly material background that is normally bracketed in favor of human agency and mastery. As a consequence, the nonhuman turn contests previous linguistic and cultural movements by proposing a very different conception of language: rather than regarding literature as a semiotic system or a tool involved in the construction of cultural identities, the focus is on literature's ability to present, perform, and create material affects. To some scholars, literature itself even becomes a "biodegradable" materiality, where the very physicality of the page obfuscates processes of meaning-making (Colebrook 118). Matter and meaning coemerge, as posited by-for instance-Karen Barad's agential realism, where the world is regarded as a constant becoming, consisting of intra-actions of material and discursive agencies: "Mattering is simultaneously a matter of substance and significance" (3).

In the context of New Materialism, Bennett's Vibrant Matter introduces the idea of a vital materiality in order to change "our earth-destroying fantasies of conquest and consumption" (Vibrant Matter ix) that have led to the Anthropocene and to help us get "a fuller range of the nonhuman powers circulating around and within our human bodies" (Vibrant Matter ix). 
Inspired by Bruno Latour's concept of the actant, which is a "source of action that can be either human or nonhuman" (Bennett, Vibrant Matter viii), Bennett draws attention to the capacity of our nonhuman environments to act upon, and affect, our lives. One example is particularly pertinent to our volume, as it demonstrates the literary inspiration of Bennett's thinking. To explain how things disclose themselves as more than inert matter, she offers the following description of objects she encountered one morning on her way to work:

[One] large men's black plastic work glove one dense mat of oak pollen

one unblemished dead rat

one white plastic bottle cap

one smooth stick of wood. (Vibrant Matter 4)

As she comes across these items, they exhibit their "thing-power," changing from passive trash to vital things producing effects both among each other and on her. Here space comes to play an important role, because it is within a spatial assemblage with the street and with Bennett's morning walk that each thing exceeds its own singularity and "started to shimmer and spark" (5). In order for her to become aware of this debris, Bennett describes "a certain anticipatory readiness" (5), which she has learned from "Thoreau, Kafka, and Whitman" (xiv). Her most recent book takes this one step further as she follows the continuity of posture in Whitman's writing, supplementing the familiar image of Whitman's "loafing" to the equally prominent postures of nonhuman figures in his writing, such as plants and animals (Influx and Efflux 11). Space and literature are thus crucial tools to acknowledge matter as vibrant. This idea is reiterated in Bennett's essay that concludes the seminal volume The Nonhuman Turn. Here she ends with a literary description of a character's living space from Joyce's Finnegans Wake and concludes that:

Perhaps the most important stake for me of the nonhuman turn is how it might help us live more sustainably, with less violence towards a variety of bodies. Poetry can help us feel more of the liveliness hidden in such things and reveal more of threads of connection binding our fate to theirs.

(Bennett, "System and Things" 235)

Literature thus becomes a means of making available a more open-minded attitude toward the nonhuman world. This collection picks up on these claims about the importance of literature.

The material ecocritics Serenella Iovino and Serpil Oppermann address the question of literature and nonhuman matter more directly than Bennett, as they lift insights from New Materialism in order to bridge the gap 
between text and matter, proposing that "all matter [is] storied matter" (1). Arguing for the implicit textuality of the way matter expresses itself in the world, Iovino and Oppermann substitute a focus "on texts and ... how they 'reflect' the world's phenomena" with a mode of reading "the world and text as an agentic entanglement" (9-10). Here interpretive practices from literary criticism are employed to read matter as an agential narrative operating outside of human practices.

An even more radical interpretation of the relation between text and matter, object and space, is found in Speculative Realism and OOO. Timothy Morton and Graham Harman define an object via its withdrawnness, another thoroughly spatial concept that goes unacknowledged as such. For OOO, every object in the world can never fully appear to us, as objects are always only present at one remove: "no object relates with others without caricature, distortion, or energy loss" (Harman, "The Well-Wrought Broken Hammer" 188). Whenever an object interacts with another object or human in space, they influence each other, and there is always some degree of "loss" in the encounter. Thus, the essence of the object can never be fully realized: "OOO is saying that behind every flow, behind every stasis, there is an object that cannot be reduced to anything whatsoever" (Morton, "An Object-Oriented Defense of Poetry" 208). Also from this perspective literature comes to play a crucial role: both as offering a possible indirect access to the withdrawn object and as itself mirroring the object's form. First, literature, with its poetic language, can allude to the object that absconds in the encounter with a human mind. In Weird Realism: Lovecraft and Philosophy, Harman shows how Lovecraft's fiction can allude to a nonhuman, indescribable world of monsters through gaps and hints in descriptive practices. Second, literature itself mirrors the object's relationality. In "An Object-Oriented Defense of Poetry," Morton shows how "the aesthetic dimension is not an optional extra ... To study a poem, rather, is to see how causality itself operates" (206). For Harman and Morton, literature makes a material object appear by translating it into language, a process analogous to the way in which, when objects in the world meet, each of them is morphed into something else.

All in all, in post-anthropocentric theories, space is the place where humans and nonhuman matter interact; it gathers and forms the background upon which we can understand the nonhuman anew. Space in the Anthropocene becomes more than just a passive background upon which humans act, it forms the vital materiality where the objects we once thought were just "dead" matter show themselves recalcitrant and agential. Literature takes a prominent role in witnessing the changed relationship between the human and the nonhuman. In the following section, we turn to narrative theory, a field that offers a number of productive concepts to study the formal strategies through which literature (and literary narrative in particular) can reveal the efficacy of the nonhuman through space. 


\section{Space and Narrative (Theory)}

A key aspect of our approach is to reorient the readerly attitude toward the nonhuman by foregrounding space and description in narrative texts. Emphasis on the nonhuman has not been a track consistently followed by narrative theory, despite a range of recent suggestions to do so (Askin; Caracciolo; James; James and Morel). Here, we will give a few examples of the discussions of space in narrative theory and point out some untrodden paths for thinking about narrative's engagement with the nonhuman.

As mentioned above, the "Toward a Theory of Description" issue of Yale French Studies is a major influence behind the genesis of this collection. In general, the essays in that issue oppose the strict boundary between description and narrative, spatiality and temporality developed by Gérard Genette. Jeffrey Kittay argues that description does not mark the frontier of narrative, as Genette claims, but rather it points out "the frontier or limits of the usefulness of the opposition" (226). The articles in Yale French Studies develop a diverse set of approaches that attempt to push the methodology of literary criticism and narrative theory to reconsider the methods that generate oppositions such as description vs. narrative and time vs. space.

But these Genettian dichotomies were generally reinforced in postclassical narratology. Gabriel Zoran isolates spatiality in order to tease out what makes literature a unique spatial object. This is the reverse of most theoretical studies of space and narrative, which reduce it to a container for events and subordinate it to the dynamism of time. Zoran brings space into the vernacular of narratology by abstracting the insights from the classic studies of space in literature-Gotthold Lessing, Mikhail Bakhtin, Joseph Frank, Gaston Bachelard-into a structure that is adaptable to new case studies. Several interesting arguments relevant to post-anthropocentric approaches stick out.

First, Zoran argues that space is tricky to analyze with precision because the critic must recognize that studying space is always a study of its transformation. In a sense, this is studying space from a "spatial point of view." Just as character, plot, and time can be represented spatially or as space is structured in time, "It is impossible to reconstruct the space of the world without structuring the information about it into some kind of a 'spatial pattern" (312). This strange doubling of spatiality is perhaps clearer if it is pointed out that Zoran's second use of "space" in this definition consists of a silent "human" modifier: some kind of human spatial pattern. Second, spatiality in literature can never, of course, be complete. It always balances determinacy and indeterminacy, though most of the time the reader does not notice these gaps. There remains a question if certain objectivities are more difficult to represent in literary narrative. Zoran isolates the difference between humans and nonhumans:

The formation of a character's external appearance constitutes a special problem, different from the formation of an inanimate object-although 
every text expresses this difference in a different way. Imagine the grotesque effect that would be created if a character was handled as a physical object. In principle, therefore, one may state that the differentiation between subject and object determines a basic differentiation within space-between the external appearance of the characters and the environmental objects.

This is Zoran's most overt reference to any kind of ontological difference between types of spaces in the text. Several of the essays in the present collection explore the validity of this distinction (Pedersen, Kankkunen) and point out the ways in which certain texts exploit this anthropocentric bias (Oulanne, Caracciolo).

Ruth Ronen is frequently cited alongside Zoran, though their approaches differ. Ronen foregrounds fictionality in order to define setting alongside other, more dynamic, spatial frames. As such, the topography of fictional entities within a literary text is defined by different modes of access to space; the setting is the "actual immediate surrounding" of the entities in a text and a frame is an organization of the sub-spaces within this setting (423). The way a text handles framing its entities is thus the origin of different character dynamics and event sequences. She describes several different types of frames, the most interesting of which are "inaccessible frames." These can either be totally "closed" in the storyworld - where "information is inaccessible to characters in another frame"or "provisionally inaccessible" - a space penetrated later on in the text (426). Most obviously, this has become a useful way of interpreting the relationship between spatial locations, focalization, and the development of the plot. But we can also consider how the nonhuman spaces in literature are another type of these closed, "inaccessible frames," which are primarily valuable because they negate the expectations that narrative should coherently structure and provide access to spatiality.

David Herman's early work on spatiality in narrative (see "Spatial Reference") follows Zoran's and Ronen's schematic designs, but its unique subject matter seems to have inspired his recent turn to the nonhuman. He focuses on ghost stories, and this "supernatural" subject encourages him to foreground nonhuman elements of his participants' storyworlds. Departing from previous structural or phenomenological models of spatiality, Herman's interdisciplinary method combines insights from semiotics with cognitive science and natural language processing. The resulting study of "cognitive mapping" presents one of the first theories for this now ubiquitous concept. He points out that cognitive approaches to narrative are largely about answering important "where" questions that orient the reader: "far from merely providing descriptive background or ornamentation for the primary action, spatial reference in narrative domains helps make storytelling possible" (Herman, "Spatial Reference" 531). In this way, space is not just important structurally, as Zoran and Ronen assert, but it is primary in both the act of storytelling and experiencing a storyworld. 
The focus on the "unnatural" dominates another strain of narrative theory that has attempted to account for stories that do not just include supernatural figures but are formed separately from natural language or conventional human storytelling (see, e.g., Alber). In this way, narrative does not just function to represent or even simulate the daily experience of space, but it destabilizes it. Jan Alber points out that this can happen through at least two forms: physically and logically impossible spaces. This is not just a continuum of in/accessibility as Ronen proposed but a categorical separation related to naturalized narrative conventions. In fact, Alber similarly identifies Danielewski's House of Leaves as an example of a narrative that foregrounds defamiliarized space. But, in distinct opposition to the analysis above, he resolves this defamiliarization by interpreting these impossible spaces as allegory, leading back to human meaning-making (189). "Impossible" spaces, as many of the following essays show, are frequently impossible to interpret in these human terms (Marcussen, Rodriguez, McAllister); impossibility, as such, is one of the signals that the text is opening up beyond anthropocentrism.

Another way of applying interdisciplinary insights to narrative space is the recent turn toward geography. This, in a sense, also deals with "impossibility" in narrative form: how do we deal with apparent transgressions between the space of the text and the space of the world? Several tracks have been developed to approach this question, using geography to introduce further tools into narrative theory. Marie-Laure Ryan, Kenneth Foote, and Maoz Azaryahu's work has led to a framework for understanding stories that quite literally extend in space. Gerald Prince, on the other hand, sees the potential for a geographical narratology as the need for a paradigm shift: moving from the study of space in narrative (the assumption of the studies described above) to narrative in space (Prince 1494).

Herman, in Narratology Beyond the Human, indeed attempts to extend narrative into space. For him, this takes the form of an "animal geography" that plays out in texts that explore biocentric perspectives (134). While the animal-centered texts that Herman studies are easy to consider as biocentric relative to the modernist texts used as examples in the previous studies of spatiality in literature, it is important to note that this is a byproduct of the increased affordances to read a text non-anthropocentrically when confronted with nonhuman figures. As is apparent in the essays included here, when reading from an intentional position "beyond anthropocentrism," even the smallest introduction of nonhuman space affords an analysis of the formal clash that is staged in literature.

This is where New Formalism, Levine's work in particular, is useful for generating new narratological models of narrative in space. Clearly, the forms that Levine discusses in her work are spatial figures: her central critique includes a deconstruction of narrative "closure." But her emphasis on form is also spatial in another sense. It seeks to identify persistent spatial figures that stretch beyond fiction into the real world as "sustainable models" (Levine, "Three Unresolved Debates" 1243; see also Levine, "Model Thinking”). She points out that certain 


\section{2}

Caracciolo, Marcussen, and Rodriguez

aesthetic forms are more sustainable than others: the novel does not afford sustainable representations of monotonous daily labor, or the dynamics of large crowds (Levine, "The Enormity Effect" 59). Other forms are perhaps more sustainable: description, in particular, is a form that affords sustainable models for imagining the environment.

Narrative is sustainable in the context of communicating human realities, but thinking about the ways in which narrative (temporality) is disrupted allows us to think about other forms that open up into nonhuman realities. What would these sustainable narrative forms look like? The dominant strains of anthropocentric narrative theory may not provide adequate tools for identifying sustainable models in the Anthropocene, which is the general theoretical assumption behind the essays collected here. Likewise, privileged narrative forms of spatiality may not be the best at creating a sustainable model for the future-hence the focus on unconventional narratives that are the subject of these essays. By identifying the affordances of narrative that extend beyond the human in previously unrecognized, or misrecognized, ways, the critic can play a role in shaping a more sustainable future.

\section{Overview of the Chapters}

The essays are organized into three parts, reflecting complementary modalities of space-based narrative interrogation of the nonhuman. In the first part, "Objects and the Resources of Description," we start from the question of how objects-even familiar human-made artifacts—can take on quasiautonomous agency in a story and thus put pressure on anthropocentric assumptions. In the second part, "Catastrophic Narrative Environments," we move on to the physical and conceptual spaces of catastrophe and their potential for destabilizing human mastery and anthropocentric knowledge practices. Finally, in the third part, "Scales and Limits of Narrative," we turn to the epistemological dimension of scalar representation in narrative. We show that confronting these spatial concepts discloses possibilities for the narrative exploration of theoretical and philosophical questions.

The first part begins with a chapter by Laura Oulanne, "Containment and Empathy in Katherine Mansfield's and Virginia Woolf's Short Stories." Oulanne investigates the spatial schema of containment and its role in literary modernism, and particularly in the narrative form of the short story. Focusing on the affective and embodied dimension of literary form, Oulanne argues that in Mansfield's and Woolf's work, containment has the paradoxical function of opening up new ways of thinking about the human mind in relation to the material world. The result is that empathy, construed in embodied terms, is extended beyond the human domain, embracing the physical objects-boxes, cupboards, and yellow dresses- that populate modernist fiction.

Chapter 2, "Floating Air-Solid Furniture: Vibrant Spaces in Virginia Woolf's 'Time Passes," by Marlene Karlsson Marcussen, continues the exploration of modernism as a period of intense engagement with spatial 
form in narrative (as argued influentially by Frank). Challenging classical narratology's strict distinction between temporal narration and spatial description, Marcussen shows how fiction can yield insight into more-thanhuman realities via narrativized description. In a close reading of "Time Passes," the middle section of Woolf's novel To the Lighthouse, Marcussen argues that Woolf narrates the nonhuman by evoking the materiality of air through formal strategies-more specifically, through the expressive use of punctuation and anthropomorphic metaphors and similes.

In Chapter 3, "The Descriptive Turn in German Nature-Oriented Neue Sachlichkeit (1913-1933)," Michael Karlsson Pedersen stays with modernism but shifts the focus from British to German literature. Developing the concept of "nonhuman literary genre," Pedersen explores the turn to description in the metaphysical naturalism theorized and practiced by Alfred Döblin and Wilhelm Lehmann. Pedersen seeks to bridge the gap between the literary forms of the Neue Sachlichkeit and the nonhuman ontology of objects articulated, in different ways, by Jane Bennett and Graham Harman. He argues that both Bennett's "horizontal materialism" and Harman's "vertical immaterialism" can be detected in the formal strategies adopted by Döblin and Lehmann. These three chapters also trace an archeology of engagements with the nonhuman in modernist narrative, anticipating and framing the discussion of contemporary fiction in the following part.

In Chapter 4, "Nonhuman Presence and Ontological Instability in TwentyFirst-Century New York Fiction," Lieven Ameel analyzes a variety of threatening nonhuman presences in contemporary fiction. This includes catastrophic weather in Teju Cole's Open City, massive storms in Ben Lerner's 10:04, and even a gigantic tiger in Jonathan Lethem's Chronic City. Ameel proposes that each of these novels presents distinct imaginative strategies for dealing with problems on vast spatial, temporal, and experiential scales. By disrupting spatial continuity, these nonhuman presences become concretizations of the possible future in the present world. Urban studies, possible worlds theory, and in particular Gilles Deleuze's concept of the fold are invoked to analyze how the palimpsestic layers of meaning in urban space and ambiguous temporal structures are newly represented in fiction that imagines catastrophic events related to climate change.

Kaisa Kortekallio uses a unique phenomenological approach in Chapter 5, "Seasonal Feelings: Reading Paolo Bacigalupi's The Windup Girl During Winter Depression." It complements the prior analytical studies to develop an affective account of the reading experience in the face of these catastrophic narratives. Kortekallio outlines her discussion of reading and rereading Paolo Bacigalupi's The Windup Girl in the context of the uncanny overlap between imagined ecological disaster and the real discomfort that is felt even in the presumed fantasies of science fiction.

Chapter 6, "Imagining Posthuman Environments in the Anthropocene: The Function of Space in Post-Apocalyptic Climate Change Fiction," also turns to dystopia to address experiments with narrative in space. Carolin 
Gebauer adapts Yuri Lotman's spatial model of narrative into a robust tool for analyzing Margaret Atwood's Oryx and Crake. Gebauer's posthuman focus shows how anthropocentric spatiality is disrupted once the notion of "stable" storyworld is put into question.

In Chapter 7, "'It Wants to Become Real and Can Only Become Prose': Anthropocenic Focalization in 10:04 and The World Without Us," David Rodriguez concludes this part on catastrophe and contemporary fiction by identifying a narrative phenomenon he calls "Anthropocenic focalization." This mode provides a new tool that figures a way of thinking about the Anthropocene not just as a concept or epoch signaling "the human age" but a distinct way of organizing perspective. Its use plays out differently depending on the fictionality of its contexts, so juxtaposing a novel such as Lerner's 10:04 and Alan Weisman's thought experiment The World Without Us provides a chance to rethink basic spatial categories in narrative.

The next part opens with "Maarit Verronen's Monomaniacs of the Anthropocene: Scaling the Nonhuman in Contemporary Finnish Fiction." In this chapter, Sarianna Kankkunen analyzes how the contemporary Finnish writer Marrit Verronen's fiction includes scalar descriptions of the nonhuman that challenge the narrative form of the novel through a strategy of enumeration. Kankkunen introduces the idea of the monomaniac as a character who is uniquely attuned to the nonhuman world. Through this figure two different psychological impulses are discussed: the need to confront the nonhuman in embodied terms and the urge to move beyond human-scale description.

In Chapter 9, "Plotting the Nonhuman: The Geometry of Desire in Contemporary 'Lab Lit," the relationship between character and space in narrative is further challenged. Marco Caracciolo adapts Alex Woloch's notions of "character-space" and "character-system" to show how desire in two contemporary lab-based novels is plotted through geometrical models that are both abstract and informed by the nonhuman. In reading Jonathan Lethem's As She Climbed Across the Table and Jeanette Winterson's Gut Symmetries, Caracciolo draws attention to how the plot of desire in the two novels is structured and thematized through two spatial forms: the triangle and the chain, thus defamiliarizing the way we normally perceive humannonhuman relations in narrative.

With Chapter 10, "Lithic Space Time in Lyric: Narrating the Poetic Anthropocene," we reach the outer limits of narrative and break away from characters and from the novel altogether. With the Anthropocene as vantage point, Brian J. McAllister turns to landscape poetry focused on geological phenomena to search for new scalar models that show aesthetic renderings of a transformed relationship between the human and the nonhuman, figure and ground. Analyzing poems by Hugh MacDiarmid, Robert Smithson, and Brenda Hillman, McAllister argues that each poem renders different aesthetic models of the lithic in ways that challenge the human understanding of space and time.

Continuing in this geological vein, Chapter 11, Ridvan Askin's "Narrating the 'Great Outdoors,"” investigates Margaret Fuller's travel 
narrative Summer on the Lakes, in 1843 in order to explore not just the limits of narrative but the limits of human understanding. Evoking Quentin Meillassoux's concept of "the great outdoors," Askin shows that Fuller uses a strategy of "pseudo-paraleptic anamorphosis" (in Askin's terminology) in order to probe a dimension beyond human experience.

Finally, Line Henriksen concludes the volume with a fictional monologue ("Inside the Great Outdoors") in which she revisits, playfully, the ideas and language introduced by the preceding chapters. This piece demonstrates how academic debates can foster the creative imagination of the nonhuman, giving rise to a two-way exchange between literary scholarship and our affective experience as readers, scholars, and writers.

\section{References}

Alber, Jan. Unnatural Narrative: Impossible Worlds in Fiction and Drama. University of Nebraska Press, 2016.

Askin, Ridvan. Narrative and Becoming. Edinburgh University Press, 2016.

Barad, Karen. Meeting the Universe Halfway: Quantum Physics and the Entanglement of Matter and Meaning. Duke University Press, 2007.

Bennett, Jane. "System and Things: On Vital Materialism and Object-Oriented Philosophy." The Nonhuman Turn, edited by Richard Grusin, University of Minnesota Press, 2015, pp. 223-239.

Bennett, Jane. Vibrant Matter: A Political Ecology of Things. Duke University Press, 2010.

Bennett, Jane. Influx \& Efflux: Writing Up with Walt Whitman. Duke University Press, 2020.

Caracciolo, Marco. Narrating the Mesh: Form and Story in the Anthropocene. University of Virginia Press, 2021.

Chakrabarty, Dipesh. "The Climate of History: Four Theses." Critical Inquiry, vol. 35, no. 2, 2009, pp. 197-222.

Clark, Timothy. Ecocriticism on the Edge: The Anthropocene as a Threshold Concept. Bloomsbury, 2015.

Cohen, Tom, et al. Twilight of the Anthropocene Idols. Open Humanities Press, 2016.

Colebrook, Claire. "The Twilight of the Anthropocene: Sustaining Literature." Literature and Sustainability: Concept, Text, Culture, edited by Richard Grusin, Manchester University Press, 2017, pp. 115-136.

Crist, Eileen. "On the Poverty of Our Nomenclature." Environmental Humanities, vol. 3, no. 1, 2013, pp. 129-147.

Crutzen, Paul J. "Geology of Mankind.” Nature, vol. 415, no. 6867, 2002, p. 23.

Danielewski, Mark Z. House of Leaves. Pantheon Books, 2000.

Frank, Joseph. "Spatial Form in Modern Literature: An Essay in Three Parts." The Sewanee Review, vol. 53, no. 4, 1945, pp. 643-653.

Grusin, Richard, editor. The Nonbuman Turn. University of Minnesota Press, 2015. Harman, Graham. "The Well-Wrought Broken Hammer: An Object-Oriented Literary Criticism." New Literary History, vol. 43, no. 2, 2012, pp. 183-203.

Harman, Graham. Weird Realism: Lovecraft and Philosophy. Zero Books, 2012.

Herman, David. "Spatial Reference in Narrative Domains." Text, vol. 21, no. 4, 2001, pp. 515-541. 


\section{Caracciolo, Marcussen, and Rodriguez}

Herman, David. Narratology Beyond the Human: Storytelling and Animal Life. Oxford University Press, 2018.

Iovino, Serenella, and Oppermann, Serpil. Material Ecocriticism. Indiana University Press, 2014.

James, Erin. The Storyworld Accord: Econarratology and Postcolonial Narratives. University of Nebraska Press, 2015.

James, Erin, and Eric Morel. "Ecocriticism and Narrative Theory: An Introduction." English Studies, vol. 99, no. 4, 2018, pp. 355-365.

Jamieson, Dale. Reason in a Dark Time: Why the Struggle Against Climate Change Failed-and What It Means for Our Future. Oxford University Press, 2014.

Kittay, Jeffrey. "Descriptive Limits." Yale French Studies, vol. 61, 1981, pp. 225-243.

Latour, Bruno. Facing Gaia: Eight Lectures on the New Climatic Regime. Polity Press, 2017.

Levine, Caroline. "Model Thinking: Generalization, Political Form, and the Common Good." New Literary History, vol. 48, no. 4, 2017, pp. 633-653.

Levine, Caroline. "The Enormity Effect: Realist Fiction, Literary Studies, and the Refusal to Count." Genre, vol. 50, no. 1, 2017, pp. 59-85.

Levine, Caroline. “Three Unresolved Debates.” PMLA, vol. 132, no. 5, 2017, pp. 1239-1243.

Levine, Caroline. Forms: Whole, Rhythm, Hierarchy, Network. Princeton University Press, 2015.

Levinson, Marjorie. “What Is New Formalism?” PMLA, vol. 122, no. 2, 2007, pp. $558-569$.

Lyotard, Jean-François. The Postmodern Condition: A Report on Knowledge. Translated by Geoff Bennington and Brian Massumi, University of Minnesota Press, 1984.

Monani, Salma, and Joni Adamson, editors. Ecocriticism and Indigenous Studies: Conversations from Earth to Cosmos. Routledge, 2016.

Morton, Timothy. “An Object-Oriented Defense of Poetry." New Literary History, vol. 43, no. 2, 2012, pp. 205-224.

Morton, Timothy. The Ecological Thought. Harvard University Press, 2010.

Prince, Gerald. “Talking French.” PMLA, vol. 131, no. 5, 2016, pp. 1489-1494.

Rigby, Kate. Dancing with Disaster: Environmental Histories, Narratives, and Ethics. University of Virginia Press, 2015.

Rohrer, Tim. "Embodiment and Experientialism." The Oxford Handbook of Cognitive Linguistics, edited by Dirk Geeraerts and Hubert Cuyckens, Oxford University Press, 2007, pp. 25-47.

Ronen, Ruth. "Space in Fiction.” Poetics Today, vol. 7, no. 3, 1986, pp. 421-438.

Ryan, Marie-Laure, Kenneth Foote, and Maoz Azaryahu. Narrating Space / Spatializing Narrative: Where Narrative Theory and Geography Meet. Ohio State University Press, 2016.

Trexler, Adam, and Adeline Johns-Putra. "Climate Change in Literature and Literary Criticism.” Wiley Interdisciplinary Reviews: Climate Change, vol. 2, no. 2, 2011, pp. 185-200.

Vermeulen, Pieter. Literature and the Anthropocene. Routledge, 2020.

Woelert, Peter. "Human Cognition, Space, and the Sedimentation of Meaning." Phenomenology and the Cognitive Sciences, vol. 10, no. 1, 2011, pp. 113-137.

Zoran, Gabriel. "Towards a Theory of Space in Narrative." Poetics Today, vol. 5, no. 2, 1984, pp. 309-335. 
Part I

Objects and the Resources of Description 


\title{
1 Containment and Empathy in Katherine Mansfield's and Virginia Woolf's Short Stories
}

\author{
Laura Oulanne
}

she could see little bits of her yellow dress in the round looking-glass which made them all the size of boot-buttons or tadpoles; and it was amazing to think how much humiliation and agony and self-loathing and effort and passionate ups and downs of feeling were contained in a thing the size of a threepenny bit.

(Woolf 54)

Human beings are often conceptualized as containers for thoughts and feelings. We see ourselves, in theory and in everyday life, as vessels further contained by the clothes and built spaces we inhabit, yet in fact our experience may extend to encompass these material containers and the world beyond them. Clothes and material spaces can separate bodies and minds from one another and create spaces of isolation; however, in the two short stories discussed in this essay, containment also becomes associated with relationality and affective connection. "Miss Brill" (1920) by Katherine Mansfield and "The New Dress" (1927) by Virginia Woolf exemplify modernist thematics such as the limits of knowledge, empathy, and sympathy between human beings, but they also have a less frequently addressed focus on the affective relationship between human characters and nonhuman things and spaces. The stories invite empathetic engagement even if their characters, like Woolf's Mabel Waring above, describe themselves as "things" verging on nonhuman. I propose that the "passionate ups and downs of feeling" that the reader of these stories is invited to engage with do not appear as the property of individual minds sealed off from others, but as affects that arise in the encounters of human and nonhuman bodies.

This essay aims to point out the formal and affective affordances of the texts for an anti-anthropocentric understanding of empathy, affectivity, and the mind. By describing the formal features of a text, as exemplified recently by the work of Caroline Levine, it is possible to make visible the way meanings are constrained, but also enabled, by literary forms. Similarly, from a cognitive perspective explored by Terence Cave, "redescribing" literary texts from the point of view of their affordances for conceptual and embodied sense-making yields insight into the plurality of interpretation. I take affect, which both Cave's and 
Levine's accounts of form and affordance risk overlooking, to be an integral part of the literary form. This essay "redescribes" the affective form and content of Mansfield's and Woolf's short stories to investigate the phenomena of containment and empathy that the stories set in conversation with one another. My readings suggest that containment as a material condition and a literary form elicits empathy, while it does not work as a model for the mind or the human individual. Thereby I also take a step toward a new reading of empathy and solipsism in modernist fiction.

Containment is a way of both conceptualizing and experiencing space. Here the term is used in three senses: concrete, material container-spaces such as rooms, boxes, and clothes in the fictional worlds of the two stories; containment as a schema of embodied origin involved in thinking (conceptualizing time, life, or the human individual as a container, for instance); and containment as a formal feature of narratives, manifested in circular structures and closure. These senses are interconnected: the metaphorical use of the schema in abstract thinking is based on our everyday experience of concrete containers (Lakoff and Johnson 2) ${ }^{1}$ and the understanding of stories as containers of events and meaning draws on such schematic thinking. Katrin Dennerlein suggests that containment is our main way of conceiving of space in fiction, based on the evolutionary importance of container spaces (62); on the other hand, relying merely on this schema risks affirming an anthropocentric focus and neglecting dynamic and networked models of space, as has been shown by Marlene Karlsson Marcussen (60). The following readings show that the schema of containment also affords non-anthropocentric, dynamic and relational understandings of space, reading, and experience. ${ }^{2}$

The conceptual areas of empathy and sympathy have been tangled since the early uses of both terms. "Sympathy" predates "empathy" and began to take on its contemporary distinctive meaning, namely "feeling for" as opposed to "feeling with" or "feeling into" (Einfühlung), around the time of writing of the modernist texts studied here. Within the limits of this chapter, it is not possible to delve into the conceptual nuances, and empathy is here used as an umbrella term for a variety of phenomena of intersubjective affectivity involving a sense of "feeling with." However, I draw especially on phenomenological approaches ${ }^{3}$ that focus on empathy as a sense of another's feeling or mood gained by virtue of their embodied expression (Zahavi 55, Zahavi and Rochat 545). To encompass even nonhuman bodies, Jane Bennett's work on the notion of sympathy in Walt Whitman's poetry offers an opportunity to broaden this complex notion to involve nonhuman spaces and things. A focus on embodiment and the challenge to views of empathy as projection, amalgamation of minds, or conscious mind-reading complements the discussion of empathy in fiction-especially when the position of the nonhuman world is foregrounded.

These approaches to fellow-feeling allow for a new point of view into the discussion of empathy and modernist fiction. Meghan Marie Hammond 
has charted the preoccupation of modernist writers with the "problem of other minds," producing texts that discuss forms of fellow feeling but being "never at ease" with it $(1-2,20)$. Kirsty Martin discusses sympathy in modernist fiction as a multifaceted, cognitive and embodied phenomenon and also points out moments of sympathy with the nonhuman world depicted by Woolf, Vernon Lee, and D.H. Lawrence. Martin reads emotion as a cognitive phenomenon as a bridge between the individual and the (material) world and shows how the authors, contrary to some received notions, are engaged with sympathy but portray the affective relations between the individual, others, and the world as troubled and ethically challenging $(10,16-17)$. Both studies draw on a variety of theories of empathy and note modernist writers' resistance to mind-body dualism (Hammond 54, Martin 24). Yet they often resort to a cognitivist model of emotion centered around the human individual, which also appears as the basis of the ethical problematic of empathy and sympathy. I propose that the investigation of sympathy and empathy in modernism could profit from the comparison of phenomenological and new materialist approaches to empathy and sympathy as an alternative to thinking through internalist and individualist metaphorical language, which many modernist authors, too, seem to be struggling away from. I follow Martin in drawing attention to the way the texts I read actually display multiple forms of affective interaction between the human and the nonhuman, realized in an experience of lived space and bodies, but suggest that the stories support approaches to empathy that may remain ethical without privileging the human individual.

Like Martin, Bennett addresses the vitalist tradition of sympathy in noting that in addition to a moral sentiment akin to pity, sympathy has persistently been described as a "vital force operating on bodies from without," a "more-than-human atmospheric force," and it is as such as it often appears in the poetry of Walt Whitman (Influx \& Efflux 27, 29). Additionally, early uses of the notion of "empathy," including its firs English usage in the psychological aesthetics of Vernon Lee, often actually discuss empathetic relations between humans and nonhuman objects (Lee, Beautiful 61-69, Martin 46, Titchener 417). ${ }^{4}$ Furthermore, phenomenological studies of the related phenomenon of affective incorporation have shown how nonhuman, inanimate things such as clothes and instruments are involved in affective states, not solely as objects of intention but as parts of the human lived body, as it were; things may enforce or sustain an affective state but also contribute to its emergence (Colombetti 238-41). The upshot of all these approaches is that affects arise not (only) from an individual psyche, but in interaction with others and also with spaces and things, by virtue of the embodied being-in-the-world that defines human experience. This also changes how the "sharing" of affect can be understood.

This point of departure is in line with David Herman's observation of modernism as not an inward turn but a turn outwards, toward the lived world. According to Herman, "mental states have the character they do 


\section{Laura Oulanne}

because of the world in which they arise, as a way of responding to possibilities (and exigencies) for acting afforded by that world" (253). Thereby the "problem of other minds" in modernism should not merely be seen as based on the access to or the inscrutability of emotions hidden within the individual, but an issue of how human and nonhuman existents share the lived world. Instead of repeating the metaphor of the human being as a sealed container for emotions, I suggest that we pay attention to "actual," material container-spaces in the fictional worlds of the stories and their affordances for imaginative, affective engagement, as well as to the affordances of the literary form as a container. This shift reveals how they work to construct affective forms of intersubjectivity/interobjectivity that suggest an ethical alternative to the dualist model of the individual sealed off from the world.

\section{Mansfield's Boxes, Cupboards, and Universal Empathy}

Katherine Mansfield is known for her creative, impressionistic experimentations with the short story form. As Ellen Burton Harrington suggests, many modernist short stories are spatial rather than temporal pieces of fiction and foreground the description of a situation over a succession of events (5). Therefore they are intriguing from the point of view of the container as a material and literary form. The relationship between empathy and short fiction has been seen as a difficult one: short stories often frustrate the reader's desire to feel with characters, and several researchers have characterized Mansfield's work as stories of separation and alienation (Hammond 91, 94; Head 110; Kokot 71). I am proposing an alternative reading of a popular story by Mansfield, in which a sense of universal community, however problematic, emerges beside the isolation of human individuals by virtue of the form of the story and its depiction of material spaces. $^{5}$

"Miss Brill" is narrated in third person but speckled with free direct and indirect discourse, focalized by the eponymous English teacher living in a French town. The story is a brief account of her Sunday visit to a public park. Its discourse begins when Miss Brill is already outdoors, but it recalls her earlier departure from her apartment, which has involved putting on a piece of fur. In the park, Miss Brill follows the actions of her fellow strollers with keen, compassionate interest, which grows into a sense of blissful unity and belonging she feels when listening to a band. The ecstatic moment is cut short when she overhears a young couple making abusive comments about her; she promptly returns home, passing by the bakery she usually delights in visiting on Sundays, and puts the fur back into its box.

Only at the end of the story do we learn more details about Miss Brill's apartment: it is described as a "little dark room" and compared to a cupboard (Mansfield 114). The parallelization of living quarters and a cupboard has already occurred slightly earlier, as Miss Brill reflects on the other people in the park: "They were odd, silent, nearly all old, and from the way 
they stared they looked as though they'd just come from dark little rooms or even-even cupboards!" (111). The short story is structured as a series of movements between fictional spaces, which coincide with the affective structure of the text: out of small, nested containers toward an open space accompanied by a liberated feeling; a rupture in this experience and a swift movement back into the containing space. The dominant impression of its whole, formed retrospectively, is a circular structure consisting of in-andout movements in space rather than a linear progression. Thus, the form of the story resembles the containers presented in it.

The beginning of the story foregrounds both Miss Brill's special relationship with a nonhuman thing and the presence of concrete container spaces:

Miss Brill put up her hand and touched the fur. Dear little thing! It was nice to feel it again. She had taken it out of its box that afternoon, shaken out the moth-powder, given it a good brush, and rubbed the life back into the dim little eyes. "What has been happening to me?" said the sad little eyes.

The small fur is a "dead" thing that retains some of its earlier animal shape. It is animated in Miss Brill's imagination: life can be rubbed "back into" its glass eyes, and emotions and verbal thoughts are attributed to it. It is not given life as the animal it once was, but rather personified as a thing to which human language is attributed; thus, there is an ontological instability to the core of the affectionate relationship between Miss Brill and the fur. It is also clear from the beginning that the fur participates in the affective structure of the story built around experiences that can be read into its human protagonist. The "actual" feelings of Miss Brill could be seen as either psychologically projected onto the fur or metonymically expressed by this leitmotif. I suggest that the "feeling with" that occurs between the woman and nonhuman things is actually at the core of the affective experiences evoked in the story. Phenomenologically considered, clothes are minimal containing spaces for the human body, yet they can also be incorporated into affective experience (Colombetti 238-41). The fur is carried close to the body and can be imagined to form part of the everyday clothes defining the body's outline, yet Miss Brill also engages with it as a separate thing. In both cases, it is an integral part of the feelings Miss Brill goes through as the story progresses.

The cupboard-space of Miss Brill's home and the box-space that is home to her animated fur are contrasted with the atmospheric phenomena of joy and openness of the park, all acted out between human beings and nonhuman things. When approaching the park, stroking her fur, Miss Brill feels something "sad—no, not sad exactly—something gentle" moving in her bosom. In the park, she notes that "the band sounded louder and gayer" 
(Mansfield 110) than on other Sundays and wonders whether the conductor is wearing a new coat; things appear more festive than usual. Miss Brill extends the affectionate interest she displayed for her fur to other people, who also become defined by clothes. There is a meeting between characters she calls an "ermine toque" and "a gentleman in grey," which ends in the gentleman humiliatingly snubbing the lady, all of which Miss Brill follows with fascination. The people appear to her as actors in a play, and they are typified by way of naming them according to their clothes. Thus the story, via Miss Brill's focalization, performs gestures of dehumanization. Miss Brill is parallelized with the reader who follows the events possibly with a degree of narrative empathy for the characters, yet remains distant from them. Neither she nor the reader gain knowledge of the "true" experiences of the ermine toque or the gentleman in grey. Nonetheless, the crowd seems capable of arousing her emotional interest and engagement, expressed in exclamations like "Dear me!" and "Oh, how fascinating it was! How she enjoyed it!" (112).

The affective tones of the story do not rest only on performance and spectatorship, however. Miss Brill's focalization displays a sensitivity to sensory experience and synesthetic connections, all of which contribute to the affective structure of the story. After witnessing the mistreatment of the "ermine toque," she senses reciprocation in music: "But even the band seemed to know what she was feeling and played more softly, played tenderly, and the drum beat, 'The Brute! The Brute!' over and over" (112). The "knowing" in the sentence can evoke a cognitive account of empathy based on conscious mind-reading, although the "knower" is a collective entity. On the other hand, empathy is "heard" in the beat of the personified drum, which in Miss Brill's mind connects with how she is feeling. ${ }^{6}$ In "Miss Brill," instead of metonymically representing empathy-as-knowing in the form of music, a more affective form of empathy is built between the focalizer, the band, and the players in the scene she has just witnessed, all assemblages of human bodies and nonhuman things.

This presentation of affectivity distributed between human and nonhuman entities becomes more explicit in what follows the ermine toque scene. Miss Brill experiences a blissful moment of universal love and empathy, tuned to and paced with the music and the materiality of the fictional space:

The band had been having a rest. Now they started again. And what they played was warm, sunny, yet there was just a faint chill-a something what was it? - not sadness—no, not sadness—a something that made you want to sing. The tune lifted, lifted, the light shone; and it seemed to Miss Brill that in another moment all of them, all the whole company, would begin singing. The young ones, the laughing ones who were moving together, they would begin, and the men's voices, very resolute and brave, would join them. And then she too, 
she too, and the others on the benches-they would come in with a kind of accompaniment-something low, that scarcely rose or fell, something so beautiful-moving. ... And Miss Brill's eyes filled with tears and she looked smiling at all the other members of the company. Yes, we understand, we understand, she thought-though what they understood she didn't know.

By virtue of its relative length and evocations of spaciousness and light, this section adds a feeling of "largeness" into the middle part of the story. Its gradually inflating expression is full of long, open-ended phrases and repetitions. Embodied metaphors of upward movement are attached to the music and light imaginable in the space of the park and build a connection between the listener and the world, much in the way Vernon Lee's contemporary work on aesthetic empathy describes the relationship of a listener to music, in which "I also, being identified with the sound, having become apparently the sound itself, must needs move and soar with [the notes]" (Lee, Laurus Nobilis 15; see Martin 42).

This kind of description of aesthetic empathy complicates the reading of the passage and the story as a depiction of cognitive isolation. The affective value of the experience for Miss Brill is evoked by the description of her embodied reactions and by thought report. "We understand" is the content of her thoughts, but it is worth noting that its meaning is different from propositional "knowing." Miss Brill not "knowing" what they "understood" can be interpreted ironically, as if the narrator/implied author was displaying the flimsy grounds of her attunement with the world and others, to which she really has no access. However, the entire passage preceding the phrase builds a non-individualistic, externalist account of this understanding, inviting the reader to join in: it grows out of the music and the atmospheric, material qualities of the situation, instead of being the property of the protagonist's erring mind. The music is "moving," the group "move together," and the understanding between them is of a nonverbal kind. The fact that the language of the story cannot directly express it testifies less of the limits of knowledge and understanding and more of the limits of language, yet the literary text seems capable of conveying even what Miss Brill cannot directly express.

The blissful moment becomes thwarted when Miss Brill overhears the young couple call her a "stupid old thing" and even insult her fur, which to them looks like "a fried whiting" (Mansfield 113). The final part of the story consists of the narrator reporting Miss Brill's actions, no longer her thoughts or feelings. She leaves the park and goes straight to her room, to sit still for a long time, and finally ("quickly, without looking”; Mansfield 114) lays the fur back in its box. The story ends with an observation: "But when she put the lid on she thought she heard something crying" (Ibid.). Thus, in the semiotic field of "Miss Brill," containment does not point toward safety 


\section{Laura Oulanne}

and happy memories as it does in Gaston Bachelard's influential Poetics of Space (1958), for instance, but toward constraint and suffocation. The ending, with Miss Brill returning to her "cupboard" and the fur returning to its box, to be stored within an actual cupboard nested within the apartment space, affords at least a twofold "closure" enacted by the material features of the storyworld and the progression of the events.

In this light, the ending might be read as supporting an ironic, internalist interpretation, as a reminder that there has been no actual connection between any of the agents of the story, and everything happens "inside" Miss Brill's mind. This is a formal feature very typical of Mansfield's stories. There may be a moment of epiphany, felt as an opening, but it tends to be followed by a blunt, negative anti-epiphany, even though her stories are usually read more in terms of open-endedness than closure (New 106, 124). The propositional "message" of the story seems clear: Miss Brill is like her fur, trapped inside a box of her life and mind, and so are the other people in the park. Her sense of "singing together" and "moving together" has been an illusion, and only her exalted mood has kept her from seeing the true state of things-people as containers sealed off from one another.

However, if we consider the whole of the story in terms of its form, the meanings it affords are not quite sealed by its closure, and its celebration of a universal kind of bodily empathy or material sympathy is not negated by the fact that the story ends by placing its main character in isolation. Caroline Levine warns of conceiving literary texts as spatial artifacts, suggesting that it is their temporal form that affords other than totalizing meanings. The form of "Miss Brill" is temporal in terms of progression but rather circular than linear, which makes the moment of ecstasy in the park appear as a peak or an opening in the circle. The closure meets the beginning, not constructing an opening into futurity akin to what Levine has in mind, but a containment of the story within itself, including all the smaller, concrete containers of the fictional world. What remains with the reader is a conceptual-experiential blend of containments and openings, but the affective weight of the ecstatic description in its middle positions all these containers as something that affords an opening. Thereby even the ending retains some of the openness of the middle part and does not need to cancel the nonpropositional "understanding" achieved there.

The story confirms an understanding of literary texts as, in Levine's words, "inevitably plural in their forms-bringing together multiple ordering principles" (40) in spite of working within the form of the bounded whole. The reader has been invited to follow Miss Brill in experiencing the intensity of being-in-the-world as being-with-others-people and things. She is also invited back to the small apartment, and further, back into the stuffy box in the cupboard, as the focalization of the story has distributed the fictional experience between Miss Brill and her furry companion. Actually none of the movements in the story are "hers" only. In the moments of connection, people do not appear as sealed containers but intensely present in an 
embodied manner, as do the nonhuman features of the storyworld. In this world, it seems possible to "feel with" a fur, a crowd of people, and a piece of music. None of this is dependent on "knowing" or even "understanding;" the sympathetic distribution of affect comes forth as an integral part of life, as Bennett puts it, "a more-than-human flow of communicative transfers, a flow that is the indispensable precursor to the interiorized sentiment that bears the same name" (Influx \& Efflux 29).

In conclusion, the story proposes the impossibility of empathy, but on the other hand, the reading of the story as an affective whole relies on a worldly kind of empathetic engagement. Metaphorically, the story itself could be described as a box containing various elements in a dynamic relation with one another. The preference of spatial description over temporal succession affords an interplay of various meanings instead of a fixed interpretation that would reveal the human condition of solipsism and the illusoriness of empathy. Even though Miss Brill's interaction with the fur may come across as a symptom of isolation, and even though her blending with human and nonhuman others seems like an illusion shattered by the reality of human meanness, the affective structure of the story hints not only at the possibility of empathy but also its being a necessary part of lived experience. As Hammond observes, Mansfield displays "human interiority [as] intrinsically networked" (111-12). To take the idea further, the networks of the story crucially involve the nonhuman world and question the entire idea of "interiority" as the defining feature of affective experience.

\section{Woolf's Yellow Dress as a Space for Empathy}

The possibilities or impossibilities of intersubjective connection and empathy are also a central theme in Virginia Woolf's fiction. As Martin notes, Woolf "explores both the feeling of the sympathy, and the sense that sympathetic connection might take place at a level removed from conscious feeling, extending beyond one's body" (82). Martin notes that Woolf experimented with rendering sympathy as a communion with the world that surpasses the individual but is wary of the ethical implications of this notion. In line with Martin's interpretation, I am reading Woolf's short story “The New Dress" as an exploration of such sympathy/empathy as a phenomenon surpassing the individual, based on embodied grasping or synchrony. Reading the formal composition of the story and its container spaces with the phenomenological perspective to embodied empathy and the idea of sympathy as a more-than-human atmospheric phenomenon, I suggest that Woolf's fiction may be read as an evocation of an anti-anthropocentric ethic, which does not necessarily privilege the contained human individual.

Woolf wrote "The New Dress" after finishing Mrs Dalloway (1925), as part of a group of eight stories all set in Clarissa Dalloway's party. Like "Miss Brill," it is an account of a social gathering from the point of view of a solitary woman. Yet as regards characters' movements in the fictional 
space, Woolf's story is structured like a mirror image of Mansfield's: it is opened by an entry into an interior space and closed by a departure from it. The story is narrated in third person but focalized by Mabel Waring, who has had a dress made for the party. The beginning of the story is marked by a rupture in her experience, initiated by an uncomfortable sense of the dress: "it was not right, not quite right ... No! It was not right" (49). The rest of the narrative relates Mabel's struggles as she interacts with other guests but simultaneously has her mind on the dress that she has deemed a failure and her recollections of trying it on at the dressmaker's. In Mabel's focalization, the main lived spaces of the story (the Dalloways' house, the dressmaker's studio, and the minimal space of the dress around Mabel's body) all appear as cramped, confined containers closing in on one. As such, they afford not only a limited set of kinesthetic actions but also limits for intersubjective engagement. However, the formal dynamics of "The New Dress" and its affective structure as experienced by the reader suggest that feelings are not all contained within characters and their restricting clothes and apartments but that spatial elements and nonhuman, material containers also bring about affective states and elicit empathy.

Readers learn that the dress is pale yellow, made of silk, with a long skirt and "high sleeves," but its description is rendered markedly subjective with the addition of "idiotically old-fashioned" (50). Mabel attributes the realization that something is "not right" to other guests' imagined thoughts, and this changes her experience of the spaces of the story: "And at once the whole of the room where, for ever so many hours, she had planned with the little dressmaker how it was to go, seemed sordid, repulsive; and her own drawing-room so shabby, and herself, going out, puffed up with vanity ... all this now seemed unutterably silly, paltry, and provincial" (49-50). This feeling is said to "explode" the moment she enters the drawing-room. Mabel's insecurity implies a class distinction between her and the Dalloways: she cannot afford a fashionable dress, so she decides to make hers special by following an old Paris fashion book, with the result of her looking different from the other guests. The dress and the drawing-room act together to change Mabel's perception of the situation, and of herself. It is impossible to say which is causally prior, her feelings about herself or her perception of the surrounding space and the effect of her dress; the two form an integral whole. As the dress keeps appearing in the story, it not only metonymically but also concretely encompasses Mabel's fictional experience and invites the reader to imagine the bodily feeling of wearing it, which can be conductive of a kinesthetic form of narrative empathy.

Mabel makes attempts toward interpersonal connection, but they seem to be thwarted by her feelings of insecurity and inferiority, which are enacted in the way she experiences her dress and the space of the drawing-room. She conjures up a mantra-like phrase, typical of Woolf's work, which she repeats to change her perspective of the party: "We are all like flies trying 
to crawl over the edge of the saucer" (50). Yet she only succeeds in seeing herself as a fly stuck in a saucerful of liquid. She also tries to put things into perspective by declaring: “There's Shakespeare! There's death! We're all weevils in a captain's biscuit'-or whatever it was that people did say" (52). Here the change from direct to indirect discourse suggests a change from the directness of exclamation to an appeal to the common opinion, Mabel remaining the focalizing agent all the while. The narration supports the impression that Mabel unsuccessfully attempts to get ecstatically "beside herself" to shed the point of view that remains tightly bound to herself; the story offers no shifts of focalization in the manner of Mrs Dalloway or Woolf's later novels.

A conversation about family illnesses continues to tweak the scale and thematize the problems of sympathy. Mabel, as quoted at the beginning, sees herself and her interlocutor in the mirror as "boot-buttons or tadpoles:"

And what was still odder, this thing, this Mabel Waring, was separate, quite disconnected; and though Mrs. Holman (the black button) was leaning forward and telling her how her eldest boy had strained his heart running, she could see her, too, quite detached in the looking-glass, and it was impossible that the black dot, leaning forward, gesticulating, should make the yellow dot, sitting solitary, self-centred, feel what the black dot was feeling, yet they pretended.

Mrs. Holman "snatches" the minimal sympathy Mabel is able to give, and Mabel thinks she is "greedy" for more-yet "in her yellow dress to-night she could not wring out one drop more; she wanted it all, all for herself" (55). The passage displays a skepticism of sympathy typical of Woolf's work. Sympathy is portrayed as a scarce substance to be dealt condescendingly between the characters, themselves closed containers; Mabel's unfortunate dress appears as a shell that covers emotions and blocks interaffective exchange. This definition of sympathy is close to the moral sentiment of pity, which suggests a hierarchical relation; it also implies two "self-enclosed" subjects who can only form imaginary "ideas" of what the other is feeling (Bennett, Whitman's Sympathies 607). However, the dehumanizing tone, referring to the characters as "this thing," "the yellow dot," suggests that the sympathy at play in the passage is not pity, but an affective assemblage whose bounds "spill out beyond the human" (612). The narrator's wording invites the reader to observe the interaction as an encounter between two bodies in space. The intersubjective exchange of the passage can thereby be seen to reside on the surfaces of the characters' bodies and in the space that they both inhabit, instead of their interior psyches. The situation, with all its difficulties, arises from its assemblage of things in space, not from an architecture of human minds nested within sealed containers. 


\section{Laura Oulanne}

Furthermore, Mabel actually senses the need for sympathy in her interlocutor, and the gestures of the "black dot" are provided as proof of this need. Following Dan Zahavi and Philippe Rochat, the bodily expression of another-even as a "gesticulating" "black button"-allows us to grasp something of their affective state. This is an intersubjective relation that the reader of the story is invited to participate in. The idea of gaining the knowledge of the other's need by "reading" or forming "ideas" may therefore be too restricted. The reader is indeed reading a text, but the passage invites the involvement of pre-reflective processes that are closer to the minimal affective, kinesthetic grasping of the imagined, fictional body and, crucially, the material containers encompassing/incorporated in it. It is this kind of "reading" that could be applicable to the instance of "mind-reading" evoked in the fictional world as well, which foregrounds the relational and the nonhuman as sites of emotion besides the rational human container of thoughts and emotions.

In another space, the dress is shown to function quite differently, as an element of distributed affectivity. The dressmaker's workroom is brought up twice in the story. When first mentioned, it is presented as an alternative, illusory reality revealed as such by the space of the Dalloways' drawing-room:

This was true, this drawing-room, this self, and the other false. Miss Milan's little workroom was really terribly hot, stuffy, sordid ... yet, when Miss Milan put the glass in her hand, and she looked at herself with the dress on, finished, an extraordinary bliss shot through her heart. Suffused with light, she sprang into existence.

(Woolf 51)

Paradoxically, in the stuffy room, expressions of containment give way to those of light, openness, and the existential feeling of being alive. Again the text points toward a material surface, a reflection of a dress in a mirror, yet Mabel describes seeing "the core of herself, the soul of herself" (51-52). Importantly, she is not alone in her bliss:

she felt, suddenly, honestly, full of love for Miss Milan, much, much fonder of Miss Milan than of any one in the whole world, and could have cried for pity that she should be crawling on the floor with her mouth full of pins, and her face red and her eyes bulging-that one human being should be doing this for another, and she saw them all as human beings merely, and herself going off to her party, and Miss Milan pulling the cover over the canary's cage, or letting him pick a hemp-seed from between her lips, and the thought of it, of this side of human nature and its patience and its endurance and its being content with such miserable, scanty, sordid, little pleasures filled her eyes with tears. 
This moment of epiphany resembles the one described in "Miss Brill," even as regards the exact choice of words ("filled her eyes with tears"). Love, a sense of togetherness, and the problematic moral sentiment of pity mingle with the perception of the other's bodily experience of crawling on the floor and expand into a vision of interconnectedness involving human beings and Miss Milan's canary, a vision that Mabel's spells do not manage to retrieve in the party space. Even though the material features of the two situations are almost identical (the dress, a mirror, two women), the workroom hosts a completely different feeling than the drawing-room. Is this a product of mere sense of socio-economical superiority, which Mabel is not able to attain at the Dalloways' party? This is a plausible reading, and Woolf's story certainly suggests that to "have" sympathy or empathy one needs certain material affordances. Yet the dominant affective tone of the passage is not of superiority but of an abstract love that encompasses Mabel, canaries, seamstresses, and party-goers alike, and a giver or a receiver of sympathy cannot be identified.

Woolf's story seems to debate the problem of empathy as an epistemological question of truth and illusion. Mabel is wavering between the view of the party as "true" and her bliss at the dressmakers' as illusion; on the other hand, "Miss Milan was much more real, much kinder" (53). None of the options sticks with Mabel affectively, which she attributes to her "vacillating character." If we read "The New Dress" as a study of how this type of personality colors perception, the epistemological outcome would be along the lines of the subjectivity of all truths. However, the affective-cognitive engagement the story invites suggests a more spatial and relational, less relativist reading. The two rooms and the dress are brought forth as material frames for all Mabel's musings, and the story foregrounds their effect on Mabel's experience in all its ambiguity, which is not only epistemological but also ontological: "a party makes things either much more real, or much less real," she contemplates (51). It is not only Mabel's "personality" that should be taken into account in reading the text from the point of view of affect and empathy, but also the relations between bodies in space, which come to the fore in the form of the story.

Even though the actual events are located in the party, Mabel's thoughts bring up other spaces. In addition to recollections of her own drawing-room and Miss Milan's workroom, she remembers a "divine moment" on the seaside and plans a visit to the London Library; the two spaces become parallel in terms of openness and possibility. She describes feeling on the beach as though she was lying "in the hand of the Goddess who was the world" (56) and rejoices in the possibility of finding a life-transforming book at the library. Punctuated with these images, the story follows Mabel's embodied mind in oscillating between containment and liberty, stuffiness and openness, all the while remaining in Clarissa Dalloway's drawing-room and within the yellow dress, which indeed is capable of containing all the imaginary spaces and "ups and downs of feeling" that the story is built on. 


\section{Laura Oulanne}

Although "The New Dress" is less clearly organized around a path from containment to opening and back than "Miss Brill," this story too ends in a material enactment of closure: as Mabel leaves the party, devastated, she wraps herself "round and round and round, in the Chinese cloak she had worn these twenty years" (58). Readers are given strong cues to follow Mabel's focalization through alternating experiences of suffocation and rapture, as concrete experiences and embodied metaphors. The tightness of the cloak and its thrice repeated enclosure of Mabel's body give experiential form to the closure of the story, but on the other hand, the ending has her exiting the interior space into the world of beaches and libraries. Taking into account the status of the story as a fictional narrative, and even one with a shared storyworld with Mrs Dalloway, the closure does not mark a totalized meaning.

Furthermore, "The New Dress," even more so than "Miss Brill”, could be described as a container without losing the possibilities of openness and ambiguity. The story does not rely on a climax of plot. It is a descriptive account of impressions for which the container metaphor is quite fitting, especially if we recall what containers are like in its storyworld: not abstract but lived, material spaces. The "plot" of the story consists in slight affective shifts in fictional lived space, which do not follow any particular order or display a pattern of development. Rather, their alternation is brought to the fore, which seems to make ambiguity and relationality, rather than solipsism and containment, the "final words" of the story. The story, like the party, has afforded experiences that feel both intensely real and shallow or deceptive.

Understanding "The New Dress" as a container of narrative experience affords two levels of reading. On the one hand, the story is organized around a timeline from Mabel's entrance to her exit contained within her cloak and read accordingly as an account of existential loneliness; on the other hand, it can be seen as a more ambiguous stream of affectivity, which experientially suggests the possibility of empathy and distributed affect that is denied by the propositional content. The blissful, exultant moments of being, accompanied by a sense of opening up, are suggested to be as experientially "real" as the moments of doubt and segregation at the party. Thereby the focus shifts from questions of peering into the minds of others to the way things and bodies exist and share space, and the human individual is removed from its center. The eponymous dress is a nonhuman thing, yet central to the production of the affective complexity of the story. Its material properties, too, afford two opposing interpretations: it is a tight, stuffy, and "wrong" container for the human body, but its color and material point toward light and lightness. It is ambiguous in its relation to intersubjective connection, both in the storyworld and as a narrative device. In the fictional world, the dress is a barrier between Mabel and others, but it also affords empathy. In line with the phenomenological account of empathy as embodied grasping, it seems to be the expressiveness of other bodies, clad in dresses of different colors, sometimes seen only in the mirror as dehumanized dots, that elicits 
what can be sensed of the feeling of the other. The reader, too, is continuously reminded of the feelings brought forth by the materiality of the dress and invited to empathize with Mabel's embodied experience, not so much with the report of her thoughts. In "The New Dress," the ontological and physical closeness of human characters and nonhuman things is therefore not an obstacle to but a vehicle of empathy.

\section{Conclusion: Feeling Into Containment}

"Miss Brill" and "The New Dress" foreground the importance of material spaces and nonhuman things for affectivity and intersubjectivity. They display psychologistic empathy and the "moral sentiment" of sympathy as highly problematic phenomena laden with power imbalances, yet present intense moments of empathy as a fellow feeling, grasping something shared in being-in-the-world between human and nonhuman entities. Seen thus, the account of the mind put forth in the stories is not one of subjective interiority, but of embodied being in an experiential world. The stories show humans contained by material spaces, but do not display the human individual as a container sealed off from the world.

This reading of the relation between the metaphor of the container and the modernist "problem of other minds" opens up new ways of thinking about the container form in literature. The mind or consciousness emerges from overlapping schemas of containment in the material world. In the storyworlds, words often come between the characters as barriers rather than something that brings them together, while material things and bodies constitute connecting surfaces as well as separating boundaries. Considering the stories as fictional artifacts made sense of in a process by an embodied reader, their spaces and materialities, as well as the lived bodies come to the reader by way of words. The stories' way of using containers as cues for imagining what it is like to be the character in the fictional, material world, and as schematic metaphors based on the shared experience of that world, does not suggest a container view of the mind but conversely a relational, interconnected, entangled existence of human and nonhuman bodies. Furthermore, the container as a spatial metaphor for the form of a short story, or of fiction in general, affords not only immobility and totality but also ambiguity and openness of meaning.

\section{Notes}

1 According to Lakoff and Johnson, conceptual metaphors that dominate our thinking arise from the way our lived bodies interact with the world: in addition to a vertical position and a forward-looking face, for instance, our bodies are experienced as containers separated from the environment by the skin, and themselves capable of being contained.

2 This direction has been explored in earlier fiction by Miruna Stanica (2014), according to whom the description of space as a container leads to a 


\section{Laura Oulanne}

non-anthropocentric, aperspectival relation to fictional space, and a focus on containers enables the mobility of characters instead of fixing them in terms of time, space, or meaning.

3 These approaches, however, build on the work of thinkers contemporary to Woolf and Mansfield, such as Edith Stein and Max Scheler.

4 Edward Titchener understands empathy to be, among other things, a "process of humanising objects;" Vernon Lee's account of aesthetic empathy discusses a projective relation between a human viewer and a work of art or a landscape.

5 For a reading of empathy in this story in conjunction with other works by Mansfield, in addition to Jean Rhys's short fiction, see Oulanne 2021.

6 Music, arising in an interaction between a musician and a thing — an instrumenthas been shown to enhance and produce affectivity by itself (Colombetti 242).

\section{References}

Bennett, Jane. Influx \& Efflux: Writing Up with Walt Whitman. Duke University Press, 2020.

Bennett, Jane. “Whitman's Sympathies.” Political Research Quarterly, vol. 69, no. 3, 2016, pp. 607-20.

Cave, Terence. Thinking with Literature: Towards a Cognitive Criticism. Oxford University Press, 2016.

Colombetti, Giovanna. “Affective Incorporation." Phenomenology for the TwentyFirst Century, edited by J. Aaron Simmons, and J. Edward Hackett, Palgrave Macmillan, 2016, pp. 231-48.

Dennerlein, Katrin. Narratologie des Raumes. De Gruyter, 2009.

Hammond, Meghan Marie. Empathy and the Psychology of Literary Modernism. Edinburgh University Press, 2014.

Harrington, Ellen Burton. Scribbling Women and the Short Story Form: Approaches by American and British Women Writers. Peter Lang, 2007.

Head, Dominic. The Modernist Short Story: A Study in Theory and Practice. Cambridge University Press, 1992.

Herman, David. "1880-1945: Re-Minding Modernism." The Emergence of Mind: Consciousness in Narrative Discourse in English, edited by David Herman, University of Nebraska Press, 2011, pp. 243-72.

Kokot, Joanna. "The Elusiveness of Reality: The Limits of Cognition in Katherine Mansfield's Short Stories." Katherine Mansfield and Literary Modernism, edited by Janet Wilson et al., Continuum, 2011, pp. 67-77.

Lee, Vernon. The Beautiful. Cambridge University Press, 1913.

Lee, Vernon. Laurus Nobilis: Chapters on Art and Life. John Lane, The Bodley Head, 1909.

Levine, Caroline. Forms: Whole, Rhythm, Hierarchy, Network. Princeton University Press, 2015.

Lakoff, George and Mark Johnson. Metaphors We Live By. University of Chicago Press, 2003.

Mansfield, Katherine. “Miss Brill.” Garden Party and Other Stories. Penguin, 1997, pp. 110-14.

Marcussen, Marlene Karlsson. Reading for Space: An Encounter between Narratology and New Materialism in the Works of Virginia Woolf and Georges Perec. PhD dissertation, University of Southern Denmark, 2016. 
Martin, Kirsty. Modernism and the Rhythms of Sympathy: Vernon Lee, Virginia Woolf, D.H. Lawrence. Oxford University Press, 2013.

New, William H. Reading Mansfield and the Metaphors of Form. McGill-Queen's University Press, 1999.

Stanica, Miruna. "Bundles, Trunks, Magazines: Storage, Aperspectival Description, and the Generation of Narrative.” Style, vol. 48, no. 4, 2014, pp. 513-28.

Titchener, Edward B. A Text-Book of Psychology. Macmillan, 1913.

Woolf, Virginia. “The New Dress.” A Haunted House. Hogarth Press, 1953, pp. 43-48.

Zahavi, Dan. "Empathy and Other-Directed Intentionality." Topoi, vol. 33, no. 1, 2014, pp. 129-42.

Zahavi, Dan, and Philippe Rochat. "Empathy $\neq$ Sharing: Perspectives from Phenomenology and Developmental Psychology." Consciousness and Cognition no. 36, 2015, pp. 543-53. 


\title{
2 Floating Air-Solid Furniture \\ Vibrant Spaces in Virginia Woolf's "Time Passes"
}

\author{
Marlene Karlsson Marcussen
}

Perhaps counter-intuitively, coming to terms with the fact that we are now living in the geological era of the Anthropocene has prompted scholars from a wide range of fields to turn to literature. Literature is in recent postanthropocentric theory regarded as a privileged medium for imagining more-than-human realities. ${ }^{1}$ In "System and Things" (2012), Jane Bennett for instance notes that "[poetry] can help us feel more of the liveliness hidden in such things and reveal more of the threads of connection binding our fate to theirs" (232). Literature is here seen as having the potential to bracket our human perspective while offering the nonhuman its own voice. An even more radical perspective can be found in object-oriented philosophy, whereby literature shows that all relations are appearances; as Timothy Morton notes in "An Object-Oriented Defense of Poetry" (2012): "for OOO what is called 'matter' is simply matter for ... an aesthetic phenomenon" (217). Overall, literature is highlighted in post-anthropocentric theory as the place where we humans may learn to have "a cultivated, patient, sensory attentiveness to nonhuman forces operating outside and inside the human body, ... to induce an attentiveness to things and their affects" (Bennett, Vibrant Matter xiv).

While we have now, as the human species, engraved our history into the Earth, this geological turn has yet to be inscribed into narratology, the field of study that most prominently deals not only with literature but with narrative as the form which enables us to construct ourselves as a species as narrative beings. Since the narrative turn it has been acknowledged that narrative is not only a tool for thinking and writing fiction but a tool integral to the ways in which we live and understand ourselves as humans. ${ }^{2}$ With the popularity of "Anthropocene" as a term, it has become obvious that we need to displace the human from the center of reality at the exact moment in history when humans inevitably have dominated the Earth. When confronted with the post-anthropocentric perspective of the Anthropocene, our current understanding of narrative is lacking in explanatory power. In narratology there has been a strong tendency toward temporality and subjectivity, and this tendency contains a latent anthropocentrism as it does not sufficiently acknowledge nonhuman forces. Instead, it reproduces the very tale that has 
dominated Western thought, sustaining the binaries of subject/object and life/matter.

In this essay, I combine the post-anthropocentric interest in literature with a new understanding of narrative in order to disrupt our habitual humanization of reality in literature. I want to understand exactly how literature presents Bennett's attentiveness to things, which she calls "thingpower." What I propose is that Bennett's philosophical attentiveness toward nonhuman forces requires an equally attentive literary reading of how nonhuman forces are represented in literature. An attentive literary reading requires a renewed understanding of the nonhuman and of the surrounding narrative world where the nonhuman is not only read as a setting or an object for characters in novels but could be a narrative "event" in its own right. I propose to do this through a close reading of descriptive details, revising the anthropocentric understanding of narrative by paying attention to punctuation and to the way objects and spaces are represented. This is something that has not yet been fully addressed by post-anthropocentric scholars such as Bennett, because of their main philosophical interests in literature, leading them to leave out formal questions.

To address these questions, I want to reopen the discussion of narration and description in narratology to arrive at a concept of narrative that can include nonhuman forces. My aim is a re-evaluation of narrative in the light of the Anthropocene; I will exemplify this through the modernist novel To the Lighthouse (1927) by Virginia Woolf, which indeed pushes back the boundaries of narrative in the novel's second part, "Time Passes." Here Woolf presents a narration of space, where characters and plot have been bracketed in favor of a vibrant space. Events take place within the summerhouse emptied of characters, engendered by the encounter between moving air and domestic things such as furniture. Through anthropomorphism, paratactic sentences and the distinctive use of brackets, commas, and semicolons Woolf depicts movement on a spatial level that does not focus on "who" is acting, but on the material, relational action of the encounter.

The following essay will consist of three steps: firstly, a brief theoretical discussion of narrative theory in light of post-anthropocentric thinking and secondly, a close reading of a short passage from "Time Passes," which through formal analysis shows how space can be more than static setting, how it too can be narrated and not simply described. Thirdly, based on a revision of the otherwise subject-centric notion of anthropomorphism, the intertwining of form and content necessitates an analytic focus on what kind of materiality the verbally described space consists of, that is, an encounter between floating air and solid furniture.

\section{Post-Anthropocentric Narratology}

In Stuff Theory: Everyday Objects, Radical Materialism (2014), Maurizia Boscagli describes the turn to post-anthropocentric theories as a way to 
"present versions of the material as unruly: they refuse to play by the rules that define materiality as passive matter. Their sense of a world in which matter is in flux, offering promising new versions of subject-object entanglements" (3). Broadly speaking, these theories strive to move beyond the dichotomy of an active vital subject and a passive or inert object and try to give voice to more-than-human realities. In her influential Vibrant Matter (2010), Bennett introduces the concept of "thing power," which "gestures towards the strange ability of ordinary, man-made items to exceed their status as objects and to manifest traces of independence or aliveness, constituting the outside of our own experience" (xvi). The question that these theories all struggle with is, as Bennett notes, "how to describe without thereby erasing the independence of things?" (xiii). Here Bennett, Boscagli, and Morton, to name just a few scholars, all turn to literature. They find in literature the strange ability to "evoke the background as backgroundto drag it into the foreground would dissolve it-it must resort to oblique rhetorical strategies" (Ecology without Nature 45), as Morton notes. What both Morton and Bennett are after is the way literature organizes a space beyond our human habitualization of reality, where the more-than-human, vital background, or environment can emerge in ways that are not entirely dominated by an anthropocentric perspective.

More-than-human realities, such as the surrounding environment, have always played only a minor role in narrative theory. The two most distinct ways of encountering the more-than-human reality in literature are through objects and space, even when these are made by humans as in the case of furniture or buildings. Space and objects are, as Marie-Laure Ryan, Kenneth Foote, and Maoz Azaryahu note in Narrating Space/Spatializing Narrative: Where Narrative Theory and Geography Meet (2016), “a relatively neglected dimension of narrative" (16). They argue that one reason why space has been an especially neglected topic is "the wide range of phenomena that can be considered spatial: narrative space extends from the individual object described in a narrative to the cosmic order in which the story takes place" (23). Consequently, they propose five basic levels of narrative space: "a) Spatial frames, b) Setting, c) Story Space, d) Storyworld, e) Narrative universe" (24-25). Though usefully addressing the concept of space in the narrative, this geographical interest only describes spaces in connection with characters and plot. They thus bracket the first part of the list of neglected topics-that of "individual object described"in favor of an anthropocentric conception of narrative space. I will argue that it is indeed in descriptions of objects and spaces that Bennett's thing power can be found in novels but only if we revise our understanding of description and narration and allow space and objects to create events. That involves focusing on passages in which space plays an active role, as unruly materiality and not as passive matter or setting.

As Ruth Ronen notes, there is a long tradition in narratology (from Gérard Genette to Ryan) that defines narrative by opposing it to description: 
"Narrative is positioned here as direct opposite to description, as everything which description is not" (276). In "Toward a Definition of Narrative" (2007), Ryan defines the two text types as "a changing world for narrative, a static one for description" (27). Narrative is typically understood as a representation of an event or of a sequence of events that are ordered according to chronology, causality, and an experiencing subject. In narrative, the focus is on an acting subject: the events must affect human characters and must be ordered through chronological markers. Space and nonhuman objects are not included as part of this definition of narrative. They belong to the static world of description. There is a latent anthropocentrism in the way that narrative always takes precedence over the description in narrative theory: as the nonhuman mostly figures in what is typically understood as description, it is always subservient to the human characters, as a series of props or a setting. Likewise, in the theory of description, the nonhuman is always only seen in relation to an acting subject and thus never as an active force or event in itself. Even Philippe Hamon, who tried to restore the role of description in narratology in a seminal issue of Yale French Studies (1981), assimilates description into narration and continues the anthropocentric bracketing of nonhuman forces. Hamon argues for the importance of description, resisting Barthes's relegation of descriptive details to a mere effet de réel. For Hamon, description either serves to show features of the characters through the setting or helps the reader interpret or predict the plot of the story. It is something to be integrated into the narrative, reflecting a normative assumption that the reader should not be burdened with excessive information. The described nonhuman things and spaces are thus not important in themselves, only in reference to a narrative whole with the character as point of reference. He ensures this by showing how characters set descriptions in motion, either in the way they view the described object, how they talk about it, or how they act with it, as his descriptive formula shows:

\section{$C+F+I T(V+P E q / P E f)$ ("What is a description" 160)}

This means that a description consists of a character (C), a form of action (F), the setting with its introductory theme of the description (IT). The form of action can be either: looking at/speaking with/acting with the setting, which can be either a milieu/landscape/collection of objects, which then triggers a series of sub-themes. The latter is described between parentheses through a vocabulary $(\mathrm{V})$, which is in a metonymic relation to the setting. The sub-themes can be expanded by a predicative (PE) that can either be qualitative (q) or functional (f). ${ }^{3}$ Despite the fact that Hamon with this formula includes the nonhuman-the "IT" element-the nonhuman is only assessed in relation to an action carried out by a character. In effect, the nonhuman (whether it is space, objects, or landscapes) is here always subjected to the human. 
The problem with narratology from a post-anthropocentric perspective is that it only allows human subjects to perform actions. The nonhuman is only seen as a static setting, where objects are not allowed to be the active part that affects and transforms the subject. What we need is an understanding of nonhuman spaces and objects that allows us to see these as an active part, so that they, just like characters, can perform and create events without any characters there to initiate them. As Ronan aptly stresses, although only in passing: "a landscape can be described as an active agent" (276).

\section{“Time Passes”-Narrated Space}

Virginia Woolf's novel To the Lighthouse does indeed depict space as an active agent. The novel is divided into three parts, where the middle section, "Time Passes," depicts the passing of ten years from the nonhuman perspective of a house with no characters present. ${ }^{4}$ This middle part is contrasted by the first and third parts of the novel which are told through different characters' inner experiences of small everyday events. By so doing, Woolf is pushing the boundaries between temporal narration and spatial description to the extreme, but she is also placing her novel in a gap between two literary traditions: the descriptive realism of the Edwardians and the fragmented subjective "closer-to-life" narrative of Georgian Modernism. ${ }^{5}$ Whereas the first part, "The Window," and the third part, "The Lighthouse," can be characterized as typical modernist narratives, what happens narratively in "Time Passes" is something altogether different. Reacting against the normative claims laid upon the novel by the previous generation of Edwardian writers, such as Arnold Bennett, yet dissatisfied with the way other modernist writers, such as James Joyce, opened new paths for the novel, Woolf developed her own distinct form of the novel that seems to anticipate many of the ideas of post-anthropocentric thinking. Here the Edwardian descriptive realism is combined with the flux of modernity, not, however, the flux of a human consciousness, but a flux intrinsic to space. Combining strategies more typical of poetry and drama, Woolf created a modernist novel that-contrary to Joyce's-sought to evoke not only the consciousness of subjects, but also "the world seen without a self," as Bernard, one of the characters from The Waves, puts it. In the essay "Modern Fiction" (1925), Woolf even calls this an "attempt to come closer to life" (161).

A well-known reading of this novel can be found in Eric Auerbach's Mimesis (1946), which laid the foundations for how we understand Woolf as a modernist writer today. What distinguishes Woolf (along with James Joyce, Marcel Proust, and Thomas Mann) is their departure from and disintegration of realistic representation of reality, their attention fixed instead on the internal experiences of small-scale, everyday events within a fragmented timeline. Auerbach emphasizes the one-day structure of their 
novels and their subjective indeterminacy vis-à-vis an objective reality. All this holds true in regard to the first and third parts of To the Lighthouse, and to Woolf's other novels such as Jacob's Room (1922), Mrs. Dalloway (1925), and Between the Acts (1941). But what happens in "Time Passes" and also in The Waves (1931) departs a great deal from this definition. In his analysis of the novel, Auerbach does not give much thought to "Time Passes," and only in passing does he refer to it as a symbol of what happens to Mrs. Ramsay. This view is quite typical in the reception of the novel. Most critics have remarked upon the temporal regime of "Time Passes," ignoring its distinctive depiction of space. If this spatial descriptive quality is noted, especially by early critics, it is as ornamental and superfluous, thus repeating the typical narratological view on the spatial description. ${ }^{6}$

"Time Passes" is indeed an excellent example of the way narration and description are intertwined as space emerges as an event. It is not just time passing but space happening. I argue for a reading of modernist fiction in the opposite direction of Auerbach's subjective reading and agree with Boscagli, who stresses that modernist aesthetics highlights "the very traffic between the subject and her 'outside', between the human and the nonhuman" (13). But unlike Boscagli, I will analyze how this traffic is formally realized by Woolf's use of punctuation, brackets, semicolons, and commas, and through the use of anthropomorphic metaphors and similes.

In "Time Passes," Woolf reverses the relationship between what a narrative text conventionally consists of and what is normally placed in brackets. The main text does not depict the actions of characters, but the actions of the spatial setting. Here it is the characters and their lives that are depicted literally in brackets; indeed, the result is the very opposite of Hamon's formula, where the description of the setting was placed within brackets. Woolf not only turns this formula upside down, as she frontloads the setting in the equation, she also turns the description of space into narration and thus inscribes a change into the otherwise static space of Hamon's description. But even more surprising in regard to Hamon's formula is the fact that Woolf's narration of plot-something not only outside of the formula, but the very thing that narratologists distinguish description from-is literally placed inside the bracket and so turned into a subtheme, assigning space the main part in the equation. Woolf is here reversing the relationship between narration and description, space and characters.

The second square bracket in "Time Passes" is perhaps the most famous line in the novel. It tells the reader about the death of the main character, Mrs. Ramsay, rather indirectly: "[Mr Ramsay stumbling along a passage stretched his arms out one dark morning, but Mrs. Ramsay having died rather suddenly the night before, he stretched his arms out. They remained empty.]" (140). Woolf thus kills off her main character, not only in a bracket, but in a subordinate clause in a bracket. The suddenness of Mrs. Ramsay's 
death stands in stark contrast to the continuity described in the chapter's opening line: "But what after all is one night? A short space, especially when the darkness dims so soon, and so soon a bird sings, a cock crows, or a faint green quickens, like a turning leaf in the hollow of the wave" (139). Continuity is here not simply a temporal aspect of "time passing" as many critics have suggested: the description of time passing has morphed into a spatial narration, with the accumulative commas narrating and not merely listing things that take place. ${ }^{7}$ Active verbs are one of the ways in which Woolf narrates and not simply describes space. This narration of space begins with "darkness dims," moving on to "a bird sings, a cock crows, a faint green quickens;" all things not simply listed but described as events, as things that actively happen; in short, each a small narrative in itself, depicting a vibrant spatial setting. In Event and Eventfulness (2011) Peter Hühn distinguishes between two kinds of events: event I and event II, where "event I is present for every change of state explicitly or implicitly represented in a text. A change of state qualifies as a type II event if it is accredited-in an interpretive, context-dependent decision-with certain features such as relevance, unexpectedness, and unusualness" (2). According to this definition, these small events are of the first type and contrasted with the suddenness of the life-changing event of Mrs. Ramsay's death. A bracketing of narration is happening on one level (the bracketing of Mrs. Ramsay's death) but is substituted on another level with a different textual regime that dismantles the relationship between spatial description and temporal narration. By bracketing the conventionally recognizable events while foregrounding nonhuman happenings that we would not normally consider events, Woolf presents a spatial narration.

Without conventional characters in "Time Passes," all that happens happens on a nonhuman level. And here, events take place in a flowing movement from a material perspective. Bennett's attentiveness to things is here shown through discrete shifts in punctuation, which require an equal attentiveness, if they aren't to merely be dismissed as a static description of a setting. One way of noticing what happens with space without any character present, apart from Woolf's use of brackets, is to look at how she uses flowing punctuation, that is, semicolons and commas. Woolf uses a paratactic way of building sentences to spatialize language and present a narration of space with its own distinct rhythm. ${ }^{8}$ Instead of the otherwise chronological linearity of a standard narrative, consisting of a chain of actions initiated by characters in a temporal flow, told with hypotactic sentences that depict the cause and effect of a given action, the paratactic sentence lets many things happen at once in space without any hierarchical levelling. The following passage depicts air moving around the summerhouse after the characters have left:

And so, nosing, rubbing, they [the little airs] went to the window on the staircase, to the servant's bedrooms, to the boxes in the attics; descending, blanched the apples on the dining-room table, fumbled the petals 
of roses, tried the picture on the easel, brushed the mat and blew a little sand along the floor. At length, desisting, all ceased together, gathered together, all sighed together; all together gave off an aimless air of lamentation to which some door in the kitchen replied; swung wide; admitted nothing; and slammed to.

The passage is divided in two by a period, but before and after Woolf uses a comma and a semicolon to show the movement of "the little airs" (138) that nose and rub around the house. Characteristic of the first part of the passage is the use of verbs, prepositions, and nouns, though the nouns are not subjects in the sentence but are part of a prepositional phrase. Woolf uses paratactic sentences with commas and semicolons to create a sense of movement, accentuating location and action instead of a character's identity. The first commas between "nosing, rubbing, they went" stress that an action is taking place. But the airs do not merely move around the house; a further sensuous dimension is added by multiplying the verbs that depict movement, and adding them one after another, so that the connotations of one verb metonymically affect the following. Next, Woolf adds two prepositional sentences after depicting where they went: "on the staircase, to the servant's bedroom, to the boxes in the attics." In this way, the verbs are grouped together at one end of the passage and the prepositions at the other end, not only lending a sensuous dimension to the movement, but at the same time positioning the movement concretely in the house. A change then occurs, and this next new movement is indicated by a semicolon: "the attics; descending." The semicolon underlines a short pause; a new movement is taking place. A shift happens on the diegetic level, as the airs change their direction (from nosing around they now descend the stairs), but the shift can also be traced on a formal level, in the sentences after the semicolon, where the prepositional sentences are replaced by verbs and direct objects, though still with no subjects: "blanched the apples on the dining-room table, fumbled the petals of roses, tried the picture on the easel, brushed the mat."

With this distinctive use of punctuation, it becomes possible for Woolf to depict what happens in a house without a human character in it. This use of punctuation allows Woolf to depict movement on a spatial level that does not focus on "who" is acting, but on the action itself and how it affects a space. This is similar to the textual phenomenon that Ann Banfield discusses in "Describing the Unobserved: Events Grouped Around an Empty Center" (1987). She argues that Woolf's specific use of language offers a possibility to experience a view of the world without focusing on who is perceiving. Arguing that Woolf draws inspiration from modern science and technology (particularly photography), Banfield shows how certain passages in The Waves and in "Time Passes" use a language that strives to grasp "the appearance of things when no one was present" (265) through a way of demonstratively referring where the here and now of the text no longer only 
"means the place and time which I occupy, as my spatio-temporal perspective" (271).

Meanwhile, there are also narrative chronological markers which infuse the text with a new rhythm. The two phrases opening the passage and starting the next sentence after the dot- "And so ... At length"-stress that what has happened so far in the passage is not a punctual event but a continual movement which changes the very rhythm of the text. When the pace changes in the second part of the passage, the change is anticipated by the use of a semicolon. Here a grammatical subject is introduced: the airs are now fused with the rooms in which they "nosed around" in the first part of the passage, and from that fusion a plural subject emerges: "all ceased together, gathered together, all sighed together; all together gave off." What has happened is a relational gathering of space, underlined by the repetition of "together" and "all." This gathering continues the flowing movement from the first part of the passage. But after the third "together" something happens, anticipating the unexpected type II event that ends this passage: a door slamming to. This very material gesture is transformed into an event II by the way it transforms the surrounding space through unexpectedness.

Woolf employs yet another formal element in narrating a nonhuman space: dialogue. Through her repetitive use of the semicolon in the last part of the passage, she stages a non-verbal dialogue between the gathering of airs and the rooms and the door. They seem to speak to each other, "all gave off an aimless gust of lamentation to which some door in the kitchen replied; swung wide; admitted nothing; and slammed to." Here, with the use of the semicolon, Woolf creates a thing-dialogue. What she depicts is a spatial narrative event that changes the situation.

\section{Vibrant Things-How to Anthropomorphize}

It is not just through her use of punctuation, active verbs, and temporal markers that Woolf creates a narration of space in "Time Passes," it is also through her use of anthropomorphic metaphors and similes that the chapter takes on narrative qualities. Once the characters have gone to sleep in the first chapter of this part, different material things and natural phenomena take over the role of agents. For instance, the little airs that move around the house are anthropomorphized in such a way that they become the concrete deictic center for the reader to follow throughout the part. ${ }^{9}$

Recent post-anthropocentric thinking has advanced a revised understanding of anthropomorphism; this position has been best expressed by Bennett, who claims that "we need to cultivate a bit of anthropomorphism-the idea that human agency has some echoes in nonhuman nature-to counter the narcissism of humans in charge of the world" (Vibrant Matter xvi). This idea is backed up by Serenella Iovino, who argues "in favor of a "strategic anthropomorphism," which liberates "things from their silence" (82). Anthropomorphism, then, can be a device used to set things free. To 
anthropomorphize is not purely a mirroring of human forms in things. Timothy Morton takes this argument one step further in "An ObjectOriented Defense of Poetry" (2012), saying that

It is impossible for me to peel myself away from the totality of my phenomenological being. Just as I fail to avoid anthropomorphizing everything, so all entities whatsoever constantly translate other objects into their own terms. My back maps out small backmorphic slice of this tree that I am leaning on. The strings of the wind harp stringmorphize the wind. ... Moreover if everything is itselfpomorphizing everything else, anthropomorphism is not as big a deal as some ecological criticism thinks.

For Morton, everything in the world translates itself onto everything else. In the relation it is not just humans who shape things, but every object is influencing and translating every other object it comes into contact with. Every relation is a translation whether or not humans are part of it. ${ }^{10}$ To acknowledge anthropomorphism as a post-anthropocentric device is to show our connection with the nonhuman reality and to emphasize the agentic powers in it.

"Time Passes" is an excellent example of how the narrative form of the novel can be used to narrate the connections between the human and nonhuman through anthropomorphism. It is indeed by staging an encounter between the natural nonhuman phenomenon of air and the humanly crafted rooms and furniture that a narrative emerges out of what at first hand seems like a static description of an empty summerhouse. Here Woolf uses different kinds of anthropomorphic metaphors and similes to create a living space without any characters there to initiate the action-what happens happens on a material level as everything "itselfpomorphizes" everything else. The materiality of one thing rubs itself onto the materiality of another, but human traits are also attributed to things. Woolf uses anthropomorphic metaphors in order to narrate the material movements of things and to ascribe a sensuous aspect to space without any character sensing it:

When darkness fell, the stroke of the Lighthouse, which had laid itself with such authority upon the carpet in the darkness, tracing its pattern, came now in the softer light of spring mixed with the moonlight gliding gently as if it laid its caress and lingered stealthily and looked and came lovingly again. But in the very lull of this loving caress, as the long stroke leant upon the bed, the rock was rent asunder; another fold of the shawl loosened; there it hung, and swayed.

The light from the lighthouse mixed with the moonlight is here anthropomorphized, "as if it laid its caress and lingered stealthily and looked," but 
this anthropomorphic metaphor is just one part of the different relations that affect each other. What Woolf depicts here seems to equally include Morton's idea of itselfpomorphism. The anthropomorphic caress thus gets its material texture from the carpet as the carpet carpetmorphizes the light from the lighthouse, which the light has laid itself upon in the previous sentence. The textual effect of the carpet, its solidity, is transferred onto the way the light moves as it "[glides] gently." This is not "the narcissistic reflex of human language and thought" (Vibrant Matter xvi), as Jane Bennett notes, but a way of letting space and things appear through poetic language as relations that are being created and affect each other.

The poetic quality of this passage is underlined by alliterations, which again emphasize a translation of relationality on a formal level as well as on the level of content. In this passage, the alliterations are dominated by the letter "l," which on a content level originates from the thing, that is, the lighthouse. The "l" is repeated in the following verbs and adjectives describing the light from the lighthouse thus: "laid, lingered and looked and came lovingly, in the very lull of this loving caress, long stroke leant and the shawl loosened." The "l-thing," the lighthouse, is not dead matter to which life is ascribed through human attributes; its very thingness rubs off, word for word. The lighthouse is not a symbol-Woolf herself stressed in a letter to Roger Fry: "I mean nothing by the lighthouse" (13 September 1926) ("Introduction To the Lighthouse" xxi)—it is what it does, and what it does is material in both content and form. The formal alliterations also add an auditory aspect to the visuality of light on the level of content. By making use of anthropomorphism, Woolf employs a human vocabulary to depict that which itself is not human.

But equally important, when this part is read in a post-anthropocentric framework, is Woolf's choice of materials, which sets her apart from other Modernists, such as T.S. Eliot, T. E. Hulme, and Ezra Pound. What characterizes "Time Passes" on a material level is air. Choosing this material as her main "agent" in the part of the novel makes it possible for Woolf to narrate space through discrete relations between the floating air and solid furniture. It is exactly opposite to the materiality by Hulme, whose favorite texture was the "dry hardness" of steel, which, according to Bonnie Kime Scott in In the Hollow of the Wave (2012), "suggests that for him the best organism is a dead, or at least a desiccated, one" (15). Where steel is a refined and industrial product and thus an example of human mastery, air is the atmospheric element surrounding the Earth as well as the bodily breathable condition for human life, as Steven Connor suggests in his study The Matter of Air (2010). The two materials articulate two different attitudes to nature in Modernism: one seeks to control and refine nature, the other accentuates the interconnectedness of human and nature.

The element of air is an element of discreetness and invisibility, which is underlined in "Time Passes" by the abundant use of negations, such as stillness, silence, and the repetitive use of "nothing." Woolf makes it appear 
as if "nothing" happens, while a number of things are happening on a different level of events. Contrary to the brackets containing extra-ordinary events in the life and death of the characters, Woolf adds a miniature level of events taking place within the house emptied of characters, engendered by the encounter between nature and the domestic things. That the role of air in "Time Passes" is significant is something that many critics agree on, but rather along the lines of Hamon's understanding of description: as a way to show features of the characters through the setting or as a way for the reader to interpret or predict the plot of the story. These critics all end up repeating the narratological omission of nonhuman reality with no regard to the materiality of the things being described. Air has been read by Paul Sheehan as a symbol of the nothingness felt by the human characters during the war, or by Eric Auerbach as "namenlosen Geister" (494) depicting the ghost of Mrs. Ramsay, or "The Greek chorus" (xxxvi) as Hermione Lee suggests. These different interpretations propose a reading of air as either nothingness (Sheehan) or as spirituality (Auerbach, Lee). In each case, air is dematerialized and considered as a symbol for a human character. This is a typical reading of air according to Steven Connor. He notes that "air is unique among the elements in having this affinity with nothingness, in signifying the being of non-being, the matter of the immaterial. ... Air is the thing that is nothing, the unbeing that is" (31).

In "Time Passes" the airs are not nothing, even if they appear just after Woolf notes that nothing seems to happen:

Nothing, it seemed, could survive the flood, the profusion of darkness which, creeping in at keyholes and crevices, stole round the window blinds, came into bedrooms, swallowed up here a jug and a basin, there a bowl of red and yellow dahlias, there the sharp edges and firm bulk of a chest of drawers.

Nothing stirred in the drawing-room or in the dining-room or on the staircase. Only through the rusty hinges and swollen sea-moistened woodwork certain airs, detached from the body of the wind (the house was ramshackle after all) crept round corners and ventured indoors. Almost one might imagine them, as they entered the drawing-room, questioning and wondering, toying with the flap of hanging wall-paper, asking, would it hang much longer, when would it fall?

The "certain airs" and the "darkness" moving around the house are material airs. They signify the "being of nonbeing." The two passages follow the point of view of the airs, and their movements are depicted with spatial directional verbs: "creeping, stole round, swallowed up, crept round, entered." It is through space that the airs gain materiality, as with the 
anthropomorphic translation of light and carpet. In the encounter between the solidity of the furniture and the floating of the airs-as the airs touch the solid furniture "the sharp edges and firm bulk of a chest of drawers"things are made dynamic, and air is made visible. In this gathering of nature and domesticity, a dynamic space emerges, where "nothing" is turned into something and where a materiality takes shape, whose agentic power lies in the relationality of things material and immaterial.

\section{Conclusion}

In "Time Passes," more-than-human reality emerges as vibrant in the narrative form of the novel. Through the reading of "Time Passes" a new aspect of the novel has emerged-countering the conventional understanding of the novel as the form which engages human relations, as also apparent in narrative theory. My reading shows that the novel is also capable of presenting relations and interactions between nonhuman entities. Here the narrative, temporal structure of the novel is used to represent an environment that is unfolding and evolving. Turning the stillness of an empty house into a narration of space proves that narrative can not only be used to enforce an anthropocentric worldview but indeed has the potential to present a vibrant nonhuman environment. Understood in this way, narrative may still be the best device to understand the human species in its current predicament: in the era of the Anthropocene, narrative can help us imagine our species in a non-hierarchical connection with the nonhuman reality. This prompts a revision of preconceived subject-centric notions of narrative; it also requires that we exchange extra-ordinary human events and characters with events happening on a smaller, nonhuman scale. In the same line of thought, but on a formal level, this also means that we should include punctuation in the analysis of narration. The non-verbal signs allow for a depiction of movement on a spatial level without focusing on "who" is acting. Woolf's use of paratactic sentences spatializes language in a way that lets many things happen at once with no hierarchical leveling, enabling things to relate to one another without a character perceiving or using them: instead, each thing itselfpomorphizes, that is, translates itself and connects itself to every other thing. Narrative, understood in a post-anthropocentric framework, gives voice to a vibrant materiality and foregrounds what is normally placed in the background in our human-scale reality.

A post-anthropocentric approach to narrative thus opens for a reengagement with novels whose spatial setting is more than just a backdrop for the story. Examples of such narratives can, apart from Woolf's other works such as The Waves (1931) and her own contemporaries such as Jean Rhys's Good Morning, Midnight (1939) for instance be found in French modern and postmodern narratives. This would mean to focus a reading of for instance Nathalie Sarraute's Tropismes (1939) not on the Parisian inhabitants and their intersubjective struggles, but on a narrative of the novel's 
objects and rooms. In a postmodern French context, La Vie mode d'emploi (1978) by Georges Perec, with its excessive descriptions of an apartment building and its rooms, could be read as placing the materiality of things at the very center of the narrative. Through such readings a reality appears which goes beyond the human subjects that inhabit the room and use the objects therein contained; indeed, spaces and objects are shown as active forces affecting and shaping the lives of the human characters.

\section{Notes}

1 I use the term post-anthropocentric theory as an umbrella term for the diverse range of theories (such as Object-Oriented Ontology, New Materialism etc.) criticizing anthropocentrism and engaged in a rethinking of the relationship between subject-object, matter-life, human-nonhuman.

2 For a discussion of the narrative turn see Martin Kreiswirth's "Narrative Turn in the Humanities" (2005).

3 To elaborate on the predicative subtheme Hamon gives the example of a fan which can be described functional, that is, "(it circulates air, should be silent etc.) and qualitative (it should be stable, attractive, compact etc.)" (175).

4 The motive of an empty house can also be found in Woolf's short story "A Haunted House" (1921), a ghost story about a couple haunting a house at night. Unlike the house in "Time Passes," which invokes the spatial characteristics of the surroundings, the house in "A Haunted House" invokes a human-centered temporal plot. The house serves as a transit point for the past and present owners, thus repeating a more typical usage of space as setting for a humancentered plot.

5 For a discussion of the novels critical heritage see Jean Mills: "To the Lighthouse: The Critical Heritage" (2015)

6 See for instance Majumdar and McLaurin's Virginia Woolf: The Critical Heritage (1975).

7 See for instance Paul Sheehan (2015) or Michael Levenson (2015).

8 In Modernism: Keywords (Cuddy Keane et al. 2014), rhythm is described as a style in modernism which brings together human and nonhuman realities: "in its most general and wide-ranging modernist usage, rhythm stood for harmony not only between sounds in a line of verse, or formal elements in a poem, or individuals in a group but between the human body and the natural world" (206).

9 Deictic center refers to the physical reference point of the text, the "embodied space-time position" ("Narrator" 17).

10 For $\mathrm{OOO}$ this relationality of translation means more radically that " $\mathrm{OOO}$ is saying that behind every flow, behind every stasis, there is an object that cannot be reduced to anything whatsoever" (Morton 208). Behind the relation there is always a withdrawn object that can never be accessed.

\section{References}

Auerbach, Eric. Mimesis: Dargestellte Wirklichkeit in der abendländischen Literatur. Francke Verlag, 2001.

Banfield, Ann. "Describing the Unobserved: Events Grouped Around an Empty Center." In The Linguistics of Writing: Arguments Between Language and 
Literature, edited by Nigel Fabb, Colin MacCabe, Derek Attridge, and Alan Durant, Manchester University Press, 1987, pp. 265-285.

Bennett, Jane. Vibrant Matter: A Political Ecology of Things. Duke University Press, 2010.

Bennett, Jane. "System and Things: A Response to Graham Harman and Timothy Morton.” New Literary History, vol. 43, no. 2, 2012, pp. 225-233.

Boscagli, Maurizia. Stuff Theory: Everyday Objects, Radical Materialism. Bloomsbury, 2014.

Connor, Steven. The Matter of Air. Reaktion Books, 2010.

Cuddy-Keane, Melba, Adam Hammond, and Alexandra Peat. "Rhythm." Modernism: Keywords. Wiley-Blackwell, 2014, pp. 203-209.

Hamon, Philip. "Rhetorical Status of the Descriptive." Yale French Studies, no. 61, "Towards a Theory of Description." Yale University Press, 1981, pp. 1-26.

Hamon, Philip. "What Is a Description." French Literary Theory Today, edited by Tzvetan Todorov, Cambridge University Press, 1982, pp. 147-178.

Hühn, Peter. "Event and Eventfulness." The Living Handbook of Narratology, edited by Peter Hühn et al., Hamburg University Press, 2011.

Iovino, Serenella. “The Living Diffractions of Matter and Text: Narrative Agency, Strategic Anthropomorphism, and How Interpretation Works." Anglia, vol. 133, 2015, pp. 69-86.

Kreiswirth, Martin. "Narrative Turn in the Humanities." Routledge Encyclopedia of Narrative Theory, edited by David Herman, Manfred Jahn, and Marie-Laure Ryan, Routledge, 2005, pp. 377-382.

Kime Scott, Bonnie. In the Hollow of the Wave. University of Virginia Press, 2012.

Lee, Hermione. "Introduction to To the Lighthouse." To the Lighthouse, edited by Stella McNichol, Penguin Modern Classics, 2000, pp. ix-xlii.

Levenson, Michael. "Narrative Perspective in To the Lighthouse." Cambridge Companion to To the Lighthouse, edited by Allison Pease, Cambridge University Press, 2015, pp. 19-29.

Majumdar, Robin and McLaurin, Allen. Virginia Woolf: The Critical Heritage. Routledge Paul, 1975.

Margolin, Uri. "Narrator." The Living Handbook of Narratology, edited by Peter Hühn et al., Hamburg University Press, 2013.

Mills, Jean. "To the Lighthouse: The Critical Heritage." Cambridge Companion to To the Lighthouse, edited by Allison Pease, Cambridge University Press, 2015, pp. 158-171.

Morton, Timothy. Ecology without Nature. Harvard University Press, 2007.

Morton, Timothy. “An Object-Oriented Defense of Poetry." New Literary History, vol. 43, no. 2, 2012, pp. 205-224.

Perec, Georges. La Vie mode d'emploi. Hachette, 1978.

Rhys, Jean. Good Morning, Midnight. Penguin, 2000.

Ronan, Ruth. "Description, Narrative and Representation." Narrative, vol. 5, no. 3., 1997, pp. 274-286.

Ryan, Marie-Laure. "Toward a Definition of Narrative." The Cambridge Companion to Narrative, edited by David Herman, Cambridge University Press, 2007, pp. 22-38.

Ryan, Marie-Laure, et al. Narrating Space / Spatializing Narrative: Where Narrative Theory and Geography Meet. Ohio State University Press, 2016.

Sarraute, Nathalie. Tropismes. Les Editions de Minuit, 1957. 
Sheehan, Paul. "Time as Protagonist in To the Lighthouse." The Cambridge Companion to To the Lighthouse, edited by Allison Pease, Cambridge University Press, 2015, pp. 47-57.

Woolf, Virginia. The Essays of Virginia Woolf, vol. 4, edited by Andrew McNeillie, Harcourt Books, 1994.

Woolf, Virginia. To the Lighthouse. Penguin Modern Classics, 2000.

Woolf, Virginia. The Waves. Penguin Modern Classics, 2000. 


\section{The Descriptive Turn in German Nature-Oriented Neue Sachlichkeit (1913-1933)}

\section{An Essay on Nonhuman Literary Genres}

\section{Michael Karlsson Pedersen}

Not all literary genres have the same interest in the nonhuman. It is possible to make a clear-cut division between literature oriented toward the human and literature oriented toward the nonhuman. Or, as Ursula K. Le Guin reflects in her illuminating piece "The Critics, the Monsters, and the Fantasists" (2007), it is possible to distinguish between realistic-anthropocentric fiction and fantastic-ecocentric fiction. Although such a distinction could be seen as exclusionary, it does in fact include a wide range of texts:

Realistic fiction is relentlessly focused on human behavior and psychology. "The proper study of mankind is Man" [quotation from Alexander Pope]. When fiction disobeys Pope and begins to include the Other, it begins to shade into the ghost story, the horror story, the animal story, or science fiction, or fantasy; it begins the movement outward to the not-entirely-human. Even "regional" fiction, always looked at disparagingly by the modernists, is part of this movement, sliding from human psychology into that which contains it, the landscape.

(Le Guin 87)

When one is interested in the nonhuman (from animals to landscapes), one must-if following Le Guin—abandon realist fiction altogether: "What fantasy generally does that the realistic novel generally cannot do is include the nonhuman as essential. ... To include anything on equal footing with the human, as equal in importance, is to abandon realism" (87). But in the interest of making such a turn to nonhuman genres of sci-fi, fantasy, horror, regional, or nature-oriented writing, Le Guin's thematic focus must be complemented by a formal reflection: what literary devices do such genres use to bring the nonhuman into their texts? I will argue that the concept of description is of vital importance.

In order to reflect and elaborate on the role of description in nonhuman genres, I want to engage with the turn to description in the nature-oriented Neue Sachlichkeit or New Objectivity in German literature from 1913 to 
1933. This descriptive turn can be seen in different nonhuman genres such as Alfred Döblin's science fiction novel Berge Meere und Giganten (1924) and Wilhelm Lehmann's nature diary Bukolisches Tagebuch (1927-1932). I will deal with both examples later in this essay. Furthermore, under the banner of a new metaphysical naturalism, Döblin develops a theory of description focusing on how the nonhuman can be approached in a literary text, a theory that then serves as the basic model for how description of nonhuman environments and objects is used in the nature-oriented Neue Sachlichkeit. But to appreciate the scope and applicability of Döblin's descriptive theory, I want to underline its resonance with more recent object-oriented and materialist theories by Graham Harman and Jane Bennett. Here a connection between nonhuman ontologies of objects and things and different types of descriptive devices is proposed as the basis for a dual model of horizontal and vertical description, which can be used to reframe and clarify Döblin's theory and thus the use of description of nonhuman environments and objects in the Neue Sachlichkeit. Thus, avoiding the often-sole focus on Anglophone literature by exploring the German context, my chapter brings forth new comparative possibilities for literary scholarship engaging with the nonhuman. ${ }^{1}$

My chapter will therefore begin with an introduction to Harman and Bennett in order to outline two types of description (vertical and horizontal), which are given a brief example through $\mathrm{H}$. P. Lovecraft's horror novel At the Mountains of Madness (1931/1936). I then turn to Döblin's theory of description, his metaphysical naturalism, which is compared with the weird realism proposed by Harman. I conclude this section by showing how Döblin's new naturalism is not only found in his theoretical reflections but also in his fiction, notably the sci-fi novel Berge Meere und Giganten. In the following section, I give a closer textual analysis of Lehmann's nature diary Bukolisches Tagebuch and how it puts to use the vertical and horizontal ways of describing the nonhuman world. In conclusion, I highlight how the turn to nonhuman genres can bring about a new comparative history of literature.

\section{Materialism/Immaterialism, Literary Description, and H. P. Lovecraft}

In the history of literary theory, nonhuman spaces such as natural landscapes and their material objects have traditionally been seen as the province of description. Ruth Ronen attests to and criticizes this long history, where the "world of objects" has traditionally been assumed to be handled by descriptive practices (275). Her point is that the divide between narration and description, between human actions and nonhuman objects, has resulted in downgrading description to something unchanging, passive and ultimately superfluous to the story (cf. 276). Such a concept of description is insufficient, as Ronen herself notes: "a landscape can be described as an 
active agent" (276). Following the old metaphysical hierarchy between subject and object, the devaluation of description stems from its connection with objects and their anthropocentric connotations of passivity and inertness. Consequently, to place a concept of description at the heart of nonhuman genres necessitates that not only description itself but also the nonhuman objects themselves be rethought as something vital and active. This means that the nonhuman (ontology), description (aesthetics)—and especially the relation between the two-must be conceptualized anew. The task of overcoming the old metaphysical dualism in order to do justice to nonhuman objects and descriptive language has been undertaken by new theories of object-oriented ontology and new materialism.

In his book Immaterialism: Objects and Social Theory (2016) Graham Harman makes a helpful distinction between new materialism and immaterialism (object-oriented ontology), that is, between immanent relationality and transcendent essentiality (cf. 14-20), which sums up two current ways of theorizing about objects and things. The materialist model stresses connectability and relationality between things in an agential matrix, whereas the immaterialist model stresses the autonomy, inaccessibility, and non-relationality of things. Harman represents the second position, as the title of his 2016 book shows, and Jane Bennett is representative of the first position. In this section, I will combine these two ontologies of things and relate them to an aesthetic vocabulary proposed by Harman in his study on H. P. Lovecraft, Weird Realism: Lovecraft and Philosophy (2012). The aim is to establish a relation between nonhuman ontology and descriptive techniques used in literary texts.

In Vibrant Matter: A Political Ecology of Things (2010), Bennett highlights that a thing has "an active, earthy, not-quite-human capaciousness (vibrant matter)" (3). This vital materialism inherent in things produces concrete effects through what she terms a "particular assemblage:" independent of human interaction, disparate things-because of their material vibrancyconnect and relate with each other, producing an assemblage of "vivid entities" (5). In a particularly rich and sensuous description, Bennett shows what such an assemblage of things looks like:

When the materiality of the glove, the rat, the pollen, the bottle cap, and the stick started to shimmer and spark, it was in part because of the contingent tableau that they formed with each other, with the street, with the weather that morning, with me. For had the sun not glinted on the black glove, I might not have seen the rat; had the rat not been there, I might not have noted the bottle cap, and so on.

Bennett's description shows how the material agency of each particular thing is directed at creating connections with other things, which in the end form a "tableau." The world of things also wants to connect with humans, 
but such a flat and nonhierarchical ontology does not privilege the human bystander over the bottle cap or vice versa. Rather, both are engaged in a centerless relational bonding, which is not mastered by anyone of the two, human or bottle cap.

Against Bennett's model of thing-relationality, Harman proposes a notion of non-relationality inspired by Heidegger: "This deeply nonrelational conception of the reality of things is the heart of object-oriented philosophy" ("The Well-Wrought Broken Hammer" 187). Harman argues that neither practical use nor theoretical speculation can exhaust the reality of the thing, as its essence is always retained in an obscure area beyond human reach. He explains this through the example of a chair:

To sit in a chair does not exhaust its reality any more than visual observation of the chair ever does. Human theory and human praxis are both prone to surprises from sudden eruptions of unknown properties from the chair-being of the chair, which recedes into the darkness beyond all human access. Pushing things another step further, it must be seen that the same holds for inanimate entities, since the chair and floor distort one another no less than humans distort the chair.

(Weird Realism 15-16)

Instead of Bennett's emphasis on how things seek each other out, forming assemblages through which they produce material effects, Harman argues that, regardless of the relationality of matter, what produces effect is the fact that the thing avoids or recedes from any connection.

Although there is a basic theoretical difference between the materialist and the immaterialist stance, these two models of objects can be productively related. When Harman moves from theory to offering actual examples of objects, he in fact describes how an object (chair) relates to another object (floor). Such object-object connections provide a common ground with Bennett's thing-assemblage, although Harman would argue that such connections never exhaust the reality of the objects themselves. Thus, a synthesis of Harman and Bennett stresses how material relationality and immaterial non-relationality are both inseparable aspects and possibilities of the thing, which can change from the act of seeking material relations with other things to the act of receding from these very relations, beyond and into immaterial obscurity. As Bennett herself briefly states at the beginning of Vibrant Matter, things feature both a "negative power or recalcitrance" and "a positive, productive power of their own" (1).

The importance of maintaining both the negative-resisting and positiveproductive sides of things becomes even more urgent when dealing with literature. This is evident in Harman's Weird Realism: Lovecraft and Philosophy, which translates nonhuman ontology into categories of aesthetic form by using the American writer H. P. Lovecraft as an example. For Harman, Lovecraft is a writer of gaps (2), that is, of both vertical 
gaps and horizontal gaps. The first kind adheres to the Heideggerian gap between "the real and the sensual" (4), that is, between withdrawnness (non-relationality) and sensuous availability. The second, horizontal kind describes the Husserlian gap between "objects and their qualities" (4), that is, between "the relatively durable objects of our perception and their swirling kaleidoscope of shifting properties" (5). In short, the vertical gap marks an immaterialist stance, which was shown above, and the horizontal gap a materialist position, which is represented by Bennett. This "dual polarization" (4) of the object thus enables Harman to understand how Lovecraft produces a certain kind of weird realism.

Based on this ontology Harman develops a corresponding pair of formalstylistic concepts: vertical and horizontal styles of description. The vertical gap expresses itself in an allusive or indirect style, because language as such can never access the immaterial reality of the object. As Harman writes, "[the] inability to make the things-in-themselves directly present does not forbid us from having indirect access to them" (17). That is exactly what Lovecraft does when faced with the noumenal ungraspability of, for instance, the Cthulhu-monster; he succeeds in describing it through allusion: "Lovecraft can allude to the physical form of Cthulhu even while cancelling the literal terms of the description" (17). Although this "vertical" or allusive aspect of Lovecraft's style, that is, "the gap he produces between an ungraspable thing and the vaguely relevant descriptions that the narrator is able to attempt" (24), fills up most of Harman's reflections, there is an equally important horizontal aspect, which is consistent with Bennett's materialism. Here the importance of maintaining both the positive-relational and the negative-transcendent side of the object becomes clear, as they correspond to two stylistic aspects found in Lovecraft's prose. If the vertical description expresses language falling short of the object, the horizontal style of description is indeed "overloaded by a gluttonous excess of surfaces and aspects of the thing" (25). The horizontal description expresses a surplus of specificity; it embraces the fact that the object offers a multitude of sensuous impressions and qualities, which overwhelms language. One could also think of Bennett's description of the tableau of things, which draws its power from the material specificity of each thing. This is not the vertical description of the immaterial-noumenal side with its shying away from any attempts at grasping its essential being but rather the horizontal description of the extensive material-phenomenal side of Lovecraft's weird monsters, landscapes, and cities.

To make the distinction between the two types of description more concrete, I will discuss a brief example from Lovecraft's novel At the Mountains of Madness (1936). The novel centers on a scientific expedition to the Antarctic told in retrospect by one of the survivors, a geologist. In this "white, aeon-dead world of the ultimate south" (19), the expedition discovers a mysterious mountain range, which hides "a Palaeogaean megalopolis" (66). It is the encounter with this inhuman city and its ancient 
forms of architecture and sculpture that sets off both horizontal and vertical descriptions. Lovecraft writes:

The Cyclopean massiveness and gigantism of everything about us became curiously oppressive; and there was something vaguely but deeply inhuman in all the contours, dimensions, proportions, decorations, and constructional nuances of the blasphemously archaic stonework. We soon realized, from what the carvings revealed, that this monstrous city was many million years old.

In the quote, the concrete architecture with its sculptural aspects is at the same time traits of an inhuman entity, which underscores the city's ungraspable and incomprehensible nature. There is a simultaneity of horizontal description of stonework ("contours, dimensions, proportions, decorations") and of vertical description of its liminality ("vaguely but deeply inhuman"). For Lovecraft, the inhuman is the prehuman in a both temporal-geological and spatial-object-oriented sense, testifying to the limits of human understanding and descriptive powers. Still, the narrator amasses a great deal of details from the various sculptures and architecture, although he knows he cannot comprehend or even represent them meaningfully: "It is useless to try to compare this art with any represented in our museums. Those who see our photographs will probably find its closest analogue in certain grotesque conceptions of the most daring futurists" (78). The dynamism of Lovecraft's descriptive prose is built on this ongoing slide from horizontal to vertical descriptions, from the manifold material contours of the thing to its negative, non-comparable, and unfathomable essence.

The non-relationality of objects must necessarily make language fall short; it thus expresses itself through vague and evasive language (vertical style) as was seen in the emphasis on the inhuman nature of the ancient city. But the material side of objects can also take over the descriptive language in such a way that it expresses an abundance of concrete descriptions (for instance, the futurist sculptural design found in the city). Thus, different types of description adhere to sides of the thing, and, as stated above, the position I propose recognizes the importance of maintaining both sides. In fact, as was also clear in the Lovecraft example, it is the very conflict between the two sides of the object that infuses the literary text with a productive, descriptive tension: the ungraspability or inhumaneness of things elicits multiple and puzzling descriptions, a move that then inevitability ends in resignation and an emphasizing of the unknown and indescribable nature of things.

Although based on Lovecraft's prose, the concepts of vertical and horizontal description offer an aesthetic vocabulary to be used in other literary contexts. I will now turn to a specific moment in German literary history, where the concept of description surfaced and nonhuman literary genres such as science fiction and nature writing became dominant. It is 
my contention that the descriptive practices developed at this time can be reconstructed through a constellation of vertical and horizontal styles, as found in Lovecraft's prose.

\section{Alfred Döblin's Metaphysical Naturalism}

The movement of Neue Sachlichkeit or New Objectivity, which was the dominant trend in German literature in the second half of the 1920s, included a wide range of authors and painters, who all reacted against expressionism. Instead of a visionary and often mythic-apocalyptic depiction of torn subjectivity in a language heavy with imagery and with the catastrophe of war as background, the authors of the Neue Sachlichkeit turned to a description of the tangible, concrete world around them. ${ }^{2}$ The term Sachlichkeit or Objectivity named not only this turn away from expressionistic subjectivism and visionary imagery, but also a new attitude toward the world at hand: cold, distanced, and sober, that is, sachlich.

The post-expressionistic literature of the Neue Sachlichkeit is not, however, one movement in unison. There are, according to Hans Dieter Schäfer, two overall strands within the movement (cf. Wilhelm Lehmann 125 and "Naturdichtung und Neue Sachlichkeit" 375). One oriented toward urban spaces (particularly Berlin), which is represented in documentary newspaper reportage and the contemporary novel. Realistic depictions of contemporary life in the city take center stage in literature, as can be found in Egon Erwin Kisch's literary reporting gathered in The Wild Reporter (Der rasende Reporter, 1924) and Erich Kästner's novel Fabian: The Story of a Moralist (Fabian. Die Geschichte eines Moralisten, 1931). The other is oriented toward natural landscapes and objects outside the city center depicted in more "timeless" genres such as poetry and short prose pieces. The latter strand is of interest because it combines a descriptive style with attention to the nonhuman world; that is, it resorts to description of nonhuman environments and objects (as opposed to the eminently subject-centric form of description found in the urban strand of the Neue Sachlichkeit). This turn is especially evident in the writings of Alfred Döblin, who as early as 1913 and in the following years developed a literary program termed Neue Naturalismus, highly influenced by the architect Adolf Loos and his seminal "Ornament and Crime" ("Ornament und Verbrechen," 1908/1910), which made him a "pioneer of the literary Neue Sachlichkeit" (Sander 140). Other writers, who can be said to follow this neusachliche program of description of nonhuman environments and objects, are Wilhelm Lehmann and Ernst Jünger; I will return to Lehmann in the next section and give an example from his Bucolic Diary. In this section, I will present the theoretical architecture of Döblin's literary program of a new naturalism, which I take to be the standard model for description in the nature-oriented Neue Sachlichkeit, and compare it with the concepts of vertical/horizontal description from the previous section. 
It is worth noting that Döblin's discussion of a new naturalism is not always consistent but takes different turns dependent on the context. In the following, I will reconstruct the turn to reality as involving a twofold argument. First, a literary argument: a turn away from psychology and subjectivism as well as decorative, metaphorical language and toward hard empiricism and descriptive practices. Second, a philosophical argument: an attempt to bridge the subject-object divide through a notion of externalization, whereby a spiritual dimension is added to the empirical world. In the end, Döblin's proposed new naturalism can be understood as a kind of spiritual or metaphysical naturalism.

The first statement published by Döblin, which inaugurates the turn to concrete reality, can be found in his article "Berlin Program" ("An Romanautoren und ihre Kritiker. Berliner Programm") from 1913. The article ends with the following call for a new naturalism in the arts:

Naturalism is not a historical "ism," but the heavy shower that always has to break out over art and break into it. Psychologism, eroticism, must be swept away; release of self, release of the author, depersonalization. The earth must steam again. Away from humans! Courage for kinetic imagination and for recognizing the unbelievable real contours! Factual imagination!

The ethos of Sachlichkeit, that is, of hard objectivity, cold factualness, and a critique of subject-centric referentiality is clearly present in Döblin's naturalism. This ethos stresses an anti-anthropocentric stance, which pushes literature away from privileging the human realm. The naturalism Döblin introduces is not a return to a former period of literary history (the epoch of Zola) but rather a new demand laid on art to turn to the actual physical world into which it is situated. Tatsachenphantasie: a new factual or empirical imagination forces literature to rediscover the physical world anew. Döblin opposes his call for concrete empiricism to useless, decorative imagery (with an echo from Loos) as well as of the use of psychology and romantic inwardness, which was present in neoromantic literature dominant from the turn of the nineteenth century. A typical example of this kind of literature is Hermann Hesse's coming-of-age novel Peter Camenzind from 1904 about the lonely sufferings and wanderings of a young man, a clear descendant of the romantic poet J. F. von Eichendorff's nameless protagonist in the novella The Memoirs of a Good-for-Nothing (Aus dem Leben eines Taugenichts, 1826). Instead of this focus on a single person (Hesse's novel is narrated in the first person and centers on the development of a single individual) or on indirect-metaphorical language (in for instance expressionistic poetry) as the basis for literature, Döblin favors a hard, direct prose, whose focus is "soulless [entseelte] reality" (121), a reality that presents "the whole world with the multiplicity of its dimensions" (122), which entails "the fanaticism 
of externalization: I am not me, but the street, the lanterns, this and that event, nothing more" (122). The new naturalist program expresses a turn to nonhuman reality, which at the same time critiques a certain notion of the human as an isolated psychological entity, which is typically seen as central to literature. In his 1913-program, the two sides of Döblin's argument for a new naturalism are already present: the anti-romantic or descriptive stance and the emphasis on the human subject as decentralized or externalized. This argument is then expanded upon and reiterated in later essays and talks.

In a critique of Filippo Tommaso Marinetti from the same year, Döblin again expresses his naturalist "desire for reality" ("Futuristische Worttechnik" 116). He emphasizes that literature must deal with the things directly and not treat them as "helpless" material for building various analogies and constructing surprising imagery: "The things are unique; a belly is a belly and not a watering can: That is the A B C of the naturalist, of the real direct artist" (117). It is through this mix of anti-psychological and anti-decorative stances and a focus on the concreteness of the actual world that description gains new importance. This becomes the main concern in Döblin's article "Commitment to Naturalism" ("Bekenntnis zum Naturalismus") from 1920. As described above, the beginning of the twentieth century was dominated by the idea that art was the realm of psychology and interiority. This realm of "true art" was seen as wholly incompatible with the superficiality of description, and it was thus deemed inadequate as a device for literature:

For a number of years in literature "description" [Beschreiben], "depiction" [Schildern] have been abhorred as hostile to art. ... The rejection of description stems from the general feeling that spiritualization is currently the most important elemental impulse of the arts; everywhere the material, "realistic" ballast is thrown overboard; there is an irrepressible demand to directly present living souls.

Any attempt at focusing on objects and their details is seen in the eye of the true, psychological artist as a shallow and empty empiricism, it is simply an expression of "Soullessness [Seellosigkeit]" (292). Because of this critique laid on descriptive practices, Döblin must elaborate on his previous notion of reality as "soulless," an argument already contained in his notion of the subject as externalized.

Döblin does not seek to establish a binary between spirit and world, subject and object, spiritualized art and descriptive art. Rather, Döblin stresses that the details of the empirical world-which was otherwise understood as "soulless reality"- are "not soulless" (292) at all. Instead, he now speaks of "soul carrier [Seelenträger]" (292), that is, every described object carries with it a spiritual side; every object is simultaneously empirical 
and non-empirical or spiritual. Thus, description is an empirically bound form of spiritualization, a way of dealing with the soul, not as something situated inherently in the interiority of human beings, but rather as something living in the nonhuman objects of the world, being embedded in the physical world at large. In the 1913-program, this was termed "fanaticism of externalization," subjectivity is turned inside out. The term "soulless reality" was then used by Döblin to distance himself from a reality completely reduced to psychology and interiority (as in the neoromantic literature); however, reality itself is not reducible to a purely empirical world. Rather, reality is seen as a kind of objectified or exteriorized spirituality. Döblin's turn to naturalism is not a way of proposing a descriptive practice that depicts the world by amassing details and collecting them into a kind of protocol, as Klaus Müller-Salget has also emphasized (cf. 11). Description must rather take notice of a spiritualized or metaphysical empiricism: every real-physical object has an unreal-spiritual side.

Döblin's call for a new naturalism thus entails both a concept of reality, which can be termed metaphysical naturalism, and a corresponding emphasis on the need for a descriptive practice at the center of literature. The very architecture of this argument (from philosophy to aesthetics) as well as the idea of a dual nature of things - a physical and metaphysical side of objects-mimic in a significant way the materialist and immaterialist stances proposed by Harman and Bennett. Indeed, with the theory of vertical and horizontal description, which connects to the negative-closed and positiveopen side of the object, a vocabulary is offered that can summarize what Döblin tried to develop. Metaphysical naturalism is, in other words, very close to what Harman calls "weird realism in which real individual objects resist all forms of causal or cognitive mastery" (Weird Realism 188); that is, the weird realist text offers objects that have an autonomy of their own. But, as was made clear in the blending of Harman's immaterialism and Bennett's materialism, it is a weird realism that not only describes these resisting objects (vertical style) but also the many facets and details of material objects (horizontal style). Döblin's metaphysical naturalism is built on a similar conceptual architecture, but its relation between vertical and horizontal description is negotiated in different ways by different texts within the nature-oriented Neue Sachlichkeit, as we shall see.

Thus, it is worth noting that Döblin did not only theorize about a new naturalism but also translated these reflections into literary praxis. Of special interest is his science fiction novel, Mountains Seas and Giants (Berge Meere und Giganten) from 1924, which depicts a 500-year timespan of humankind's evolution from the twenty-third to the twenty-eight century. ${ }^{4}$ The novel centers on humankind's technological endeavors and capabilities: because of overpopulation a plan is formed to de-ice Greenland in order to obtain more land. As this hugely ambitious plan succeeds-Greenland is indeed made into two great islands fit for habitation-unexpected side effects occur: old dinosaur-like life forms, which slumbered under the ice, as 
well as new monstrous animals begin to appear. These latter so-called giants then begin to wreak havoc on the civilization that created them-nature strikes back in the form of huge monsters.

Not unlike Lovecraft's expedition to the Antarctic in At the Mountains of Madness, Döblin's narrative of human hubris is built on a combination of naturalistic facts and monstrous depictions. Thus, the novel uses a great deal of geological information, which-as Ritchie Robertson has pointed out-creates a dehumanized and hard-to-grasp "poetry of geology" (222). The specificity of such a horizontal-naturalist mode of description borders, however, on a mere amassing of facts of the nonhuman world, as is clear in the initial description of Greenland: "Greenland, the massif made of gneiss and granite, pushed itself, a wedge, from the pole into the Atlantic waters. It covered two million square kilometers" (363). But the confident and precise descriptions of this massive and self-contained world are effectively contrasted by the depiction of rising monstrous beings, the vertical description of which underlines the difficulties in grasping their heterogenous bodies made of both organic-biological and inorganicmineralogical matter:

They were beings the likes of which the Earth had never seen before. The waters the salts earth gathered themselves around bare limbs, heads bones teeth tails vertebrae, around fern leaves stamping parts root stumps; often it grew into creatures that resembled the ancient times of the Earth, often strange beings shaped themselves, absorbed the earth, danced.

The difficulties in describing these grotesque beings is not only present in the emphasis on their weirdly mixed material bodies (the mineralogy of bone and teeth clashes with the biological matter of leaves and roots), which are uniquely new life forms but also in the analogy to the ancient geological times of the earth, well beyond the time span of human civilization. Of course, the difference to Lovecraft's monsters is quite clear as his old ones are prehumen entities, whereas Döblin's are newly made as a consequence of human action. Still, both underscore the ancient qualities and appearances of their monsters, which reflect their inherent material strangeness and ungraspability. In sum, Döblin's novel serves as an example of his own metaphysical naturalism through its mingling of detailed naturalisthorizontal descriptions of geological processes and of metaphysical-vertical depictions of materially heterogenic monsters.

Döblin's science fiction novel thus uses vertical and horizontal descriptions as a means of staging a clash between human civilization and a monstrous, revengeful nature. As in Lovecraft's novel, the emphasis is laid on the fact that the earth does not exist only for scientific and technological exploitation. Much in the same ecological and critical vein, though without 
monstrosities and exotic setting, Wilhelm Lehmann explores the more mundane nature of Northern Germany in his short prose pieces. I will now turn to Lehmann's Bucolic Diary to give a more elaborate example of how vertical and horizontal descriptions are used in the nature-oriented Neue Sachlichkeit.

\section{Worlds Apart: Wilhelm Lehmann's Bucolic Diary}

Wilhelm Lehmann's Bucolic Diary was published as a column between 1927 and 1932 in the newspaper Die Grüne Post and later collected into a book and published in 1948. The pages of the diary register a post-anthropocentric notion of reality, where the human as such is radically decentered and pushed almost into oblivion, and the life of nonhuman phenomena takes center stage. Lehmann's nature diary is a mix of close, detailed observations of botanical, zoological, entomological, geological, and meteorological phenomena and reflections on these nonhuman phenomena in relation to the human world. As such, Lehmann's diary is the kind of nature writing or environmental nonfiction often associated with American authors such as H. D. Thoreau, John Muir, and Aldo Leopold (cf. Goodbody). One of the basic definitions of the genre of nature writing, as Lawrence Buell argues, is indeed that "[the] nonhuman environment is present not merely as a framing device but as a presence that begins to suggest that human history is implicated in natural history" (The Environmental Imagination 7). In Lehmann's nature diary, this is not only suggested but acted out, as the nonhuman world of natural history takes center stage, and humans are left in the periphery, as mere observers.

A very basic assumption that underpins Lehmann's relation to nonhuman reality is what could be called an ontological biocentric stance, as it is for instance expressed in the following short reflection from the Bucolic Diary:

He [human being, MKP] cannot help himself, he has to immerse everything in his world. ... He may do so, if only he sometimes thinks in deep amazement that snake and bird, mosquito and grass, jellyfish and water and cloud are worlds apart and ward off the merry intruder.

The notion of "worlds apart" expresses the core of Lehmann's thinking: although humans must see everything in relation to themselves, as for instance by representing the nonhuman world in language, they must never forget the autonomy or "warding off" of the natural world. The inherently anthropomorphizing nature of humans' relation to the nonhuman reality is, however, acknowledged and cherished by Lehmann: human presence in nature is seen as a "merry" intrusion, not a destructive act; he especially privileges the poetic act of naming as a primordial way of relating to or 
"intruding” upon nature: “And a playful humanization [Vermenschlichung] never speaks from the authentic names, rather they rise from deepest immersion [Versenkung], from the most serious closeness" (208-9). But the previous quote does, at the same time, highlight the fact that it is the difference between human and nonhuman that produces "deep amazement." This suggests a link between Harman's vertical gap between "real" and "sensual" and Lehmann's gap between "worlds apart" and human intrusion or naming, as both emphasize the inherently negative or autonomous nature of the object, which—as Lehmann puts it—-wards off" human access and language. The task of the poet is then to gather and describe this dynamic of "deep amazement" in language through the act of naming, channeling both the "deepest immersion" (horizontal materialism) and a sense of ontological limitation, "worlds apart" (vertical immaterialism).

A telling example of this poetic endeavor to describe how natural objects are both material and immaterial can be found in an entry from a cold March day by the sea in 1928 :

The earth is strong here, its bones are protruding, the granite boulder blocks, and the ocean is so sure it can play with the sweetest colors, just as the tiger stains his skin with the red of the nasturtium blossom. Everything turns back and meets. The cloud of the sky meets itself as puddle of the earth, and the plumage of the brambling is reflected in the bowl of the crab, which the gull consumed.

The striking thing about this description is how every object is seeking out other objects, "meeting" and "playing" with each other, which in effect produces an assemblage of material interconnectedness: the granite stones of the earth protrude into the air, the surface of the ocean plays with the color of the light. This is a clear example of a horizontal description, whose focus is on how an object has-in Bennett's sense-a vital material agency, which enables it to connect with other objects. Not unlike Bennett's own "contingent tableau," Lehmann here grasps a similar moment of positive, material connectivity. His descriptive practice is horizontal and relational, governed by the circular law of "everything turns back and meets." Central is Lehmann's use of the word "play" ("Spiel"). The natural space is disclosed as a kind of playground, where every object acts freely and independently, without being there for either use or exploitation. As such, the inter-play of natural objects emphasizes their free aesthetic and sensuous nature: the ocean plays with color and the tiger plays with nasturtium.

The concreteness of these horizontal descriptions, which for Lehmann are descriptions of object-object play, is however loosened, when the material-relational law of "everything turns back and meets" is further developed as a dematerializing law of mirroring: the circularity produces concrete connectivity, but it also abstracts the integrity of object itself. The 
objects meet each other, but in doing so they also mirror and reflect each other, whereby the object itself transgresses and in effect loses itself: the cloud of the sky is transformed into a puddle on the ground, that is, it meets itself as an otherness, just as the brambling is transformed into an image in the emptied out back bowl of the crab. The affirmative playful relationality of objects is at the same time dematerialized and slides into a non-relational otherness. The horizontal playground is turned into a vertical mirroring space, where the object is drawn away from itself, abstracted and transformed into something else. The natural object may then show itself in its relational play mode but can at the same time escape into its nonrelational otherness by giving up its material integrity, by becoming in a sense abstract and immaterial: when the cloud and the brambling transform and dematerialize, they confirm their inexhaustible nature for otherness.

Lehmann's short prose piece confirms the connection between the aesthetic-horizontal inter-play of objects and the vertical mirroring or dematerialization of the object itself. The juxtaposition of concrete objects implies a sense of sliding into absence. As such, the assemblage of objectobject-play builds the empirical foundation for a sense of "deep amazement," which in effect hints at and thus maintains the negative ungraspability of the object, a "world apart." The nature of Lehmann's descriptive text rests on this sliding connection: the combination of minute detail and the depiction of a natural scene such as the shore offers a realm of contingent phenomena, which are then formatted through ontological laws of first object-play and then object-mirroring. As Döblin argued, the new naturalism is always also a kind of metaphysical naturalism, not only a description of material details but also a description of their transcendent otherness. Lehmann's nature diary never leaves the boundedness of a specific place and its material dynamisms, but at the same time it exposes the inherent otherness of this otherwise mundane landscape.

\section{Conclusion}

In the interest of examining and expanding upon a notion of nonhuman genres, my chapter has developed a theory of description based on recent object-oriented and materialist theories. At the center of this theory is the relation between ontology and aesthetics, which suggests that the being of objects as such calls for specific modes of literary description. In other words, ontological categories are turned into aesthetic ones: the materialism/ immaterialism-divide translates into the opposition between vertical and horizontal description.

To give credence to such a theory, I discussed two examples from German literature of the early twentieth century. It thus became clear that the categories developed in contemporary philosophy were compatible and indeed helped to illuminate the specific kind of description and naturalism proposed by Döblin and later adopted by the nature-oriented Neue 
Sachlichkeit. This new metaphysical naturalism negotiated the relation between materialism and immaterialism in a new way: Lehmann's prose laid great emphasis on the mundane reality of natural phenomena and spaces but also maintained a vanishing point into which such reality could escape. This dynamism was made clear in an example taken from the Bucolic Diary, where material connectedness of object-object-play gave way to a dematerialized mirroring of the object, which thus evades a final fixation and exhaustion in a described scene. The act of describing the nonhuman is thus both an engagement with the material richness of its various facets as well as an acknowledgment of its autonomous nature.

Metaphysical naturalism in the German context demonstrates the potential of prose centered on the description of nonhuman reality. The internal dynamics of these texts are not based on plot or human protagonists but rather on the life of nonhuman phenomena and spaces such as Lehmann's “worlds apart” of the North German landscape and Döblin's giants rising from a de-iced Greenland as well as Lovecraft's inhuman city in the Antarctic. Indeed, the focus on nonhuman genres discloses new national and even transnational correspondences, which transcend traditional genre boundaries. It seems, for instance, that nature writing and fantastic literature are very closely linked, as Le Guin also hinted at. From the perspective of the nonhuman, it thus makes sense to place Lehmann's pastoral depictions of the Northern German landscape in relation to J. R. R. Tolkien's green and idyllic Middle Earth from the Lord of the Rings-trilogy (written 19371949, published 1954-1955). Or, it is productive to relate Ernst Jünger's sense of the natural elements' prehuman powers in his travels to Norway in 1935 (Myrdun, published 1943) or Brazil in 1936 (Atlantische Fabrt, published 1947) to Lovecraft's depictions of an utterly alien world in At the Mountains of Madness. A genuine possibility then arises for rediscovering and rewriting literary history from the perspective of nonhuman genres, revealing surprising correspondences across languages, genres, and literary traditions. The example of the descriptive turn in German literature becomes, then, part of a larger attempt at placing the nonhuman environment and its plenitude of objects at the center of literary endeavors.

\section{Notes}

1 The need to inhabit more comparative modes of dealing with the nonhuman in literary studies thus transcending the dominant trend of Anglocentrism is for instance voiced by ecocritic Lawrence Buell in his essay "Ecocriticism: Some Emerging Trends" (cf. 107).

2 See, for instance, Georg Heym's poem "Der Krieg” from 1911 or Georg Trakl's poem "Grodek" from 1914.

3 All the following German quotes are translated by me.

4 It is worth noting that the literary interest in vast temporal scales and how they can offer a new perspective on human civilization is also present in British sci-fi writer and philosopher Olaf Stapledon's novel from 1930, Last and First Men: A Story of the Near and Far Future. Stapledon's cosmic vision builds a narrative 
that spans two billion years and depicts the colonization of other planets, closing with the end of the human species.

\section{References}

Bennett, Jane. Vibrant Matter: A Political Ecology of Things. Duke University Press, 2010.

Buell, Lawrence. The Environmental Imagination: Thoreau, Nature Writing and the Formation of American Culture. Harvard University Press, 1995.

Buell, Lawrence. "Ecocriticism: Some Emerging Trends." Qui Parle, vol. 19, no. 2, 2011, pp. 87-115.

Döblin, Alfred. “An Romanautoren und ihre Kritiker: Berliner Programm.” Schriften zu Ästhetik, Poetik und Literatur, edited by Erich Kleinschmidt, Walter-Verlag, 1989, pp. 119-123.

Döblin, Alfred. "Bekenntnis zum Naturalismus." Kleine Schriften I: 1902-1921, edited by Anthony W. Riley, Walter-Verlag, 1985, pp. 291-294.

Döblin, Alfred. Berge Meere und Giganten. Suhrkamp Verlag, 2001.

Döblin, Alfred. "Futuristische Worttechnik: Offener Brief an F. T. Marinetti." Schriften zu Ästhetik, Poetik und Literatur, edited by Erich Kleinschmidt, WalterVerlag, 1989, pp. 113-119.

Goodbody, Axel. "Lehmanns 'Bukolische Tagebücher': Der Dichter als 'Nature Writer." Wilhelm Lehmann zwischen Naturwissen und Poesie, edited by Uwe Pörksen, Wallstein Verlag, 2007, pp. 51-67.

Harman, Graham. Immaterialism: Objects and Social Theory. Polity Press, 2016.

Harman, Graham. "The Well-Wrought Broken Hammer: Object-Oriented Literary Criticism." New Literary History, vol. 43, no. 2, 2012, pp. 183-203.

Harman, Graham. Weird Realism: Lovecraft and Philosophy. Zero Books, 2011.

Le Guin, Ursula K. "The Critics, the Monsters, and the Fantasists." The Wordsworth Circle, vol. 38, 2007, pp. 83-87.

Lehmann, Wilhelm. "Bukolisches Tagebuch aus den Jahren 1927-1932." Gesammelte Werke in acht Bänden: Band 8, edited by Verena Kobel-Bänninger, Klett-Cotta, 1999, pp. 175-309.

Lovecraft, H. P. "At the Mountains of Madness." The H. P. Lovecraft Omnibus 1: At the Mountains of Madness and Other Novels of Terror, Voyager Books, 1999, pp. 9-139.

Müller-Salget, Klaus. Alfred Döblin: Werk und Entwicklung. Bouvier Verlag, 1988.

Robertson, Ritchie. “Alfred Döblin's Feeling for Snow: The Poetry of Fact in Berge Meere und Giganten." Alfred Döblin: Paradigms of Modernism, edited by Steffan Davies and Ernest Schonfield, De Gruyter, 2009, pp. 215-228.

Ronen, Ruth. "Description, Narrative and Representation." Narrative, vol. 5, no. 3, 1997, Ohio State University Press, pp. 274-285.

Sander, Gabriele. "Alfred Döblin und der Großstadtrealismus." Realistisches Schreiben in der Weimarer Republik, edited by Sabine Kyora and Stefan Neuhaus, Königshausen \& Neumann, 2006, pp. 139-150.

Schäfer, Hans Dieter. "Naturdichtung und Neue Sachlichkeit." Die deutsche Literatur in der Weimarer Republik, edited by Wolfgang Rothe, Reclam, 1974, pp. 359-381.

Schäfer, Hans Dieter. Wilhelm Lehmann: Studien zu seinem Leben und Werk. H. Bouvier u. Co. Verlag, 1969. 


\section{Part II}

\section{Catastrophic Narrative Environments}




\title{
$4 \quad$ Nonhuman Presence and Ontological Instability in Twenty-First-Century New York Fiction
}

\author{
Lieven Ameel
}

This chapter explores the appearance, in three contemporary New York novels, of ontological instability and disturbing nonhuman presence in urban space. ${ }^{1}$ Ontological instability is understood here as shifts in what is deemed as real or unreal in the storyworld and the resulting uncertainty (for characters as well as for readers) as to the stable ontological attributes of the narrated world. Such shifts feed into broader apocalyptic undercurrents in the novels discussed here. They are also important for an understanding of how fictional texts come to grips with complex environmental threats and have relevance for the relationship between human vision, consciousness, and the environment. The literary texts I will analyze are Teju Cole's Open City (2011), Jonathan Lethem's Chronic City (2009), and Ben Lerner's 10:04 (2014), novels that thematize palimpsestic layers of meaning in urban space and that are informed by an interest in the impact of imagined futures on the present. In these fictional texts, I will argue, the ontological stability of the narrated storyworld is threatened by continuous references to menacing weather conditions and by a sense of unsettling nonhuman presence.

In terms of methodological framework and theoretical approaches, my work will draw on a renewed interest in the analysis of narrative space, especially within literary urban studies (Ameel et al.; Finch et al.), and will explore ontological instability in narration from the perspective of possible world theory (Ryan, "Impossible Worlds") and Gilles Deleuze's concept (in his work on Leibniz) of the fold (Deleuze). A key question is how nonhuman presences in the urban environment, and the (visionary) perception of such occurrences, are bound up with ontological instability of the described storyworlds. I will argue that these menacing appearances are not only (or not primarily) located in spatial coordinates, but rather, that they tend to point to possible futures and to alternative possible worlds. Nonhuman presence, in these novels, tends to refer back to the unknown in temporal terms - to the threats of a possible future beyond the immediate temporal horizon.

Literary fiction has arguably had difficulties in rendering the impact of uncertain planetary futures within the formal confines of the novel (see Heise). The description of disturbing nonhuman presence-natural patterns, 
unseasonal weather conditions, and strange occurrences in the urban environment-in urban spatial environments in the novels under discussion can be seen as a particular kind of narrative strategy to render the position of human experience vis-à-vis the nonhuman and including slow-moving ecological changes. While the nonhuman intimations inhabiting urban space function on massively different, and larger, scales than the human protagonists, the sense of interconnectedness that appears from an examination of narrated space in these texts is ultimately able to convey a profound sense of entanglement between language and planetary materialities, between narrated storyworlds and the referential world.

The presences in these novels appear not only menacing to the protagonists' lives but to the very ontological attributes of the narrated storyworlds. The uncertainty as to what can be considered real or unreal, as well as the interaction between human character and nonhuman presences cannot be meaningfully unpacked with the help of dualistic approaches (pitting culture against nature, inner against outer, mind against material), but rather by approaches that allow for an integration of inner and outer. Such an approach is attempted here by drawing on Gilles Deleuze's concept of the fold.

What connects the three novels discussed here is not only that they were all written by American authors (in the case of Teju Cole, NigerianAmerican) in the early twenty-first century but also that they take place in New York City. Apocalyptic threats are a recurring feature in city literature, and New York City is a particularly conspicuous site of creative destruction (cf. Salmela and Ameel), a favored setting for catastrophic destruction in the Western cultural imagination. 9/11 looms large in the existing research on all three novels, but it will play a more minor role here. Discussing different novels that all take place in the same referential city and in the same first decade of the twenty-first century will also put into sharper contrast the wide diversity of possible worlds that may emanate from one and the same geographical referent.

\section{Ontological Instability and the Fold}

Following Brian McHale's (1987) Postmodernist Fiction, postmodern literature is seen here as primarily concerned with ontological questions (as opposed to epistemological questions in modernist literature), with ontological instability being one of the key issues at stake in postmodern literature. What is this world we find ourselves in as readers? And what is its relationship to the referential world we live in? In grappling with such questions, and in examining the relationship between a fictional storyworld and the actual world, literary scholars have tended to utilize a range of metaphors-"storyworld" itself is such a metaphor, meant to describe what takes place when a reader conceptualizes the ontological construct evoked by a literary text. Other such metaphors are the "mirror" of mimesis 
that literature is supposed to hold up to the real world; the concept of a fictional world as a separate "heterocosm" (McHale); and, more generally, possible worlds theory (Ryan, Possible Worlds). In Ryan's possible worldsbased model of narrative, such metaphors are used not only to describe the relationship between the "real" world and an "imagined," textual actual world but also that between different worlds (textual actual worlds, dream worlds, fear worlds) within the diegesis.

I propose here a different metaphorical approach to the relationships between different worlds in postmodern literature and their relationship to the actual world: that of the fold, drawing on Gilles Deleuze's reading of Leibniz (Deleuze 1988, 1993). The possibilities for applying the concept of the fold to narrative storyworlds in postmodern literature is noted in passing by Bertrand Westphal in Geocriticism (2011). Examining multiple worlds in postmodern literature, Westphal argues that "the representation of the referential world ... in fiction engages in a process of interactivity between instances of heterogeneous nature brought together in the same world through an interface ... [which] is also the means of connection between the elements of this world," and he adds that "this approach is something like the concept of the fold, developed by Leibniz in his theory of monads and taken up by Deleuze in his book on Leibniz" (Westphal 99). While Westphal does not further elaborate on this idea, the concept of the fold presents a particularly helpful metaphorization to account for ontologically problematic forms of interactions, overlaps, or distortions between different possible or actualized worlds. Not only does the fold appear as a useful concept for describing ontologically unstable worlds, it may also shed light on the way in which many of these texts are fundamentally involved in problematizing the status of the world(s) in which they take place and for questioning the chiasmus between inner and outer layers, between what is represented and what representscrucial questions in postmodern literature (cf. McHale 26-27; Westphal 88 ). Moreover, the fold also enables a way of approaching the interaction between the human protagonist and the nonhuman environment in the storyworld, an interaction which defies ready hierarchical relationships in the novels under discussion.

In Deleuze's book The Fold: Leibniz and the Baroque, the fold is a way of describing worlds that are not merely interconnected but fundamentally acting on the same plane. Conceptualizing the world in terms of the fold is to think of a fabric that, by way of the infinitely complex manners in which it is folded, connects everything material and immaterial. For Deleuze, the fold is something that examines spatial attributes-Deleuze repeatedly returns to structural elements of baroque architecture and sculpture-in a way that shows that what is thought to be outward is part of the inner, and vice versa. The whole project is, for Deleuze, as it was for Leibniz, an examination of the soul and its relation to the body, which is described in the metaphor of the spatial interior and exterior: 
The infinite fold separates, or passes between matter and the soul, the facade and the sealed room, the interior and the exterior. For the line of inflection is a virtuality ceaselessly differentiating itself: actualized in the soul it is realized in its own way in matter.

(Deleuze 242)

As a concept aimed at transgressing the distinction between interior and exterior, or superior (soul) and inferior (body), the fold as a necessary connection between two different levels provides a useful addition to the conceptual framework used for describing narrative worlds, their interrelations, and their relations to the actual world. Such relationships have long tended to be examined in terms of separations. Drawing on Benjamin Hrushovski, McHale points out that

all literary texts involve a 'double-decker' structure of reference. Literary texts project at least one internal field of reference, a universe or semantic continuum ... constructed in and by the text itself. In addition, they inevitably refer outside their internal field to an external field of reference: the objective world, the body of historical fact or scientific theory.

(McHale 28-29)

McHale draws attention to the instances in which such separations are disturbed, positing approaches such as Roman Ingarden's metaphors "iridescence" or "opalescence" and the "flickering effect" (Ingarden; McHale 32). Such metaphors, with their frame of reference of light effects and reflections, I believe, do not go far enough in problematizing more traditional notions of separation between actual and textual actual world or between textual actual and textual possible world. The fold enables a metaphorization that affords a view of simultaneously existing storyworlds that move into each other almost imperceptibly. The fold may also be helpful in conceptualizing relationships between diegetic worlds and the actual world and in describing how a literary world unfolds in the process of reading-a process that, before the age of the codex, was literally a process of unfolding (see also Caracciolo).

\section{A Commotion from an Earlier Time}

Teju Cole's Open City stands out among recent novels set in New York City for the way it reads the texture of the city in terms of simultaneously present, often threatening and overlapping layers of meaning. In Cole's novel, the protagonist Julius, a Nigerian psychiatric intern in post-9/11 New York, documents his aestheticized wanderings through the city, all the while engaging with the painful memories of the city and of his own past. The protagonist is continuously reading the space for signs of violent 
dislocations and transformations, whose lingering presences seem able to erupt in the world, as if an earlier city becomes suddenly present. In a scene early in the novel, Julius notes how one afternoon "the heart of the city was gripped by what seemed to be a commotion from an earlier time. I feared being caught up in what, it seemed to me, were draft riots" (Cole 74). ${ }^{2}$ The sense of the "heart of the city ... gripped" by an earlier commotion is one of the many examples in the novel of the "correspondence technique" (Keunen 365-66), a rhetorical trope pioneered by Charles Baudelaire by which afflictions of a narrator are transferred to the built environment (or vice versa). In this instance, it is thus arguably the protagonist himself (not the city) who is affected by a "commotion from an earlier time," and it is his privileged aestheticizing perspective which enables the reader to sense the appearance of an earlier timeframe, although the narration places the disruption as an almost tangible event in urban space.

While the superimposition of various possible layers of meaning in the process of reading the signs in the urban space could point to ontological instability (is the past really intruding in urban space?), the storyworld in Open City may well be interpreted as stable, with any folds between different temporal layers to be read as emanating from the consciousness and narration of the aestheticizing and highly self-conscious flâneurnarrator. One possible cityworld unfolds and coalesces into another on the continuous plane of the narrator's aestheticizing conscience. Such a reading would see Open City as essentially drawing on (high) modernist literary antecedents, in which, as Malcolm Bradbury noted, "one city leads to another in the distinctive aesthetic voyage into the metamorphosis of form" (Bradbury 101).

While traumatic memory and the traces of past atrocities in the present are foregrounded in the novel, Open City also displays a keen interest in intimations of the future. Fears for what the future may hold in store, informed by past layers of meaning, infuse the experience of the presence. In such instances, the protagonist takes on the role of a visionary, a Teiresiaslike character with privileged access to possible future upheavals threatening the city. An instructive scene in this respect is the description of Central Park after a torrent of rain:

The intensity of the rain blurred my sight ... The torrent had overlaid the park with a primeval feeling, as though a world-ending flood were coming on, and Manhattan looked just then like it must have in the 1920s or even, if one was far enough away from the taller buildings, much further in the past.

(Cole 36)

Different temporal levels collapse in ways that make Manhattan resemble itself as it was in earlier moments in its history-or, indeed, in its future, with the reference to "a world-ending flood." The protagonist is described 


\section{Lieven Ameel}

as having a privileged, visionary sense of future layers hidden in sight, in this case set on by a moment of temporary blindness caused by the rain. Immediately subsequently to his walk in the park, Julius ponders romantic associations between blindness and "second sight" and blindness as a "shortcut to the gifts of memory and of prophecy" (37). The same idea recurs later, in Open City's Brussels section, when another character speaks with Julius about Paul de Man's theory of blindness and insight (127; see de Man). Significantly, Julius is a reader of natural signs and described, in the beginning of the novel, as "taking auspices" like a latter day "augur" (4). Seeing two blind men on another occasion, Julius considers that his visionary senses were "under the aegis of Obatala, the demiurge charged by Olodumare with the formation of humans from clay" (25). But it is in particular nonhuman elements intruding upon the urban space, such as sudden weather phenomena or the migratory patterns of birds (e.g., 3-4) and the appearance of whales in the New York City waters (49-50), which are presented in the novel as omens of future catastrophe. The question whether the protagonist is merely imagining or correctly interpreting the meaning of such sightings is one of the ambiguities in the novel. There is a continuous obsession with the uncanny presence of natural occurrence and patterns in the city, the intimation that these may well spell a dark fate of the world, and that they are the apparitions of past or future possible versions of the present world.

Often, it is not so much a presence that points to future threats but rather the appearance of absences of what would be expected to be present. This play on simultaneous presence and absence is one way in which Open City undermines its storyworld's ontological stability. It is possible to postulate, in the background of such experiences, the experience of the "absent presence" or "present absence" of the twin towers in the wake of 9/11 (see Ameel "Reading Signs"). But the experience of absence can also be seen as looking forward to the theme of mourning future losses, which has become one of the themes of climate change fiction (what has been called proleptic mourning; see Garrard). Repeatedly, disturbing absences in Open City point to weather conditions in the city:

The absence of this order, the absence of cold when it ought to be cold, was something I now sensed as a sudden discomfort. The idea that the weather was changing noticeably bothered me.

(Cole 28)

The unseasonability of the weather is an indication that all is not right-not with the protagonist, who, as it turns out, is running away from his own past guilt; and not with the city, which appears to be reliving its own traumatic pasts time and again and in which the weather and partly inexplicable animal patterns point to possible future disaster. In Open City, a recognizable New York City is stratified with past, possible, and future layers of 
meaning, of which weather conditions and natural patterns seem to be the harbingers. Echoing Deleuze's thinking on the fold, such different layers (for example, past draft riots as resonating with early twenty-first-century New York City demonstrations) are presented as simultaneously present, as in the folding of different temporal planes of meaning. There is a strong sense of the inner and outer world colliding, and of a correspondence between the protagonist's inner world and the urban environment, for example when Julius senses "the commotion" at the "heart of the city."

\section{Two Temporalities Collapsed into a Single Image}

In Ben Lerner's 10:04 (2014), the reader again meets unseasonable weather, strange omens, and the visionary capacities of an aestheticizing narrator walking a New York City that appears both recognizable and yet a defamiliarized version of its referential self. The "unseasonable warmth" is noted in the first sentence (3), and further mentions to the warming planet (7-8) and the weather's unseasonability are repeated throughout the novel $(32,107)$. To the narrator, a keen walker and aestheticizing figure like the protagonist in Open City, the appearance of an out-of-place heat (in the following passage re-written in a third person novel-within-the-novel), is reminiscent of a photographic visual effect:

The unusual heat felt summery, but the light was distinctly autumnal, and the confusion of seasons was reflected in the clothing around them. ... It reminded him of a doubly exposed photograph or a matting effect in film: two temporalities collapsed into a single image.

(Lerner 63)

In 10:04, unusual climatological circumstances take center stage. But the effect of out-of-time conditions is not described in terms of unusual weather replacing that of earlier times but with an image from photography, as the co-existence of two different temporalities- "two temporalities collapsed into a single image." ${ }^{3}$

Centered on the experience of Hurricanes Sandy and Irene, the plot of 10:04 deals with how the city and its inhabitants cope with the threat and then impact of life-threatening storms. But the issue of changing, threatening weather conditions and the intimation of out-of-place presences in the urban space also points to the overlapping folds of simultaneously present storyworlds: the blurring or fading of a world as we know it. The tangible presence of possible futures and different pasts is described as encroaching on the ontological stability of the present. 10:04 takes a cue from the 1985 movie Back to the Future, in which the protagonist Marty, traveling in time, disturbs the meeting between his own father and mother, thus potentially erasing his present self $(9-10,52)$. The title 10:04 is a reference to the moment when lightning strikes the clock tower in the movie, enabling 


\section{Lieven Ameel}

Marty to return to his own time. The playful reference is re-enacted on the mundane level of the protagonist's personal life: while waiting with his close friend Alex in her apartment for a once-in-a-generation storm to strike New York, the two have a moment of intimacy. But when the storm, whose anticipation triggered their intimacy, does not materialize, their experience feels to have passed into the unreal:

[It] was as though the physical intimacy with Alex, just like the sociability with strangers or the aura around objects, wasn't just over, but retrospectively erased. Because those moments had been enabled by a future that had never arrived, they could not be remembered from this future that, at and as the present, had obtained; they'd faded from the photograph.

While the experience is personal and mundane, the consequences of the unrealized natural occurrence are felt within the storyworld beyond the personal sphere, affecting also the memory of the communal experience ("the sociability with strangers") in expectation of the storm, as well as the "aura around objects." The ontological status of the world is impacted by the way the future is imagined, and when such imagined futures are transformed, so are the characteristics of the present. 10:04 constantly plays on the effect, not only of natural occurrences and presences but also on that of absences. The present is determined by how past and future layers of meaning-or their absence-are narratively folded into the present, lending the present and lived storyworld distinctly unstable and unreal characteristics.

The unseasonable weather strongly feeds into broader world-threatening strands of the novel. The protagonist lives in anticipation of apocalypse, and the sense of impending doom in the novel is continuously reinforced by the protagonist's reading of incongruous presences, such as the "ominous medium" of "tropical humidity that wasn't native to New York" (18). $\mathrm{He}$ is described as someone who imagines "the global apocalyptically" (14), as taking mundane decisions in his life "because ... the city would soon be underwater" (153), and imagining a "not-so-distant future where New York was largely submerged" (132). This imagined disastrous future strongly informs his readings of the present, as when he imagines that the water damage to paintings is the result of the coming catastrophic flood (132). All this is bound up with the protagonist's distorted or hypersensitive senses, especially his vision. Early in the novel, with the city bracing for the coming storm, the protagonist is struck by how things have taken on a new "radiance," only to realize "the alteration was most likely in my vision" (18).

The foregrounding of vision is a reminder that the instability of the storyworld is located in the narrator, whose senses and cognitive capacities are presented as idiosyncratic and untrustworthy. In the opening pages, he 
intuits within himself " an alien intelligence ... and affects that did not, properly speaking, belong to me" (3)-a possible reference to the residue of the baby octopus he eats alive just moments before (see also De Bruyn 963). The reader learns to further distrust the narrator when it becomes clear that he has a heart condition that affects his cognitive capacities. Fearing an upcoming medical test, he notices he is affected by psychosomatic "[headaches], disordered speech, weakness, visual disturbances, nausea, numbness, paralysis ... The momentary sense of having traveled back in time" (74). The awareness of unseasonable weather could be attributed to a confusion of the senses, as when the narrator realizes that the sensation of a "false spring ... might have been a mild olfactory hallucination triggered by memory—or, I found myself thinking, a brain tumor" (108). The simultaneous co-existence of remainders of earlier times or forebodings of future times in the present is thus suggested to emanate from the narrator's disturbed consciousness and senses. The "doubly exposed photograph," in which "two temporalities [are] collapsed into a single image" (63), it is suggested, does not exist other than in the imagination (or the delusion) of the onlooker. And yet it would go too far to argue that the many nonhuman layers of meaning the protagonist senses have no anchoring in the actual storyworld. Rather than the one causing the other, they are constituted on the same plane, in the manner of Deleuze's fold. In describing the relationship between consciousness and the threatening urban environment as an intertwinement, not a causal linkage, Ben Lerner inscribes himself in a recent literary paradigm that Heather Houser has described as "ecosickness." Ecosickness is a literature in which "humans and the more-than-human world do not only interact but, more importantly, are coconstitutive. This literature shows the conceptual and material dissolutions of the body-environment boundary through sickness and thus alters environmental perception and politics" (3). In 10:04, the nausea and sensory disturbances of the protagonist are coeval (a word with special resonance for Lerner and 10:04 in particular; Lerner 66-67, 71) with environmental disturbances in a way that resonates with past and future events and defies clear linear or causal relationships. While this impression of resonating with the environment is clearly informed by somatic and psychosomatic disturbances in the protagonist, there is also a sense of the narrator as a privileged visionary: the idea that it is exactly his condition and the "visual disturbance" he experiences that help him to feel with his environment.

In the notion of the early twentieth-century sociologist Robert Park, the city is a "mosaic of little worlds that touch but do not interpenetrate" (608). Similarly, Timothy Morton, when reflecting on the fragile and contingent nature of cities in Dark Ecology, states that "[places] contain multitudes" (12). It is in the visionary, aestheticizing consciousness of a narrator such as Lerner's that these multiple worlds can for a moment coexist, together with a variety of past and future presences-including that of the reader. Walking in the shadow of the "felt absence of the twin 
towers" (237) and in the shadow of another "historic storm that had failed to arrive" (231), Lerner's narrator enables a range of worlds to coexist for a brief moment and draws a comparison with the New York City cabs which, for this short crisis moment, accept multiple fares, "fares from multiple worlds" (237).

The presence of temporally uncoupled layers of meaning also draws on an aestheticizing and intertextual play on other literary cities. This becomes explicitly spelled out in one of the culminating scenes of the novel, when Ben and Alex walk through lower Manhattan and across Brooklyn Bridge, with the narrator imagining "all of us were dead, flowing over London Bridge" (239). The reference to T.S. Eliot's The Waste Land, with its reverberations of Dante's Divina Commedia (in a 10:04 passage already heavily, and explicitly, indebted to Walt Whitman's poetry), opens up the text to a complex interplay of meanings, driven by intertextual references activated in the reader and folding into the narrator's collapse of past and futures presences in the singular moment. 10:04 has also been read, recently, in terms of its continuations of a realist mode (De Bruyn), but references such as these gesture, rather, to a continuation of the aestheticizing and associative mode of high modernism. The result is an "unreal city"-but in ways that are different from Baudelaire's Les Fleurs du mal (the original reference of "unreal city") and Eliot's The Waste Land: the narrator is not merely invoking a literary trope when suggesting, as Baudelaire does in Le Spleen de Paris, "that all these things think through me, or I think through them" (Baudelaire 4). In 10:04, the narrator describes how he feels his "senses and the city vibrating at one frequency" (28), but he is also hinting at the planetary dimension of such correspondence, in the references to the affinity between narrator and octopus (3); in his hypersensitive awareness "that water surrounded the city, and that the water moved" (28), and the intuition of planetary warming (7).

More radically, it is not only potential futures and past readings of other cities that are folded within the present storyworld, but also the physical world of the reader. Following the reference to London Bridge, the narrator continues the description of the communal spectacle of people gathered on Brooklyn Bridge in the dark, describing how the "fireworks celebrating the completion of the bridge exploded above us in 1883, spidering out across the page" (239), inviting the reader to contemplate the material texture of the page she holds. For a brief moment, the canvas of the night sky and the page of the book held by the reader coexist, in a metaleptic operation that is also at work in use of photographs on the page and in the occasional address to the reader with a compelling you (see Gibbons). Here the novel attains, by folding multiple planes simultaneously, what the baroque fold had endeavored: to break down the boundaries between the worlds of spectator and artwork, while simultaneously giving the onlooker a glimpse of how the artwork relates to a cosmic (or, in Lerner's case, planetary) scale. 


\section{Ellipses, Hiccups, and Pocket Universes}

In Jonathan Lethem's Chronic City (2009), intimations of nonhuman presences and absences in urban space are taken to a new level of threat and uncertainty. The New York City of Lethem's novel is clearly not to be mistaken for the referential New York in the early twenty-first century. To begin with, the basic information the reader receives does not match with the real-world city on the East Coast of the US: the mayor is called Jules Arnheim, the twin towers are still standing, and Russia and the United States are allied in a space war conflict with China. Moreover, there are a range of nonhuman presences, bordering on the fantastic, that demand the reader's attention: a mysterious "fog" that has settled on lower Manhattan (13); a giant tiger (itself with unclear ontological status, since it is rumored to be a tunnel digging device on the loose [163]) is slowly destroying the underground (35-36); gigantic chasms are opening up in the city as part of radical conceptual art work. Several characters share a preoccupation with strange animal movement in the city: a sub-plot involves the habits of a pair of eagles; a "minke whale, its motives perhaps deranged by ocean fungus," has become stranded near New York's Hell Gate and died (68); and the protagonist is repeatedly described as fascinated by the patterns of flight of the birds around the tower he sees from his window (e.g., 125-26; 465-66). While Open City and 10:04 draw heavily on the aestheticizing tendencies of modernist city writing, in which an oversensitive consciousness reads mythical meanings into the everyday and in which ontological uncertainties can still arguably be attributed to an aestheticizing (and unreliable) narrator, Chronic City moves closer to the ontological instability described in McHale's Postmodernist Fiction (1987). If Chronic City differs from 10:04 and Open City in how it locates ontological instability more firmly outside of the narrator's consciousness, this is also in part because the reader comes to know New York City through multiple perspectives and by way of the protagonist's-Chase Insteadman's-friend Perkus Tooth, who acts as Chase's guide to the many hidden and often contradictory layers of the city. The novel begins when Chase meets Perkus, a socially awkward castout with a tendency for drawn-out conspiracy theories. In lieu of a plot, the novel presents a series of events which see Chase navigate the labyrinthine city in a journey that increasingly resembles a quest to distinguish the real from the illusory. Perkus's point of view gradually becomes the protagonist's - and thus the reader's "door to my life in the city as I knew it now" (404). The dependence on the perspective of Perkus foregrounds again the importance of (erratic) vision for constructing knowledge of the world. He has a lazy, "deviant" eye (16) and a "double and wandering vision" (262). Chase is described as gradually becoming initiated into this mode of seeing, and describes himself as having become "an acolyte to his brand of ... vision” (262). 


\section{Lieven Ameel}

More radical than a mere lazy eye, Perkus is beset by conditions described as "ellipsistic," in which time and space appear as ellipses, expanding uncontrollably $(26 ; 45)$ : a "species of blank interval, a nod or fugue in which he was ... [merely] between" (3). Throughout the novel, there is a strong suggestion that this disturbing vision enables access to crucial and otherwise inaccessible information: Perkus notes that ellipsis "is like a window opening” (27). Intriguingly, Perkus speaks of such visionary information in terms of seeing an animal: the "blot" on his vision during one "ellipsistic" seizure was like "an elephant in my apartment ... crowding to the edges of the room" (83). Of course, the "elephant in the room" is a figure of speech. But the elephant is here, for Perkus, to be taken almost literally: "I felt like I could stroke its pebbly hide" (83). In this elliptic mode, it is suggested, metaphorical utterances may be taken literally, and the figural becomes accessible as a tangible material reality. Throughout the novel it is asserted-similarly to Open City and 10:04-that a disturbed or impaired vision may enable one to gain access to privileged knowledge. Perkus notes that "[most] of his proudest writing ... was born of some glimpse of ellipsistic knowledge" (26). Crucial features of the environment in Chronic City tend to appear at the edges of vision-Major Arnheim, the center of power in the city, is described by Chase as "almost impossible to regard directly, like a black hole or a blot on my vision" (280).

The focus on vision and on the importance of glimpses of other worlds lurking at the edge of vision takes on two important aspects. The first one is that of the frame. Perkus Tooth insists that "[that] glimpse is intolerable. When your gaze slips beyond the edge of a book or magazine, you notice the ostensible texture of everyday reality" $(79) .{ }^{4}$ There is the suggestion that the "texture of everyday reality" is hidden just out of sight or at the edge of sight-a world to be discovered if only we could look more clearly from the corner of the eye. An echo of such a vision is found also in Morton's Dark Ecology, which argues that

[nearness] does not mean obviousness ... When massive entities such as the human species and global warming become thinkable, they grow near. They are so massively distributed we can't directly grasp them empirically. We vaguely sense them out of the corner of our eye while seeing the data in the center of our vision.

What is seen from the corner of the eye in Chronic City's Manhattan is not a single, coherent world but multiple spaces folded into spaces,

worlds squirreled inside one another, the chaotic intricacy with which realms interleave, like those lines of television cable and fresh water and steam heat and outgoing sewage and telephone wire and whatever else which cohabit in the same intestinal holes that pavement-demolishing 
workmen periodically wrench open to the daylight and to our passing, disturbed glances.

This observation of spaces enfolded in spaces, "worlds squirreled inside one another" is repeated throughout the novel. Perkus has the capacity to glimpse "bonus dimensions, worlds inside the world" (27). And the super-rich Woodrows' concealed home, a "house within-a-building," has an elaborate entrance that (to the narrator) seems to tell the neighbors that "your indoors is our outdoors" (28; italics in the original)-thus announcing, like the baroque fold, "that the inside is nothing more than a fold of the outside" (O'Sullivan 107).

What is hovering at the eye is thus not a singular, stable reality but the existence of numerous worlds. As Oona, Chase's love interest in the novel, imagines: "we're just one of innumerable universes living in parallel" (197), reminding one of Leibniz's theory of monadology, with its multiple worlds, from which the concept of the fold developed. The image of "innumerable universes" is no mere metaphor from Oona but an endeavor to access accurately the ontological status of the world they live in, because Oona and Perkus are considering the odds that they are living in a computer simulation (a view of the world popularized by, amongst others, the 1999 movie The Matrix, and which has more recently gained a more serious following in Silicon Valley circles; see Solon 2016). Perkus's and Oona's fantasies of multiple computer simulations are variations on a more mundane theme: that of individual humans as single, self-centered worlds (the novel uses for this the term "demimonde," literally half-world), with limited access to other worlds. Perkus insists that "no body ... really believes in the news from beyond the boundaries of their neighborhood or pocket universe. Manhattan is one of those, you know, a pocket universe" (328; original emphasis). It is a position that enables people to be blind to others' realities, or amnesiac-a position Perkus criticizes Chase for and which he deems typically American (in a statement that could easily be read as both a reference to the memory of $9 / 11$ and the international repercussions of the subsequent war on terror): "You're like the ultimate amnesiac American, Chase. You never can imagine anything actually happened before you wandered along" (207).

If the emphasis on glimpses of alternative realities and problems caused by visionary blots accentuate the inaccessibility of reality, there is also a pull in another direction: if vision is so central to our relation with reality, the reality of the world is perhaps determined by how one sees, rather than the other way round. Did the world exist before some cognitive being "wandered along"? This position comes close to idealism, a philosophical movement associated amongst others with Bishop Berkeley, whose thinking in this respect is conventionally summed up in the argument "esse est percipi (aut percipere)"- to be is to be perceived (or perceive) (Downing). It is a 
position repeatedly hinted at in Chronic City. Perkus argues that such an idealist view, in which matter is conceived as not existing unless observed, may be an ontological prerequisite for the world in which they live (if it is, indeed, as he and Oona consider, a computer simulation world), because it would, within multiple computer simulations, take too much energy "to make everything exist whether we look at it or not" (229; original italics).

Not only are the ontological bearings of the world determined by how one sees, but there are also suggestions that the world functions according to the words coined to describe it. It is a narrative strategy common in postmodern literature and used to great effect in the work of Thomas Pynchon- "the literalization of a situation initially implied as metaphorical" (Simonetti 57). One example of such literalization is the description in Chronic City of "money men ... slumping through the gray fog" (30), and lower Manhattan under a "cloud bank" (201)—a condition that turns out to be not figurative but literal (and open, of course, to interpretation as allegory for 9/11). Words seem to have power over the world, and this goes most obviously for Chase himself, who turns out to be living a script written by Oona and produced for the entertainment of the city. There's also the suggestion, for example, that the New York Times "is getting its material" from a drug dealer's invented marihuana brand names, rather than the more obvious reverse interpretation (187). Such complications between the world and words also invite the reader to reconsider her own world and the extent to which it is constructed according to narrative frames.

The relationship between human observer/narrator and the nonhuman environment (including strange weather, disturbing natural occurrences, animal patterns) oscillates in Chronic City between two positions on how human language and vision interact with the nonhuman world: on the one hand, the idealist conceptualization that the world (in its very ontological existence) is dependent on conscious vision; on the other hand, a much more skeptical idea of reality as a collection of (potentially infinite) worlds that can be accessed only with difficulty and through compromised senses. It's an oscillation that has antecedents also in nineteenth century literature's preoccupation with modes of seeing as knowledge and deception (Goulet), in Baudelaire's correspondences, and before that the romantic mode's searching relationship with the environment, which incorporated monist tendencies (see De Man 187-228). Chronic City presents a conglomerate of worlds in which nonhuman occurrences (such as the fog in southern Manhattan) affect the senses (vision, smell), and animal patterns force inhabitants out of their homes (the pair of eagles, the tiger). On the other hand, the novel also presents an environment where words used to denote that very world may affect its ontological attributes. When Perkus claims that "[something] happened, Chase, there was rupture in this city. Since then, time's been fragmented" (389), the hiccups in the soliloquy can be seen to correspond to the holes being torn in New York, but raise the question whether there is a causal relationship between the gaps in speech 
and gaps in space-and in what direction that relationship moves? It is noteworthy that the hiccups are presented as a natural force, since Perkus contracted them from his dog. This much is certain: that the hiccups appear as real gaps in the textual matter on the page.

What in both interpretations remains is a sense of radical interconnectedness. And similar to Ben in 10:04 and Julius in Open City, it is the protagonist's privilege to move through these multifarious worlds and to provide a connection point. In what he calls "another wave of my straddling-universes feeling," Chase feels he is the link between otherwise unconnected worlds (in this specific case, those of Perkus and the conceptual artist Noteless): "Only I had the freedom to dabble in each of their realities and feel the native absurdity of their simultaneous distance and proximity" (229-30). Chase himself is, in his quest for reality, enacting the operations of the fold-moving between "the façade and the closed room, the outside and the inside" (Deleuze 39). Making sense of the numerous worlds to which he is introduced by Perkus is described literally as a folding operation, Chase's "attempt to collate and refold his many crumpled maps of the universe" (404), the result of which is the narration presented in Chronic City.

\section{Conclusion}

In Open City, 10:04, and Chronic City, natural patterns, unseasonal weather conditions, and strange occurrences in the urban environment are bound up within a larger frame of reference that emphasizes as well as questions human vision and memory and that carries intimations of possible worldthreatening scenarios. In all three novels, apocalyptic strains can be read through the lens of 9/11, as mediations on remembrance and trauma and as endeavors to give past traumatic experiences a meaningful place in the present (see, e.g., O'Gorman, Severs). But there are other things at stakethe emphasis in all three novels on strange weather patterns, on experiences of visionary correspondences with the environment, and on the shadow cast by uncertain futures also feeds into narratives of climate change and into contemporary preoccupations with ontological questions.

In Open City and Chronic City, the way in which nonhuman presences, as well as past and future temporal layers, are imbued with meaning can arguably be located in the aestheticizing tendencies of the narrators. But there is also a sense that the visionary narrators are able to feel with the environment, rather than being sovereign attributors of meaning. Both texts can be approached as forms of "Ecosickness," a literature in which the human and the nonhuman appear as coconstitutive (Houser); especially so in the case of 10:04. In Chronic City, ontological instability is further multiplied, and the world is represented as open to a range of different explanationsmoving from extreme forms of idealism to skepticism as to the possibility of experiencing anything beyond one's immediate "demimonde" or "pocket universe.” 
The overlap between various (possible mutually exclusive) storyworlds and temporal layers in these three novels-although realized in different degrees and by using different narrative strategies-cannot be meaningfully unpacked by looking at the narrated ontological instability in terms of worlds "flickering" (Ingarden), or as "Swiss Cheese," in which the "irrational is contained in delimited areas that pierce the texture of the fictional world" (Ryan 377), or by positing heterotopian zones (McHale 43 ff.). ${ }^{5}$ Rather, it proceeds by way of folds, similar to paper or cloth folding and unfolding: the present of past trauma and future possibility coexisting in a raindrenched Central Park in Open City; temporal layers superimposed like "a doubly exposed photograph" in 10:04; worlds "squirreled inside one another" in Chronic City, with the narrator left to "collate and refold" the various maps.

Human consciousness, and its ability to connect with the world, is at once "blind" and, paradoxically, capable of visionary "insight," as the protagonist of Open City, drawing on Paul de Man, infers. The visionary experiences of Ben, in 10:04, driven by something close to hallucination, and the insights provided by "blots on vision" and by looking out of the corner of one's eye in Chronic City, point to a similar flawed yet insightful sensitivity, in a way that defies binary oppositions or causal hierarchies. The real, the possible, and the imaginary are described as continuations of the same plane, coeval with human perception. In 10:04 and Chronic City, in particular, there are endeavors to extend that folding of inner and outer into the world of the reader, such as the hiccups of Perkus in Chronic City, visualized on the page in blank spaces and the fireworks above Brooklyn Bridge, in 10:04, which are imagined on the physical page in the hands of the reader, thus extending tangibly into the reader's physical world.

Approaching ontological instability and the interaction between human perception and nonhuman environment through the concept of the fold helps home in on those elements that spill out from the fictional representation into the actual world. Such spill-over effects re-enact the Baroque breaking of spatial boundaries; Deleuze was intrigued, following Wölfflin, in how Baroque form was "always put in motion" ending "in the manner of a horse's mane or the foam of a wave," and how "matter tends to spill over in space" (4). The endeavors to reach out into the reader's referential world, evident especially in Chronic City and 10:04, are one particularly tangible example of such overspill. In language, a tentative overlap between the consciousness of reader and narrator is attempted, a moment of "coeval readership" (Lerner 93). Similar to Perkus's view of New York City, which becomes for Chase an "ellipsistic" experience that starts to affect his own perception of the surrounding world, some of the visionary experiences in these novels may color the reader's view of the referential world, enabling a sense of interconnection with the nonhuman environment, in the way of a fold connecting inner and outer, actual and possible. 


\section{Notes}

1 A shorter and amended version of this article appeared in Style 55 no. 3 under the title "Ontological Instability and Nonhuman Presence in Twenty-First-Century New York Fiction."

2 The draft riots of 1863, in which underprivileged New Yorkers-many often only recently arrived in America-revolted against being drafted into the Union Army and targeted the authorities as well as African Americans. The reference feeds into Open City's overall examination of the theme of migration, violence, and uneasy racial relationships.

3 Brian McHale mentions "double vision" in his treatment of postmodernist fiction and the zone, but rather than retaining this idea of the simultaneity of two different temporal levels, when discussing Elkin's George Mills and Pynchon's Gravity's Rainbow, he returns to metaphorizations that suggest the separation of different levels, moving from "double vision" to "split-screen effect" to different temporalities that "flicker back and forth" (93).

4 For more on the importance of the concept of "frame" in the work of Lethem, and its links to the work of Heidegger, see O'Gorman 45-47.

5 It could be argued that Lethem's Chronic City does refer to McHale's concept of the zone explicitly and repeatedly (e.g., 107, 174, 382) - and yet these zones (sometimes with zone between quotation marks; 243) never appear as radically set apart from the rest of the narrated world but rather as overlapping, or folding in, with other, less defamiliarized spatial environments.

\section{References}

Ameel, Lieven, Jason Finch, and Markku Salmela. Literature and the Peripheral City. Palgrave, 2015.

Ameel, Lieven. "Open City: Reading Signs of Uncertain Times in New York and Brussels." Mielikuvituksen maailmat/Fantasins världar/Worlds of Imagination, edited by Merja Polvinen, Maria Salenius, and Howard Sklar, Eetos, 2017, pp. 290-308.

Bradbury, Malcolm. "The Cities of Modernism." Modernism, edited by Malcolm Bradbury and James McFarlane, Penguin, 1976/1986, pp. 96-104.

Baudelaire, Charles. The Parisian Prowler: Le Spleen de Paris, Petits Poèmes en Prose. Translated by Edward K. Kaplan, University of Georgia Press, 1869/1989.

Caracciolo, Marco. "Ungrounding Fictional Worlds: An Enactivist Perspective on the 'Worldlikeness' of Fiction." Possible Worlds Theory and Contemporary Narratology, edited by Alice Bell and Marie-Laure Ryan, University of Nebraska Press, 2019, pp. 113-131.

Cole, Teju. Open City. Faber and Faber, 2011.

De Bruyn, Ben. "Realism $4^{\circ}$ : Objects, Weather and Infrastructure in Ben Lerner's 10:04.” Textual Practice, vol. 31, no. 5, 2017, pp. 951-971.

De Man, Paul. Blindness and Insight: Essays in the Rhetoric of Contemporary Criticism. University of Minnesota Press, 1983.

Deleuze, Gilles. Le pli: Leibniz et le baroque. Éditions de Minuit, 1988.

Deleuze, Gilles. The Fold: Leibniz and the Baroque. Translated by Tom Conley and Athlone Press, 1993.

Downing, Lisa. "George Berkeley." The Stanford Encyclopedia of Philosophy, edited by Edward N. Zalta, 2013, https://plato.stanford.edu/archives/spr2013/ entries/berkeley/. 
Finch, Jason, Lieven Ameel, and Markku Salmela, editors. Literary Second Cities. Palgrave, 2017.

Garrard, Greg, "Climate Change and the Art of Memory." thememorynetwork.net, 18 March 2014, http://thememorynetwork.net/climate-change-and-the-art-of-me mory-greg-garrard/.

Goulet, Andrea. Optiques: The Science of the Eye and the Birth of Modern French Fiction. University of Pennsylvania Press, 2006.

Gibbons, Alison. “Autonarration, I, and Odd Address in Ben Lerner's Autofictional Novel 10:04." Pronouns in Literature: Positions and Perspectives in Language, edited by Alison Gibbons and Andrea Macrae, Palgrave, 2018, pp. 75-96.

Heise, Ursula. Imagining Extinction. University of Chicago Press, 2016.

Ingarden, Roman. The Literary Work of Art: An Investigation on the Borderlines of Ontology, Logic, and Theory of Literature. Northwestern University Press, 1980.

Keunen, Bart. "The Decline of the City as Modernist Symbol: City Images in Postmodern Urban Fiction and in Collective Memory." The Urban Condition: Space, Community and Self in the Contemporary Metropolis, edited by Dirk De Meyer et al., 010 Publishers, 1999, pp. 359-376.

Lerner, Ben. 10:04. Faber and Faber, 2014.

McHale, Brian. Postmodernist Fiction. Routledge, 1987/2003.

Morton, Timothy. Dark Ecology: For a Logic of Future Coexistence. Columbia University Press, 2016.

O'Gorman, Daniel. Fictions of the War on Terror: Difference and the Transnational 9/11 Novel. Palgrave, 2016.

O'Sullivan, Simon. "Fold." The Deleuze Dictionary: Revised Edition, edited by Adrian Parr, Edinburgh University Press, pp. 107-108.

Park, Robert E. "The City: Suggestions for the Investigation of Human Behavior in the City Environment." The American Journal of Sociology, vol. 20, no. 5, 1915, pp. 577-612.

Ryan, Marie-Laure. Possible Worlds, Artificial Intelligence, and Narrative Theory. Indiana University Press, 1992.

Ryan, Marie-Laure. "Impossible Worlds." The Routledge Companion to Experimental Literature, edited by Joey Bray, Alison Gibbons, and Brian McHale, Routledge, 2012, pp. 368-379.

Salmela, Markku and Lieven Ameel. "New York Fiction.” Palgrave Handbook of Literature and the City, edited by Jeremy Tambling, Palgrave, 2016, pp. 317-332.

Severs, Jeffrey. "Memorializing Post-9/11 New York in Jonathan Lethem's Chronic City." Representing 9/11: Trauma, Ideology, and Nationalism in Literature, Film, and Television, edited by Paul Petrovic, Rowman and Littlefield, 2015, pp. 17-28.

Simonetti, Paolo. "Historical Fiction after 9/11: Thomas Pynchon's Against the Day." Modern Language Studies, vol. 41, no. 1, 2011, pp. 26-41.

St. Clair, Justin. "The Reality of Fiction in a Virtually Postmodern Metropolis: Jonathan Lethem's Chronic City and Thomas Pynchon's Bleeding Edge." The City Since 9/11: Literature, Film, Television, edited by Keith Wilhite, Fairleigh Dickinson University Press, 2016, pp. 89-105.

Solon, Olivia. "Is Our World a Simulation? Why Some Scientists Say It's More Likely Than Not." The Guardian, 11 October 2016, https://www.theguardian.c om/technology/2016/oct/11/simulated-world-elon-musk-the-matrix.

Westphal, Bertrand. Geocriticism: Real and Fictional Spaces. Palgrave, 2011. 


\title{
5 Seasonal Feelings \\ Reading Paolo Bacigalupi's The Windup Girl During Winter Depression
}

\author{
Kaisa Kortekallio
}

In Helsinki, November 2017 has been exceptionally cloudy and rainy. ${ }^{1}$ I have been reading Paolo Bacigalupi's climate fiction dystopia novel The Windup Girl. The narrative weaves together the societal and ecological crises of a future Bangkok, generating an atmosphere of fear and violence. During the two weeks of reading, feelings of anxiousness and tension have gathered in my body, intensified by the resonance between the weather and the novel.

The day after finishing the novel, November 15, brings with it a partial resolution of the tension. After weeks of heavy skies, the cloud cover parts, revealing a harsh white winter light. I walk the early afternoon streets in a quiet old district of Helsinki, Kruununhaka, and cry. At the moment of crying, my bodily experience is still permeated by the tensions and intense affects of the novel. I become aware of my body as a unified material thing, a block of flesh that carries itself along the streets. My perceptual awareness of the physical space is heightened, and along with the awareness comes a feeling of bodily porousness: the harsh afternoon light not only surrounds me but enters me, my whole body is weighed down by the pull of the earth and the cold weight of the nineteenth-century stone and brick buildings. The muted colors and ornate details of the buildings impress me with unusual force.

In this chapter, I propose that crying on the street after reading a climate fiction novel is a moment that opens up to both New Materialist and phenomenological analyses and that the experience can also loop back to literary interpretation in the cognitive-narratological vein. My affective response emerges from the interaction of human and nonhuman forces: the clouds, the light, the novel-and the theory. Under the influence of New Materialism and cognitive narratology, I pay more attention to my bodily feelings and to the nonhuman forces present in the situation.

The experience of reading a novel is, however, not yet an interpretation but a complex tangle of thoughts, feelings, impressions, and associations that does not follow any particular theoretical model. In describing and analyzing the act of reading the novel, including the crying episode that immediately followed, I aim to retrospectively and partially explain the 
cognitive and affective dynamics involved. The chapter discusses how reading a novel participates in embodied experience and asks whether an affective response such as crying could be employed as part of literary interpretation. I propose that in the crossroads of New Materialist and enactive perspectives on literature, the reading body can be considered as an affective being that makes sense of its environments through bodily feelings (cf. Colombetti and Thompson; Neimanis). As an embodied being constantly adjusting to and conversing with the surrounding materialities, the reader may creatively involve many kinds of events and things, human and nonhuman, into the reading experience. As a scholarly subject, the same reader can analytically describe the threads and knots that form this everchanging tangle.

While the focus of this chapter is on the phenomenology of reading, I will also attend to the formal features of the novel that participate in the affective experience-descriptions of material things and forces, as well as the structure and pace of narrative events. I suggest that during the course of reading the novel, affective responses to these features accumulate and give rise to bodily feelings of anxiousness and tension that play into the general depressive mood generated by the seasonal darkness of Finnish winter. Building on both cognitive reading studies and New Materialist philosophy, I call this effect reciprocal amplification (cf. Kuzmičová "Does It Matter"; Neimanis).

Reading climate fiction in the year 2017, one cannot dismiss the physical environment. The weather is increasingly strange: even in Southern Finland, which tends to have a moderate climate, the fall of 2017 is characterized by freak storms and unusually high temperatures. To read in November is to read during heavy rains and rapidly decreasing sunlight. The darkness, while not dependent on the weather as such, is made unusually depressing by the heaviness of the cloud cover and the lack of snow. In some parts of Finland, including Helsinki, the cloud cover does not break for three consecutive months. In an autumn this dark, the symptoms of seasonal affective disorder are exceptionally severe too. In this chapter, I describe my personal experience with seasonal affective disorder as a "space of possibility" (Ratcliffe 358) that shapes my affective encounter with the novel. ${ }^{2}$ In my view, the seasonal mood should be considered an environmentally emergent phenomenon rather than merely an "inner" state of an individual experiencer.

In adopting an approach that considers both mood and physical environments as part of the reading experience, I take a critical stance toward the common literary-theoretical metaphors of transportation and immersion. In analyses and theories of reading that apply these terms, the reader's consciousness is figured as carried away to a fictional realm, "not only assumed to engage in mental travel into distant imaginary worlds, but also become temporarily decoupled from their own world as part of the same process of transportation" (Kuzmičová "Does It Matter” 291). ${ }^{3}$ In the metaphorical 
model of transportation and immersion, physical environments are mostly treated as distractions that hinder a fully immersive aesthetic experience. This chapter considers what happens when the reader's consciousness is not decoupled from the world but rather allows the physical environment to enter and shape the reading experience.

\section{Enactivism and New Materialism}

The enactive approach to literature and cognition focuses on the reciprocal dynamics between environments and reading minds. Enactive theory draws from cognitive sciences, systems biology, ecological psychology, and phenomenology, building on to the notion that cognition is embodied, situated, and co-emergent with the cognizer's environments (Varela et al; Noë; Thompson). The approach centers on the hypothesis that cognition involves skillful activity-perceiving, for example, "isn't something that happens in us, it is something we do" (Noë 216). Crucially to the main theme of this chapter, the theory also views affect and emotion as aspects of cognitive activity (Colombetti; Colombetti and Thompson).

From an enactive perspective, reading a fictional narrative is a "skillorientated interaction between a reader's embodied mind and the literary object" (Polvinen 140). Focusing on imaginary environments, enactivist literary research has discussed the "presence" of the reader in terms of virtuality: when encountering fictional environments, the reader experiences something like bodily echoes or traces of actual events, movements and feelings, creating mental images based on both the cues provided by the narrative and their personal experiential backgrounds (Caracciolo "The Reader's Virtual Body"; Kukkonen; Polvinen). This focus already acknowledges that actual environments participate in the reading process but discusses them on a rather general level. However, as demonstrated by Anezka Kuzmičová ("Presence," "Does It Matter"), the theory also allows for a mode of thinking that puts more emphasis on the particularity of actual environments.

New Materialist perspectives provide means for considering the particularity and materiality of actual environments more closely. Moreover, they propose practical techniques for materialist reading. Some New Materialist thinkers have suggested that conscious orientation toward nonhuman material agencies-and toward embodied experience as an interface between the human and the nonhuman-can be employed as a means of developing posthumanist sensibilities (e.g., Coole and Frost, Neimanis). In New Materialist ontology, material things are considered as dynamic and active: in friction, movement, growth, and breakdown, they generate difference. Matter refers to "phenomena in their ongoing materialization" (Barad 151). The focus of New Materialist analyses is thus on the dynamicity of material processes, including processes that involve humans.

Reading can also be considered as a material process. In their formulation of material ecocriticism, Serenella Iovino and Serpil Oppermann propose 


\section{Kaisa Kortekallio}

that a New Materialist approach to reading can "focus attention on bodily experiences and bodily practices (where 'body' refers not only to the human body but to the concrete entanglements of plural 'natures,' in both human and more-than-human realms)" (Iovino and Oppermann 76). They also propose that material-ecocritical reading has "the ethico-cognitive potential to upgrade our sensorium" (Iovino and Oppermann 87). I appreciate their assessment and suggest that the ethico-cognitive potential could be explored and developed with the help of the enactive approach. Instead of subscribing to the transhumanist term "upgrade" that metaphorizes the sensorium as a technological apparatus undergoing linear improvement, I would suggest that the potential can unfold in countless directions. If different dance styles and musical preferences "cultivate different forms of bodily awareness" (Colombetti 164), our reading habits can have similar effects as they inform our bodily patterns of response (see Warhol; Caracciolo "Perspectives").

I begin the main part of the chapter with a brief discussion of moods evoked by seasons and narratives, outlining how moods are constituted through bodily feelings as part of environmental experience. I consider how my affective responses to Paolo Bacigalupi's novel The Windup Girl both resonate and clash with my seasonal mood and analyze the affectivity of descriptive passages in the narrative. I explain how the notions of environmental propping (Kuzmičová, "Does It Matter") and amplification (Neimanis) can help articulate the experiential dynamic of materialist reading. In conclusion, I suggest that materialist analyses of this kind can make the more-than-human affectivity of both environments and literature more readily available to perception.

\section{Seasonal Mood, Bodily Feelings, and Affective Responses to Narratives}

An embodied subject is always in a mood of some kind (Ratcliffe 362). Discussing depression in particular, Ratcliffe stresses that deep moodsor existential feelings, as he terms them-give shape to the possible engagements with the environment: sadness, for example, is "how one finds oneself in the world rather than an emotion that one has within the world ... [one] cannot see outside it" (360). Mood is also often theorized through weather analogies (see, e.g., Colombetti). Sadness, like rain, envelopes the experiencing subject completely-in a specific location, or a specific body, there is no "outside" to either mood or weather. Whereas affects and emotions are episodic, like bouts of rain or gusts of wind, moods are considered in terms of cold or warm fronts or climate fluctuations. An anxious mood generally lasts for longer than an episode of fear, and whereas fear targets a specific object, say a speeding car, anxiousness generally does not have a specific target. Anxiousness can also be "in the air," outside of individual bodies rather than emerging from them, a collective phenomenon (Colombetti 77-82). The notion of mood can thus be 
very close to the notion of atmosphere-it is somewhere between feeling and environment, an affective relationality. ${ }^{4}$

Ratcliffe emphasizes that moods should be considered in terms of bodily feelings. This does not mean that moods should be conceived as feelings internal to the body or even experienced as associated with the body. Rather, the body can be something through which we feel something else or relate to the world (363). In the case of seasonal affective disorder, seasonal and meteorological conditions are experienced through long-term bodily feelings, such as fatigue or heightened sensitivity to light. ${ }^{5}$

Weather-related moods are common folk-psychological knowledge, and for art and literature, the connection is described often enough to have become clichéd. ${ }^{6}$ Clinical-psychological research also strongly suggests that weather affects mood-differently depending on the individual but significantly nonetheless. Seasonal affective disorder is associated both with personal vulnerabilities (retinal sensitivity, genetic variations, hormonal levels, attitudes) and environmental conditions (the availability of natural light, weather patterns), and it typically presents itself during the dark winter seasons of Arctic areas (Rohan and Rough). The phenomenon of seasonal moods highlights not only the embodied nature of cognition but also how the mind-body is constituted in systemic interactions with its environments. The severity of the symptoms of winter-type seasonal affective disordermost typically, fatigue, depressed mood, and anhedonia-tend to vary from winter to winter, and even if there is no consensus about the exact reasons for the variation, the Oxford Handbook overview points to "climatological variables"-i.e., changes in weather (Rohan and Rough 256). ${ }^{7}$

Even though seasonal moods are not necessarily as deep or persistent as the depressive states Ratcliffe discusses, they too envelope subjective experience, including the experience of reading fiction, affecting one's expectations, judgements, and affective responses. We can thus assume that mood, and the link between mood and physical environment, matters to reading. But how can we describe the interplay between seasonal moods, on the one hand, and the affective responses evoked by a narrative, on the other?

Building on Ratcliffe's notion of moods as bodily feelings, Marco Caracciolo has argued that narratives can elicit moods through evoking emotional responses ("Perspectives"). Caracciolo argues that "mood is not just a function of narrative contents-the situations and characters represented by a text, and the circumscribed emotions they elicit-but of narrative style and structure as well" (18). I share this view and seek to demonstrate in my reading how a number of factors in the text work together to elicit bodily feelings-specifically, tension and anticipationand how these feelings mesh with seasonal mood.

Viewing mood as part of environmental experience calls for a conception of feelings as something else than manifestations of interior emotions-a model that allows factors external to the body, such as weather and fiction, 


\section{Kaisa Kortekallio}

to play into the formation of feelings. Robyn Warhol has mobilized such a model in the context of feminist narratology, considering feelings as performative rather than expressive. In the performative model, the body is understood "not as the location where gender and affect are expressed, but rather as the medium through which they come into being" (10). According to Warhol, literary criticism and film theory have tended to use the expressive model and thereby "granted privilege to the idea that every person harbors 'real' feelings, whether consciously or subconsciously expressed, and that literary texts tap into those feelings in more or less legitimate ways" (14). Warhol links this claim to the modernist prejudice against popular forms that "so readily and mechanically arouse emotion: it's too easy; it must not be 'authentic"' (35). In the performative model Warhol advances, feelings are always socially and culturally constructed to some extent, and bodily events such as crying over a sentimental novel are considered in terms of generating rather than expressing feelings.

The role of narrative form in this model is somewhat technological. Resonating with certain enactivist views of narrative (Polvinen), Warhol's view considers narrative structures as "devices that work through readers' bodily feelings to produce the physical fact of gendered subjectivity" (24). Crying, in such a view, is a response that generates bodily feelings in a pattern typical to the narrative form in question-the marriage plot, the family drama, or in the case of the act of reading described in this chapter, the catastrophic structure of a climate fiction narrative. Even if the exact constituents of mood are difficult if not impossible to pinpoint on the textual level (Caracciolo, "Perspectives"), Warhol's work suggests that one fruitful way to proceed toward an analysis of the constitution of mood is to conduct analyses of how bodily feelings are generated in response to specific textual features.

\section{Seasonal Mood as a Space of Possibility}

The Windup Girl is usually characterized as climate fiction or dystopia. ${ }^{8}$ It envisions a twenty-third-century Thailand based on contemporary climate science scenarios. In the storyworld, global warming has raised the sea levels, fossil fuel sources have become depleted, and an ecosystemic collapse has occurred on a global scale. People and crops alike have been decimated by recurring pandemics. Weather has become unreliable, as the dry and wet seasons do not follow each other in a predictable pattern. The plot of the novel follows the development and outbreak of a societal crisis in Bangkok, entangling human life projects with political and ecological events.

In November 2017, I read The Windup Girl in the affective context of the immediate physical environment of reading. On most days, I read on the top floor of the university library, with a view over the roofs of Kruununhaka and the shifting masses of rain clouds. Every day around 2 PM, the sky starts turning dark. During reading, I write notes that track both my frustration with 
the novel's manipulative narrative techniques and my affective responses to the season. ${ }^{9}$ In them, I recognize the structure of feeling that characterizes the novel: tension is first created and accumulated through affective descriptions and plot events (the details of which I will not discuss here) and then resolved through fast-paced and violent narrative events.

It isn't just the characterization, it is the narrative structure too: the rhythm, the cues. The first bloodletting. Manipulation of affect. I feel constricted by these devices, more so than when reading PB's short stories.

I yawn; my eyes water. I am tired under the fluorescent lights, in the whir and hum of the snack cooler in the corner of the reading hall.

(Kortekallio 9.11.2017)

The note mentions some of the typical expressions of seasonal affective disorder: increased sensitivity to artificial light and sound and a feeling of being constrained. It also records a feeling of irritation with the narrative structure of the novel and with the obviousness of its techniques. At the time of reading, I recognize the pull of the narrative as an invitation for a particular kind of excited, forward-leaning engagement typical to thrillers, and yet my prevailing mood does not provide a possibility for such excitement. I continue to feel the affects particular to individual scenes in the novel, which I will describe more closely in the following section. The violence of the scene I refer to as "the first bloodletting," in which the Thai Environment Ministry officials terrorize the streets in vengeance of the death of their popular leader, still causes my throat to tighten in fear and disgust. I recognize this feeling as a response proper to the design of the narrative and the scene as the first mark of the turning of the narrative's atmosphere: the accumulated tension of weather and political climate begins to crack, to be resolved in the ending climax.

Anezka Kuzmičová has discussed the ways in which literary imagination is affected by physical environments ("Does It Matter"). She calls this process environmental propping (299). In her example: when reading Heart of Darkness by Joseph Conrad, your mental images of the fictional Congo River could be affected by the sound of water from a nearby fountain, and the author's descriptions of the Congo can in turn make you more acutely conscious of the sound of water in your own immediate environment (296). ${ }^{10}$ Kuzmičová also mentions that physical environments may shape mental imagery more intensely in the case of affective genres such as horror fiction or thrillers (298). Fiction that foregrounds environmental affects, as climate fiction does with its descriptions of weather phenomena, could arguably also provide more cues for environmental propping. ${ }^{11}$

This reciprocal model of environmental propping helps to articulate the attentional and affective dynamics of my reading experience. The fictional environment of The Windup Girl and the actual environment of 


\section{Kaisa Kortekallio}

my reading are partly juxtaposed-the novel portrays a busy city during a hot and dry season, whereas Helsinki in November is chilly and rainy with very few people on the streets. However, there are some shared aspects to the experientiality of these environments, primarily the weather-related anxiousness and increasing bodily tension described above. The experiential similarity of these affects serves to amplify the overall experience of anxiousness and bodily tension.

Within the space of possibility created by a weak and persistently tired mood, I am not capable of feeling the thrill proposed by the novel. Rather, I grow weary of the affect.

Chapter 40: excessive violence and destruction. I am almost completely desensitized. My feelings are all meta: I am frustrated by the novel. I doubt its merits. Very little immersion here. Maybe it was different the first time.

(Kortekallio 13.11.2017)

In the second note, written in forced, short-worded bursts of effort, feelings of fatigue and frustration clash with the affect suggested by the narrative, as its pace and intensity increase toward the end. In my seasonal mood, I have no interest or strength for encountering the novel's intensities-whether they are violent, as in the climax of the novel, or liberating, as in the epilogue in which the slave girl Emiko finds freedom in the flooded city. The ending of the novel falls flat. ${ }^{12}$

Environmental propping and phenomenology of mood help to explain how the affects of anxiousness and bodily tension are amplified in the reading experience. To describe the dynamics of this event more closely, I now turn to a textual analysis of the affective descriptions in the novel.

\section{Building Tension Through Affective Descriptions}

In The Windup Girl there is no single protagonist, nor a hero; rather, the storyworld and its events are explored through a number of prejudiced, traumatized, profit-seeking characters from many walks of life. The individual perspectives also represent different sectors of the future Thai society, reiterating popular character types: the spy, the action hero, the sly Oriental merchant, and the artificial girl. Bacigalupi's formulaic characterization does not invite me to engage with the characters as individual personalities, to whose goals and aspirations I would emotionally commit. It does, however, offer many opportunities for attuning to bodily feelings, as the characters move and act in their surroundings. The emphasis on bodily feeling and action is so prevalent that it seems more appropriate to refer to these constructs as "fictional bodies" rather than "characters." 
Due to this formulaic yet robustly corporeal style of characterization, the focus of my reading is on the affective responses elicited by the material aspects of the narrative rather than the emotional responses Caracciolo discusses ("Perspectives"). The affectivity of narrative contents and style, such as the glare of a fictional sun or the fast pace of action sequences, is experienced as sensory and kinesthetic but not necessarily as emotionally valenced. I veer away from conceptualizing the characters primarily as fictional personae who the reader is supposed to encounter primarily through social and psychological schemata. Rather, I consider the fictional bodies and experiences in terms of their material affectivity, which is comparable to the affectivity presented by the fictional nonhuman forces and things (e.g., sunshine and windup springs) and the materiality of narrative style (e.g., the pace and rhythm of the text).

In spite of their variation, the fictional bodies are fairly similar: the prevailing tropical heat wave affects all of them in visceral ways. All bodies are objects to this nonhuman force. In the story, the yearly monsoons are months late, and the heat and drought are becoming intolerable. Bacigalupi's Bangkok is a city below sea level, and a great dike and a system of pumps protect it from the rising water. The presence of the blocked water of the Chao Phraya River emerges as both a threat of destruction and a hope of relief:

The heat of the Yaowarat slum is full of shadows and squatting bodies. The heat of the dry season presses down on him, so intense that it seems no one can breathe, even with the looming presence of the Chao Phraya dikes. There is no escape from the heat. If the seawall gave way, the entire slum would drown in nearly cool water, but until then, Hock Seng sweats and stumbles through the maze of squeezeways, rubbing up against scavenged tin walls.

In the first sentence of this passage, it is heat that is full of shadows and squatting bodies-not the slum. Heat is thus subtly positioned as the encompassing condition-or a space of possibility-for the described events. The word heat is bluntly repeated in three consecutive sentences, underscoring the inescapability of the seasonal weather. Moreover, the affective imagery of the passage consists of phrases that point to heavy, constraining forces above and around the experiencer: "the dry season presses down on him," and "the looming presence" of the dikes evoke a feeling of oppression from above, and the "maze of squeezeways" through which the focalizer "sweats and stumbles," "rubbing up" against the walls, evoke a feeling of being constrained from all sides. The potentiality of the flood, the "nearly cool water," emerges as the force that could wipe away all these oppressive constraints. 


\section{Kaisa Kortekallio}

Descriptions of this kind are frequent in the novel. My bodily feelings attune to the descriptions of oppressing heat in which the sun "glares down" (171) and "hammers down" (147), "no breezes blow" (125), and "nothing with any intelligence is moving" (125): the characters sweat, their "lungs burn" (147) and they "breath shallowly" (147). Through these simple descriptions, formulated with consistent wording and tone independent of the particular focalizer, the affects of heat and sweating under the sun become present as experiential traces that enable sympathetic attunement to the fictional bodies in the novel. I feel their need for fresh air and water, their fatigue, and the intensity of waiting for the rains. As mentioned above, this is an effect linked to the affective descriptions, not so much to characterization or narration.

To highlight the more-than-human aspect of this bodily response, we can compare it to response elicited by the affective descriptions of nonhuman bodies: iron springs and working animals. A particularly forceful description of materiality in the first chapter of the novel accounts for the winding of a large iron spring used to kinetically store the energy with which factories and electric devices are run. The spring is "tortured into its final structure, winding in on itself, torquing into a tighter and tighter curl, working against everything in its molecular structure as the spring is tightened down" (15).

As with the above passage, the affectivity of the description rises from the blunt repetition of a keyword ("tight") and to indicators of motion (winding in on itself and tightened down, suggesting a gradually spiralling motion). The structure of the sentence also plays into affectivity by way of cranking out phrase after phrase before ending to a full stop-the iterative rhythm of the sentence matches the feeling of eager anticipation or the increasing muscular tension experienced when completing a heavy physical task.

The "tortured" metal of the springs is wound by giant bioengineered elephants, "megodonts," that "groan against spindle cranks, their enormous heads hanging low, prehensile trunks scraping the ground as they tread slow circles around power spindles" (11-12). Note, again, the constrained and downward motions. I feel the kinaesthetic echo of the physical tension in both the springs and the megodonts' muscles as a tension in my neck and jaw. In this affective response, I experience the materiality of fictional human bodies in a similar manner as I do the materiality of fictional nonhuman bodies, animate and inanimate alike. ${ }^{13}$

During the act of reading the novel, the increasing tension affects the reader both through singular descriptions, such as those above, and through the dynamics of narrated action. The accumulation of affective responses can evoke an anxious or constrained mood in the reader, depending on the reader's previous experience with actual constraints, such as forced labor or distressing weather. ${ }^{14}$ In this way, the fictional environment affects my reading body by calling up bodily memories of previous experiences of weather and material things and by evoking more general bodily feelings of tension and movement. Before reaching the end of the novel, such bodily 
feelings can accumulate into a considerable mood-amplifying force. Robyn Warhol has discussed this kind of accumulation in the context of watching soap-opera television as a daily routine.

For some viewers, the intensities are a form of background noise in a life otherwise detached from the concerns of the soap-opera plot; for others-particularly those who are moved enough by the story line to want to write about it online (or, in my case, in this chapter)-the intensities are more present, more vividly a part of daily consciousness. To watch every day is to be carried on that wave of intensities, to experience the build-up, the crisis, and the undertow of response as one of the structuring principles of daily life.

Warhol discusses this dynamic in the context of gendered feeling, but her insights can be applied more generally to other patterns of feeling. While Warhol argues that the soap-opera viewer is "continually regendered as effeminate, whether you are male or female" (119), we can argue that continued engagement with affective narratives of any kind plays into the patterns of feeling performed by the reading/viewing body. However, from a New Materialist perspective, we should also consider how other factors, such as seasonal conditions, play into these patterns.

\section{Conclusion: Reciprocal Amplification of Affect}

In this chapter, I have considered mood from the phenomenological perspective put forward by Matthew Ratcliffe, as bodily feelings. I have shown how a seasonal mood in particular opens up to phenomenological analysis. However, as seasonal mood is so prominently dependent on environmental factors, other perspectives are also needed in considering it. From an enactive perspective, seasonal mood is an emergent phenomenon arising from the interactions of human bodies and environmental conditions. In New Materialist terms, seasonal mood is generated in the entanglement of the material forces of weather, human embodiment, and literature.

In my reading of Paolo Bacigalupi's The Windup Girl, I considered how affective responses to descriptive and narrative techniques can accumulate bodily feelings and evoke moods. By using kinaesthetic and spatial language, Bacigalupi's descriptions of material forces call up experiential traces of previous embodied experiences, generating bodily feelings of tension, weight, constraint, and movement. During reading, these feelings add up to a considerable mood-amplifying force. The experiential dynamic of mood is further amplified by mutual environmental propping between experiencing the dark season and the imaginative rendering of the fictional bodies and spaces.

Based on this instance of reading The Windup Girl, it appears that focusing one's attention to bodily feelings and experiential patterns tends to 


\section{Kaisa Kortekallio}

either enhance or entirely deflate their intensity. In both cases, the bodily feelings are more available to consciousness than in casual modes of reading. Kuzmičová's notion of environmental propping begins to articulate this dynamic of reciprocal amplification, and New Materialist perspectives on experience may help theorize it further. Reciprocal amplification may provide a way for cultivating posthumanist forms of experience (cf. Iovino and Oppermann). New Materialist scholar Astrida Neimanis has suggested that artworks and scientific findings can amplify our experiences of nonhuman forces and entities, serving as "mediating prostheses that open certain experiences for us, but foreclose or restrain others" (Neimanis 61). When this line of thought joins the thread of enactivist philosophy, we can articulate the experience of crying on the street after reading a novel as an instance of embodied and environmental sense-making.

On November 15, I walk the streets of Kruununhaka and cry. The physical act of crying can be described as something of a cognitive epiphany, enmeshed in what Ratcliffe describes as a temporary shift in deep mood (366-67). My seasonal mood breaks, unveiling a moment of silent clarity. If there is a convergent pattern connecting my moods and the weather, it is only fitting that epiphany emerges on the one bright day after weeks of watching rain clouds shift and roll.

Within this epiphany, the realization about the novel-the beginning of a new interpretation-comes through an experiential analogy. Walking the momentarily bright streets, the fatigue and tension gathered in my body present themselves in their full weight. I feel permeated by both the bleak affect of the novel and the darkness of the past weeks' weather, muscles and intestines heavy with fatigue. The oppressiveness of the weather is matched and merged with the oppressiveness of the novel. In analogy, the novel is a material force, not unlike the clouds and the light. I live with it like I live with the weather, feeling the shifts and weights in its affective patterns. It affects both my momentary bodily feelings and my general mood.

In a New Materialist vein, the literary artifact The Windup Girl can be considered as a mediating prosthesis that amplifies my awareness of nonhuman materialities and sensitizes me to their effects. On the other hand, my physical surroundings, including the season and weather phenomena, provide environmental propping that guides my attention to the affective cues of the novel. Through attending to the shifts in bodily feelings, we can begin to make sense of the reciprocal amplification of affect that is generated in the entanglement of human bodies, literary artifacts, and physical environments. In deliberate experiments such as this, the material and nonhuman aspects of lived experience are made available to perception in a striking way. However, those aspects inform our experience all the time, in modes subtler than epiphany. I suggest that attending to bodily feelings and carefully articulating them-not as peripheral but as integral to both New Materialist and enactivist approaches to literary interpretationdevelops a richer sense of the material dynamics of bodily reading. 


\section{Notes}

1 This chapter was written during a research period in the consortium project Instrumental Narratives: The Limits of Storytelling and New Story-Critical Narrative Theory (2018-2022), funded by the Academy of Finland (no. 315052). It has been constructed from a pile of notes with the generous and significant help of the editors of this volume. I want to thank all of them, and Marco Caracciolo especially, for guiding me to the work of both Anezka Kuzmičová and Robyn Warhol.

2 Ratcliffe grounds his idea of moods as "spaces of possibility" in Heidegger's notion that mood is a "background sense" of belonging to a world (rather than an intentional state in itself). In different moods, different objects in the world matter to us in different ways, and we experience the world as offering different kinds of significant possibilities. "Mood constitutes a phenomenological background in the context of which intentionally directed experience is possible" (Ratcliffe 357).

3 See also Gerrig; Green and Brock.

4 Ahmed argues that moods can define the borders of collective bodies, producing both in-groups (the ones who share a mood) and "affect aliens" (the ones who do not). In popular media and academic accounts, epochs are often defined in terms of a dominant public feeling: an emotion that when named expresses something about what it feels like or felt like to live in that particular period. For example, the Cold War 1950's in the USA and UK was called a time of paranoia, and our current epoch has been characterized as "the age of anxiety" or "the age of fear" (Anderson 107-108).

5 As the examples demonstrate, bodily feelings should not be equated with emotions. Bodily feelings vary from emotionally neutral sensations to deeply emotional bodily experiences. Bodily feeling and affect can be used as partly overlapping concepts, but whereas bodily feeling is tied to an individual body, affect can be considered as a collective or cultural phenomenon that informs feeling (cf. Ahmed; Seyfert; Vermeulen).

6 To mention a few examples: seasonal moods and atmospheres play a significant role in Victorian and Gothic imagination (the mists and storms in Charlotte Brontë's Jane Eyre), in magical realism (the immobilizing dry season in Gabriel Garcia Marquez's A Hundred Years of Solitude), in speculative fiction (the psychologically warping effect of the flooded tropical areas in J. G. Ballard's The Drowned World), and in contemporary climate fiction (the hopelessness of a parch-dry Earth in the film Interstellar).

7 The overview also stresses the relevance of other factors, listing "the time of year assessed, length of residency, acclimatization, sociocultural factors, and withintime zone longitude, which affects wake time relative to sunrise" (Rohan and Rough 256).

8 The reading of The Windup Girl that I describe here is not a first readingrather, it is an experimental exploration of a narrative I already know well. The Windup Girl is a climate fiction novel that features plenty of descriptions of bodily experiences connected to weather phenomena. Reading these descriptions during the darkest time of the year, during which seasonal affective disorder always reliably affects my bodily experience, is a choice that deliberately amplifies the situational aspects of a singular reading.

9 The reason for citing my original notes rather than just paraphrasing them lies in their communicative force. I believe that the particular phrasing and rhythm of notes written during the reading event carries traces of the feelings of that time and that those traces can evoke experiential echoes in the readers of this essay-much in the same way as fictional texts can. The notebook entries thus contribute to my communication of the reading experience. 


\section{Kaisa Kortekallio}

10 As Kuzmičová notes, this scenario is atypical in its clarity: in most natural reading situations, imagination and stimuli would mingle in less clear-cut ways. Kuzmičová also discusses instances of epistemic awareness in which the environmental stimuli (e.g., the sound of running water) are not consciously perceived but still affect the formation of mental images (Kuzmičová, "Does It Matter" 296; see also Schwitzgebel).

11 Material ecocritics have suggested that nonhuman entities-such as rivers-can participate in the writing process through affecting and impressing the writer's human body (Iovino and Oppermann). The cognitive aspect of this kind of material-creative dynamic could also be discussed in terms of environmental propping. For critical work that combines material ecocriticism and cognitive theories of affect, see Weik von Mossner.

12 Were this a clinically depressed mood, the desensitization could become habitual, making it difficult or impossible to feel with the novel altogether. In the case of seasonal affective disorder, however, the mood can shift and fluctuate with the weather.

13 The winding movement is evoked as both a component of and a metonym for the societal tensions. Within the tension, there is the promise and risk of release: controlled release brings success, uncontrolled release causes violent destruction. In the first chapter of the novel, one of the working megodonts goes mad and wreaks havoc in the factory, foregrounding the chaotic release of long-wound societal tensions that takes place at the climax of the novel. The central image of windup springs is also foregrounded in the title of the novel, emphasizing the importance of increasing tension as a central kinaesthetic motif.

14 This experiential dynamic has been theorized extensively in the enactive approach (see Caracciolo, Experientiality, for an overview and a theoretical model and Kortekallio for a provisional method).

\section{References}

Ahmed, Sara. "Collective Feelings: Or, The Impressions Left by Others." Theory, Culture and Society, vol. 21, no. 2, 2004, pp. 25-42.

Anderson, Ben. Encountering Affect: Capacities, Apparatuses, Conditions. Ashgate, 2014.

Bacigalupi, Paolo. The Windup Girl. Nightshade Books, 2009.

Barad, Karen. Meeting the Universe Halfway: Quantum Physics and the Entanglement of Matter and Meaning. Duke University Press, 2007.

Caracciolo, Marco. "The Reader's Virtual Body: Narrative Space and Its Reconstruction.” Storyworlds, vol. 3, 2011, pp. 117-138.

The Experientiality of Narrative: An Enactivist Approach. De Gruyter, 2014.

"Perspectives on Narrative and Mood." How to Do Things with Narrative: Cognitive and Diachronic Perspectives, edited by Jan Alber and Greta Olson, De Gruyter, 2017, pp. 15-28.

Colombetti, Giovanna. The Feeling Body: Affective Theory Meets the Enactive Mind. MIT Press, 2008.

Colombetti, Giovanna and Evan Thompson. "The Feeling Body: Toward an Enactive Approach to Emotion." Developmental Perspectives on Embodiment and Consciousness, edited by Willis F. Overton, Ulrich Müller, and Judith Newman, Lawrence Erlbaum, 2008, pp. 45-68. 
Coole, Diana and Samantha Frost. "Introducing the New Materialisms." New Materialisms: Ontology, Agency, and Politics. Duke University Press, 2010, pp. $1-43$.

Gerrig, Richard J. Experiencing Narrative Worlds: On the Psychological Activities of Reading. Westview Press, 1988.

Green, Melanie C. and Timothy C. Brock. "The Role of Transportation in the Persuasiveness of Public Narratives." Journal of Personality and Social Psychology, vol. 79, no. 5, 2000, pp. 701-721.

Iovino, Serenella and Serpil Oppermann. "Material Ecocriticism: Materiality, Agency, and Models of Narrativity.”Ecozon@, vol 3, no. 1, 2012, pp.75-91.

Kortekallio, Kaisa. Reading Mutant Narratives. The Bodily Experientiality of Contemporary Ecological Science Fiction. PhD dissertation, University of Helsinki, 2020.

Kukkonen, Karin. "Presence and Prediction: The Embodied Reader's Cascades of Cognition.” Style, vol. 48, no. 3, 2014, pp. 367-384.

Kuzmičová, Anežka. "Presence in the Reading of Literary Narrative: A Case for Motor Enactment." Semiotica, vol. 189, 2012, pp. 23-48.

Kuzmičová, Anežka "Does It Matter Where You Read? Situating Narrative in Physical Environment." Communication Theory, vol. 26, no. 3, 2016, pp. 290-308.

Neimanis, Astrida. Bodies of Water: Posthuman Feminist Phenomenology. Bloomsbury, 2017.

Noë, Alva. Action in Perception. MIT Press, 2005.

Polvinen, Merja. "Cognitive Science and the Double Vision of Fiction." Cognitive Literary Science: Dialogues Between Literature and Cognition, edited by Michael Burke and Emily T. Troscianko, Oxford University Press, 2017.

Ratcliffe, Matthew. "The Phenomenology of Mood and the Meaning of Life." The Oxford Handbook of Philosophy of Emotion, edited by Peter Goldie, Oxford University Press, 2009, pp. 349-372.

Rohan, Kelly and Jennifer N. Rough. "Seasonal Affective Disorder." The Oxford Handbook of Mood Disorders, edited by Robert J. DeRubeis and Daniel R. Strunk, Oxford University Press, 2017, pp. 255-266.

Seyfert, Robert. "Beyond Personal Feelings and Collective Emotions: Toward a Theory of Social Affect." Theory, Culture and Society, vol. 29, no. 6, 2012, pp. 27-46.

Schwitzgebel, Eric. "Do You Have Constant Tactile Experience of Your Feet in Your Shoes? Or Is Experience Limited to What's in Attention?" Journal of Consciousness Studies, vol. 14, no. 3, 2007, pp. 5-35.

Thompson, Evan. Mind in Life: Biology, Phenomenology, and the Sciences of the Mind. Harvard University Press, 2007.

Varela, Fransisco, Evan Thompson, and Elena Rosch. The Embodied Mind. Cognitive Science and Human Experience. MIT Press, 1992.

Vermeulen, Pieter. "Posthuman Affect." European Journal of English Studies, vol. 18, no. 2, 2014, pp. 121-134.

Warhol, Robyn. Having a Good Cry: Effeminate Feelings and Pop-Culture Forms. Ohio State University Press, 2003.

Weik von Mossner, Alexa. "Vulnerable Lives: The Affective Dimensions of Risk in Young Adult Cli-Fi.” Textual Practice, vol. 31, no. 3, 2017, pp. 553-566. 


\title{
6 Imagining Posthuman Environments in the Anthropocene
}

\author{
The Function of Space in Post- \\ Apocalyptic Climate Change Fiction
}

\section{Carolin Gebauer}

The age of the Anthropocene is characterized by a growing awareness of the possible catastrophic consequences of anthropogenic climate change. ${ }^{1}$ This ecological concern is being increasingly dealt with in climate-change or "Anthropocene" (Trexler) fiction that evokes post-apocalyptic scenarios brought about by a combination of natural as well as anthropic causes. ${ }^{2}$ Nature qua environmental materiality plays a major role in these narratives, as it presents a ubiquitous and overwhelming danger for humanity: thunderstorms and hurricanes devastate towns, tsunamis and tidal floods threaten seaports, wildland fires destroy suburban settlements, and earthquakes raze high-rise city buildings. ${ }^{3}$ By presenting nature as an autonomous force that serves as an antagonist to human civilization, post-apocalyptic Anthropocene fiction creates storyworlds in which the human species struggles to survive. ${ }^{4}$ The typical setting of these climate change novels thus constitutes what I will describe as a posthuman environment- that is, a space that gradually obliterates humanity while still being affected by its previous actions. $^{5}$

Being generally located at the intersection of literary criticism, historicism, and critical theory, work on Anthropocene fiction has mainly focused on thematic aspects of the genre rather than its structural or formal features. Only recently did narrative theorists start to investigate the narrative form of climate change fiction, ${ }^{6}$ with the result that the analysis of genrespecific narrative strategies, such as the representation of time and space, plot development, and the narrative situation, has received relatively little attention so far. This previous neglect of a narratological perspective tends to sideline the fact that climate change novels produce what Brian McHale calls "models for the world"-that is, alternative possible worlds which deviate from reality. As the vision of the posthuman transcends lived experience, literature and other forms of art are vital cognitive tools that allow us to come to terms with unknown worlds. Anthropocene fiction, in particular, helps readers to conceive of the elusive notion of the posthuman 
predominantly through its spatial structure. So far, however, narratology has not yet provided any models to adequately describe how such posthuman space may be staged in the novel.

This chapter investigates how climate change fiction allows readers to become immersed in imaginative environments which offer what Marco Caracciolo would characterize as "new 'story-driven' experiences" of the Anthropocene (Experientiality 5). Taking Margaret Atwood's Oryx and Crake as an example, I will explore the specific narrative strategies climate change narratives deploy to portray their setting as a posthuman space which poses a serious threat to survivors. More specifically, by drawing on Yuri M. Lotman's classical model of the spatial structure of narrative texts, I will show that posthuman storyworlds lack semantically charged subspaces or concrete fictional places which, thanks to their different symbolic meaning, divide the storyworld into two parts. The spatial semantics of Anthropocene fiction has important implications for narrative design: even though the absence of symbolic subspaces impedes the development of a complex plot, these texts resort to a series of other effective narrative techniques to convey their story to the reader. As my close reading of Atwood's novel will reveal, post-apocalyptic climate change fiction makes use of two strategies: internally focalized descriptions and analepses (i.e., flashbacks). ${ }^{7}$ The former serve to specify the storyworld from the perspective of a specific character, encouraging readers to become immersed in this imaginary space, whereas the latter detail moments from the characters' pasts before the natural disasters have taken place. Since these flashbacks refer to a storyworld that still contains two symbolic subspaces, they facilitate more sophisticated plot configurations. I will argue that it is only through these descriptive passages and anachronies that post-apocalyptic climate change narratives eventually exhibit a certain degree of tellability (or noteworthiness) and thus the potential to sustain the reader's interest.

\section{The Semantics of Space in Narrative Fiction: Lotman's Classical Model}

One of the earliest approaches to the systematic study of spatial configurations in narrative texts is Yuri M. Lotman's semantics of space, a theory inspired by the works of Russian formalism. In The Structure of the Artistic Text, Lotman attributes significant value to the cultural function of the concept of space. Anticipating the work of contemporary cognitive scholars who emphasize the relevance of spatial metaphors in human thought processes, ${ }^{8}$ he contends that "the language of spatial relations turns out to be one of the basic means for comprehending reality" (218). The reason for this, he argues, is that we tend to draw on spatial concepts to "[construct] cultural models with completely non-spatial content" (218). Every culture produces an individual image of the world in which topological distinctions (e.g., high-low, right-left, near-far) translate into 
binary opposites that have a particular semantic meaning (e.g., valuable-not valuable, good-bad, accessible-inaccessible) as opposed to a merely spatial one. For Lotman, topological characteristics therefore represent essential features of the different conceptualizations of the world shared by specific cultures: "The most general social, religious, political, and ethical models of the world, with whose help man comprehends the world around him at various stages in his spiritual development, are invariably invested with spatial characteristics" (218).

Our understanding of reality by means of spatial relations, Lotman continues, also underlies the structure of artistic texts. As he demonstrates in a detailed analysis of a series of examples from Russian poetry, literary texts produce distinct spatial models, so-called topoi (231), which function in analogy to those spatial world constructions we resort to in order to comprehend reality (218-29). Literary texts, consequently, can be divided into two distinct subspaces which are not only topologically distinct (e.g., top-bottom, right-left, inside-outside), but also semantically polar (e.g., good-evil, familiar-strange, natural-artificial). The semantic topology of worlds represented in literature concretizes in specific topographical opposites (e.g., town/safety-forest/danger, mountain/repose-valley/stress, heaven/good-hell/evil), and these subspaces are separated by a boundary which, according to Lotman, constitutes the most essential topological feature of the text: "The boundary divides the entire space of the text into two mutually non-intersecting subspaces" (229), each of which exhibits a completely different internal structure. What is more, the boundary is impenetrable, meaning that the different characters represented in the text belong to either of the two subspaces and are usually not allowed to leave these allocated spaces (230).

Yet the "spatial continuum of a text" (231) forms not only a certain topos but may also influence a text's classification as a specific text type. ${ }^{9}$ Lotman considers the existence of two symbolically charged spaces which are separated by an impenetrable boundary as a structural prerequisite for narrative (240). Although he does not use the term narrative explicitly, his elaborations clearly imply that he has this specific discourse type in mind. Drawing on the concept of plot, frequently considered one of the most important distinctive features of narrative, ${ }^{10}$ he distinguishes between two types of texts: plotless texts and plotted texts (232).

Lotman understands plot as the global structure of the storyline presented in a specific text. At the heart of each plot construction, he argues, lies its "smallest indivisible unit" (232), the event, which he defines as "the shifting of a persona across the borders of a semantic field" (233). Plotless texts-that is, descriptive texts like calendars, telephone directories, and lyric poemslack such an event, for they exclusively contain immobile elements (e.g., names or dates) or characters (e.g., the lyric persona) that cannot violate any fixed text-internal structure (236). Plotted (or rather narrative) texts, on the other hand, feature at least one mobile character, the so-called hero-agent 
(240), who can move across the different semantic spaces established by these texts because he or she is able to cross the seemingly impenetrable boundary separating these subspaces (238).

Lotman's theory states that a text can only develop specific narrative dynamics if it includes the crossing of a conceptual boundary between two symbolic subspaces on the part of the protagonist: "a plot can always be reduced to a basic episode - the crossing of the basic topological border in the plot's spatial structure" (238). However, as Matías Martínez and Michael Scheffel point out, Lotman discusses as instances of narrative not only texts in which a boundary crossing is successfully executed but also texts in which this event fails or is eventually reversed (142). On the basis of this observation, Martínez and Scheffel reason that, contrary to Lotman's contention, it is not so much the occurrence of the event itself which constitutes a mandatory element of narrative as the existence of a semantic field which is divided into two complementary subsets by a conceptual boundary (140).

At first glance, this implies that Lotman's model of the spatial structure of narrative texts anticipates David Herman's claim that the aspect of space "plays a crucial, not an optional or derivative, role in stories" (Story 264). "[Spatial] reference," Herman stresses, "helps constitute narrative domains" (285; italics in original), as it allows readers to construct mental models of fictional worlds which have a specific spatial structure (264). Herman's insistence on the significance of narrative space forms a stark contrast to classical, or structuralist, approaches to narrative, which consider temporality the cornerstone of narrative (266-67). Indeed, by foregrounding spatial configurations of narrative texts, Lotman attaches greater importance to narrative space than his structuralist contemporaries do. At the same time, he works with a far broader definition of narrative space than Herman or most postclassical narratologists. In Herman's understanding, the category of diegetic space relates exclusively to the physical setting of a narrative (263-99); for Lotman, on the other hand, narrative space is always bound up with a set of ethical, social, and cultural values that are negotiated by the narrative. He thus apprehends contemporary work on the concept of "sense of place" in narrative, which brings forward the argument that narrative space may adopt a pronounced experiential quality for both fictional characters and flesh-and-blood readers (see Caracciolo, "Narrative Space"; Easterlin 111-51). Nonetheless, Lotman's conceptualization of narrative still displays a clear bias toward temporality since, in his theory, space predominantly functions to facilitate the development of a plot.

By making the distinctive quality of the narrative discourse mode conditional on the possibility of a plot, Lotman disregards that a text's narrativity involves more than just a specific aspect of event sequencing. ${ }^{11}$ More complex definitions, such as those advanced by Herman (Basic), Marie-Laure Ryan ("On the Theoretical Foundations"), and Werner Wolf ("Narrative"), each offer a list of different criteria a story may exhibit in order 
to be conceived as narrative. Synthesizing these "multidimensional accounts" of narrative, Caracciolo provides an overview of the most important "basic elements of narrative" (Herman's formulation) or "narratemes" (Wolf's term) that feature in each of these definitions (Caracciolo, Experientiality 31). Accordingly, a text (or any other type of semiotic object) is likely to be perceived as a narrative if it (1) enables the reader to imagine "a storyworld populated by characters and structured around a specific temporal-causal logic;" (2) displays "a certain degree of thematic coherence;" (3) presents events which diverge from the reader's expectations, meaning that the story can be regarded as "being worth telling;" and (4) concentrates on representing "the experiences and evaluations of one or more anthropomorphic entities" (32). ${ }^{12}$ As Caracciolo's synopsis of multilayered definitions of the narrative discourse mode reveals, the quality of being narrative depends on an interplay of various factors, including temporality, sequentiality, and causality, spatiality as well as "tellability" (see Baroni) and "experientiality" (see Caracciolo, Experientiality; Fludernik, Towards). Against this backdrop, then, the category of plot can be conceptualized as a narrative phenomenon which emerges from the functional interaction of these factors. Depending on the specific circumstances given in a narrative, this combination may either emphasize eventfulness or not. ${ }^{13}$

These considerations inevitably challenge Lotman's argument that a story's narrativity hinges exclusively on the existence of a plot that evolves from the text's spatial semantics: does the spatial structure as outlined by Lotman's semantics of space really constitute an indispensable characteristic of narrative? What happens if a novel does not evoke a spatial model that conforms to this particular structure? More precisely, what happens if a narrative constructs a storyworld which does not provide at least two symbolic subspaces that divide the narrative's setting into different parts, thus defying the existence of any conceptual boundary between such spaces? Are these narratives still able to facilitate the development of a plot? If not, which other narrative strategies do these texts deploy to compensate for this lack of eventfulness and to prevent losing the reader's interest in the story? The following close reading of Margaret Atwood's Oryx and Crake will deal with these questions.

\section{The Spatial Structure of Post-Apocalyptic Climate Change Fiction: Margaret Atwood's Oryx and Crake}

\section{Posthuman Spaces}

Published in 2003, Oryx and Crake is the first novel in Margaret Atwood's MaddAddam trilogy. ${ }^{14}$ Combining the voice of a covert thirdperson narrator with the fixed internal perspective of the protagonist, ${ }^{15}$ the narrative recounts the fate of Snowman (formerly known as Jimmy), who seems to be the last human survivor of a viral plague on Earth. Prior 
to the onset of the novel, Snowman's friend Crake initiates a worldwide epidemic by inventing and distributing a lethal and highly infectious virus. Snowman is not affected by the pandemic, though, for Crake has secretly injected him with a vaccine, making him immune to this bioterrorist attack. Crake saves Snowman because he has chosen him to take care of the Crakers, a group of immortal, albeit simple-minded, human-like mutants whom Crake created in his laboratory to succeed humanity. After the apocalypse, Snowman (in accordance with his friend's wishes) guides Crake's "children" from the laboratory to a safe place in open nature, where they settle down.

The post-apocalyptic world in which Snowman and the Crakers now coexist does not resemble the world as the protagonist knows it from his former life. Previously inhabited places such as cities, towns, and gated communities have turned into abandoned, decrepit spaces. Due to climate change and global warming, the Earth has, moreover, metamorphosed into a tropical site where the hot weather never changes (regardless of location). Yet the novel's setting offers anything but idyllic beach holiday scenery; on the contrary, it constitutes a nightmarish space which constantly challenges human existence. Not only does Snowman's new living environment confront the protagonist with regular attacks by wild animals such as genetically manipulated boars ("pigoons") and dogs ("wolvogs"), but his surroundings themselves also pose a threat to him: the "evil rays" (37) of the "punishing sun" (6) burn his skin, "[t]he forest blots up his voice" (169), and the heat turns his brain into "melted cheese" (283). Nature is personified as a deadly enemy against whom the human species does not stand any chance of survival. Snowman accordingly has to admit to himself that he is "the last Homo sapiens - a white illusion of a man, here today, gone tomorrow, so easily shoved over, left to melt in the sun, getting thinner and thinner until he liquefies and trickles away altogether" (224; italics in original).

However, not only does the posthuman space in Oryx and Crake corrupt the human body, it also destroys material aspects of human culture. The "semi-flooded townhouses" of "minnow city" (148) are suggestive of a previous deluge which has already inundated entire building complexes, while the uncontrolled proliferation of vegetation has started to eliminate the last remainders of human civilization:

The buildings that didn't burn or explode [during the time of the riots immediately following the apocalypse] are still standing, though the botany is thrusting itself through every crack. Given time it will fissure the asphalt, topple the walls, push aside the roofs. Some kind of vine is growing everywhere, draping the windowsills, climbing in through the broken windows and up the bars and grillwork. Soon this district will be a thick tangle of vegetation. 
The quotation illustrates that Atwood visualizes the threatening characteristics of her novel's setting by skillfully exploiting the potential of metaphoric language. Personifying botany in general and vine in particular (see the use of the active verbs thrust, fissure, topple, push, drape, and climb), she presents vegetation as a vital power that slowly, but surely, erases "all visible traces of human habitation" (222). ${ }^{16}$

The way in which the environment is represented in Atwood's novel has an impact on the storyworld's spatial structure. The reason for this is that the spatial expansion of nature in Oryx and Crake dissolves the symbolic boundaries which generally organize our cultural thought patterns. Given that water is flooding entire cities and whole compound districts are overgrown with plant life, nature is everywhere in Atwood's post-apocalyptic storyworld. Its omnipresence threatens to collapse the distinction between the two symbolic subspaces underlying the spatial structure of the narrative. In the present of the narrative's storyworld, the distinction between wilderness and civilization is on the verge of vanishing, with the former absorbing the latter. The semantic difference which is usually associated with these opposites-the opposition between nature and human culture-is about to lose its significance as well.

The only spatial opposition which still seems to be valid in Snowman's world is the topological distinction of "up" vs. "down." He sleeps on a tree because the wild animals which are most dangerous to him cannot intrude upon these arboreal night-quarters. Furthermore, during his "pilfering excursions" (45) through the wilderness in search for food, he climbs up ruins of compound walls or buildings to escape sudden attacks by pigoons or wolvogs. Yet this conceptual opposition does not create different symbolic subspaces, as it cannot be associated with concrete fictional places that divide Atwood's post-apocalyptic storyworld into two parts. Neither does "up" correlate with a specific space, considering that it can mean, for instance, "on a tree," "on the upper level of a building," or "on top of a wall," nor is Snowman always safe when he is 'up,' meaning that neither the jungle canopies nor the remnants of former infrastructures are capable of protecting him from other environmental perils such as thunderstorms and lightning. In a posthuman world, even the most essential boundary between human shelter and wilderness risks becoming invalid.

Ironically enough, although Atwood's post-apocalyptic storyworld appears to be a posthuman space, it is humanity itself that has produced Snowman's living environment in the first place. Both climate change and the biological as well as physical changes to the planet Earth that result from it are caused by human action. Atwood's novel thus raises readers' awareness of the fact that the relationship between the notions of nature and humanity, or nature and (human) culture, goes beyond a simple binary divide. Ecocritical terms like the "mesh" (Morton, Ecological Thought 28-38) or "natureculture" (Haraway) lay stress on the interconnectedness between nature and humanity, postulating that we should construe the two 
concepts as one circulating system rather than two juxtaposed terms (Iovino and Oppermann 454). The reason for this is that humans interact with their environment to such an extent that it is impossible to neatly distinguish humanity from nature and nature from humanity.

Atwood does justice to this insight by illustrating the reciprocity between human action and natural force. As human action increasingly relies on advanced technology (specifically genetic engineering), it not only influences but also tries to control the environment, eventually culminating in the catastrophe. After the apocalypse, however, the situation is reversed, for now it is the environment which has a dramatic impact on humanity. While nature is increasingly expanding, it eliminates the last remainders of human civilization so that the storyworld becomes increasingly inhospitable. Because of their attempt to dominate the environment, humanity has produced a posthuman world which gradually annihilates their own species. This ostensibly paradoxical scenario of Oryx and Crake emphasizes the new materialist stance that we should no longer think of our world as an ecosystem in which humans, as active subjects, are superior to matter, as the sum of all (allegedly passive) objects. Instead, we should acknowledge the "vitality of matter" and question our "habit of parsing the world into dull matter (it, things) and vibrant life (us, beings)" (Bennett vii; italics in original). For in the age of the Anthropocene we can no longer deny that we are entangled with nature, which Atwood so drastically shows us by envisaging Snowman's fate as the seemingly last human being within a posthuman world.

\section{Episodic Plot Structures}

The particular spatial structure of Atwood's text-that is, the fact that it forgoes symbolic subspaces which divide the post-apocalyptic storyworld into different parts-influences the novel's overall "narrative dynamics," or rather its "movement ... from its opening to its end" (Richardson 1). According to Lotman's model, a text's narrativity hinges on the development of a plot or storyline, which, in turn, is realized through the transgression of boundaries. However, by dismantling the hierarchy between humanity and physical matter, Atwood's post-apocalyptic storyworld undermines the preexistent symbolic subspaces of civilization and wilderness, with the result that the act of crossing the boundary between these two spaces becomes irrelevant. With that said, Lotman would probably conclude that the spatial structure of Oryx and Crake does not facilitate a plot, hence diminishing the novel's narrativity.

Indeed, the part of the narrative's storyline which unfolds after the apocalypse is quite basic. Refusing to starve to death, Snowman decides to go on a quest for food which leads him back to the headquarters of the RejoovenEsense Compound, the place where Crake planned and initiated the original catastrophe. Snowman's trip back to the end of the world 


\section{Carolin Gebauer}

(ironically referred to as Paradice) can be divided into brief episodic tales, the majority of which are marked by one or several consecutive chapters. These episodes can be summarized as follows:

- Episode 1 (Chapter "RejoovenEsense"): Upon his arrival at the compound, Snowman first comes across an abandoned house in which he searches for food (227-33).

- Episode 2 (Chapter "Twister"): Setting off on his way again after searching the house, Snowman is surprised by a twister, from which he takes shelter in a former checkpoint building, where he also spends the night (234-38).

- Episode 3 (Chapters "Pigoons" and "Radio"): When he wants to continue his journey to Paradice the next morning, he is chased by pigoons, which causes him to again take refuge in the tower of the checkpoint building, where he finally finds some food and beverages (265-74).

- Episode 4 (Chapters "Rampart," "Pleebcrawl," and "Crake in Love"): After spending another night in the checkpoint building, he resumes his journey on top of the rampart surrounding the compound, where he is caught in a thunderstorm $(275-80,283-84,307)$.

- Episode 5 (Chapters "Bubble" and "Scribble"): He eventually arrives in Paradice, where he searches for nourishment and attends to the cut under his foot which he has sustained during his trip (333-38).

This synopsis shows that Atwood's novel features a "tour structure," one of the oldest forms of narrative and one which we know from early genres such as the epic narrative, the medieval romance, and the picaresque novel (Ryan et al. 31-32). As the story follows Snowman's expedition through the postapocalyptic wilderness, it is the temporal course of his journey (rather than causality) that determines the narrative's unfolding: the different episodes are arranged in a chronological order, yet they are not causally connected. As a result, it makes no difference in which order the events occur, meaning that they are randomly interchangeable (except for the first and last episodes, of course, which logically mark the beginning and ending of the trip).

By resorting to the tour structure to present Snowman's trip to the end of the world, Atwood's novel defies the notion that narratives are designed around a particular temporal-causal logic constituting their plot. According to definitions of narrative which emphasize plot, narrative texts usually feature "motivated actions" which fulfil the following criteria: (1) they "involve anthropomorphic agents;" (2) they "are interrelated not only by chronology but also by causality and teleology;" and (3) they "lead to, or are consequences of, conscious acts or decisions, frequently as results of conflicts" (Wolf, "Description" 24). The events depicted in the account of Snowman's quest meet only the first criterion, as Snowman is an anthropomorphic agent who actively decides what to do. However, 
since he moves within a posthuman environment, he can no longer influence the impact of his actions. For, due to the lack of symbolic spaces in the post-apocalyptic diegesis, ${ }^{17}$ there are no longer any socio-cultural structures which might allow him to anticipate the consequences of his deeds and to manipulate his nonhuman adversaries accordingly: he can neither protect himself from attacks by wild animals nor circumvent the forces of nature. His actions have no impact whatsoever, which means that the different events which happen to him are neither mutually dependent, in the sense that one event causes the other, nor do they work toward a specific closure: after his excursion to Paradice, Snowman simply returns to the Crakers and the shelter of his familiar tree.

Strikingly, this lack of teleology is additionally reflected by the novel in that the very first and the very last chapters commence in exactly the same way (except for one omission at the beginning of the novel's last chapter, which is reproduced in the following quotation):

Snowman wakes before dawn. He lies unmoving, listening to the tide coming in ..., wish-wash, wish-wash, the rhythm of heartbeat. $\mathrm{He}$ would so like to believe he is still asleep.

On the eastern horizon there's a greyish haze, lit now with a rosy, deadly glow. Strange how that colour still seems tender.

The absence of any teleological structure demonstrates that Lotman's theory of the semantics of space-namely that plot depends on spatial structurealso applies to Atwood's novel. Since the post-apocalyptic storyworld does not exhibit any subspaces of socio-cultural relevance, the protagonist's human deeds and actions remain insignificant in the context of his inhospitable living environment. By impeding the development of a complex plot in which events are causally linked to lead to a certain outcome, Atwood's novel defies any sense of eventfulness and thus violates an important core trait of narrative. Contrary to Lotman's implications, however, the fairly simple event structure of Atwood's text does not necessarily entail that Oryx and Crake does not qualify as a proper narrative. As I have argued above, the category of plot per se does not constitute an essential "narrateme" or "basic element of narrative." In the remaining part of this essay I will therefore investigate the other narrative properties displayed by Atwood's novel.

\section{Dynamic Descriptions}

Refraining from presenting a complex plot in which events are causally intertwined to fit a certain teleology, Snowman's quest predominantly serves to depict the post-apocalyptic setting of Atwood's storyworld. The account of Snowman's trip consequently contains numerous long passages 


\section{Carolin Gebauer}

of description, which allow the reader to form a rich mental image of the posthuman space in Atwood's novel. As the following examples serve to illustrate, the majority of these descriptive passages are internally focalized, with Snowman serving as the focalizer: ${ }^{18}$

\section{Quotation 1}

After an hour of walking, Snowman comes out from the former park. He picks his way farther inland, heading along the trashed pleebland boulevards and avenues and roads and streets. Wrecked solarcars are plentiful, some piled up in multi-vehicle crashes, some burnt out, some standing intact as if temporarily parked. There are trucks and vans, fuel-cell models and also the old gas or diesel kind, and ATVs. A few bicycles, a few motorcycles-not a bad choice considering the traffic mayhem that must have lasted for days. On a two-wheeled item you'd have been able to weave in and out among the larger vehicles until someone shot you or ran into you, or you fell off.

\section{Quotation 2}

The walking has become an obstacle course for Snowman: in several places he's needed to make detours. Now he's in a narrow sidestreet, choked with vines; they've festooned themselves across the street, from roof to roof. Through the clefts in the overhead greenery he can see a handful of vultures, circling idly in the sky.

(223-24; my emphasis)

\section{Quotation 3}

Up ahead, the houses thin out and vanish. There's an interval of parking lots and warehouses, then barbed wire strung between cement posts, an elaborate gate off its hinges. End of urban sprawl and pleeb city limits, beginning of Compound turfdom.

Snowman's perception of the urban wasteland of a former city ("pleebland") is conveyed to the reader by means of a strategy which, in cognitive linguistics, is known as "route perspective" (Fludernik, "Description" 466) or "tour strategy" (Ryan, "Cognitive Maps" 218). That is to say, the narrative enables the reader to adopt Snowman's point of view by positioning him or her "within the described space ... as a moving focal point" (Fludernik, "Description" 466). As it permits us to join Snowman on his forays through the post-apocalyptic storyworld, the narrative offers us a virtual tour through the abandoned city: it first leads us through the main roads of the city's periphery (Quotation 1 ) and subsequently guides us 
through the narrow sidestreets of the centre (Quotation 2); after traversing the entire inner-city area, we eventually reach the suburbs, which give way to more rural compounds again (Quotation 3).

This dynamic walking tour influences the ways in which we can become immersed in the novel's storyworld. Immersion is an act of imagination which takes place during the process of reading fiction when readers mentally project themselves into the fictive worlds evoked by these texts (Ryan, Narrative 61-114). The strategy of the route perspective intensifies this experience, as it draws on what David Herman refers to as "projective locations" (Story 280-82): representations of space that rely less on the invariant geometric properties of objects ("topological locations") than on the orientative framework of their viewer. Projective locations, Herman explains, do not provide a topological description of the textual world, which would resemble looking at a static map, but rather create the impression that the reader is being led through the mapped area. In lieu of giving an aerial—or at least elevated-view of narrative space, projective locations present a narrative's storyworld from an on-the-ground perspective internal to that world. Erin James therefore argues that this specific strategy of spatial representation "draws readers into the locality of the text" (58) and thus encourages them to experience the imaginary places represented in the narrative as if "being physically in them" (153; italics in original).

The immersive impact of projective locations also extends to Atwood's representation of the post-apocalyptic storyworld in Oryx and Crake. Because the novel makes us follow Snowman's path through the city, it induces us to perceive this place at street-level. We come to know that the entire pleebland infrastructure is covered with smashed or burnt vehicles which are still reminiscent of a former "traffic mayhem," whereas the city centre has already turned into an impassable area which is overrun with botany and frequented by vultures. By creating this atmosphere of urban devastation and decay, Atwood's depiction of Snowman's environment allows readers to get a vivid idea of this place.

The linguistic make-up of the text further strengthens this sense of readerly immersion. Since Snowman's trip through the post-apocalyptic storyworld is relayed in the present tense, the narrative creates the impression of immediacy which enables readers to directly transport themselves into the here-and-now of this world and right onto the narrative scene. This effect, which I designate as the immersive function of present-tense narration (see Gebauer, Chapter 5.3), is reinforced by the narrator's use of the secondperson pronoun at the end of Quotation 1. As James points out, such an intermittent "reference to an unspecified narratee calls out to a hypothetical 'you' that hails all readers, no matter their reading location" (57). The narrator hence invites us to imagine ourselves riding a motorcycle through the traffic chaos. Even if this little thought experiment relates to a point in time which lies before the storyworld's present (i.e., the period shortly after Crake's fatal viral assault when everyone was trying to flee from the city), 
it once more prompts us to imaginatively project ourselves into Snowman's environment.

Although the narrative depicts its setting in great detail and thus grants readers a rich environmental experience, the above descriptions nevertheless neglect to delineate the spatial structure of the diegesis. We merely learn that there are different types of vehicles on the main streets of the city, while the smaller sidestreets are empty and overgrown with vines. When picturing the suburbs, the text, moreover, induces us to imagine parking lots and warehouses as well as the rest of the barbed wire fence that once separated the city from the adjacent compound territory. However, we do not come to know anything about the spatial arrangement of the different vehicles and buildings, nor can we say anything about the individual routes of the different streets. Atwood's depiction of the post-apocalyptic storyworld in Oryx and Crake is remarkably thin on topological information or geographic coordinates, which makes it difficult to derive any concrete cartographic data from it (Ryan, "Cognitive Maps" 219-21). Consequently, if different readers were asked to draw a map of the setting presented in the novel, they would probably come up with completely different places. ${ }^{19}$

From a cognitive perspective, this lack of any map-like specificity fulfils two functions, both of which intensify the readers' immersion in Atwood's storyworld. On the one hand, it foregrounds the internal perspective of the focalizer who travels through this imaginary space. Since readers get a direct insight into Snowman's mind, they can immediately share his perception of his surroundings. Topographical specifications would impede this effect of immediacy, as they would suggest the interference of the heterodiegetic narrator, who has, by definition, an external and elevated view of the storyworld. ${ }^{20}$ This, in turn, would have an impact on readers' imaginative act of projecting themselves onto the narrative scene: if Oryx and Crake featured an overt narrator speaking within the text, readers might well interpret Atwood's use of the fictional present as a referential tense that takes the narrator (rather than the protagonist) as its temporal anchor point (see Gebauer, Chapter 5.2). The present tense would then refer to the narrator's here-and-now on the discourse level-the level of narrative transmission on which the narrator relates the events in retrospect (see Gebauer 187-90)_and the novel would no longer sustain its potential of facilitating readers' imaginative transportation to the diegesis.

On the other hand, the text's lack of spatial orientation emphasizes the fact that topological distinctions (e.g., left-right, front-back) are no longer relevant in the here-and-now of Atwood's storyworld, the sole exception being, again, the differentiation between "up" and "down" (see my emphasis in Quotation 2). This means that cognitive templates based on orientational metaphors (see Lakoff and Johnson), metaphorical blending (see Schneider), or spatial semantics offer little help in the process of naturalizing the postapocalyptic space depicted in this narrative (see Fludernik, "Naturalizing"). Atwood's novel introduces a possible world which clearly interferes with 
readers' tendencies to apply what Marie-Laure Ryan refers to as "the principle of minimal departure" (Possible, Chapter 3). According to this principle-an interpretive rule Ryan establishes to describe how readers may reconstruct textual universes during the process of reading- "we reconstrue the central world of a textual universe in the same way we reconstrue the alternate possible worlds of nonfactual statements: as conforming as far as possible to our representation of AW" (51), that is, the actual world which forms the center of our system of reality. More specifically, this means that when constructing mental models of the worlds evoked in fictional narratives, we "project upon these worlds everything we know about reality," making no adjustments except for those dictated by the texts (51). Oryx and Crake, however, deviates from reality in that its storyworld exhibits a new kind of experientiality (see Caracciolo, Experientiality, Fludernik, Towards): it confronts readers with an unfamiliar experience of space which they do not recognize from real life. Atwood's representation of the post-apocalyptic diegesis as an inhospitable environment thus creates an impression of nonhuman materiality which readers can not only comprehend, but also experience first-hand through the act of reading.

\section{Anachronies}

So far, my analysis of Oryx and Crake has shown that the account of Snowman's adventures contains many "dynamic descriptions" (Wolf, "Description" 24) which detail his journey through "No Man's Land" (Oryx and Crake 353). Since the main function of these descriptive passages is to increase narrative immersion, they stimulate readers to mentally transport themselves into Atwood's post-apocalyptic storyworld. If readers allow themselves to perform this act of mental projection, the text rewards them with a new environmental experience: they can imaginatively move within a posthuman space which is unfamiliar to them because it conflicts with the common spatial thought patterns according to which humans try to make sense of the world. This effect of an alien experience of space becomes even more explicit when comparing the information we have of the protagonist's current environment to what we know about the spatial structure of the preapocalyptic storyworld. In addition to the quest motif (i.e., Snowman's trip to Paradice in search of food), the novel contains a second plot that reveals Snowman's backstory-his life before the apocalypse. The quest part of the novel, which happens in the here-and-now of the storyworld, is written in the present tense. All information on the storyworld's past is inserted into this present-tense account by means of a series of flashbacks that Snowman experiences while wandering through the post-apocalyptic landscape. ${ }^{21}$

Interestingly enough, the design of these analepses is distinct from the passages that are set in the diegetic present. Not only are Snowman's reminiscences written in the past tense rather than the present tense, ${ }^{22}$ but they also depict a storyworld which has not yet transformed into a posthuman 


\section{Carolin Gebauer}

space and which is therefore completely different from Snowman's hereand-now. Before the apocalypse, the world is defined by bio-engineering, and private research corporations assume power over the rest of humanity. Rich people and elite researchers can afford to live in compounds guarded by private companies, whereas mediocre professionals are made to reside in modules (i.e., less secure gated communities). Everybody else has to live in the pleeblands, the crowded cities in which violence and crime prevail. The privately organized compounds and modules are associated with wealth, scientific knowledge, authority, and order; the insecure public pleeblands, on the other hand, involve poverty, scientific incompetence, inferiority, and chaos. Since the pre-apocalyptic storyworld of Oryx and Crake can thus be divided into two different symbolic spaces, the conventional structure of narrative space is still intact.

Within this ordered spatial structure, human characters try to break out of their allocated spaces because they want to climb up the social ladder. A case in point is Jimmy's (i.e., Snowman's) best friend Crake, who manages to work his way up to the top of this hierarchy. When Jimmy and Crake live together in the OrganInc Compound, they go to the same school. After graduation, however, their ways part, for both enter different colleges. While Jimmy leaves home to study at a less prestigious university, Crake continues his education at one of the most highly esteemed academies, which eventually enables him to gain access to the RejoovenEsense Compound, "one of the most powerful Compounds of them all" (252). It is only in this elitist place that Crake can implement his vision of a "better" posthuman species (i.e., the Crakers) and instigate his fatal bioterrorist attack on the (human) world population. In contrast to the present-tense passages, the past-tense analepses consequently allow for the development of a complex plot which shows the reader how the unethical and unscrupulous approval of all forms of genetic engineering eventually brings about the extinction of the human species. The events of this plot are not only linked chronologically but also causally, ultimately leading to one and the same irreversible goal: the apocalypse. By introducing the pre-apocalyptic diegesis as a space that consists of symbolic subspaces which imply different degrees of power and human agency, Snowman's reminiscences compensate for the simple quest motif brought forth by the posthuman environment in Snowman's hereand-now: given that the numerous flashbacks depict a boundary crossing on the part of Crake, they yield a second storyline which fulfils the criteria of narrative along the lines of that described by Lotman.

\section{Conclusion}

As I have sought to demonstrate in this essay, post-apocalyptic climate change fiction integrates the notion of the posthuman by means of its spatial structure. More specifically, my reading of Oryx and Crake has shown that Atwood's narrative imagines a world where the entire 
biosphere turns against human civilization. Rather than constructing different symbolic subspaces, the novel establishes a single homogenous space in which topological and semantic (and, to a certain extent, also topographical) distinctions lose their significance in terms of the classical model posited by Lotman. This particular structure of narrative space has two main effects. The first is the creative manipulation of cognitive templates. Oryx and Crake lacks concrete spatial orientation, to the point that readers need to largely refrain from common interpretive principles like orientational metaphors or spatial semantics when imagining the world depicted in this text (the sole topological aspect of space that still retains some significance is the dichotomy "up" vs. "down"). Secondly, this spatial structure has an impact on the narrative dynamics in Atwood's novel. The protagonist's quest for survival is depicted as a chronological sequence of events which, however, do not form a genuine plot where one event causes the other. Instead, we are faced with a series of interchangeable episodesrandomness seems to have replaced the principle of causality. ${ }^{23}$ In lieu of presenting a complex teleological storyline, the account of Snowman's struggle for survival rather focuses on providing a detailed depiction of the post-apocalyptic storyworld. The narrative thus contains numerous instances of long descriptions which specify Snowman's surroundings to the reader.

In his article "Towards a Typology, Poetics and History of Description in Fiction," Ansgar Nünning notes that "in novels description never informs an entire work" (107). Wolf supports this claim ("Description" 50 ), adding that, in the genre of narrative fiction, longer descriptive passages always need to be motivated by the narrative context in which they occur; otherwise these passages risk losing the reader's interest: "descriptions, and in particular extensive ones, tend to interrupt the story-line and are therefore not infrequently skipped by the impatient reader, eager for action and adventures" (54). My analysis of the function of space in Oryx and Crake has illustrated that Atwood's extensive passages of description are motivated by the texts' spatial structure, which is why I believe that Wolf's contention about the motivation of lengthy descriptions in narrative fiction is justified. The notion that "the interest of narrative text can take ... a variety of shapes" (Herman and Vervaeck 111) and is not necessarily dependent on a narrative's story, on the other hand, contradicts his claim that such descriptive passages automatically curtail a novel's narrative interest. In the case of Oryx and Crake, this interest lies in the readers' willingness to make a new-to use Caracciolo's formulation again- "'story-driven' experience" of unfamiliar environments: by offering readers an insight into Snowman's perception of the post-apocalyptic storyworld, Atwood's dynamic descriptions encourage readers to mentally project themselves into this posthuman space and to explore it from within. Thanks to this high degree of experientiality and readerly engagement with Snowman's surroundings, Atwood's narrative does not forfeit its tellability-that is, its 
quality of being considered "worth telling” (Baroni 836) and thus worth reading as well.

Apart from its long passages of internally focalized description, Atwood's novel uses a second strategy to counterbalance the low degree of narrativity of the survival plot. The narrative contains a great number of analepses which refer back to a former storyworld whose spatial structure still yields tellable events. Owing to these flashbacks, which take the form of memories on the part of the protagonist, the narrative eventually introduces a certain "noteworthiness" (Baroni 836) even with regard to its story. In the light of these findings, then, one could conclude with McHale that Anthropocene fiction can function as a sophisticated and effective model for the world: not only does it warn readers of possible consequences of anthropogenic climate change but it also helps them, in a surprisingly illustrative way, to visualize the inconceivable notion of the posthuman. Climate change novels hence shine a light on the central function of literature and art, that is, to make the unimaginable imaginable and even representable.

\section{Notes}

1 This essay is a revised and updated version of an argument presented in Gebauer, Chapter 8. I wish to thank Roy Sommer, Ryan Dorr, and the editors of this volume for their insightful comments on earlier drafts of this essay.

2 In their survey article "Climate Change in Literature and Literary Criticism," Adam Trexler and Adeline Johns-Putra state that " $[\mathrm{t}]$ he past two decades have seen an increasing amount of fiction dealing with this issue [i.e., anthropogenic climate change], and a particular explosion in the numbers of such novels in the past 10 years" (186). They substantiate their claim by providing a historical overview of climate change novels which pertain to both genre fiction and literary fiction (186-88). Trexler further examines a considerable number of climate change novels in his monograph Anthropocene Fictions.

3 Although the term nature carries various connotations and implications which this essay does not intend to address (see Morton, Ecology 14-21), I here use the term to exclusively refer to a conglomerate of material entities that make up the environment.

4 Sylvia Mayer distinguishes two different types of climate change fiction: the narrative of catastrophe and the narrative of anticipation. While the former portrays a disastrous future scenario in which climate change has already culminated in a "global climate collapse" (23), the latter depicts a storyworld in which natural disasters (as a consequence of climate change) have not yet happened, but are nevertheless realistically conceivable in light of the environmental conditions depicted. The focus of this chapter restricts itself to the former subtype of climate change fiction.

5 This essay prefers the term posthuman to the term nonbuman when referring to post-apocalyptic spaces which result from anthropogenic climate change. The reason for this is that the prefix post-insinuates the (former) existence of both humanity and human agency, whereas the prefix non- negates it.

6 See, e.g., Bracke; Caracciolo, "Form, Science, and Narrative," "Notes for an Econarratological Theory;" as well as the contributions in Chihaia et al. and James and Morel (here especially in Part III). 
7 The classical narratological paradigm of narrative fiction distinguishes between the two categories of "narration" and "focalization" (see Genette 212-34 and 185-94, respectively). While the former relates to the question of "who speaks" in a narrative text, the latter refers to the question of "who sees," or more precisely perceives, the events depicted in the text (186). "Internal focalization," then, means that the narrative events are presented from the perspective(s) of one (or several) character(s) involved in the story rather than from the perspective of the narrator, who, being located outside the world of which he or she tells, has an external view of these events (see Rimmon-Kenan 75-78).

8 See Fauconnier, Mappings; Mental Spaces; Lakoff and Johnson; and Turner.

9 Seymour Chatman distinguishes three different text types: description, narrative, and explanation (see Coming to Terms 6-21). For a thorough discussion of the similarities and differences between these text types, see also Herman (Basic 75-104).

10 For a comprehensive survey of narratological studies that treat plot as "a key constituent of narrative," see Kukkonen (here 715).

11 According to $\mathrm{H}$. Porter Abbott, the term narrativity can signify either "the 'narrativeness' of narrative" or "the 'narrativeness' of a narrative" (587; italics in the original). While the first use of the term refers "generally to the concept of narrative," the second "[applies] comparatively to particular narratives" (587). I here use the term in the latter sense.

12 Since the various multidimensional definitions taken into account by Caracciolo constitute descriptions of the prototype of narrative, each thereby comprehends the quality of narrativity as a graduated scale that covers all possible degrees ranging from high to low (Wolf, "Narrative" 183).

13 Peter Hühn distinguishes two types of events: the type I event and the type II event. While the former "is treated as a defining feature inherent to every kind of narrative," the latter "is integral to a particular type of narrative, providing the foundation for its raison d'etre, or tellability" (160). My use of the term eventfulness in this essay always refers to type II events.

14 In addition to Oryx and Crake, Atwood's popular novel series comprises The Year of the Flood and MaddAddam, published in 2009 and 2013 respectively. Both sequels exhibit a different spatial structure than the first installment in the trilogy as they evoke a storyworld in which human civilization and its concomitant cultural spaces either still exist (The Year of the Flood) or are being reestablished (MaddAddam). Since this chapter, however, is particularly interested in the narrative representation of posthuman spaces that threaten to obliterate humanity, I here confine my discussion of Atwood's work to Oryx and Crake.

15 The category of the "covert narrator," introduced by Seymour Chatman, refers to a narrator who recedes so much into the background that his or her presence is no longer graspable in the text: "In covert narration we hear a voice speaking of events, characters, and setting, but its owner remains hidden in the discoursive shadows" (Chatman, Story and Discourse 197).

16 For a further discussion of Atwood's depiction of the loss of human culture in the post-apocalyptic storyworld of Oryx and Crake, see Gebauer (183).

17 In narratological terminology, the concept of diegesis refers to the storyworld evoked by narrative texts. I here use the terms diegesis and storyworld interchangeably.

18 For a definition of the term focalization, see note 7 .

19 As Ryan points out, any graphic map of a specific narrative world is "only the more or less faithful image of a cognitive map" ("Cognitive Maps" 222), that is, a holistic representation of that world which readers create in order to be able to follow the narrative's plot. It logically follows that individual cognitive maps of 
a particular textual world always differ to a certain degree, for every reader may imagine that very same world differently on the basis of their previous (reading) experiences. Still, it seems safe to assume that the deviation between different mental models of a specific diegesis increases in direct proportion to the text's lack of specificity with regard to the topographies it projects.

20 In his structuralist taxonomy, Gérard Genette distinguishes between heterodiegetic and homodiegetic narrators. While the former are "absent from the [stories they tell]" (244), the latter are "present as [characters] in the [stories they tell]" (245).

21 There is no doubt that Atwood resorts to a narrative pattern here which we also encounter in other post-apocalyptic climate change narratives (Mayer 26). Cormac McCarthy's 2006 novel The Road, by way of example, similarly draws on flashbacks to inform readers of the state of the depicted storyworld before the apocalypse.

22 I have shown elsewhere (see Gebauer, Chapter 8.2) that these tense shifts mainly serve to enhance readers' spatiotemporal orientation within the novel's diegetic universe. However, Atwood's use of fictional tense in Oryx and Crake is not restricted to what I call the referential function of past- and present-tense narration (Chapter 5.2), but she deploys the present tense in various ways, with the result that it fulfills many different functions in her novel.

23 This conclusion is consistent with Caracciolo's argument on "evolutionary plotting" in Kurt Vonnegut's satirical novel Galápagos (see "Posthuman Narration").

\section{References}

Abbott, H. Porter. "Narrativity." Handbook of Narratology, vol. 2, edited by Peter Hühn, Jan Christoph Meister, John Pier, and Wolf Schmid, De Gruyter, 2014, pp. 587-607.

Atwood, Margaret. Oryx and Crake: A Novel. Anchor Books, 2004.

Baroni, Raphaël. "Tellability." Handbook of Narratology, vol. 2, edited by Peter Hühn, Jan Christoph Meister, John Pier, and Wolf Schmid, De Gruyter, 2014, pp. 836-845.

Bennett, Jane. Vibrant Matter: A Political Ecology of Things. Duke University Press, 2010.

Bracke, Astrid. Climate Crisis and the 21st-Century British Novel. Bloomsbury, 2018.

Caracciolo, Marco. The Experientiality of Narrative: An Enactivist Approach. De Gruyter, 2014.

Caracciolo, Marco. "Form, Science, and Narrative in the Anthropocene." Narrative, vol. 27, no. 3, 2019, pp. 270-289.

Caracciolo, Marco. "Narrative Space and Readers' Responses to Stories: A Phenomenological Account.” Style, vol. 47, no. 4, 2013, pp. 425-444.

Caracciolo, Marco. "Notes for an Econarratological Theory of Character." Frontiers of Narrative, vol. 4, no. 1, 2018, pp. 172-189.

Caracciolo, Marco. "Posthuman Narration as a Test Bed for Experientiality: The Case of Kurt Vonnegut's Galápagos.” Partial Answers, vol. 16, no. 2, 2018, pp. 303-314.

Chatman, Seymour. Coming to Terms: The Rhetoric of Narrative in Fiction and Film. Cornell University Press, 1990.

Chatman, Seymour. Story and Discourse: Narrative Structure in Fiction and Film. Cornell University Press, 1978. 
Chihaia, Matei, Sandra Heinen, Matías Martínez, Katharina Rennhak, Michael Scheffel, and Roy Sommer, editors. "Narrative Theory and the Anthropocene." Special issue of DIEGESIS: Interdisciplinary E-Journal for Narrative Research, vol. 9, no. 2, 2020.

Easterlin, Nancy. A Biocultural Approach to Literary Theory and Interpretation. Johns Hopkins University Press, 2012.

Fauconnier, Gilles. Mappings in Thought and Language. Cambridge University Press, 1997.

Fauconnier, Gilles. Mental Spaces: Aspects of Meaning Construction in Natural Language. Cambridge University Press, 1994.

Fludernik, Monika. "Description and Perspective: The Representation of Interiors." Style, vol. 48, no. 4, 2014, pp. 461-478.

Fludernik, Monika. "Naturalizing the Unnatural: A View from Blending Theory." Journal of Literary Semantics, vol. 39, 2010, pp. 1-27.

Fludernik, Monika. Towards a "Natural" Narratology. Routledge, 1996.

Gebauer, Carolin. Making Time: World Construction in the Present-Tense Novel. De Gruyter, 2021.

Genette, Gérard. Narrative Discourse: An Essay in Method, translated by J. E. Lewin, Cornell University Press, 1980.

Haraway, Donna. The Companion Species Manifesto: Dogs, People, and Significant Otherness. Prickly Paradigm Press, 2003.

Herman, David. Basic Elements of Narrative. Wiley-Blackwell, 2009.

Herman, David. Story Logic: Problems and Possibilities of Narrative. University of Nebraska Press, 2002.

Herman, Luc, and Bart Vervaeck. "Narrative Interest and Cultural Negotiation." Narrative, vol. 17, no. 1, January 2009, pp. 111-129.

Hühn, Peter. "Event and Eventfulness." Handbook of Narratology, vol. 1, edited by Peter Hühn, Jan Christoph Meister, John Pier, and Wolf Schmid, De Gruyter, 2014, pp. 159-178.

Iovino, Serenella, and Serpil Oppermann. "Theorizing Material Ecocriticism: A Diptych." Interdisciplinary Studies in Literature and Environment, vol. 19, no. 3, 2012, pp. 448-475.

James, Erin. The Storyworld Accord: Econarratology and Postcolonial Narratives. University of Nebraska Press, 2015.

James, Erin, and Eric Morel, editors. Environment and Narrative: New Directions in Econarratology. Ohio State University Press, 2020.

Kukkonen, Karin. "Plot." Handbook of Narratology, vol. 2, edited by Peter Hühn, Jan Christoph Meister, John Pier, and Wolf Schmid, De Gruyter, 2014, pp. 706-719.

Lakoff, George, and Mark Johnson. Metaphors We Live By. University of Chicago Press, 2003.

Lotman, Yuri M. The Structure of the Artistic Text, translated by Gail Lenhoff and Ronald Vroon, University of Michigan Press, 1977.

Martínez, Matías, and Michael Scheffel. Einführung in die Erzähltheorie. C. H. Beck, 2009.

Mayer, Sylvia. "Explorations of the Controversially Real: Risk, the Climate Change Novel, and the Narrative of Anticipation." The Anticipation of Catastrophe: Environmental Risk in North American Literature and Culture, edited by Sylvia Mayer and Alexa Weik von Mossner, Winter, 2014, pp. 21-37. 


\section{Carolin Gebauer}

McHale, Brian. "Model and Thought Experiments." Why Study Literature? edited by Jan Alber, Stefan Iversen, Louise Brix Jacobsen, Rikke Andersen Kraglund, Henrik Skov Nielsen, and Camilla Møhring Reestorff, Aarhus University Press, 2011, pp. 135-155.

Morton, Timothy. The Ecological Thought. Harvard University Press, 2010.

Morton, Timothy. Ecology Without Nature: Rethinking Environmental Aesthetics. Harvard University Press, 2007.

Nünning, Ansgar. "Towards a Typology, Poetics and History of Description in Fiction." Description in Literature and Other Media, edited by Werner Wolf and Walter Bernhart, Rodopi, 2007, pp. 91-128.

Richardson, Brian. "General Introduction." Narrative Dynamics: Essays on Time, Plot, Closure, and Frames, edited by Brian Richardson, Ohio State University Press, 2002, pp. 1-7.

Rimmon-Kenan, Shlomith. Narrative Fiction: Contemporary Poetics. Routledge, 2002.

Ryan, Marie-Laure. "Cognitive Maps and the Construction of Narrative Space." Narrative Theory and the Cognitive Sciences, edited by David Herman, CSLI Publications, 2003, pp. 214-242.

Ryan, Marie-Laure. Narrative as Virtual Reality 2: Revisiting Immersion and Interactivity in Literature and Electronic Media. Johns Hopkins University Press, 2015.

Ryan, Marie-Laure. "On the Theoretical Foundations of Transmedial Narratology." Narratology Beyond Literary Criticism: Mediality, Disciplinarity, edited by Jan Christoph Meister, De Gruyter, 2005, pp. 1-23.

Ryan, Marie-Laure. Possible Worlds, Artificial Intelligence and Narrative Theory. University of Indiana Press, 1991.

Ryan, Marie-Laure, Kenneth Foote, and Maoz Azaryahu. Narrating Space / Spatializing Narrative: Where Narrative Theory and Geography Meet. Ohio State University Press, 2016.

Schneider, Ralf. "Blending and the Study of Narrative: An Introduction." Blending and the Study of Narrative: Approaches and Applications, edited by Ralf Schneider and Marcus Hartner, De Gruyter, 2012, pp. 1-30.

Trexler, Adam. Anthropocene Fictions: The Novel in a Time of Climate Change. University of Virginia Press, 2015.

Trexler, Adam, and Adeline Johns-Putra. "Climate Change in Literature and Literary Criticism.” WIREs: Climate Change, vol. 2, 2011, pp. 185-200.

Turner, Mark. The Literary Mind: The Origins of Thought and Language. Oxford University Press, 1996.

Wolf, Werner. "Description as a Transmedial Mode of Representation: General Features and Possibilities of Realization in Painting, Fiction and Music." Description in Literature and Other Media, edited by Werner Wolf and Walter Bernhart, Rodopi, 2007, pp. 1-87.

Wolf, Werner. "Narrative and Narrativity: A Narratological Reconceptualization and Its Applicability to the Visual Arts.” Word \& Image, vol. 19, no. 3, 2003, pp. 180-197. 


\title{
7 "It Wants to Become Real and Can Only Become Prose”
}

\author{
Anthropocenic Focalization in 10:04 \\ and The World Without Us
}

\section{David Rodriguez}

In this essay I will confront the spatialization of narrative in the context of the Anthropocene and identify one form of its expression called Anthropocenic focalization. This departs from a habit of ecocriticism in which space plus Anthropocene equals thinking about scale, popularized by Timothy Morton's now ubiquitous term "hyperobject." While a usefully broad concept, hyperobjects are most often projected into geometric space, where objects with mismatched sizes means difference to be overcome by "bigger" thinking on "longer" or "deeper" scales. ${ }^{1}$ This way of thinking constructs the Anthropocene as a concept that affords novel representations for thinking on presumably different, nonhuman scales or about new, vibrant materialities. ${ }^{2}$ The other, temporal, use of "Anthropocene" as a proposed epoch results in a search to find the geological expression of the "golden spike" with which to pinpoint its lower bound. ${ }^{3}$ These conceptual and epochal uses are functional in the context of describing the actuality of the Anthropocene, but they are not as useful for considering how the Anthropocene appears in imagination. That is, precision is given primacy over the seemingly essential ambiguity that is apparent in the current difficulty of pinpointing what the term can possibly mean, conceptually, or when it is possibly located, temporally. Alternatively, the term is valuable as a node that organizes multidisciplinary images of the possible; "Anthropocene" is peculiarly flexible and can contain a multitude of different conceptual figurations or temporal origins. Edward S. Casey would call this the "possibilizing" function of imagining; ${ }^{4}$ the image of the Anthropocene is not limited by its representation of climate futures or as an expression of a definitive "age of man."

In this way "Anthropocene" can mean a type of imaginary point of view rather than a definable conceptualization of contemporary reality or definite temporal epoch. If we are to think about how climate currently manifests in literary works, shifting the definition of Anthropocene toward this more formal mode will be useful. Using "Anthropocene" as a point of view already seems to be a potential use of the term. Eileen Crist suggests this as she notes how Anthropocene discourse is a troubling part of the historical trajectory of the imperial "I." The normalization of the Anthropocene as definitive 


\section{David Rodriguez}

and total resembles the form of other historical conquests, "echoing as it does the widespread belief that there exist no perspectives (other than human opinion) from which anthropogenic changes to the biosphere might actually be experienced as devastation" (Crist 133). "Anthropocene" in this reading is the concretized point of view of the "victors," as she notes, even if it is a neutralized perspective and assumed as scientifically or historically objective. This places Anthropocene discourse in proximity with other debates about theoretical containers for contemporary culture. Titles of books such as Anthropocene Fictions, Anthropocene Poetics, Anthropocene Feminism, and Anthropocene Reading - not to mention the popular genre label "Anthropocene-" or "climate-fiction"-suggest a similar flexibility to modifiers like "postmodern" or "postcolonial." But unlike these, the dominant use of "Anthropocene" as a hybrid geologic-humanistic term attempts to project something materially real (and so really urgent) onto familiar concepts. ${ }^{5}$ This standard definition has a different inflection from other cultural and literary critical categories. For example, Brian McHale playfully states in Postmodernist Fiction:

one thing is certain: the referent of "postmodernism," the thing to which the term claims to refer, does not exist ... There is no postmodernism "out there" in the world any more than there ever was a Renaissance or a romanticism "out there." ... If as literary historians we construct the objects of our description ("the Renaissance," "romanticism," "postmodernism") in the very act of describing them, we should strive at the very least to construct interesting objects.

Contrast this definition of postmodernism with the treatment of the Anthropocene, which is not only definitively "out there" but literally set in stone:

the Anthropocene has inspired such intense debate, from the biophysical sciences to the humanities, because it identifies a problem, a problem of how emergent forms of causality, operating across sociohistorical and planetary systems, have come to be read in the Earth's strata and then conceptualized and communicated.

(Menely and Taylor 4)

But is the Anthropocene really out there? The silent, totalizing implications of Anthropos in its conceptualization has been challenged recently, ${ }^{6}$ but the assumptions about precisely what space the Anthropocene occupies should also be queried. As literary critics now work alongside scientists with the term "Anthropocene," the question arises whether this real-world urgency has stifled attempts, adapting McHale's phrase, to construct an interesting Anthropocene. "Interesting" in the sense of Bruno Latour's 
"attractor:" a common space that draws humanity's interest away from the anthropocentric progress of history embedded in the apocalyptic reality of "the Anthropocene" and toward a possible, collective, imaginary point of view. ${ }^{7}$ As Crist puts it, shifting to a perspective that "would render the 'I' of the human enterprise as something less glamorous than a show of power; as more likely due to blundering into the condition of species arrogance and existential solipsism" (138). ${ }^{8}$ Literary possible worlds are a potential resource for encountering new forms of this common space. A version of an "interesting" Anthropocene, for the literary critic, is one that is working its way into narrative structures at the same time that scientists are identifying how it is redefining natural structures. Seeing "Anthropocene" in this way, it becomes significant not only on the level of what it signifies (humankind's intervention in geological time) but in how it signifies (negating past images of the environment). Because of its indeterminacy, it is a powerful resource for literary imagination.

In the following three sections, I will define one element of this emergent narrative structure: the mode of Anthropocenic focalization that foregrounds the spatial form of fiction, possible worlds, and pronominal reference. The Anthropocene is thus a point of view by which anthropocentric perception is negated by imagination. Though this finds original manifestations in contemporary literature, it can also be seen as an updated version of an "ambient" focalization, in which the teller is not defined by the "distance" from the storyworld in regards to the plot or mismatched knowledge between narrative levels but instead presents a perspective that is pervaded by indeterminacy. ${ }^{9}$ This indeterminate sense has been called "nescience" by Anahid Nersessian, and Kathryn Yusoff deploys a similar, though nonliterary, formulation of the primacy of indeterminacy in the sociopolitical context of toxicity. She argues for thinking about "indetermining relations:" "indeterminacy both releases and generates the call for another order of relation" (97). In the same way, the term I am developing here, Anthropocenic focalization, is differentiated from determinate, narratological conceptions of focalization that rely on perspective and so human perspective-taking, by foregrounding how images of the nonhuman disrupt anthropocentricism. To flesh this out I will contrast The World Without Us by Alan Weisman and 10:04 by Ben Lerner-both squarely within the category of "Anthropocene literature" - to consider the use of poetic images to construct probable and possible spaces, respectively, though various strategies of Anthropocenic focalization.

The World Without Us is an expansion of an earlier article in Harper's by the journalist Alan Weisman that explores what would happen to the Earth if humans simply and fantastically disappeared. ${ }^{10}$ The book includes a massive amount of research that is, in the conventional style of literary journalism, mostly conveyed via indirect discourse. While it may not be comparable alongside the core of the mode found in poetic works by Norman Mailer or Joan Didion, it brings to popular science writing a contemporary "literary" 


\section{David Rodriguez}

style that is reminiscent of the aesthetics of Rachel Carson's Silent Spring, particularly the motif throughout her book that imagines a world without birds. Nineteen chapters construct a narrative that moves from place to place, developing what cities without humans will look like one hundred, one thousand, or one million years in the future; the fate of infrastructure like subways, bridges, tunnels, and energy grids; and the reclamation of the Earth by both native and invasive species after humankind's disappearance.

10:04 has a similar textual origin as The World Without Us. An agent saw a great idea in a New Yorker short story by Ben Lerner, and so Lerner speculatively sold his next project based on expanding it into a novel. Though there are fundamental differences between a poet and novelist like Lerner and a journalist like Weisman, the track each takes from this shared starting point is significant. Lerner creates an autobiographical novel thematizing the very impossibility of fulfilling the publisher's wish for him to deliver a future work based on his past work, while Weisman seriously extrapolates his speculations that started as an article about Chernobyl and methodically considers the same humanless scenario in nearly every ecosystem. Contra Weisman's method, 10:04 is anxious about rather than inspired by the endless possibilities presented in the relationship between past work and its projection into the future. Not only do the different fictional and nonfictional modes present these attitudes, but the texts each integrate these problems formally through their use of focalization.

In the next three sections, I will configure Anthropocenic focalization by examining three different spaces in these texts: 1 ) the human scale of literary narrative, 2) the projection of catastrophe into possible worlds, and 3) the space of pronominal reference. While both of these texts are experiments with Anthropocenic focalization, The World Without Us ultimately does not sustain this mode because of its reliance on an image of the future that directly resembles its construction of an image of the ancient past trusted as "real" or at least "probable." 10:04 turns the screw just a bit more, staging the productive ambiguity of the concept of the Anthropocene as imaginary by using reflexivity to present the techniques of Anthropocenic focalization in their "possible" forms. The differences that arise in the next three sections are: 1) The World Without Us maintains a discrete, scalar relationship between humans and world while 10:04 attempts to exist on the blurry edge in between; 2) Weisman transposes catastrophic images of the past world onto the future world while the narrator of 10:04 prioritizes the openness of the future; 3) the represented world "without us" becomes a coded version of the world "for me to imagine," whereas 10:04 explores the second person plural through invoking the audience and the shared space of the poetic image. The techniques in these texts are examples of Anthropocenic focalization, but in 10:04 the potential for redefining the meaning and function of the conceptualization of "the Anthropocene" is foregrounded because of its development of a new imagination that recognizes that reality is born of the image, not vice versa. In his study of poetic images in Air and 
Dreams, Gaston Bachelard presents an axiom that is a useful starting point for thinking about this relationship between the real and the imaginary Anthropocene: "there is no reality that precedes the literary image" (249).

\section{Edges and Imaginary Space}

The obvious problem when comparing these two texts is the different affordances of fiction and nonfiction. The World Without Us has received ample analysis as part of emerging nonfictional treatments of documentary apocalypse across media. ${ }^{11}$ Similarly, 10:04 has been examined as part of a formal shift in contemporary fiction, as well as an example of literary climate fiction. ${ }^{12}$ What has not been examined are the overlaps between these two realms: how a "thought experiment" like The World Without Us utilizes some techniques of contemporary fiction and is comparable to the storyworlds of texts like 10:04.

10:04 is a quintessential example of contemporary autofiction, addressing the reader directly and announcing that the book is written "for you, to you, on the very edge of fiction" (Lerner 237). This "edge" is a spatial image that reinforces the illusion of autobiographical fiction even more than the conventional use of actual and familiar names, places, and events. ${ }^{13}$ Instead of relying on hyper-local referential overlaps alone, the narrator invites the reader to perform a spatializing projection and ask: am I also on this "edge of fiction" while reading the novel? Does my "actual" world or the author's "nonfictional" storyworld lie on the other side of this edge? 10:04 anticipates these questions and stages the possibility of naively reading the novel as nonfiction or autobiography, short-circuiting the reader's potential error and displacing it to another reference space: the indeterminate "edge of fiction" that does not form a border between the actual world of the autobiographical author and its fictionalization but rather is an imaginary, occupiable, shared possibility space.

The edge, in this way, is not the cut between two discrete spaces-reality and fiction, author and reader-but a space to pause and consider how one could confidently identify one or the other. One of the oppositions included in this "edge" is the reality of the Anthropocene and its possible existence in imagination. A major narrative thread in 10:04 is the developing relationship between the narrator and his best friend Alex, as she chooses him to be her sperm donor, and he negotiates with himself what this means for his future as a potential father and the life of the child on an uncertain Earth. His anxiety makes up the core of the novel and is structured by the problem of overpopulation and reproduction, especially in the context of imaginary reproduction; $;^{14}$ the narrator tells his writing students that "we shouldn't worry about our literary careers, should worry about being underwater" (217). The uncertainty of the narrator's culpability in this underwater future is essentially the uncertainty of where the "edge" of the Anthropocene is located. 10:04's unique contribution is that it indicates that 


\section{David Rodriguez}

the Anthropocene is not determinable through the analysis of its constituent parts—such as overpopulation or sea-level rise-but that this threshold is most accessible for examination from this speculative perspective on the "edge of fiction."

Edges are a problem with spatial metaphors-they most immediately assert an ontology of "thin rigid boundaries" 15 by assuming that the edge or the threshold does not signal any kind of identifiable space, just the limits of a category. Timothy Clark configures the Anthropocene as an indeterminate space with a "blurred and messy threshold" (86). He argues for the need to perceive, define carefully, and so use the identified "scale effects" of the Anthropocene to make this concept less blurry for use as a new tool for ethics, criticism, and action. But his conception of this initially blurry threshold still maintains a kind of geometric (and geologic) precision: for Clark, humanity is positioned somewhere on either edge of the Anthropocene, configured as a threshold of history, climate, and culture. It is not a space that can be occupied, as it is this shifting edge that is redefining what it means to live in the world.

Clark considers space with a determinacy in which "inside" and "outside" perspectives create new problems once crossed. His "threshold" or "edge" eliminates any strange point of view that is at once "on the edge" or "within the threshold." Instead, the Anthropocene is sighted just up ahead or is already passed through: "the Anthropocene also forms an indeterminate but insidious threshold at which many actions previously normal or insignificant have become, often in all innocence, themselves destructive, simply by virtue of human numbers and power" (61). Clark's "indeterminacy" only pertains to the temporal location of the Anthropocene; he does not consider the point of view from which we imagine dwelling "within" this threshold, which is arguably humanity's current condition as culture wrestles over the definition of "Anthropocene."

Despite this, Clark argues productively that the scale effects of the Anthropocene are not congruent with the standard historical method of literary criticism for which the novel functions "as enacting in fictional miniature a cultural politics that could be held usefully to apply, scaled-up again, to innumerable people and situations in actual life" (77), but this critique does not apply to all modes of "miniaturization." Rather than his reduction of "fictional miniatures" as historical models, "miniaturization" also can apply to a kind of concentrated, dense, and autonomous imaginary. For example, Bachelard notes:

In line with a philosophy that accepts the imagination as a basic faculty, one could say, in the manner of Schopenhauer: "The world is my imagination." The cleverer I am at miniaturizing the world, the better I possess it. But in doing this, it must be understood that values become condensed and enriched in miniature. Platonic dialectics of large and small do not suffice for us to become cognizant of the dynamic values 
of miniature thinking. One must go beyond logic in order to experience what is large in what is small.

The Anthropocene is not valuable conceptually because it allows new methods for "scaling up" our thinking but because its edge enters fiction; it is a real issue that preordains an indeterminate future, the domain of fiction. Experiencing indeterminacy in this fictional space, then, becomes an opportunity to explore the manifestations of the Anthropocene in daily life. As such, Bachelard, appropriating Schopenhauer, reverses the typical conception of images as representations of the world and asserts that the world as it appears is a result of the ability to imagine.

This is not dissimilar from recent work in New Formalism that asserts that literary narrative is a site in which sociopolitical forms collide and that literary form has a potential influence to disrupt the patterns of other forms in daily life. Caroline Levine argues that literary representations do not have any clear ability to "scale up" and affect the actual world. Instead, literary form, because of its "imaginary" potential, exists alongside other "actual" forms in a complex mix: "Rather than asking what artists intend or even what forms $d o$, we can ask instead what potentialities lie latent-though not always obvious-in aesthetic and social arrangements" (Levine 6-7). ${ }^{16}$ One of the latent potentials of the form of Anthropocenic focalization is the way it stages the collision between the modes of "miniaturizing" the world through various models. We can ask: is climate change primarily understood through scientific climate models, realistic thought experiment, or fiction?

One way Anthropocenic focalization plays out is in how the narrator of 10:04 straddles this edge that is the space between fiction and "the Anthropocene." Perspective opens up to multiple conditional possibilities when confronted with immanent threat. "An unusually large cyclonic system with a warm core" (Lerner 16) begins to alter the narrator's environment through its growing imposition on regular experiences of scale, specifically the default human perspective: "I mean the city was becoming one organism, constituting itself in relation to a threat viewable from space, an aerial sea monster with a single centered eye around which tentacular rain bands swirled" (17). As reality starts to reconfigure as a singular organism, the narrator converts his perspective into multiple conditional possibilities to embody the strangeness of daily routine, shopping for supplies:

I want to say I felt stoned, did say so to Alex, who laughed and said, "Me too," but what I meant was that the approaching storm was estranging the routine of shopping just enough to make me viscerally aware of both the miracle and insanity of the mundane economy. 


\section{David Rodriguez}

He begins to see everything with an "aura" that marks each object "as a little changed, a little charged" (18). The reader can wonder whether this aura is a literal glow, as in a possible hallucination, but the stranger differentiation is the split in modality between, "I want to say," "did say," and "what I meant." Intention, narration, and meaning are split into three possible spaces that function as an aura of possibility around the speech act. Just as the objects in the store are now reflexively visible as absurd commodities, so the narrator reflects on his own function in the transaction between fictional world and reader. Anthropocenic focalization asserts that this "edge of fiction" is an autonomous space in which the reader is presented with a variety of possible interpretations. This recurs throughout the novel in the form of a modal "say" to remind the reader that the present narration is open to a multitude of possibilities: "Say they join his family ..." (74); "Say that it was standing there I decided ..." (194); "Say that, from a small swivel chair ..." (233). Rather than utilize "scale" or a geometric spatiality that makes the narrator feel "small" in the face of the unfathomable patterns of climate miniaturized in the storm, the narrator begins to focus even more closely on the "small" things around him-objects, transactions, speech.

At the end of the novel, a second storm apocalyptically threatens the future once again. This mode of focalizing multiple presents is tinged with the threats of the Anthropocene, as the unusually strong storm has landed in Lower Manhattan, and, simultaneously, the feasibility of reproduction is questioned. While the narrator sits in a doctor's office, watching a screen showing Alex's ultrasound and another with a weather report, the two images begin to blend: "the coming storm, its limbs moving in real time, the brain visible in its translucent skull," and the risk of miscarriage means "the chances the creature will never make landfall remain significant" (233). Rather than leveraging what Clark conceives of as a discrete threshold, described above, the narrator layers images. The form of this spatialization of possibility differs from standard accounts of scalar "miniatures" available in fiction. The literally miniature images of the radar-rendered storm or the ultrasound scan of the fetus visible on the screens are not mapped metaphorically onto one another but offered from the narrator's point of view as simultaneous images of a possible world. From the narrator's perspective, the apocalyptic storm and the hope of reproduction are being born in his act of imagination.

On the other hand, The World Without Us is promoted as a "thought experiment" and so backgrounds its usage of fictionality; Bill McKibben's cover blurb claims, "This is one of the grandest thought experiments of our time, a tremendous feat of imaginative reporting!" This is a paratextual sign very similar to 10:04's "edge of fiction" particularly in this contradictory space between imagination and reportage. Nonetheless, the documentary mode that opens the prelude to The World Without Us will be familiar to the reader: "One June morning in 2004, Ana María Santi sat against a post beneath a large palm-thatched canopy, frowning as she watched a gathering 
of her people in Mazáraka" (1). The opening vignette is a conventional micro-narrative about modernization, with the South American Záparas "frozen" in time as "something happened far away"-industrializationthat destroys their environment (2). The story is extrapolated to the current destruction of the total environment for the book's Western audience and becomes the springboard to speculate about the most extreme solution to accelerating consumption and industrialization, the elimination of the human species:

Look around you, at today's world. Your house, your city. The surrounding land, the pavement underneath, and the soil hidden below that. Leave it all in place, but extract the human beings. Wipe us out, and see what's left. How would the rest of nature respond if it were suddenly relieved of the relentless pressures we heap on it and our fellow organisms? How soon would, or could, the climate return to where it was before we fired up all our engines?

Weisman's process of scaling up the apocalyptic storyworld from Ana María to the Záparas to humankind is close to the standard definition of the Anthropocene, resembling Ursula Heise's definition of the Anthropocene as "the sum of all environmental havocs humans have wreaked on the planet" (Heise 206).

Contrary to 10:04's preoccupation with indeterminate edges, The World Without Us is imbued with a geometric spatiality that is familiar to representational models of images as scale models of the world. Weisman uses this spatiality to concretize the apparent lack in humanity's ability to imagine things on a "larger-than-human" scale throughout the book:

The notion that someday nature could swallow whole something so colossal and concrete as a modern city doesn't slide easily into our imaginations. The sheer titanic presence of a New York City resists efforts to picture it wasting away.

(21; emphasis mine)

How can we even contemplate a world without us? Fantasies of space aliens with death rays are, well, fantasies. To imagine our big, overwhelming civilization really ending-and ending up forgotten under layers of dirt and earthworms-is as hard for us as picturing the edge of the universe. The Maya, however, were real. Their world had seemed destined to thrive forever, and, at its zenith, it was far more entrenched than ours.

(224; emphasis mine)

Yet the biggest elephant of all is a figurative one in the planet-sized room that is ever harder to ignore, although we keep trying. Worldwide, 


\section{David Rodriguez}

every four days human population rises by 1 million. Since we can't really grasp such numbers, they'll wax out of control until they crash, as has happened to every other species that got too big for this box.

(271; emphasis mine)

These images present the subject as a medium-sized figure standing, mute, separate, and beside unimaginably large material presences (the city, civilization, the universe) in which s/he is normally embedded. Presumably, even though this scalar incongruence apparently defeats imagination, a book (as "thought experiment") such as The World Without Us helps the subject develop a new point of view in which hyperobjects such as the planet or civilization can be reconceptualized and miniaturized.

The Anthropocene is not a thing out there to which the text-fictional or nonfictional-points but is a point of view from which human and nonhuman worlds can be described. The "edge of fiction" in 10:04 and the command "Look around you" in The World Without Us are spatial images that utilize metalepsis to evoke not just the space of the reader but an altogether new mode of focalization. Anthropocenic focalization thus transcends fictionality and projects a unique configuration of space onto the text. This space has been partially explored by possible worlds approaches to narratology, which can be supplemented by a complementary notion of calamity in the pervasive images of possible worlds.

\section{Possible Worlds}

Marie-Laure Ryan uses an outer space exploration metaphor to compare different modes of immersive reading: "Both counterfactuals and fictional statements direct our attention toward nonactual possible worlds, but they do so in different modes: counterfactuals function as telescopes, while fiction functions as a space-travel vehicle" (73). The reader remains "home" and peers into the nonfictional world or is launched on a space shuttle and "recentered" into the fictional world. In the present texts, this could be exemplified in the fantastic counterfactual of The World Without Us and the command to "look around you" as if through a telescope and the explicit recentering of the reader into 10:04's spatialized "edge of fiction."

Ryan's model can be extended beyond immersive reading, which remains anthropocentric for its focus on experientiality. ${ }^{17}$ Both the "telescope" and the "space shuttle" modes of exploring an imaginary world can be subsumed under another mode of immersion-typical of the Anthropocene-in which perspective-taking involves an affective relation to both the storyworld and its referents and not just a transportation "into" the text. Anthropocenic focalization stages the conventional assumption that the imaginary space of the text is "out there" before inviting the reader to negate this perspective.

For example, in 10:04 the narrator considers the long future of aesthetic structures during a residency in Marfa, Texas. During this residency he has 
a defamiliarizing encounter with Donald Judd's " 100 untitled works in mill aluminum" which he can only encounter by rejecting his first impressions and even negating his subjective point of view. This experience is an epiphany about the work's extreme inhumanity from his perspective as "an alien with a residency in the high desert" (178). The narrator is punning "alien," as he is already conscious about being a visitor in borderland southwest Texas, but he also begins to occupy alternative meanings of this "alien" perspective as he contemplates the work. The boxes are "a structure that was clearly built by humans but inscrutable in human terms, as if the installation were waiting to be visited by an alien or god;" they are "tuned to an inhuman, geological duration ... all those orders of temporality-the biological, the historical, the geological-combine and interfere and then dissolve" (180). The narrator is able to access the inhuman spatial presence of all these timescales at once through this shift to an inhuman, "alien" perspective, and he settles into this position of indeterminate meaning. The Judd boxes invite him to bracket human temporality and foreground spatial juxtaposition. He is able to access Judd's work in Marfa unlike "in museums or small gallery installations," and he feels World War II history collapsed into the warehouse previously used to house German prisoners of war (178). He begins to view the work as the concretization of an "impossible mirror," a term from a William Bronk poem previously referenced in the novel.

The description's repeated emphasis on the inhuman develops an unfamiliar point of view that affords a very brief encounter that embeds not just an inhuman point of view, but a nonhuman animal:

All those windows opening onto open land, the reflective surfaces, the differently articulated interiors, some of which seemed to contain a blurry image of the landscape within them-all combined to collapse my sense of inside and outside, a power the work had never had for me in the white-cube galleries of New York. At one point I detected a moving blur on the surface of a box and I turned to the windows to see two pronghorn antelope rushing across the desert plain.

Here aesthetic experience collapses the planes of history, environment, and the animal, only accessible from the narrator's "alien" perspective. What unites the human memories of war, the contrast of "open land" and "whitecube galleries," and the mirrored antelope is an immense sense of loss: "the changing rhythm of the boxes' interiors felt like a gesture toward a tragedy that was literally uncontainable" (180). This "impossible mirror" negates the precision of focalization normally determined by human perception in this type of ekphrastic description, and instead opens up narrative space to an "uncontainable," or indeterminate sense of form, defined by rhythm, juxtaposition, and loss. 


\section{David Rodriguez}

Ryan's possible worlds model can be altered to fit more closely with texts like 10:04 and The World Without Us that experiment with focalization in a context where the imagination of possible worlds tends to configure all possible worlds as tinged by tragedy and catastrophe-like this description of encountering the Judd boxes or the image of the baby and the storm-as is prevalent in texts that attempt to represent the Anthropocene. Rather than the science of semiotics from which possible worlds theory is based, we can retain its propositional form while imposing a sense of nescience-or a lack of knowledge, discussed by Anahid Nersessian. Contemporary literature is often tinged by one major, shared-though still indeterminate-possible world defined by the Anthropocene. Nersessian calls this instantiation of the Anthropocene as possible world "calamity form:" "a poetic technique that shapes the uncertain experience of anticipating, living through, and remembering ecological catastrophe. It allows even evanescent changes in the world to become apprehensible as well as apprehensive-objects of experience and sources of anxiety" (311). Anthropocenic focalization is geared toward this anxious space. Ironically, the narratological concept of possible worlds presents a structurally predictable storyworld; it is tuned toward how knowable space is configured by the reader rather than how our stable concepts of space are eroded by their uncertain existence.

Nersessian takes this further, arguing that the identification of calamity form opens up the study of literature not as a science but as defined by nescience:

Instead, it contemplates the impossibility of knowing how behaving differently in the past would have made a difference in the future. To put it another way, nescience is the cognitive expression of irony: the painful or unsettling sense that there is no meaningful link between what is known and what can be known, or what has taken place and what might take place.

The space between reader and text is not crossable via a "telescope" or a "space shuttle" because it is not linked to the perception of linear time and space but simultaneity and the imaginary. Anthropocenic focalization enacts this nescience, where the reader is not sure if what is being represented is referring to the fictional storyworld or the real world. A "thought experiment" like The World Without Us, as Heise notes, paradoxically pulls from the most familiar science-fiction tropes to reinforce the reality of climate change. ${ }^{18}$ The appropriation of these fictional tropes reinforces the reality of a problem that is functional not on the scale of a genre or style, but as Nersessian claims, as an "operation performed on language" (324).

The "calamity form" of these two texts provides some challenges to Ryan's standard possible worlds model, as they use Anthropocenic focalization to 
experiment with the irrelevance of conventional temporality and abstract spatial models for possible worlds in narrative. ${ }^{19}$ For Ryan, "In fiction, the reference world is inseparable from the image, since it is created by the text, and the contemplation of the image automatically transports the reader into the world it represents" (74). 10:04 revels in this transportation model of reading experience at the same time that it challenges it. The refrain from the novel's epigraph "Everything will be as it is now, just a little different" finds its most significant meaning when the narrator goes to view The Clock by Christian Marclay (consequently, another use of ekphrastic description to widen the "edge of fiction"). In this work, a twenty-four-hour film made up of scenes from films with clocks show the hour and minute in real time. Absurdly, while watching the film, the narrator pulls out his phone to check the time:

I'd heard The Clock described as the ultimate collapse of fictional time into real time, a work designed to obliterate the distance between art and life, fantasy and reality ... When I looked at my watch to see a unit of measure identical to the one displayed on the screen, I was indicating that a distance remained between art and the mundane.

The narrator continues: "Now I think it was while looking from The Clock to my cell phone and back again that I decided to write more fiction" (54). In this way, the novel collapses the distanced spectrum between reference world and actual world with the parallel reference in its title; 10:04 is a time, a film reference (Back to the Future), and a fictional object. As the reader sees the "space shuttle" model of fictional possible worlds represented in the narrator's ekphrastic description of The Clock, the narrator also describes his own act of fictionalization as he prepares the short story for the New Yorker and how "the story would involve a series of transpositions" (54), the names, events, and details changed from the present storyworld as they will exist in the New Yorker story he is writing.

The existence of possible worlds in nonfiction functions differently. For Ryan, the reader engages with representation in a similar way to a fictional text but then enters an evaluative mode based on the actual world-through "the telescope:" "In the first phase, the reader contemplates the textual world from the inside in, and in the second, from the outside in" (74). The possible world in the nonfiction text exists in direct correspondence to the reader's actual world and relies on the reader's interest in contemplating its validity according to reality rather than its own textual rules. The World Without Us evokes this mode through its constant, conventional journalistic reference to scientific authority as it constructs a rational model of the future world.

Despite the familiar use of journalistic form, the standard possible worlds model is transgressed in The World Without Us when representing aesthetic 


\section{David Rodriguez}

experience, as in 10:04. Perhaps the most peculiar part of Weisman's thought experiment is the short chapter, "Art Beyond Us," "beyond" being an even more overt spatialization than "without." In chapters such as this, the fictionality that is always the premise for a scientific thought experiment returns. The art Weisman studies is mostly public works that he reduces to their materiality in order to rationally judge their half-life as it extends beyond the fragile concrete frames of urban environments. But art is also "beyond us" as its meaning becomes independent of human observation; where architectural methods constantly change to become more economical, though not necessarily more stable, "The process of immortalizing art in bronze is essentially the same" from the ancients to the moderns (245). While buildings quickly corrode, the Statue of Liberty will maintain "the sculptor's artistic intention ... for the fish to ponder" for millions of years, even "forever" (247). He notes that un-smashed ceramics should survive just as long, and even paintings and other works on paper have a chance to last thousands of years if sealed in a dry space. While memory is what is lost in Weisman's other examples of material collapse (see 224, quoted above), here, the strange human artifact of "intention" is left intact, translatable and imaginable for a nonhuman audience.

The image of the Statue of Liberty covered in a layer of stone while maintaining its form to be read by the fish is absurd and perhaps cliché, but the perspective that Weisman constructs to make this image available is unique. Its rhetorical function projects nostalgia into the future, where the monument is conceivable as both destroyed-because the act of human interpretation is impossible-and renewed-explorable by nonhuman animals because it still exists materially in its new context. Rather than the progression of reading from the "inside in" to the "outside in," as Ryan proposes, the reader is never projected back "outside:" Anthropocenic focalization negates a human perspective of the Statue of Liberty. Interestingly, Weisman's aesthetic intention with this image-reducing art to its material to continue the narrative of culture recovered by idealized natural processes-is subverted by the imaginative act it affords-reading the sunken Statue of Liberty as a fish. This perspective is reminiscent of the narrator of 10:04's alien, inhuman experience of the Judd boxes in the desert: human intention is defied when juxtaposed by the "impossible world" of the nonhuman.

\section{Person and Reference Space}

As I have shown in the previous sections, both The World Without Us and 10:04 productively utilize Anthropocenic focalization to present an image of the world that plays with the realistic assumptions about anthropocentric spatiality. But The World Without Us relies more on traditional narrative conventions compared to 10:04, and analyzing this difference is useful to highlight a final aspect of Anthropocenic focalization. Pronouns 
implicitly evoke a spatial field through deictic reference, especially with second-person and inclusive pronouns. ${ }^{20}$ 10:04 in particular foregrounds the indeterminate spatiality created by pronominal reference rather than the spatial separation or distance implied by "my space" versus "his space," for example. This space becomes an opportunity to break down anthropocentrism through the projection of nonhuman perspectives. ${ }^{21}$ This indeterminate reference space is the third component of Anthropocenic focalization.

The World Without Us attempts to obtain this nonhuman spatial reference through a superficial negation: "without us." The example in the previous section of "art beyond us" is localized, and the book as a whole does not escape the anthropocentrism determined by humanistic scientific reason. Clark locates a common theme in these types of nonfictional texts:

innumerable popular science books on the crisis, how "we" got here and the cultural transformations "we" must urgently undergo to avert further disaster, are all implicitly investing in the Enlightenment faith that a deficit of understanding is at the root of the issue.

The World Without Us remains unreflective about the ultimate failure of human efforts to see "beyond" itself. It does not reflect on an actual negation of "we" or "us" but only its temporary suspension to construct descriptions that superficially remove humans in order to deliver the reader novel images to inspire-as the conclusion proposes—sustainability, stewardship, and ultimately some form of population control: an ideal world without too many of us. The project ultimately dodges questions relevant to the Anthropocene, as it absolves humans of responsibility. Matthew A. Taylor concisely notes:

the text's entire gambit is that we-late to our own funeral-witness the aftermath of our extinction, which means that the demise of our thingly offspring, last artifacts of our extinguished humanity, is not their tragedy but ours. Observing their deaths, we feel our loss, mourn our passing, our phantom presence forever attending our absence.

Weisman doubles down on this prospect of a haunting return, with halfseriousness, by concluding the book with the speculation that maybe our thoughts and prayers bounce out to space like radio waves: "one day-long after we're gone, unbearably lonely for the beautiful world from which we so foolishly banished ourselves-we, or our memories, might surf home aboard a cosmic electromagnetic wave to haunt our beloved Earth" (275). This presents a stark contrast to 10:04's highly self-conscious image of what it is like to become neurotically preoccupied with responsibility. A reflexive 
skepticism of the construction of human perspective is required to subvert the trap Clark locates in "Enlightenment faith."22

Thus The World Without Us and 10:04 are examples of two types of Anthropocenic focalization: positive and negative, probable and possible. They fall on a spectrum of attempts to construct an aesthetic form of what Christine Marran calls "ecology without culture." While The World Without Us is innovative in its use of Anthropocenic focalization, it mainly does so as the result of a conventional apocalyptic mode. ${ }^{23}$

The premise to "Wipe us out and see what's left" (Weisman 4) presents a peculiar series of elisions in the book's thought experiment. The text is heavily mediated by a narrating figure and takes the inevitable form of a "last-man" narrative, evident already in the evocation of the singular "you" of "Look around you" (Weisman 4). The represented world of the text is neither without us nor plural, and "us" ends up meaning "everyone-butme," where I am both the primary witness of the elaborate descriptions of disrepair and regeneration during the reading experience, as well as the figure in the last-man reverie the empty cityscapes invite. The initial projection beyond human scales of space and time invites this dual meaning of "us" and is present in all texts that project a conventional end-of-the-world scenario. But ultimately these types of nostalgic texts end up quickly constructing another human subject out of this negated "us"; Morton notes:

Apocalypticism tries to see beyond death, to remain sighted after there is nothing left to see. In ecological apocalyptic fantasies of the last man, everyone dies-except for the viewer or the reader. They reproduce a fundamental Cartesian and semantic split between the "I" who is narrating, and the "I" who is the subject of the story.

(Ecology Without Nature 185)

While The World Without Us does not conform to apocalyptic fantasy per $s e$-as it is a nonfiction text without a single, cohesive plot-it retains this feature in which the hopeful "us" is most often split into the rational "I" who synthesizes the scientific research and the reading "I" who is invited to fantasize.

In this way, The World Without Us is identifiably structured in the terms of what Lubomír Doležel calls a "one-person world," in stark opposition to the emptied world it claims as its imaginary premise. In the typical oneperson fictional world, the human figure is primarily pitted against nature, both passively—reacting to events driven by what Doležel calls "N-force"and actively-reducing the likelihood of accidents. The goal is to convert "the world-without-man into a world-for-man" (Doležel 38). Doležel's prototype for the one-person world is Robinson Crusoe, and The World Without Us shares the novel's exaggerated claims to real-world truths. But the speculative, empty Earth that is laid out to match a scientific image of the probable future in The World Without Us defies categorical identification 
as generically nonfiction. Each image from this "one-person world" is used, tactically, to transition from narrative set piece into rational explication from scientific experts-indeed converting the represented world "without us" into a "world-for-man." As the overt proposition of a one-person world is necessarily fictional, The World Without Us attempts to bury this sense of impending fictionality through overtly exaggerating absurd and fantastical premises for the disappearance of humans: pandemic, alien abduction, rapture, instantaneous erasure.

This extinction scenario is fabulated in order to present a simple solution. The most notable slippage is that the book conflates the world without us to the world having forgotten us: "To imagine our big, overwhelming civilization really ending - and ending up forgotten under layers of dirt and earthworms-is as hard for us as picturing the edge of the universe" (Weisman 224). Equating these two-retreating from "calamity" and into myth-is what eases the turn back to the past to apply what is known about extinction to modern humanity's potential disappearance. This temporal structure is used throughout the book: evoke the reader's present reality, recount a notable historical example, invite a scientific expert to extrapolate this into a model, and finally construct images of the future based on this model. ${ }^{24}$ While the above statement overtly suggests the impossibility of confronting these problems head-on, thus the need of some form of discursive assistance, the book asserts that this is most efficient through knowledge of the probable, rather than through indeterminate literary images.

To illustrate what would happen to nuclear power plants if engineers were not present to maintain them, Weisman turns to Chernobyl as "a tombstone to the intellect that created it-and, for thousands of years thereafter, to innocent nonhuman victims that approach too closely" (214). The next section, following directly after this comment, begins:

They began approaching within a year. Chernobyl's birds disappeared in the firestorm when Reactor Number Four blew that April, their nest building barely begun ... But the following spring the birds were back, and they've stayed. To watch barn swallows zip naked around the carcass of the hot reactor is discombobulating, especially when you are swaddled in layers of wool and hooded canvas coveralls to block alpha particles, with a surgical cap and mask to keep plutonium dust from your hair and lungs. You want them to fly away, fast and far. At the same time, it's mesmerizing that they're here. It seems so normal, as if apocalypse has turned out to be not so bad after all. The worst happens, and life still goes on.

There is a direct contrast between the "entombed" human and the free and flying (and ignorant) nonhuman. Weisman uses this image to illustrate that once humans are gone, the birds flying "naked" over the radioactive "metallic 


\section{2}

\section{David Rodriguez}

blob" will no longer be able to appear discombobulating or mesmerizing, because there is no human perspective to perceive them this way. This presents the possibility of the autonomous existence of the birds who adapt to their near-permanently destroyed habitat, but it does so by paradoxically inserting "you" back into the apocalyptic scene. The temporality is collapsed: Chernobyl is presently a tombstone for human intellect, projected into the thousand-year future as a danger zone for helpless birds and then brought back to the present for the reader to consider how "normal" it all appears.

10:04, in contrast to this evasion, attempts to directly entangle the reader through increasing second-person reference as the novel progresses. Rather than bury the "last man" fantasy through claims that the world without us is "unimaginable," 10:04 presents the terror of how these images are always present through a sense of prevailing possibility. For example, after a party one night during his time in Marfa, the narrator runs into another resident who invites him to go see the "Marfa Lights" out in the desert. Once there, the narrator does not actually see anything resembling the mysterious "glowing spheres," believed to be somehow "alien," government experiments or just car headlights. His experience of the Marfa Lights is imaginary; while he does not see what he believes others refer to as the Marfa Lights, he "did see something-but it was in the other direction, and there weren't any spheres" (193). He formalizes this experience of not-seeing by quoting an excerpt from his poem to express the possibility enacted in the attempt to see the Marfa Lights. The narrator configures the light he does see as "campfires or preventative controlled burns" (193). These two possible images separated by "or" is an instantiation of Anthropocenic focalization in the narrator's descriptions. The narrator is preoccupied with the uncertainty of how to interpret the environment, which results in these flickering images of the possible.

The split, contradictory image of the Marfa Lights as simple campfire or organized controlled burn is not just a negation of knowability in general but a negation of human knowing. Lerner states this point twice, in prose and poetry: "I saw no spheres, but I loved the idea of them-the idea that our worldly light could be reflected back to us and mistaken as supernatural"; in the quoted, embedded poem: "but why dismiss / what misapprehension can establish, our own / illumination returned to us as alien, as sign?" (193). The narrator is confused that people are only interested in the fantasy, not the immediate impulse to project an "alien" interpretation onto a simple, natural "mistake" or "misapprehension." $\mathrm{He}$ becomes interested in the nonhuman space between us and our beliefs-the quite clearly "worldly light" of fires or glow from headlights is naturally interpreted as nonhuman in this desert space. But most interesting is his projection of his earlier experience of the Judd boxes onto these imaginary lights he does not see: "I fantasized that a couple of aluminum boxes were positioned in the distance to facilitate the mysterious radiance" (193). He then imagines the perspective of this alien illumination, looking back at 
himself, which causes, finally, not just his perspective but his person to waver and expand into the second-person: "Tonight I see no spheres, but project myself / and then gaze back, an important trick because / the goal is to be on both sides of the poem, / shuttling between the you and I" (193).

The narrator re-inscribes this into yet another aesthetic experience of space, Walt Whitman's view of Manhattan from Brooklyn, which he has been studying while in Marfa. He answers Whitman's call as he "thought of Whitman looking across the East River ... looking across time, emptying himself out so he could be filled by readers of the future" (193). The narrator then transposes this onto every image of distant lights he can imagine:

I imagined the lights I did not see weren't only the reflections of fires and headlights in the desert but also headlights from Tenth Avenue and the brilliant white magnesium of the children's sparklers in the community garden of Boerum Hill and a little shower of embers on a fire escape in the East Village, or the gaslights of Brooklyn Heights in 1912 or 1883 or the eyeshine of an animal approaching in the dark, ruby taillights disappearing on the curve of a mountain road in a novel set in Spain.

These are mostly references to descriptions elsewhere in the novel, but the final image of "ruby taillights" is a direct quotation of a description in the author Lerner's previous novel, Leaving the Atocha Station.

10:04 is also trying to imagine a world without us. It reflexively spatializes imagination by prioritizing the inclusive and open "we" that embodies the point of view by which a productive image of the future can be constructed, rather than foregrounding the singular "us" who will be eliminated from the world. The novel ends with another image of lights in the distance: "at the time of writing, as I lean against the chain-link fence intended to stop jumpers, I am looking back at the totaled city in the second person plural" (240). Catastrophe does not totally wipe "us" out; it "totals" the world and decommissions the default associations that structure an anthropocentric conception of our existence in this space. What is left in this image is a variety of luminous auras, most significantly, the aura of possibility. It does not rely on generic recognition of "apocalypse" as such but the uncertainty of its possibility. As the narrator reads Whitman's Specimen Days in Marfa—an uncompleted work-he, ironically, describes the work in a poem: "It's among the greatest poems and fails / because it wants to become real and can / only become prose, founding mistake / of the book from which we've been expelled" (194). The narrator of 10:04, and in some sense The World Without Us as well, attempts to capture the reality of life during and after the Anthropocene but ends up realizing that it can only be pointed to negatively through the failure of prose. 


\section{David Rodriguez}

\section{Conclusion}

Both The World Without Us and 10:04 become speculations about population and reproduction-10:04 in its premise and The World Without Us in its epilogue..$^{25}$ But the main difference between the approaches of these texts, I hope to have shown, is not due to the differences in fiction and nonfiction but the utilization of images. The intention of Weisman's "world without us" image is to prove its existence and convince the reader that this vision of the future is probable if humanity does not minimize our population to match the quantitative sense of a world without us. 10:04 brackets this apparent responsibility to depopulate the world and invites a reconsideration of the function of imagining a possible world in the first place: would depopulating our apocalyptic images of the future also bring about a similar change in our relationship to the Anthropocene?

Weisman presents the fantasy of total lack of management of both natural resources and cultural infrastructure-bridges rust when not painted, subways flood when water is not pumped. But 10:04 presents a less apocalyptic presentation of mismanagement-when an expected, approaching storm will have lasting effects because of the unexpected results of mismanaged recovery. The novel stages this mismanagement on every level and most effectively enacts this problem of the Anthropocene through its projection back onto the reader, the function of what I've been calling Anthropocenic focalization. The "real" storms in the novel do not manifest in wind and rain, but they become mobilized in imagination-how they become prose. By turning toward the reader through the second-person plural, 10:04 asserts that a storm's aftermath is not visible from a rational authorial perspective but from a shared mode of access to a world that crosses from image to reality. Anthropocenic focalization locates the autonomous, anxious space of catastrophe in the Anthropocene as an "interesting" space-it has the ability to draw our attention to its indeterminate position on the edges of our imagination.

\section{Notes}

1 See Morton, Hyperobjects 66-67 on hyperobjects and spatial scale.

2 The most recent example is Jeffrey Jerome Cohen's detailed historic, literary, and geologic focus on the lithic in Stone.

3 See Menely and Taylor 7-8.

4 Throughout this essay I use "possible" in Casey's configuration of the autonomy of imagination, in which "The possibilizing activity of imagination in art opens up an experiential domain that would not otherwise have been available either to the artist or to the spectator. This domain is one in which everything appears as purely possible" (206).

5 This is the historicist thread began by Dipesh Chakrabarty's foundational essay, "The Climate of History," particularly his urgency to update familiar sociopolitical realities because "To call human beings geological agents is to scale up our imagination of the human" (206). 
6 Particularly by Kathryn Yusoff (2018), who argues "the racial blindness of the Anthropocene [is] a willful blindness that permeates its comfortable suppositions and its imaginations of the planetary" (xiii).

7 Latour calls this new space of this "attractor" the terrestrial: "If it is hard to understand, today, what epoch we belong to, it is because [this attractor] is at once known to everyone and completely foreign" (42). Given the ambiguity inbuilt in the Anthropocene, it is most productive to consider where it pulls us rather than its final determination.

8 Similarly, Claire Colebrook (2014: 28) considers the term "Anthropocene" disingenuous because it projects a surviving human "reader" of the geological strata in the future that will be able to perceive the "Anthropocene" epoch from the perspective of a logically contradictory "Post-Anthropocene."

9 See Jahn on the term "ambient focalization:" "In ambient focalization, the field of subjectivity is shown as an ellipse: like a geometrical ellipse, which has two foci, ambient focalization is based on two (or more) [focalizers], depicting a thing summarily, from more than one side, possibly from all sides, considerably relaxing the condition of specific time-place anchoring, and allowing a mobile, summary, or communal point of view" (98).

10 See Weisman (277) for this textual history.

11 See Jendrysik; Taylor; Garrard.

12 See Vermeulen; Ameel in the present volume.

13 Marjorie Worthington writes how this reflexivity is key to the mode: "autofiction revels in ambiguity by evoking the name of its author and including nonfictional information about him/her, while consciously fictionalizing the author-character at the same time" (3).

14 See also Garrard 56 on reproduction in Weisman.

15 See Morton, Dark Ecology 76, though he uses this term in a number of contexts.

16 Morgan (139-40) is another critic who reads Levine in the context of the Anthropocene. He points out that her "conception of form is unapologetically Anthropocentric." I agree, but cautiously adapt it here and elsewhere (see Rodriguez) as it is a useful expansion of form potentially found in environmental forms.

17 See Caracciolo (305-6) on anthropocentrism and experientiality.

18 See Heise (216).

19 In addition to Ryan's model described here, other class formulations that rely on abstract space are Richard Gerrig's psychological account of transportation and immersion in a text from Experiencing Narrative Worlds.

20 See Monika Fludernik, Towards a 'Natural' Narratology, Chapter 6.

21 In fact, this is an extension of the previous critique of Ryan's "transportation model" of possible worlds, as she claims that "the pronoun you retains the power to hook the attention of the reader and to force at least a temporary identification with the implied referent. Through this identification, the reader is figuratively pulled into the textual world and embodied on the narrative scene (unless, of course, the I-you communication is of the metafictional type, in which case the effect is a decentering)" (138).

22 Alongside 10:04, other autobiographical novels like MacArthur Park by Andrew Durbin and, to some extent, Saison brune by Philippe Squarzoni similarly use the representation of fictionalization to integrate the Anthropocene as a speculative position rather than as a concrete, probable reality.

23 The book constructs a positivistic model of the world projected into the future as defined by the most probable scenarios available by rational scientific thought. The world of the text ultimately becomes a fantasy which fits into a benign mode that "determines that all natural phenomena must eventually refer back to the 
human's creation and re-creation of itself as subject" and "presumes humanity as the relevant subject for whom we read and write and film" (Marran 24).

24 A representative example of this linear past-present-future image is of the movement of ice sheets in Southern England: "Several ice ages froze enough of the planet's water solid to drop ocean levels and allow today's world to take shape. The last of these sent a mile-high ice sheet right down the Prime Meridian. Where it stopped is where Dartmoor begins. Atop its granite hilltops, known as tors, are remnants from those times that may be portents of what awaits if yet a third climatic alternative proves to be the British Isles' destiny" (166).

25 See also the conclusion of Garrard.

\section{References}

Bachelard, Gaston. Air and Dreams: An Essay on the Imagination of Movement. Dallas Institute Publications, 1988.

Caracciolo, Marco. "Posthuman Narration as a Test Bed for Experientiality: The Case of Kurt Vonnegut's Galápagos.” Partial Answers, vol. 16, no. 2, 2018, pp. 303-314.

Casey, Edward S. Imagining: A Phenomenological Study. Indiana University Press, 1976.

Chakrabarty, Dipesh. "The Climate of History: Four Theses.” Critical Inquiry, vol. 35, no. 2, 2009, pp. 197-222.

Clark, Timothy. Ecocriticism on the Edge: The Anthropocene as a Threshold Concept. Bloomsbury, 2015.

Cohen, Jeffrey Jerome. Stone: An Ecology of the Inhuman. University of Minnesota Press, 2015.

Colebrook, Claire. Death of the Posthuman: Essays on Extinction, vol. 1. Open Humanities Press, 2014.

Crist, Eileen. "On the Poverty of Our Nomenclature." Environmental Humanities, vol. 3, no. 1, 2013, pp. 129-147.

Doležel, Lubomír. Heterocosmica: Fiction and Possible Worlds. Johns Hopkins University Press, 1998.

Garrard, Greg. "Worlds Without Us: Some Types of Disanthropy.” SubStance, vol. 41, no. 1, 2012, pp. 40-60.

Grusin, Richard, editor. Anthropocene Feminism. University of Minnesota Press, 2017.

Hartsock, John C. Literary Journalism and the Aesthetics of Experience. University of Massachusetts Press, 2015.

Heise, Ursula. Imagining Extinction: The Cultural Meanings of Endangered Species. University of Chicago Press, 2017.

Jahn, Manfred. "More Aspects of Focalization: Refinements and Applications." GRAAT, no. 21, 1999, pp. 85-110.

Jendrysik, Mark S. "Back to the Garden: New Visions of Posthuman Futures." Utopian Studies, vol. 22, no. 1, 2011, pp. 34-51.

Latour, Bruno. Down to Earth: Politics in the New Climatic Regime. Polity Press, 2018.

Lerner, Ben. 10:04. Picador, 2014.

Levine, Caroline. Forms: Whole, Rhythm, Hierarchy, Network. Columbia University Press, 2015. 
Marran, Christine L. Ecology Without Culture: Aesthetics for a Toxic World. University of Minnesota Press, 2017.

McHale, Brian. Postmodernist Fiction. Routledge, 1987.

Menley, Tobias, and Jesse Oak Taylor, editors. Anthropocene Reading: Literary History in Geologic Times. Penn State University Press, 2017.

Morgan, Benjamin. "Scale as Form: Thomas Hardy's Rocks and Stars.” Anthropocene Reading: Literary History in Geologic Times, edited by Tobias Menley and Jesse Oak Taylor, Penn State University Press, 2017, pp. 132-149.

Morton, Timothy. Dark Ecology: For a Logic of Future Coexistence. Columbia University Press, 2016.

Morton, Timothy. Ecology Without Nature: Rethinking Environmental Aesthetics. Harvard University Press, 2007.

Morton, Timothy. Hyperobjects: Philosophy and Ecology after the End of the World. Minnesota University Press, 2013.

Nersessian, Anahid. “Two Gardens: An Experiment in Calamity Form.” Modern Language Quarterly, vol. 74, no. 3, 2013, pp. 307-329.

Rodriguez, David. "Narratorhood in the Anthropocene: Strange Stranger as Narrator-Figure in The Road and Here.” English Studies, vol. 99, no. 4, 2018, pp. 366-382.

Ryan, Marie Laure. Narrative as Virtual Reality: Immersion and Interactivity in Literature and Electronic Media. Johns Hopkins University Press, 2001.

Taylor, Matthew A. "Whither Life?” Subjectivity, vol. 5, 2012, pp. 276-289.

Trexler, Adam. Anthropocene Fictions: The Novel in a Time of Climate Change. University of Virginia Press, 2015.

Vermeulen, Pieter. "How Should a Person Be (Transpersonal)? Ben Lerner, Roberto Esposito, and the Biopolitics of the Future." Political Theory, vol. 45, no. 5, 2017, pp. 659-681.

Weisman, Alan. The World Without Us. Thomas Dunne Books, 2007.

Worthington, Marjorie. The Story of "Me": Contemporary American Autofiction. University of Nebraska Press, 2018.

Yusoff, Kathryn. "Indeterminate Subjects, Irreducible Worlds: Two Economies of Indeterminacy.” Body \& Society, vol. 23, no. 3, 2017, pp. 75-101.

Yusoff, Kathryn. A Billion Black Anthropocenes or None. Minnesota University Press, 2018. 


\section{Part III}

\section{Scales and Limits of Narrative}




\title{
8 Maarit Verronen's Monomaniacs of the Anthropocene
}

\author{
Scaling the Nonhuman in \\ Contemporary Finnish Fiction
}

\author{
Sarianna Kankkunen
}

In Luolavuodet ("The Cave Years"), a novel by Maarit Verronen, a team of speleologists explores an underground passageway. It is a long walk along the ancient subterranean riverbed, and since the terrain is challenging, members of the group focus solely on the practicalities of their exploration. They share their observations, negotiate over the phases of the expedition and their proper order, and speculate on the formation and width of the cave system. In the middle of this pragmatic discussion, the protagonist suddenly comes up with an anecdote she wants to share with the rest of the group:

"There was once a thinker, you know, who said that if you're not willing to find out what is and what has been within a ten-kilometer radius of your home, you're essentially an uneducated person, I say aloud. The thought springs to my mind suddenly - the way ideas always occur to me in the cave-and it seems important enough to be passed on."

"Did he mean those ten kilometers to be measured also underground?"

(Verronen, Luolavuodet 22) ${ }^{1}$

In this short conversation, the scales are tilted, figuratively speaking, in favor of a new understanding of human habitat, one that includes the underground environment, usually considered hostile and alien to human species. Moreover, the scene foregrounds the spatial aspect of human experience and presents the recognition of that aspect as a moral obligation. The final comment of the scene challenges the scales we use to measure and map our spatial experience. Our scales might be accurate, the speaker seems to suggest, but our use of them should always be open to critical examination and renegotiation.

In the field of literary studies, questions of scale have started to emerge along with the spatial turn and the onslaught of globalization, the Anthropocene, and other contemporary phenomena. Understanding scalar mismatches and synergies between the human and the nonhuman is a task in which the imaginative power of literature can prove its strength. As Michael Tavel Clarke and David Wittenberg argue in Scale in Literature and Culture: 


\section{Sarianna Kankkunen}

"humans' ineptitude in comprehending scale in the real world is likely the flipside of the tremendous ease with which we are able to rescale things in our imaginations" (3). What we lack in understanding can be compensated in our literary imagination.

The literary imagination needs forms to function, and as Ursula Heise claims, the forms of narration have started to change in order to "convey a more panoramic view" on the contemporary world of global environmental crises (55). In Imagining Extinction, Heise brings together Franco Moretti's conception of the modern epic and Lev Manovich's notion of database as an emerging cultural form, suggesting that environmental concern is more and more often expressed with different forms of enumeration: lists and catalogues accompanying narrative fiction, and outside the sphere of fiction, with biodiversity databases and Red Lists of endangered species. The problematics triggering these forms of enumeration are of scalar nature: according to Heise, classical narrative devices do not equip us with tools for grasping the magnitude of environmental threats. Strategies of enumeration, on the other hand, are a way of producing and expressing a numerical sublime, a sense of numbers and scales that transgresses everyday experience (see Heise 56).

This chapter focuses on how questions of scale are probed through a number of strategies, including enumeration, in Maarit Verronen's fiction. Verronen (1965) is a contemporary Finnish author whose works span three decades, more than twenty titles, and several modes from realism to allegory, fantasy, and dystopian fiction. She has gained a reputation as a novelist portraying onlookers and bystanders of society: people who seem to be more intimate with desolate places and natural phenomena than with the rest of humanity (see, e.g., Lehto; Majander). This links her with the tradition of Finnish literature, which has always cherished a close connection between human cultures and wilderness. As Pertti Lassila (1819) points out in his study on nature in Finnish literature, eminent literary historians, such as Viljo Tarkiainen (1879-1951), have emphasized the role nature and depictions of wilderness play in Finnish prose and poetry. The foundations for this reading of the Finnish literary tradition are inlaid in the nineteenth-century national epic Kalevala, which revived the magical and shamanistic world-view of the oral folk tradition, disseminating it for the purposes of nationalistic ideologies. But beside the shamanistic folk beliefs, Protestant Christianity played a role in cementing the role of nature in the Finnish literary tradition. As Lassila (28-30) notes, the roots can be traced back to the Baroque period, which was in the Finnish context the period of solemn, pious nature poetry instead of the more light-hearted bucolic poetry that took over Europe. Ideals of Enlightenment and Christianity fused and resulted in the so-called natural theology, which was one of the dominating features of Finnish literature well into the times of nationalist awakening (Lassila 30). In this tradition, the enumerative form emerges: lists of animals and plants are used as a way to praise the complexity and beauty of the 
godly creation (Lassila 31). This resonated with the oral folk tradition and its later adaptation, Kalevala: as Lassila (19) points out, the epic itself names and depicts multiple species accurately. In the epic, species of plants and animals are singled out in their particularity and simultaneously presented in the repetitive form of the Kalevala meter. All in all, both the pagan and the Christian traditions underlying Finnish culture emphasized the significance of nature and engaged with it through literary forms.

Looking at country statistics instead of the literary tradition, the presence of nature in Finnish literature has been further strengthened by societal structures: compared to other European countries, in Finland the process of urbanization started late, peaking in the 1960s. Today, Finland is the third most sparsely populated country in Europe (European Commission Eurostat: Population 2019). The influence of pagan folklore, the association between nature and the Finnish national identity, and the everyday reality where over 800,000 Finnish households (of a nation of 5.5 million) have access to a summer cottage typically set in the middle of nature, have all contributed to the fact that Finnish literature has been and still is interpreted in close relation to the realm of nature.

Maarit Verronen, with a professional background in natural sciences, moves beyond traditional nature writing and its logics of national symbols and opposing literary tropes, such as pastoralism and wilderness. She depicts the state of affairs of a late modern world, a world where the relationship between nonhuman nature and human cultures has to be renegotiated, a world of shifting scales. This chapter focuses on Verronen's novel Luolavuodet and another specimen of her prose fiction, Keihäslintu. As the caving scene quoted above suggests, Verronen's body of work depicts protagonists with a curious obsession with nonhuman environments and counterparts. I will start by exploring this obsession and linking it with the nineteenth-century concept of monomania. My main purpose is to analyze the tension between these two impulses: the need to focus, presented by the monomania, and the equally pressing urge to expand in order to comprehend nonhuman scales. After presenting the two novels and their monomaniacs, the chapter will then zoom in on the forms of enumeration both novels use to depict nonhuman scales. Since the forms of enumeration evoke a sense of sublime, I will relate it with the novels at hand and see how the struggle for representing the nonhuman-the struggle to expand the scale-is carried out in Luolavuodet.

\section{The Bird and the Caveman: Two Cases of Monomania}

Keihäslintu (2004, "The Spearbird") consists of independent short stories divided into two sections, Villi lintu ("Wild bird") and Sukupuutto ("Extinction"), and a third section titled "Keihäslintu [geirfugl; Pinguinus impennis]" ("Garefowl [geirfugl; Pinguinus impennis]"). In the third section, the fragments revolve around a single protagonist and her passion for the 


\section{Sarianna Kankkunen}

great auk, also known as the garefowl. The great auk is a species that went extinct over 150 years ago, mainly due to uncontrolled hunting. After seeing a stuffed specimen for the first time, the protagonist's obsession for the bird takes the form of an urge to travel around Europe from researcher to researcher and from one museum to another to see the remaining eggs and the preserved remnants of the great auk. She also takes the task of listing all the eggs and carries out thorough research on the fate of a mounted auk skin whose whereabouts are unknown. There is no practical reason for this enterprise, nor does she want one: it just happens that the bird has come to play a central part in her life.

Verronen's novel is a contemporary take on monomania, a concept introduced by early nineteenth-century psychiatrists, such as JeanneÉtienne Dominique Esquirol and Pierre Janet, and eagerly adopted by the French novelists. The symptoms of monomania, a preoccupation turning to a pathological obsession, may vary, but, as Marina van Zuylen remarks, "each one of its enactments is part of an abstract, autonomous desire to reorganize the world according to a long-lost model of wholeness" (Zuylen 5). Monomaniacs have "a love-hate relationship with permanence" (Zuylen 10); their obsessive interests are mental barriers against change, and their compulsive acts of examining and collecting are attempts to establish a stable state of affairs. These tendencies of monomania can be traced back to Freud's theories on melancholy, death drive and religious rituals, as for Freud, neurosis is a form of private religiosity (Zuylen 5). Freud draws a parallel between obsessive behavior and religious rites, claiming that the former is a distorted version of the latter: a pathological way to establish coherence where it is broken. In other words, as Zuylen $(5 ; 19)$ puts it, obsessive behavior is a way to grasp the absolute whenever it is threatened by change or flux. As Zuylen points out, the need to reinstate a former state of affairs is a key component of Freud's understanding of melancholia, but in Beyond the Pleasure Principle, this same drive or instinct appears as a central feature of the human-or even nonhuman-mind (Zuylen 13,19). In a highly contested (see, e.g., Smith; Weatherill) section of his study, Freud suggests that beyond all instincts and drives that function as catalysts for change, there exists an opposite drive: a drive for re-instituting an earlier condition, something what he poetically calls "the expression of inertia inherent in organic life" (Freud 30). Freud suggests that this inertia directs the organic towards inorganic, an attraction which eventually results in the death drive. "We are primarily great preservers, haters of change," Zuylen (13) writes and presents the subject's longing for stasis and immobility as the driving force behind monomaniac behavior.

The call of the inorganic is the key theme of the caving novel of Verronen. In Luolavuodet, it is the subterranean world of the caves that fixates the mind of the protagonist. In the novel, Vjeshta, the protagonist, measures up to the standards of an educated person presented earlier, for she carefully studies the surroundings of her new home. After relocating to 
a small town on the western coast of Finland, she memorizes the maps of the area, visits the local museum, hikes around her home, and delves into the archives of the town paper. These edifying activities have a hiddenor more precisely, buried-meaning. The protagonist has an obsessive interest: to go underground. She is a part-time caving enthusiast drawn to the area by her most recent discovery, a network of caves under the town. As the underground exploration progresses, the caves unfold a multitude of forgotten histories, both natural and cultural. But a richer and more nuanced relationship develops between the protagonist and the caves. In the course of the story, the protagonist spends nearly a decade digging and climbing, carrying out analyses of bat feces, taking geological measurements, and producing an ever-expanding map of the network of caves. Only then the underground world reveals its secrets. During these years, the protagonist abandons her academic work as mathematician, devotes most of her time to the study of the caves, and manages not only to rewrite the history of human settlement in the area but also to build a vivid network of specialists working around the caves.

The novel is a depiction of the strength and persistence of an obsession but also a description of the bond developing between a place and a person. The quest of mapping the cave turns into a process of developing self-awareness:

Mapping gives me pleasure. Explicit, finished maps of caves are beautiful. They are always incomplete-but that's an advantage, not a shortcoming. There's always a corridor extending beyond the edge of the map, heading to a place that's not visible. A place which I know nothing about. There's always more to find out; there's always more pleasure of finding and investigating.

I'm out of my depth while trying to explain this to someone else; rarely do I try. Most of the time, I have a feeling that people don't listen to me. The issue is too wide and large; it encompasses everything. Go ahead, try explaining the reasons for caving, while new reasons keep appearing and the old ones lose their meaning

$(\text { Luolavuodet } 53)^{2}$

In this passage, the protagonist has already embraced the states of uncertainty and incompleteness that are an essential part of any research project. The novel bears close resemblance to the post-structuralist criticism of maps and cartography as tools of power (see, e.g., Harley). The novel's approach to mapping is very different from the one depicted in the colonialist novel, especially Joseph Conrad's Heart of Darkness: instead of being steps towards dominance over something, these maps are meant to transform the subject itself, as they are tools for character formation. Instead of coloring the blank spots on the map, the protagonist keeps extending the map beyond the edge, already aware of the limits of her knowledge and power. Instead of a finished product, the process itself is the desired outcome. The 


\section{Sarianna Kankkunen}

passage draws a parallel between the unfinished, ever-expanding nature of the map and the protagonist's passion for mapping, which is "wide and large" and "encompasses everything." The nonhuman world is constantly changing and growing and so is human passion. Simultaneously, the passage sheds light on the monomaniac state of mind: the troubles the protagonist encounters in map-making are very similar to the ones she experiences in social contexts, but the monomaniac is willing to fight only on one front, while surrendering the other, namely, that of human interaction. By this I mean that in the case of the caves, the pathological preoccupation of mapping renders the challenges of scale and the difficulties of limitlessness into something tolerable, but in the social context, the strategy wavers, and the protagonist gives up the effort of explaining herself.

\section{Scaling Up, Scaling Down: Aesthetics of Restriction and Expansion}

In Verronen's Keihäslintu, the protagonist observes a preserved specimen of the great auk, a penguin-like, flightless alcid that became extinct in the nineteenth century:

Vladimir M. came back. He carried the bird. It was wonderful, incredibly beautiful. Black and white; lively eyes, a curious expression, a handsome, streamlined beak. Black back, little wings, head, neck, beak and flippers. ... She turned it around, took measures even. Sixty centimeters from tail to head, but because of the posture, the top of the head was fifty-five centimeters from the pedestal. The beak, eight centimeters, just like the flippers; the whole foot, fourteen. The diameters of the white spots on the head, four and two and a half centimeters.

"I love this bird"

$($ Keibäslintu 154)

In the scene, measurements taken from the mounted bird turn into an expression of its emotional significance: "I love this bird." The seemingly objective and external act of measuring evokes a response that is fully subjective, evaluative, and sentimental. The scene thus juxtaposes two possible approaches: rational and emotional, objective and subjective. Both approaches share the same agent; it is the measure-taker, Tanja, who utters the declaration of love for the bird. Her confession seems to suggest that it is not only the relevance of measurement that is questioned in this scene; the roles of the subject and the object are shifting. The bird, stuffed, mounted, and now measured, is the object of the scientific scrutiny. But it is actually Tanja, the subject of this examination, who is affected the most and of whom the narrated scene reveals the most. The scene illustrates an attempt to apply human scales to a nonhuman object. The result of this examination, a confession of love, is much more than a sudden burst of emotional release: 
engaging, physically and conceptually, with the nonhuman other, leads into an ethical stance. ${ }^{4}$ But as the scene demonstrates, this heightened selfunderstanding requires an embodied, physical contact as well as some sort of conceptual work with the nonhuman counterpart.

What about the formal aspects of this scene? The joyous, ecstatic testimony on the beauty of the bird almost turns into a report of its body parts and, later, their measurements. Sentences shorten, verbs disappear, and the narration takes the form of a list. First, the focalizer is blown away by the beauty of the bird, then, her attention is drawn to a smaller and smaller details of it. Aesthetic evaluations and emotional responses turn into a monotonous, detached listing of various measurements; the narrative form mimics the attentive consciousness of a monomaniac, whose obsessive concentration is a defense against emotional turmoil. The passage thus demonstrates how monomaniac behavior is linked with the need to organize and preserve: the protagonist's instant reaction to measure the body parts of the bird is an attempt to classify, categorize, and memorize the desired object.

In Luolavuodet, a similar kind of breathless account takes place when the narrator describes the caves:

Caves are filled with small eternities. How long did it take from the limestone to form from the shells and skeletons of animals in the bottom of the sea; how long did it take from the sea to withdraw, the land to rise into mountains, and wear out into hills; how long did it take from the water to erode those massive spaces! How long did it take from the calcite solution to precipitate into hard mineral in the dry air of the caves and to take the shape of stone curtains and pillars?

$(\text { Luolavuodet } 17)^{5}$

The repetition and the rhetorical question the narrator poses give the passage a lyrical, solemn tone. Nevertheless, the description is also a list that chronologically catalogs the stages of the cave formation in limestone bedrock. The description presents multiple scales and alternates between them: modest shells and skeletons make up masses of limestone; land turns into mountains and mountains into hills; soft water carves the hard stone and drops of calcite solution compose pillars of stone. The small composes the big, and the big is taken apart by the small. The enumerative form of the passage and the whole chapter is in accordance to this alternation: a list is a form of writing that directs one's attention simultaneously to the detail and the whole, demanding constant comparison between the two.

In both passages, the scales conflicts with the human experience. In the bird scene, the measurements taken are only a pale reflection of the emotional turmoil caused by the mounted bird. It is the beauty and the materiality of the bird that challenges human understanding. In the cave scene, the narrator lists question after question without any real attempt 


\section{Sarianna Kankkunen}

to answer them; the stages of the cave formation are represented only to highlight their unrepresentability. As for the caves, it is their spatiotemporality, their sheer volume of space, time, and matter, that exceed human imagination. As demonstrated by the two quotes above, in Verronen's novels, enumeration functions as a way to convey the disparity between the human subject and the nonhuman counterpart, be it a bird or a network of caves. As a literary form, enumeration also evokes the confusion the human agent experiences while confronting the nonhuman. A list is a demonstration of unwillingness to choose: as a multielement whole, a list is created by a reluctance, or incapability, to limit and focus. However, in the context of these two texts, the enumerative form can also be read as a sign of openness to various perspectives and as an attempt to avoid fixed viewpoints. Like a Cubist painting, a list as a form of literary description aims at describing multiplicities, simultaneities, and various viewpoints. In contemporary fiction, this may be one of the most effective ways to approach nonhuman counterparts. This is further enhanced by the fact that the list seems to convey truth value. It may be linked with what Roland Barthes calls the reality effect, the effect produced by the descriptive elements of the narrative or with our habit of associating lists in literature with their everyday counterparts, pragmatic lists, as Robert Belknap (5) calls them. In other words, the enumerative form might disrupt the plot, but it enhances the mimetic function of the literary text. In the case of Luolavuodet, the enumerative form is connected with the scientific description of a natural historical event, cave formation. The list simulates the discourses of natural science and historiography by imitating the collection and organization of data in these fields (see Young 15). Despite its openness and limitlessness, in Verronen's novels, the enumerative form introduces the epistemologies of science.

Lists, catalogues, and other forms of enumeration are an emerging strategy in fiction discussing the species extinction and environmental threat, claims Heise (61). In the already mentioned Imagining Extinction, she presents this "database aesthetic" as a possible, and even desirable, alternative to the elegiac mode more commonly found in extinction fiction. Catalogs and lists in the narrative evoke what she calls "a numerical sublime of sorts," a sense of numbers that is unattainable by more traditional narrative devices (Heise 56). The turn to the strategies of enumeration is a narratological-aesthetic reaction to the current status of the world's biodiversity loss, also known as the sixth mass extinction or the Holocene / Anthropocene extinction.

In literature and the arts, as Clarke and Wittenberg (4) note, the connection between human imagination and nonhuman scales has been typically discussed through the discourse of the sublime. The classic Kantian conception on the sublime emphasizes the transcendental nature of the experience: when facing a greatness too large to comprehend, the human subject is led to sense the limitations of their perception-and then, surpassing these limitations, to a state of recognition of their subjectivity, a 
state of supersensibility (Clarke and Wittenberg 4). Kant thus breaks away from the previous understandings of the sublime, which considered it the experience of being overcome; for him, it is precisely the subject's resistance against the act of being overpowered that becomes the core of the experience (Ryan 278).

In The Physiological Sublime: Burke's Critique of Reason (2001), Vanessa L. Ryan argues that the Kantian interpretation of the sublime has taken over both continental and English thought. According to Ryan, the key difference between the two sublimes, the Kantian and the Burkean, concerns the nature of the sublime experience: is the sublime experience located in the mind-or rather in the body? The Kantian conceptualization shifts the focus from the external object, the source of the sublime, to the perceiving and thinking mind. In Kant's formulation, the recognition of the superiority of the self over nature-the sublime experience-is also the source of moral feeling (Ryan 278-79). In contrast, Irish philosopher Edmund Burke's treatise A Philosophical Enquiry into the Sublime and Beautiful (1757) considers the physiological aspects of the experience, accentuating the physical affect and simultaneously reducing the role of the conscious mental activity sparked by the sublime (Ryan 270). This leads to a significantly different interpretation of the concept. According to Ryan, "The sublime for Burke is a question not of the subject's increasing self-awareness but of the subject's sense of limitation and of the ultimate value of that experience within a social and ethical context" (Ryan 266). For Burke, the sublime is the recognition of the limitations of the self, in other words, a sense of danger, which awakens the natural instinct for self-preservation. And most importantly: this new, heightened state of self-preservation and activity directs the subject towards sympathy for others. The sublime, for Burke, is the instinct of selfpreservation extended beyond the self and thus refined into moral actions (Ryan 277-78).

Verronen's novels present a highly interesting combination: a protagonist succumbing to the lures of monomania-that is, a depiction of the drive for constraint-together with a narrative device of enumeration-a narrative strategy evoking the sense of vast numbers. The first one aestheticizes restriction, the second one expansion. By juxtaposing these two, both novels foreground comprehension of spatial scales as well as shifts in scale. Nonhuman space, in this case, presents itself as a challenge for human cognition and imagination-but at the same time, this challenge is solved through a cultural-aesthetic mediation. The aesthetics are coupled with ethics: as demonstrated above, the emotional response to the presence of the nonhuman results in an ethical stance. In both novels, the monomaniac obsession that generates limitations and restrictions results in a sense of overcoming these very limitations. The key to this is the physical and spatial contact between the human subject and the nonhuman counterpart. These novels take a stance that resembles closely the Burkean sublime: the sublime that is bodily instead of mental, and physiological instead of intellectual, and 


\section{Sarianna Kankkunen}

produces a moral feeling (Ryan 277-79). In Keihäslintu, the encounter with the bird leads the protagonist to discuss her loss-the loss of the specieswith her husband. The couple mourns together. In Luolavuodet, the massive scale of the caves and their beauty motivates the nihilistic protagonist to share her findings with the local inhabitants-the map she's been crafting, turns out, can be a means of communication, she discovers. Verronen's narratives do not, however, renounce the rational and the intellectual: it is through the scientific work and measure-taking, through the obsession, that the protagonists are able to work their way to the sublime encounter.

\section{Losing a Sense of Proportion: Representing the Nonhuman}

Another case of overcoming limitations is presented in Verronen's caving novel. In the climactic scene of Luolavuodet, the protagonist is determined to finish the map of the caves she has been drafting. In order to do this, she has to venture to an unknown area of the caves, and there, in the heart of the labyrinthine cave system, a scene of wildly running animals, a tour de force of the Neolithic cave art waits for her: "The paintings have been assembled on the cave walls with skill and a careful eye for the formations of rock. They emerge from the stone, they are alive in the stone" (Luolavuodet 12526). ${ }^{6}$ The stone is turning alive, as the vivid images of reindeers, horses, and woolly rhinoceroses gallop to the protagonist's sight. Moreover, the stone is turning human: the scene blends culture with nature, as the nonhuman space shows its intertwining with an earlier human culture. The cave of the novel is presented as a canvas for the human imagination, a shift which emphasizes the role that activities of meaning-making play for the human spatial understanding. The rational quest for mapping the cave is contrasted with the expressive power of the images. Two forms of spatial meaningmaking, the rational and the artistic, or the material and the spiritual, come together.

While presenting his conceptions of the organic's yearning for inorganic, Freud leaned heavily on the nature philosophy of the German Romantics (McGrath). According to Schelling, nature seeks to become spirit and spirit seeks to become nature, a notion that captures the importance the Romantics gave to the idea of constant transformation and sublimation. In nature, the processes of transformation were especially visible in the world of minerals, which was interpreted as a middle realm between the organic and the inorganic. This philosophical doctrine was one of the reasons why the tropes of mine and cave became so central for the German Romantic literature. The mine, a source of precious metals, became a metaphor representing the shift from unconscious to conscious (Ziolkowski 30-32).

In the caving novel, it is not only the stones that turn human, since humans, too, turn into stone. After discovering the cave paintings, the protagonist continues her mapping journey and stumbles into a previously uncharted cave hall. 
The cave hall is almost round, its diameter is twenty meters. The ceiling rises to three meters and is bare of any paintings. The only vertical surface left blank is a calcite curtain of green and white, a beautiful set of petrified folds. It conceals a small recess that I can barely enter if I squeeze myself between the curtain and the painting of the horse.

I shine light on the recess before stepping in. I see a calcite bench, created by the drops falling from the cave ceiling, and on the bench, a dark bundle. The bundle is glazed by thin layers of translucent calcite.

The bundle is a child. A small, delicate child, curled up on her side.

It looks starving and cold. The stone cover over the child must have been formed rather quickly, for the corpse is well preserved: the clothes, the hair, everything is still there.

(Luolavuodet $125-26)^{7}$

The process of stratifying calcite solution which earlier in the narrative, while producing the cave pillars, triggered the protagonist's awe, has preserved the body of a Neolithic cave-dweller. Marvels of the underground world go hand-in-hand with the horrors; the eternities of the nonhuman scale that the caves conceal produce the utmost terror while conjoined with the human condition. Since the development of modern geology in the eighteenth century, caves have been seen as the archives of Earth's history, keepers of "deep time" (see, e.g., Ziolkowski chapter 2; Faflak). But, as Theodore Ziolkowski notes in his study of German Romanticism, already Antiquity and the Renaissance held the belief of the spelunca aevi, or the cavern of eternity. This notion of a specifically underground temporality, widely spread in German culture, was invigorated by the Romantics (Ziolkowski 34). The motif was treated by several authors from Johann Peter Hebel to E.T.A. Hoffman, especially after inspiration from an event in the Falun copper mines in Sweden, where the body of a miner gone missing in 1670 was found in 1719 in a perfect condition, preserved by a vitriol solution (Ziolkowski 53). Verronen's novel regenerates the Romantic motif and the alternation of organic and inorganic. The Romantic belief that inorganic minerals could turn into organic life-forms is represented by the girl turning into a calcite statue; the ancient idea of the cave as the place of deviant temporality is accompanied with the monomaniac's obsession for organizing and preserving the desired object.

This very obsession is at the same time questioned in the scene. At first, the protagonist takes great pains to map out the cave system, to preserve and organize a mass of lifeless stone; what she finds beneath it is a girl turned into stone. The narrative establishes an analogous relationship between the protagonist and the petrified corpse, and the monomaniac is reminded that the union between organic and inorganic might result in feelings of horror. This is, without a doubt, the culmination point of the novel: a moment in which the isolated, self-sufficient monomaniac faces her obsession, a symbolical presentation of the organic's yearning for the 


\section{Sarianna Kankkunen}

inorganic. The stone, which turned alive with the cave paintings, continues its transformation-but it is impossible to say to which direction. Is the calcite girl a symbol of death or a symbol of eternal life? The interpretation vacillates between these two poles and produces a sense of uncanny.

Verronen's contemporary take on the cave motif also modifies its content. Both the legend of the spelunca aevi and Hoffmann's famous novella The Mines of Falun (1819) entail an element of seduction and allure: the underground world tempts the human protagonist with delight and knowledge but in the end, brings nothing but "the sinful knowledge of sensuality, which leads to madness and death" (Ziolkowski 57). Verronen's novel, too, represents the cave as a place of knowledge-the girl, a member of a pre-glacial tribe living in the area, entered the cave to see the paintings the men of her tribe are working on, irritated by her exclusion of the painting ceremonies-but unlike the Romantic version of the motif, the novel doesn't eroticize the underground setting. The emphasis of the novel's cave metaphor is on different ways of knowing: the girl is drawn to the cave because of mythical-religious representations, and the protagonist feels the same temptation in the form of scientific interest, her speleological obsession. The girl is fascinated by the cave paintings representing wild animals, and the speleologist, on the other hand, is enchanted by the work of her own hands, a map of the cave network. They are both driven to danger because of their urge to perceive and represent something nonhuman: animals and their spirits, or the network of caves.

\section{Conclusion}

Verronen's monomaniac protagonists and their all-encompassing passions present simultaneously an analogy and an alternative to the dominant obsession of contemporary times, that of the profit-seeking and economic growth. In Keihäslintu, this is highlighted by the extinct bird, which was lost because of hunting. In Luolavuodet, the idea is even more pronounced, as one of the cave halls discovered by the protagonist tumbles down under a racetrack, the economic powerhouse of the whole region. In the character of a monomaniac, the novels present a critique of what is considered sane or reasonable. The monomaniac is always out of scale-but because of this, they are also more attuned to the nonhuman. The enumerative form, which is linked with the rationalist and scientific pursuits of the protagonists, offers an alternative to the ecomysticism, ecospirituality, and other forms of belief systems often offered as a solution to the crisis of the Anthropocene: aesthetics and empirical research, which make up the intellectual work, are still viable ways of meaning-making.

It would be unjust to suggest, however, that the monomaniac is the role model of the Anthropocene, the ideal human of the nonhuman era. They clearly are not. The monomaniac is a reflection of the isolated, hyperindividual subject: an atom among the others, adrift in the society, deprived 
of any meaningful interaction, lost in the light of their idée fixe. Hope, for them, comes in the form of physical, embodied contact with the nonhuman and the sublime experience, which connects them with their communities, again. The scalar shock of the sublime uncouples the obsessed, isolated mind; it doesn't undo the obsession, but it makes the subjects eager to share their experiences and seek the company of others who might view the world differently but are willing the listen, nevertheless. If these narratives have something to say, I suggest it is this: the encounter between the human and the nonhuman might be a solitary experience, but it has to be passed on to others.

\section{Notes}

1 “'Tiedätkö, eräs ajattelija on sanonut, että jokainen, joka ei halua tietää, mitä on ja on ollut kymmenen kilometrin säteellä hänen kodistaan, on perimmältään sivistymätön ihminen, sanon ääneen. Ajatus tulee mieleen yhtäkkiä-sillä tavalla kuin asioita aina tulee luolassa mieleen-ja se tuntuu riittävän tärkeältä eteenpäin kerrottavaksi.' 'Tarkoittiko hän sen kymmenen kilometriä mitattavaksi myös maan pinnan alapuolelle?" (Luolavuodet 22).

2 "Kartoittaminen tuottaa minulle nautintoa. Selkeät, valmiit luolakartat ovat kauniita. Ne ovat aina epätäydellisiä-mutta se on etu, ei puute. Aina jokin käytävä jatkuu kartan reunan yli jonnekin, jota ei enää kuvassa näy ja josta en tiedä mitään varmaa. On siis vielä lisää selvitettävää; vielä lisää nautintoa siitä, että jotakin löytyy ja selviää.

Sitä on vaikea selittää kenellekään ulkopuoliselle, enkä kovin usein edes yritä. Tavallisesti minulla on tunne siitä, ettei minua kuunnella. Koko asia on niin laaja; siihen sisältyy kaikki. Selitä nyt sitten, miksi tutkit luolia, kun koko ajan uusia syitä löytyy ja entiset menettävät merkitystään” (Luolavuodet 53).

3 "Vladimir M. palasi. Hän kantoi lintua. Se oli ihana, uskomattoman kaunis. Mustaa ja valkoista; eloisat silmät, utelias ilme, komea sulavalinjainen nokka. Musta selkä, pienet siivet, pää, kaula, nokka ja räpylät...Hän käänteli sitä, mittaili jopa. Kuusikymmentä senttiä pyrstöstä päähän, mutta asennosta johtuen päälaki oli viidenkymmenenviiden sentin korkeudella jalustasta. Nokka kahdeksan senttiä, samoin räpylät; koko jalka neljätoista. Pään valkoisten laikkujen halkaisijat neljä ja kaksi ja puoli senttiä. 'Rakastan tätä lintua'” (Keihäslintu 154).

4 As philosophy of emotions, led primarily by Martha Nussbaum, has claimed, emotions are not just impulses but "intelligent responses to the perception of value" (Nussbaum 1).

5 "Luolat ovat täynnä pieniä ikuisuuksia. Kuinka kauan onkaan mennyt siihen kun kalkkikivi on muodostunut eläinten tukirangoissa meren pohjassa; siihen kun meri on väistynyt ja maa kohonnut vuoriksi ja kulunut kukkuloiksi; siihen kun vesi on syövyttänyt kiveen nuo valtavat tilat! Tai siihen kun veteen liuennut kalsiitti on kuivassa luolailmassa saostunut kovaksi mineraaliksi ja muodostanut kiviverhoja ja-pylväitä?” (Luolavuodet 17).

6 "Maalaukset on sijoitettu paikalleen luonnollisesti, aivan kuin ne olisivat syntyneet seinän kivestä, eläisivät siitä ja olisivat osa sitä” (Luolavuodet 12526).

7 “Sali on miltei pyöreä, läpimitaltaan parikymmentä metriä. Katto on runsaan kolmen metrin korkeudella; siinä ei ole maalauksia. Ainoa laaja maalaamaton pystysuora pinta on kaunis valkovihreä kalsiittiverho jähmettyneine 


\section{Sarianna Kankkunen}

laskoksineen. Se kätkee taakseen pienen komeron, jonne voi pujahtaa seinän vieritse, hevosenkuvan ohi.

Valaisen komeroa ennen kuin astun sinne. Näen kalsiittipenkin, jonka katosta putoilleet pisarat ovat synnyttäneet, ja penkillä tumman mytyn, jonka läpikuultava kalsiitti on peittänyt kokonaan, ohuesti.

Mytty on pieni ja hento kyljelleen käpertynyt lapsi.

Se näyttää nälkiintyneeltä ja palelevalta. Kattavan kivikuoren on täytynyt muodostua lapsen päälle hyvin nopeasti, sillä ruumis on säilynyt hyvin, vaatteineen, hiuksineen, kaikkineen" (Luolavuodet 125-26).

\section{References}

Belknap, Robert E. The List: The Uses and Pleasures of Cataloguing. Yale University Press, 2004.

Burke, Edmund. A Philosophical Enquiry into the Sublime and Beautiful. Routledge Classics, 2008.

Clarke, Michael Tavel, and David Wittenberg. "Introduction." Scale in Literature and Culture, edited by Michael Tavel Clarke, Michael Tavel, and David Wittenberg, Springer, 2017, pp. 1-25.

Conrad, Joseph. Heart of Darkness. Penguin, 1994.

European Commission. Eurostat: Population 2019.Demo_R_D3DENS. Updated 15.3.2021. Accessed 8.6.2021.

Faflak, Joel. "Introduction." Marking Time: Romanticism and Evolution, edited by Joel Faflak, University of Toronto Press, 2017, pp. 3-25.

Freud, Sigmund. Beyond the Pleasure Principle. Translated by James Stratchey, Norton, 1975.

Harley, J. B. "Deconstructin the Map." Cartographica: The International Journal for Geographic Information and Geovisualization, vol. 26, no. 2, 1989, pp. 1-20.

Heise, Ursula. Imagining Extinction: The Cultural Meanings of Endangered Species. University of Chicago Press, 2016.

Lassila, Pertti. Metsän autuus. Luonto suomalaisessa kirjallisuudessa 1700-1950. Suomalaisen Kirjallisuuden Seura, 2011.

Lehto, Silene. "Maarit Verronen-oman tiensä kulkija." Kirjasampo.Fi, January 2012, https://www.kirjasampo.fi/fi/node/310.

Majander, Antti. "Liikettä oivalluksen tähden. Maarit Verronen ei ujostele humanistisuutta.” Helsingin Sanomat, 13 December 1996, https://www.hs.fi/ku lttuuri/art-2000003584506.html.

Manovich, Lev. The Language of New Media. MIT Press, 2001.

McGrath, S. J. "Is Schelling's Nature-Philosophy Freudian?” Analecta Hermeneutica, vol. 3, 2011, pp. 1-20.

Moretti, Franco. Modern Epic: The World-System from Goethe to García Márquez. Translated by Quentin Hoare, Verso, 1996.

Nussbaum, Martha C. Upheavals of Thought: The Intelligence of Emotions. Cambridge University Press, 2003.

Ryan, Vanessa L. "The Physiological Sublime: Burke's Critique of Reason.” Journal of the History of Ideas, vol. 62, no. 2, 2001, pp. 265-279.

Smith, Mr Robert Rowland. Death-Drive. Edinburgh University Press, 2010.

Verronen, Maarit. Keihäslintu. Tammi, 2004.

Verronen, Maarit. Luolavuodet. Kirjayhtymä, 1998. 
Weatherill, Rob, editor. The Death Drive: New Life for a Dead Subject? Rebus Press, 1999.

Young, Liam Cole. List Cultures: Knowledge and Poetics from Mesopotamia to BuzzFeed. Amsterdam University Press, 2017.

Ziolkowski, Theodore. German Romanticism and Its Institutions. Princeton University Press, 1990.

Zuylen, Marina. Monomania: The Flight from Everyday Life in Literature and Art. Cornell University Press, 2005. 


\title{
9 Plotting the Nonhuman The Geometry of Desire in Contemporary "Lab Lit"
}

\author{
Marco Caracciolo
}

In a well-known psychological study conducted by Fritz Heider and Marianne Simmel in the 1940s, participants were shown a short animated film with several geometrical shapes-two triangles, a circle, and a rectanglemoving against a white background. The study found that participants were quick to anthropomorphize the shapes' interactions, ascribing agency and personality traits even as these geometrical figures did not display any overt human characteristics. The two triangles, for instance, were widely perceived as "fighting," the circle was seen as a friend (or lover) of the small triangle; when the large triangle "threatens" the circle, the latter finds shelter inside a "building" (the rectangle). The experiment demonstrates how easy it is to interpret abstract visual properties-such as size or the pattern of movement-in terms of affective qualities of human experience, even without any explicit representation of the human body.

The phenomenon I will be investigating in this chapter is, in many ways, the diametrical opposite of Heider and Simmel's film. I will address narratives, and more specifically novels, that focus on recognizable human characters engaging in recognizably human activities. And yet, I will argue that these works ask us to pay close attention to spatial patterns that are abstract and quasi-geometrical. Consider as a preliminary example of this narrative strategy of abstraction an excerpt from "Problems," a short story by John Updike:

During the night, A, though sleeping with $\mathrm{B}$, dreams of C. C stands at the farthest extremity or (if the image is considered two-dimensionally) the apogee of a curved driveway, perhaps a dream-refraction of the driveway of the house that had once been their shared home. Her figure, though small in the perspective, is vivid, clad in a tomato-red summer dress; her head is thrown back, her hands are on her hips, and her legs have taken a wide, confident stance. She is flaunting herself, perhaps laughing; his impression is of intense female vitality, his emotion is of longing. He awakes troubled. The sleep of $\mathrm{B}$ beside him is not disturbed; she rests in the certainty that $\mathrm{A}$ loves her. Indeed, he has left $\mathrm{C}$ for her, to prove it.

PROBLEM: Which has he more profoundly betrayed, B or C?

(Updike 1957-58) 
Three characters are reduced to points in an abstract geometry presented in the language and form of a mathematic problem. The moral dilemma explored by Updike arises from the discrepancy between the space of the setting (where A is close to B and distant from C) and the characters' affective configuration (A's sexual desire for $\mathrm{C}$ ). What comes to the fore is the emotional and narrative significance of the characters' spatial relations: readers are made aware of the abstract schema behind the plot.

A useful point of departure to understand this phenomenon is Alex Woloch's The One Vs. the Many, where Woloch introduces the notions of "character-space" and "character-system" to discuss how characters are situated within plot. Character-space is the semantic space occupied by each individual character, while character-system is the sum total of character-spaces. In Woloch's words, the character-system is "the arrangement of multiple and differentiated character-spaces-differentiated configurations and manipulations of the human figure-into a unified narrative structure" (14). Woloch lays out in a conceptual space the tension between individual consciousness, societal structures, and narrative demands, which he sees as central to the nineteenth-century novel. Moreover, the idea of character-space points to a formalist understanding of characters, as entities existing in an abstract space and dynamically interacting with each other, like the geometrical shapes of Heider and Simmel's film. The formalism of this approach is apparent in statements such as Woloch's claim that the

distribution of attention to different characters, unfolding only through the intersection and entwinement of story and discourse, always generates a rich double vision: we have two superimposed patterns or arrangements that will rarely overlap or coincide and will frequently, and to great effect, diverge significantly.

Interactions between characters are here abstracted-and therefore formalized-into Woloch's language of "patterns or arrangements," which builds on a geometrical understanding of plot structure.

This way of paraphrasing Woloch is reminiscent of Joseph Frank's influential concept of spatial form, by which he referred to the way in which modernist works foreground spatial patterns (through, for instance, strategic juxtapositions) at the expense of plot. But Woloch's approach allows us to appreciate how spatial form and plot are anything but opposed: on the contrary, the plot advances due to structural oppositions internal to the character-system. In a book on space and narrative, Ryan, Foote, and Azaryahu distance themselves from this formalist understanding of space:

When the notion of space refers to a formal pattern, it is taken in a metaphorical sense, since it is not a system of dimensions that determines 
physical position but a network of analogical or oppositional relations perceived by the mind.

Yet one shouldn't be too hasty in dismissing Woloch's character-space and character-system as mere metaphors not relevant to a discussion of the spatial dimension of narrative; on the contrary, as both Heider and Simmel's experiment and Updike's short story show unambiguously, the character-system is not just a set of "analogical or oppositional relations perceived by the mind" but one that can become deeply bound up with the space of the setting.

Likewise, it is possible to see plot as deeply structured by spatial experience. Cognitive linguist Michael Kimmel discusses plot in terms of "image schemata," which are Gestalt-like templates derived from our embodied experience of space (see Hampe and Grady). Examples of image schemata are "balance" or "obstacle," two concepts thatwhile arising from people's negotiation of physical space-can be used to grasp non-physical scenarios (such as the "balance of power" between two nations or inadequate access to education as an "obstacle to equality"). Kimmel suggests that such image schemata also underlie readers' apprehension of plot, generating a "scaffold that lets us recognize the similarity to other scenes populated with agents, props and settings of different size, color, orientation and other details, but the same action logic" (171). My interest in this chapter is in how particular narratives may lay bare this abstract scaffolding of plot by highlighting the geometry of their character-systems. Both novels I will engage with, Jonathan Lethem's As She Climbed Across the Table and Jeanette Winterson's Gut Symmetries, explicitly draw attention to the spatial logic of the narrative progression via two spatial analogies: the chain, in Lethem's novel, and the triangle, in Winterson's. The metaphor of the character-space is thus not a theoretical construct, as in Woloch's model, but something that the narratives themselves thematize.

At the same time, I seek to go beyond Woloch's focus on the human figure. I will argue that, by way of spatial, formal patterns, Lethem's and Winterson's novels take us out of our anthropocentric comfort zone; they ask us to confront realities that are as far from the human form as Heider and Simmel's geometrical shapes-but also much more recalcitrant to an anthropomorphic understanding. My case studies achieve this critique of anthropomorphism in different ways: Lethem introduces within the character-system a physical anomaly akin to a black hole, an entity that is extraneous to human (and human-scale) interactions and yet, incongruously, destabilizes the narrator's marriage; Winterson uses the language of quantum physics to model intersubjective relations between human characters engaged in scientific research, so that sexual desire displaces epistemological curiosity. 
These novels belong to the genre of "lab lit," a term introduced by Jennifer Rohn (see Bouton) to account for fiction that focuses on the personal and professional lives of scientists in a realistic setting (unlike science fiction). Lab lit is closely affiliated with the so-called campus novel but places greater emphasis on how science interacts (and sometimes clashes) with scientists' personal beliefs and experiences. Fiction of this kind becomes a way of enacting some of the intuitions of Bruno Latour's actornetwork theory, particularly its expanding the notion of "actant" to include technical machinery and scientific models (see, e.g., Latour). Examples of this genre include Ian McEwan's Solar and Barbara Kingsolver's Flight Behavior. My case studies offer an innovative take on the genre, bringing out the clash between scientific research and everyday experience-including the experience of sex and love-by drawing on the emotional registers of the absurd (in Lethem's novel) or magical realism (in Winterson's). More specifically, Lethem and Winterson explore the counterintuitive implications of contemporary physics, the same implications that Karen Barad discusses-in a scholarly mode-in Meeting the Universe Halfway. For Barad, "contemporary physics makes the inescapable entanglement of matters of being, knowing, and doing, of ontology, epistemology, and ethics, of fact and value, so tangible, so poignant" (3). Lethem's and Winterson's novels resonate with Barad's quantum physics-inspired critique of distinctions between subject and object, agency and "mere" matter; they enact these distinctions through the narrative pattern created by their characters' romantic and sexual ties: respectively, a chain of displaced desire initiated by a nonhuman entity (in Lethem) and a love triangle that mirrors the underlying structure of physical reality (in Winterson). While seemingly grounded in interactions between human bodies, sexual desire thus serves as a bridge toward the perplexing realities investigated by Barad. The foregrounding of character-space as a formal configuration that underlies the plot is what enables this "leap" from the human scale to the nonhuman. In the next section, before turning to my case studies, I will expand on the challenges involved in this leap. This will also enable me to contextualize my approach vis-à-vis contemporary discussions taking place under the heading of the "nonhuman turn" (see Grusin).

\section{Metaphorical Bridges}

A substantial body of work in ecocriticism has identified "scale" as perhaps the most significant challenge involved in representing nonhuman realities. This challenge works at multiple levels and applies to phenomena as diverse as geological history, the temporality of natural evolution, global warming, or globalization. These "hyperobjects," to use Timothy Morton's (The Ecological Thought 130-32; Hyperobjects) terminology, are distributed in time and space in a way that resists understanding, particularly the kind of understanding that is bound up with everyday experience and perception. 


\section{Marco Caracciolo}

Put bluntly: we may be able to experience the effects of climate change, sometimes dramatically, but climate change per se is a reality that cannot be experienced directly, because it operates on a planetary scale. This is why we need scientific abstraction to generalize beyond the facts of experience. Once we have done so, we are left with the problem of closing the gap between an embodied, experiential understanding of the world and the more abstract scale at which scientific models tend to operate. Timothy Clark calls this challenge "scale framing," noting that a

constitutive, unavoidable element of any representation, evaluation or literary reading is to presuppose or project a certain scale in space and time for its issues. A certain scale must make up the fundamental structure of any imaginable experience, or of any model of the world.

This point about the embeddedness of scale in any cultural representation resonates with arguments advanced by cognitive linguists working in the tradition of George Lakoff and Mark Johnson's Metaphors We Live By. At the same time, work in this area suggests one way in which the gap between the human scale and more abstract phenomena (such as climate change) can be bridged. The point of departure of cognitive linguistics is "experientialism" (see Rohrer) or the notion that our conceptual apparatus is grounded in the human scale, which is in turn defined by the make-up and affordances of the human body. Even abstract concepts are never completely divorced from embodied experience, which is fundamentally spatial. As philosopher Peter Woelert puts it, "spatialization, particularly in the form of metaphoric structures, participates in the formation and functioning of human conceptual thinking in both a constructive and a restrictive sense" (123). This means that spatial experience is constrained by the link between our cognitive and our physical make-up (the "restrictive" element of spatialization), yet spatialization also offers invaluable resources for meaning-making (the "constructive" element), potentially helping us distance ourselves imaginatively from the human scale. As researchers in cognitive linguistics have persuasively argued, metaphor is the cognitive tool that allows humans to leverage embodiment toward more abstract forms of thinking.

Consider, for instance, a visual metaphor used by the World Wildlife Fund in a campaign for climate change designed by Belgian studio VVL BBDO: we see a cone topped by a scoop of melting ice cream that was digitally edited to look like the Earth. This is a version of the famous "blue marble" picture taken during the Apollo 17 mission in 1972-an image whose ideological implications and role in environmentalist discourse have been critiqued by, among others, Ursula Heise in Sense of Place and Sense of Planet (22-25). In this montage, the planet is turned into something as volatile as ice cream. The melting substance stands for our planet's diminishing ice caps; the cone 
is something that we can hold in our hand, yet the consequences of climate change are distributed in time and space. The visual metaphor, thus, reduces a nonhuman phenomenon occurring on a planetary scale to embodied interaction in human-scale space. There may be dangers involved in this metaphorical reduction, as Heise reminds us, since scientific models may be distorted and their complexity flattened to a relatively linear message, but, from the point of view of science communication, there is also a good deal of potential in that the metaphor affords insight into a global scale that we cannot, normally, experience directly. The conceptual insight into the morethan-human goes hand in hand with an affectively charged realization: comparing the Earth to a scoop of melting ice cream complicates and blurs boundaries between the human-made and the natural, the effects of human activities and climatological processes.

My case studies in this chapter also build on and extend metaphorical language to question the common-sense separation between human societies and nonhuman realities. Just like the melting ice cream metaphor, these novels use embodied experience as a bridge toward a phenomenon that resists human-scale imagination. But whereas the image of the ice cream foregrounds perception and physical action (grasping, eating), Lethem and Winterson explore the equally embodied experience of sexual desire; more specifically, they draw on sexual desire to gain purchase on the puzzling nonhuman (that is, nonhuman-scale) realities revealed by physics. Clearly, this use of sexuality resonates with a tradition of conceiving sex as an experience that takes us beyond ourselves, putting us in touch with otherness in ethical and even spiritual terms, as in many strands of mysticism (see Cornwall). But the otherness known through sex in these novels is radical, perhaps as radical as it gets. As Morton puts in Humankind, "What could be more nonhuman than a blackhole?" (Humankind 160). The notion of falling in love with something like a black hole-the premise of Lethem's novel-involves a good deal of humorous incongruity. The stakes of such incongruity are high and raise fundamental questions about the interrelation between humans and realities beyond the human scale. Perhaps, and this is the core idea I am developing in this chapter, sexual desire can serve as a way of thinking-metaphorically-beyond the anthropocentric subject; it can pave the way for an embodied understanding of the co-constitution of human societies and cosmic, geological, or climatological phenomena beyond the human scale.

For this to happen, everyday notions of sexuality have to be transformed and defamiliarized. This defamiliarization follows the logic that I posited in a co-authored article on nonhuman characters in fiction (Bernaerts et al.): both Lethem and Winterson build on recognizably human experiences of sex and physical attraction, but the irruption of nonhuman elements into the narrative unsettles and transfigures these experiences, creating a sense of nonhuman alterity. In this process, the abstract and quasigeometrical nature of the characters' spatial arrangement is emphasized. 


\section{Marco Caracciolo}

Put otherwise, the foregrounding of the character-system, in what is fundamentally a gesture of narrative abstraction, helps extract sexuality from its anthropocentric set-up. My approach thus revisits Luciana Parisi's notion of "abstract sex," which seeks to undermine dichotomies between nature and culture by seeing sex as something that affects "all levels of organization of a body-biological, cultural, economical [sic] and technological" (10). But here the abstraction is scaled up to the level of phenomena that are fundamentally extraneous to the human body and its technological augmentations. Further, it is abstraction realized in a particular narrative pattern, and the nature of this pattern is revealed to be deeply spatial and geometrical.

\section{Becoming Lack}

In addition to their generic affiliation with "lab lit," my case studies have two things in common: they were first published in 1997, and they have a scientist named, certainly not coincidentally, "Alice" among their main characters. In Lethem's As She Climbed Across the Table, Alice is the narrator's partner. She is a physicist working in a department that, as the narrator puts it, "specialized in the pursuit of tiny nothingness" (3). The physicists make a major breakthrough when they are able to generate and stabilize a bubble of nothingness, which—they speculate-could lead to another universe, although no one knows exactly what lies beyond it. As the narrator (who is an anthropologist) observes, various metaphors are deployed in an attempt to understand this physical anomaly, and they are all space-based metaphors: "I was liking the way it defied theory, the way it had the physicists scrambling. Breach, gap, gulf, hub-the lack was obviously an explosion of metaphor into a literal world" (26). The anomaly thus serves as a stand-in for the deeply perplexing realities explored by contemporary physics: it is fundamentally nonhuman, in that it defies anthropocentric conceptualization and opens the door to a reality not commensurable with human existence. It is only when rumors about the discovery begin spreading through campus that the metaphors stop spinning, and the physical anomaly receives the humorous nickname "Lack." From this point onward, Lack becomes a full-fledged character in Lethem's novel: it no longer only operates in the realm of the symbolic, as a paradoxical embodiment of the nonhuman, but it becomes central to the mechanics of the plot as well.

Lack is defined by its spatial form-it is a portal-like structure sitting, rather incongruously, on a table in a university lab. But the same spatial language is used by the narrator to refer to embodied intersubjectivity. This is, for instance, the description of an embrace between the narrator and Alice:

I crawled across the margin of floor and held her. I put my arms around her shoulders, my face in her hair. We cried together. Our bodies made 
one perfect thing, a topological whole, immutable, complete, hollows turned to each other, hollows in alliance. We made a system, a universe.

Sex itself is likened to an interaction between abstract spaces: "II feel an initial singularity,' I whispered. 'Pressed against your spherical symmetry.' Nothing. She was deaf to me. 'I want to adhere my Schwarzshild [sic] space to your De Sitter space,' I said" (4). The characters' bodies-and their somatic experience of sexual desire-are thus metaphorically blended with the theoretical entities of geometry (a "topological whole," "spherical symmetry") and physics itself (the "De Sitter space").

"Blended" is here a technical term, referring to Gilles Fauconnier and Mark Turner's account of "conceptual integration" or "blending" as an operation intrinsic to the workings of metaphor: for Fauconnier and Turner, metaphor creates an imaginative space-the blend-in which source and target of the metaphor (in this case, respectively, scientific language and human embodiment) converge and interact. But the directionality of Lethem's metaphorical blending is particularly intriguing. One of the basic assumptions of cognitive metaphor theory, as we have seen above, is that metaphor tends to explain the abstract and intangible via the concrete (see, e.g., Semino 6). Understanding an abstract idea, for instance, is ordinarily referred to as "grasping" in English, with an extension of the bodily action of grasping a physical object. Thus, the experience of physical interaction in space is a crucial resource for metaphorical language, because it gives language users purchase on realities that cannot be experienced directly. This is precisely what happens in the case of the melting Earth visual metaphor discussed above. Lethem's treatment of the human body works in the opposite way, which helps explain its counterintuitive nature: the characters' bodies are defamiliarized by being compared to more abstract, mathematical realities.

But Lethem goes even farther than that. In fact, the conceit of As She Climbed Across the Table is that science is not just a source of metaphorical expressions for the human body; rather, the perplexing realities revealed by science become a literal object of sexual desire: Alice-the narrator's partner-falls in love with Lack. She tries to enter Lack, in what is obviously a sexually loaded gesture, and is repeatedly rejected. Concurrently, a woman named Cynthia Jalter makes sexual advances toward the narrator, and he-still in love with Alice-cannot reciprocate. This is the basic structure, the character-system, at the heart of Lethem's novel: the tensions it generates sustain the plot's movement from the beginning to the end. The narrator explicitly calls attention to the spatial form of this system: "I was numb to Cynthia Jalter the way Alice was numb to me, the way Lack was numb to Alice. Were we links in a chain?" (107). The image of the chain ties the characters together, in an explicit spatialization of the novel's character-system, but 


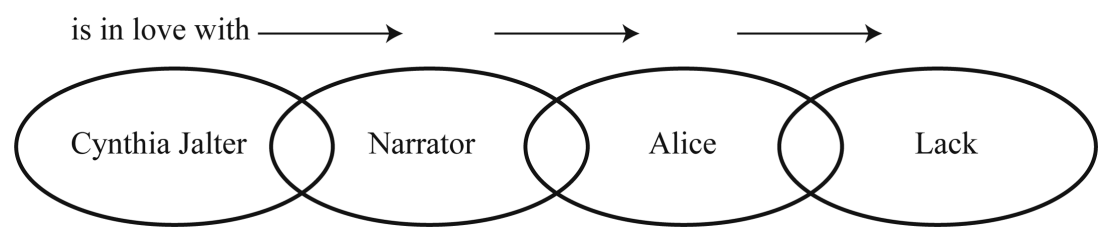

Figure 9.1 The chain-like character-system of Jonathan Lethem's As She Climbed Across the Table. Author's creation, reprinted from Marco Caracciolo, Narrating the Mesh: Form and Story in the Anthropocene. University of Virginia Press, 2021.

it also suggests how the plot is set in motion by the irruption of Lack, a manifestation of the nonhuman in the human-scale world of a college campus. The "chain reaction" initiated by Lack is one where desire is continuously displaced, passed on to the next link without the possibility of reciprocation: Cynthia Jalter is in love with the narrator, who is still in love with his partner, Alice, who is in love with Lack (see Figure 9.1). The chain thus suggests unexpected linkage between levels of reality that both cognitive predispositions and culture present as separated by an unbridgeable gulf: namely, embodied experience, including the experience of sexuality, and the phenomena that fall within the scope of contemporary physics. Put otherwise, Lack brings together the human-scale and the nonhuman through the chain of embodied desire the character gives rise to.

It is perhaps not a coincidence that the novel ends when the narrator, an anthropologist, folds the chain back on itself. In his pursuit of Alice, he confronts Lack in the physics laboratory and eventually climbs onto a table next to it, in an attempt to enter Lack. The scene is narrated in explicitly sexual language: "I gripped the sides of the table and vaulted up, first on my knees, then flat on my stomach. Or almost flat. I had an erection. It was rock-hard and almost insensate. Some part of me had mistaken this for a sexual event" (174). That it is not a sexual event, at least not in the familiar sense, is shown by its result: the narrator emerges into a world that resembles the old one in its spatial layout, but whose appearance is greatly simplified-abstracted, one could say. One of the buildings on campus, for instance, "had been robbed of its color, texture, vitality. It looked like it had been reproduced in chewing gum" (175). The narrator's intercourse with the nonhuman Lack destabilizes his experience of space, and causes the abstraction of the character-system to trickle down into the diegetic space of the storyworld. But this is only a first step. When the narrator attempts to enter Lack a second time, his experience of space collapses completely, and so does his embodied consciousness: "I lacked, as I completed a quick inventory, legs or arms to swim or struggle with, mouth 
to scream with, nose, ears, etc.-i.e., the whole deal, works, caboodle. My body wasn't there" (186; emphasis added). The narrator merges with Lack, becomes himself a lack, a nothingness-and this is the only mode of being in which he can be reunited with Alice. In the final scene of the novel, Alice appears-literally out of nowhere-and steps onto the table facing Lack's "entrance": in the narrator's words, "I saw her eyes then, as she came across, and they were clear, and full of love" (192).

What just happened? Simply put, the human narrator and the nonhuman other, the Lack, converge into an experience of pure, abstract, and yet deeply affective pattern: this impression of abstraction is reinforced by the elusive movement of "coming across," which is an echo of the climbing in novel's title, of course. Space, embodiment, and quasi-geometrical abstraction: these are the conceptual domains brought together by Lethem's novel as it establishes connections between the quotidian and arcane physical models. These connections may be based on metaphors for human intersubjectivity, as we have seen, but they are more than just metaphorical; they are performed in the novel's plot through its chain-like structure.

\section{Gut Thinking}

If the spatial form underlying Lethem's narrative is a chain, Winterson's novel Gut Symmetries builds on the familiar image of a "love triangle." The protagonist, Alice, is again a physicist; she meets Jove, a famous physicist working at the Princeton Institute for Advanced Studies, and they start an extramarital relationship. Jove's wife, Stella, finds out about the affair, and decides to openly confront Alice. But when that happens, the unexpected ensues: Alice and Stella fall in love. Figure 9.2 is a visualization of this triangular narrative configuration, or character-system.

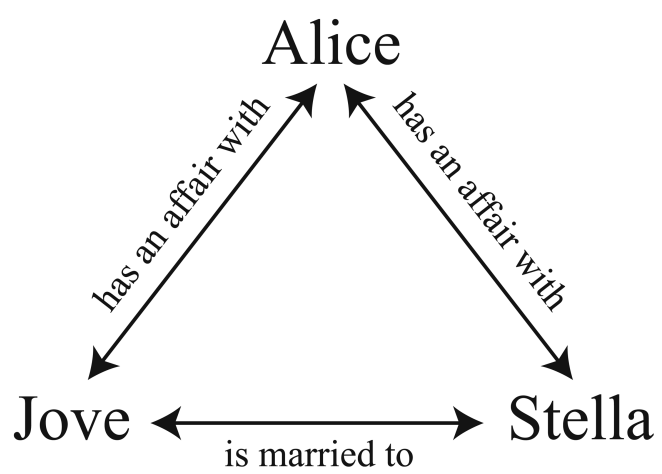

Figure 9.2 The symmetrical character-system of Jeanette Winterson's Gut Symmetries. Author's creation. 
Just like Lethem's novel with the image of the chain, Winterson's narrative draws attention to the abstract, geometrical structure underpinning the plot:

If you want to know how a mistress marriage works, ask a triangle. In Euclidean geometry the angles of a triangle add up to 180 degrees and parallel lines never meet. Everyone knows the score, and the women are held in tension, away from one another. The shape is beguiling and it could be understood as a new geometry of family life.

This character-system is immediately absorbed into the work's thematic structure and justified at the level of the novel's engagement with contemporary physics: the narrator emphasizes the way in which this "new geometry of family life" mirrors the "symmetries of the three fundamental forces, weak force, strong force, electromagnetic force. Difficulties begin when these three separate forces are arbitrarily welded together. His wife, his mistress, met" (99). The concept of spatial symmetry is thus directly foregrounded, providing linkage between the embodied intersubjectivity of sexual attraction and the invisible fabric of physical reality. This conceptual blending, to use again Fauconnier and Turner's term, is facilitated by Winterson's adoption of a third kind of vocabulary in addition to love and science-namely, the premodern and prescientific discourse of alchemy.

We read at the beginning of the novel that the

mediaevals were entrail-minded and Paracelsus often delivered his lectures over a scalpelled corpse. This was not the nineteenth-century model of diagnosis by pathology. It was, if it was anything, diagnosis by cosmology. Paracelsus was a student of Correspondences: "As above, so below." The zodiac in the sky is imprinted in the body. "The galaxa goes through the belly."

The passage suggests a fundamental symmetry between the somatic and the cosmic, which in turn inflects and reinforces the parallel between human bodies, with their inevitable attractions, and the physical structure of reality. This parallel is captured by the pun in the novel's title: "gut" is, of course, the bodily organ, but it is also a reference to the grand unified theory (GUT in short) that is the Holy Grail of contemporary physics-a theory capable of uniting "the strong, weak, and electromagnetic quanta in a sympathetic symmetry that would include gravity," as the novel explains (99).

Both through its symmetrical character-system and through the conjoined discourses of physics and alchemy, the novel suggests that "human nature and the cosmos are patterned together" (100), another thematization of abstract pattern. Sexuality is, for Winterson, a way of sensing this 
entanglement and metaphor is its stylistic manifestation. Consider the following passage:

What did we hope for, heating and re-heating ourselves to absurd temperatures? As matter heats up it is subject to demonstrable change. Boiling in our vessel, our water molecules would begin to break down, stripping us back to elemental hydrogen and oxygen gases. Would this help us to see ourselves as we really are?

Heated further, our atomic structure would be ripped apart. He and she as plasma again, the most common state of matter in the universe.

If we had the courage to cook ourselves to a quadrillion degrees, the splitting, the dividing, the ripping, the hurting, will be over. At this temperature, the weak force and the electromagnetic force are united. A little hotter, and the electroweak and the strong force move together as GUT symmetries appear.

And at last? When gravity and GUTs unite? Listen: one plays the lute and another the harp. The strings are vibrating and from the music of the spheres a perfect universe is formed. Lover and beloved pass into one another identified by sound.

This sexual encounter erases boundaries, first, between the subjects participating in it, and, second, between their bodies and the physical world, in a striking case of what Stacy Alaimo calls "transcorporeality"-the extension of human embodiment into the inanimate or natural world. Bodies function like particle accelerators, and in fact the extended metaphor underlying the passage compares sex to heating up matter in a physical experiment. This metaphorical process allows the lovers to descend into the atomic structure of reality, exposing the fundamental forces of physics and even sensing their coming together in a unified vision that physics itself has so far been unable to achieve. What is left, after this climax, is a sense of pure patterning, here captured in musical terms. This abstract rhythmicity-the "music of the spheres"-erases boundaries between embodied subjectivity and physical matter, thus performing a critique of dualistic thinking. The pivotal image of the "gut" corroborates this critique. Reminiscent of Elizabeth Wilson's concept of "gut feminism," the gut is-for Winterson - the organ in which the body embraces the outside world. Ordinary perception takes in the world from a distance, which can be more or less significant but always lends itself to a dualistic reading ("this is me," "this is the world I perceive"). By contrast, the gut absorbs and incorporates in a way that leaves no doubt as to the biochemical continuity between our bodies and the supposedly "external" reality. Winterson seeks to elevate this organ to a mode of thinking: "This story is a journey through the thinking gut" (13).

The abstract notion of symmetry, encoded as it is in the novel's charactersystem, is central to the materialist project of the thinking gut: the characters' love triangle lays out in conceptual space the symmetry that, according 


\section{Marco Caracciolo}

to Winterson, encapsulates the affective patterning of the physical world, as revealed by science. In this way, Winterson's narrative works toward a sense of intimate, and constitutive, interrelation between our embodied experience and physical levels of reality beyond the human scale.

\section{Conclusion}

In his seminal Reading for the Plot, Peter Brooks argued that "narratives portray the motors of desire that drive and consume their plots, and they also lay bare the nature of narration as a form of human desire" (61). Brooks thus draws attention to how desire, including sexual desire, is not just one of narrative's many thematic interests but a key factor in its progression: desire makes a series of events tellable; on the reception side of things, desire sustains an audience's emotional involvement and steers it, in anticipation, toward the narrative outcome. But desire, for Brooks and for virtually all other theorists of narrative, is "human desire," as this quote makes explicit.

My case studies explore the consequences of displacing desire through the language and models of physics. In these narratives, human desire embraces entities that are deeply and constitutively nonhuman: scientific abstractions-a black hole-like nothingness, the fundamental forces of physics-that not only fall outside of the scope of the human, or even the animate, but resist human perception and everyday experience. The main difference between the two novels is that, in Lethem's As She Climbed Across the Table, the nonhuman makes a direct intervention in the plot, becoming a full-fledged (if humorous) character; by contrast, in Winterson's Gut Symmetries the nonhuman is both a metaphorical frame superimposed on sexual desire and the paradoxical outcome of that desire: sex puts the characters in touch with the physical structure of reality.

Both Lethem and Winterson conflate sexual arousal, romantic attachment, and scientific curiosity, and in doing so they endow nonhuman realities with a degree of experiential substance. These novels thus participate in the project outlined by Kathryn Hume in a discussion of fiction's engagement with science: "we must augment the revelations of science if our view of the universe and of ourselves is to give us a sense of meaning. We need to experience the cosmos imaginatively as well as analytically" (47-48). In my two examples, this imaginative augmentation is incongruous in that it contradicts readers' basic ontology, a sense of separation-partly fostered by culture, partly grounded in evolutionary biases-between the animate and the inanimate, the subjective and the material.

Lethem's and Winterson's critique of dualism is articulated not just at the thematic level but through formal patterns that span the gap between literary devices and the formal abstraction involved in scientific models. The argument laid out in this chapter thus ties in with the recent reappraisal of form in literary studies, within the movement known as New Formalism (Levinson; Levine). But while scholars like Levine stress the continuity between literary form and 
social and political formations, my specific interest was in how formal strategies at both the stylistic and the plot level can help literary fiction move beyond what Monika Fludernik calls narrative's "anthropomorphic bias" (13), incorporating scientific models. At the stylistic level, we have seen that both my case studies make use of metaphorical expressions bridging between the human, and in particular human embodiment, and the nonhuman objects of scientific investigation. These scientific realities are blended with the human scale, as when Lethem's style transfigures bodies into geometrical shapes or Winterson compares sex to the breakdown of matter at extremely high temperatures. This process of blending is counterintuitive, I have argued, because it renders the quotidian body in terms of puzzling and unfamiliar concepts-thus resisting and reversing a well-known tendency to use bodily metaphors to understand abstract ideas.

Working alongside metaphorical blending is the foregrounding of spatial patterns through the characters' configuration or the character-system in Woloch's terminology. In both novels, the patterning of human-nonhuman desire gives rise to a particular intersubjective constellation, which is explicitly named and thematized by the text: it takes the form of a chain in Lethem's narrative, a triangle in Winterson's. There is a mechanism of abstraction at work here, such that the novels expose the spatial logic of their own organization: how even the most sophisticated and intricate plots build on a quasi-geometrical arrangement of characters and situations. This move toward abstraction is diametrically opposite to the anthropomorphization of geometrical figures I have discussed at the beginning, via Heider and Simmel's study. Ultimately, what Lethem and Winterson attempt is much more defamiliarizing, insofar as their narratives seek to erase the distinction between human agents and nonhuman things and processes. Just as human characters fulfill a structural role in the narrative that exceeds their conscious intentions, nonhuman entities radically shape the plot. Through their extension of desire across the human-nonhuman divide, and through their strategic laying bare of the character-system as a conceptual space, these novels probe the deep interrelatedness of human and nonhuman realities. ${ }^{1}$

\section{Note}

1 While working on this chapter I received funding from the European Research Council (ERC) under the European Union's Horizon 2020 research and innovation program (grant agreement no. 714166). For more on narrative and the nonhuman, including an extended version of some arguments offered in this chapter, see also my Narrating the Mesh, especially chapters 4 (on nonhuman actants) and 6-7 (on metaphor).

\section{References}

Alaimo, Stacy. Bodily Natures: Science, Environment, and the Material Self. Indiana University Press, 2010. 


\section{Marco Caracciolo}

Barad, Karen. Meeting the Universe Halfway: Quantum Physics and the Entanglement of Matter and Meaning. Duke University Press, 2007.

Bernaerts, Lars, et al. "The Storied Lives of Non-Human Narrators.” Narrative, vol. 22, no. 1, 2014, pp. 68-93.

Bouton, Katherine. "In Lab Lit, Fiction Meets Science of the Real World." The New York Times, 3 December 2012, https://www.nytimes.com/2012/12/04/science/in -lab-lit-fiction-meets-science-of-the-real-world.html.

Brooks, Peter. Reading for the Plot: Design and Intention in Narrative. Knopf, 1984.

Caracciolo, Marco. Narrating the Mesh: Form and Story in the Anthropocene. University of Virginia Press, 2021.

Clark, Timothy. Ecocriticism on the Edge: The Anthropocene as a Threshold Concept. Bloomsbury, 2015.

Cornwall, Susannah. Theology and Sexuality. SCM Press, 2013.

Fauconnier, Gilles, and Mark Turner. The Way We Think: Conceptual Blending and the Mind's Hidden Complexities. Basic Books, 2002.

Fludernik, Monika. Towards a "Natural” Narratology. Routledge, 1996.

Frank, Joseph. The Idea of Spatial Form. Rutgers University Press, 1991.

Grusin, Richard. "Introduction." The Nonbuman Turn, edited by Richard Grusin, University of Minnesota Press, 2015, pp. vii-xxix.

Hampe, Beate, and Joseph E. Grady. From Perception to Meaning: Image Schemas in Cognitive Linguistics. De Gruyter, 2005.

Heider, Fritz, and Marianne Simmel. "An Experimental Study of Apparent Behavior." The American Journal of Psychology, vol. 57, 1944, pp. 243-259.

Heise, Ursula K. Sense of Place and Sense of Planet: The Environmental Imagination of the Global. Oxford University Press, 2008.

Hume, Kathryn. "Science and Imagination in Calvino's 'Cosmicomics." Mosaic, vol. 15 , no. 4, 1982, pp. 47-58.

Kimmel, Michael. “Analyzing Image Schemas in Literature.” Cognitive Semiotics, vol. 5, 2009, pp. 159-188.

Lakoff, George, and Mark Johnson. Metaphors We Live By. University of Chicago Press, 1980.

Latour, Bruno. Reassembling the Social: An Introduction to Actor-Network-Theory. Oxford University Press, 2005.

Lethem, Jonathan. As She Climbed Across the Table. Vintage, 1998.

Levine, Caroline. Forms: Whole, Rhythm, Hierarchy, Network. Princeton University Press, 2015.

Levinson, Marjorie. “What Is New Formalism?” PMLA, vol. 122, no. 2, 2007, pp. 558-569.

Morton, Timothy. Humankind. Verso, 2017.

Morton, Timothy. Hyperobjects: Philosophy and Ecology after the End of the World. University of Minnesota Press, 2013.

Morton, Timothy. The Ecological Thought. Harvard University Press, 2010.

Parisi, Luciana. Abstract Sex: Philosophy, Biotechnology and the Mutations of Desire. Continuum, 2004.

Rohrer, Tim. "Embodiment and Experientialism." The Oxford Handbook of Cognitive Linguistics, edited by Dirk Geeraerts and Hubert Cuyckens, Oxford University Press, 2007, pp. 25-47.

Ryan, Marie-Laure, et al. Narrating Space / Spatializing Narrative: Where Narrative Theory and Geography Meet. Ohio State University Press, 2016. 
Semino, Elena. Metaphor in Discourse. Cambridge University Press, 2008. Updike, John. Problems and Other Stories. Random House, 1979.

VVL BBDO. Ice Cream. 2004, http://www.unep.fr/scp/communications/ad/details.a sp id $=49872 \&$ cat $=3$.

Wilson, Elizabeth A. Gut Feminism. Duke University Press, 2015.

Winterson, Jeanette. Gut Symmetries. Random House, 1997.

Woelert, Peter. "Human Cognition, Space, and the Sedimentation of Meaning." Phenomenology and the Cognitive Sciences, vol. 10, no. 1, 2011, pp. 113-37.

Woloch, Alex. The One vs. the Many: Minor Characters and the Space of the Protagonist in the Novel. Princeton University Press, 2003. 


\title{
10 Lithic Space-Time in Lyric \\ Narrating the Poetic Anthropocene
}

\author{
Brian J. McAllister
}

This essay has two beginnings: the first aesthetic, the second ecological. The first beginning: Viktor Shklovsky's essay “Art as Technique” (1916), which distinguishes art's purpose, "to impart the sensation of things as they are perceived and not as they are known," from its technique, "to increase the difficulty and length of perception" (16). For Shklovsky, this difficulty and length reinforces "the artfulness of an object; the object is not important" (16). His example is lithic: art makes "the stone stony." Its defamiliarizing conditions render objects as sites of contemplation and invigoration. In stone, defamiliarization renders bedrock as a thing in the world. The second beginning is September 2016, when the Anthropocene Working Group, part of the International Commission on Stratigraphy, proposed formal acknowledgement of a new geological epoch and set its measurable beginning in the mid-twentieth century, when human activity began to "leave a permanent record in the Earth's strata," ending the Holocene's 12,000 years of climatic stability ("Media Note" n. pag.). This proposal identifies humans as a geological force while also acknowledging our incapacity to control effects of that transformation, which are "geologically long-lasting" and "effectively irreversible" ("Media Note" n. pag.).

These two beginnings, a century apart, emphasize relationships between aesthetics and geology-the way that the Anthropocene and its radical ecological changes defamiliarize our sense of space and time while also asking that we turn to aesthetics to grasp our position in geological history. Understanding the Anthropocene and our situation in it transforms relationships between subject and object, human and nonhuman, figure and ground. Aesthetic renderings of human-lithic disjunctions can be found in the lyric spaces of landscape poetry, specifically poetry focused on the geological, using James Phelan's sense of lyric as a rhetorical mode involving "somebody telling somebody else ... on some occasion and for some purpose that something is," a definition he distinguishes from narrative, a mode focused on something that "happened" (22). ${ }^{1}$ In their lyric modes, these poems engage scales of time and space that complicate ontological boundaries between human and nonhuman. Three poems, with roughly forty years between each publication, negotiate these disparate scales of 
space-time through their attention to the lithic. Hugh MacDiarmid's "On A Raised Beach" (1934) overwhelms human space-time by confronting its feebleness on lithic scales and foregrounds lithic space-time in order to reflect on artistic ephemerality. Robert Smithson's lyric-narrative hybrid, "Strata: A Geophotographic Fiction" (1970), shifts its emphasis to human spatiotemporality as site for the production of problematic lithic narratives. Lastly, Brenda Hillman's “A Geology" (2001), prioritizes neither human nor lithic, instead working to balance spatiotemporal scales. In her work, we see the clearest instance of lyric struggling to link geologic and human while rendering its incapacity at the level of form. Each poem models spatiotemporal flexibility, negotiating engagements between seemingly disparate scales of space and time.

In David Herman's sense, these works produce polychronic frameworks that "root themselves in more than one place in time" ("Limits" 75). But, rather than focusing solely on multiple temporalities, these poems present interconnections of space and time within these frames. They explore the "aeonic insistence" of stone that, for Jeffrey Cohen, "thickens time into multiple, densely sedimented, and combustively coincident temporalities" (78). By engaging with radically different scales of space and time, these poetic structures articulate the complexities of climate change, establishing perspectives in which ecological transformation becomes more seeable and speakable.

This critical method builds on Jesse Matz's sense of "time-work" that sees narratives as phenomenological sites for temporal transformation, what he calls "forms of imagination necessary to rethink the singularities of time today and to subject its totalities to the diversity of narrative's provisional designs" (281-82). But, whereas Matz focuses on time, the Anthropocene demands attention to the interrelationship between time and space. The poems in this study engage those questions directly, offering sites for rethinking the totalities of space-time through scalar engagements between human and lithic spatiotemporality. In other words, they tentatively imagine structures of space and time in which disparate scales interact to produce provisional Anthropocenic narratives, whether they are narratives about the conditions of living in the Anthropocene or narratives that situate the Anthropocene in larger planetary histories. ${ }^{2}$

\section{Space-Time and Landscape Poetry}

For many, the Anthropocene and climate change have reframed our relationship with time. ${ }^{3}$ In Andreas Malm's terms,

There is no synchronicity in climate change. Now more than ever, we inhabit the diachronic, the discordant, the inchoate: the fossil fuels hundreds of millions of years old, the mass combustion developed over the past two centuries, the extreme weather this has already generated, 
the journey towards the future that will be infinitely more extremeunless something is done now - the tail of present emissions stretching into the distance ... history has sprung alive, through a nature that has done likewise.

Malm goes so far as to state that climate change shifts conditions of time and space from Fredric Jameson's postmodernity, in which space dominates time, to a "condition of time and nature conquering ever more space" (11). For Malm, climate change thrusts time back into postmodernity's constant presence. Our inability to think beyond the near future creates the illusion "that the future now in the balance is a relatively short one," when in fact the consequences of climate change will last for thousands of years (8). The Anthropocene collapses two incongruent timescales: a human scale of days, months, years, or centuries and a lithic scale of thousands, millions, or tens of millions of years. At the planetary level, the lithic is the most alien temporality possible, if we understand temporality in Monika Fludernik's terms as "the choice of significant episodes that establish a configuration and meaning for [narrative]" (608). And yet, as Dipesh Chakrabarty explains, understanding climate change and the transformations of the Anthropocene requires moving "back and forth between thinking on these different scales at once" (9).

Still, I would not go as far as Malm to say that climate change reasserts time's dominance over space. Instead of shifting one dominant to another, climate change and the Anthropocene resist the conceptual separation of time and space. In the geologic narrative, they become more difficult to untether, unlike their easier conceptual separation at human scales. Of course, even at human scales, space and time can only be conceptually separated. Their actual fusion at any scale has long been acknowledged, whether in Albert Einstein's special theory of relativity, Hermann Minkowski's geometrical space-time, Joseph Frank's spatial form, Gaston Bachelard's phenomenological space, Henri Lefebvre's dialectical lived space, or the "spatial turn" in narrative theory (e.g., in the work of Marie-Laure Ryan). Similarly, M. M. Bakhtin's chronotope emphasizes "the intrinsic connectedness of temporal and spatial relationships that are artistically expressed in literature" (84). In the Anthropocene, intrinsic connectedness becomes extrinsic.

This inseparability and co-presence of human and geologic scales of space-time presents a narrative problem: human narratives exist within the lithic's nonhuman spatiotemporal frames. Studies of the nonhuman, like William Nelles's or David Herman's work on animal narratives, often discuss instances in which human and nonhuman space-times exist on relatively equivalent scales (see Herman, "Modernist"). Even narratives beyond human scales, such as Italo Calvino's interstellar narrator in Cosmicomics (1965), understand nonhuman narrators through human cognitive structures. This move from nonhuman to human makes sense; readers 
engage narratives through anthropocentric frames. But the Anthropocene requires a stranger move, ejecting us from a position that sees geological history as stable ground for dynamic, human temporality. Rather than understanding geological history through a human lens, human space-time must also be understood on a geological scale, in Timothy Morton's sense, "thinking of beings on a number of different scales, none of which has priority over the other" (22). Having joined the exclusive club of geological forces-or, more accurately, having recognized our membership-humans must negotiate these two scales of space and time in order to tell our unified story, if such a unified story is even possible. This negotiation transforms phenomenological experience of space-time and challenges core aesthetic concepts by which we engage these spatiotemporal dimensions. In Shklovsky's sense, it defamiliarizes the way we understand and represent the relationship between culture and nature or between humans and the planet on which they reside.

As Stephen S. Sawyer describes, the Anthropocene requires

not simply a reconsideration of the role of man in climate change and the relationship between the natural and the cultural, but a somewhat mind-bending reorientation of the temporal scales that make up a sophisticated historical method. Indeed, in the Anthropocene, just as culture no longer sits upon a natural context or backdrop, the short term does not sit upon the long term, but quite the opposite: it is the short term that governs the long. This could have important consequences for how we construct historical and literary narrative.

The landscape poems examined in this essay offer this "mind-bending reorientation" through interactions between lithic and human space-times: landscape articulating and negotiating congruence between disparate, disorienting scales. Rather than scalable systems of spatiotemporality, these lyric texts notice and negotiate complicated, interacting, and dynamic spatiotemporal registers. That is, lyric can teach spatiotemporal flexibility, moving readers back and forth between a sense of the planet at human and vastly nonhuman scales of space and time.

Despite their attention to the land, Hillman, Smithson, and MacDiarmid's poems are not conventional examples of landscape poetry, i.e., pastoral reflections of "nature" disconnected from humanity. They are better situated with poets like Basil Bunting, Lorine Niedecker, Ian Hamilton Finlay, Geraldine Monk, Maggie O'Sullivan, and Thomas A. Clark. Harriet Tarlo labels these authors "radical landscape poets," who interrogate gaps between language and world in landscape representations (7). They resist oversimplification by challenging boundaries between ecology and society, defying pastoral sentimentality, and refusing harmonious depictions of the rural, instead representing ecology in flux and dependent on the interaction 
between human and nonhuman. This flux imagines transformed relationships between human and lithic space-time.

This attention to lithic spatiotemporality is different from work by scholars like Wai Chee Dimock, who situate literary history in deep time through expansive historiographic narratives. ${ }^{4}$ Instead, defamiliarizing techniques within these poems negotiate this vast spatiotemporality and are more attuned to Mark McGurl's "posthuman comedy," critical fictions that "draw together a number of modern literary works in which scientific knowledge of the spatiotemporal vastness and numerousness of the nonhuman world becomes visible as a formal, representational, and finally existential problem" ("Posthuman" 537). For McGurl, literature is a scaling device that defamiliarizes by moving through scales of perception. The posthuman comedy, however, tests this process by scaling to extents that undermine accessibility. Ultimately, these works cannot succeed; scaling breaks down. And while failure points to the limitations of human imagination, enacting that failure allows us "to know and feel our presence in the world as something in particular. Although the opposite is equally true, it's only in the failure of imagination that we find a reason to live" (McGurl, "Posthuman" 542).

Anna Tsing recognizes scalar expansion as transformative to both form and content, cautioning against what she calls "precision nesting:" expansion placing smaller scales within identically structured larger scales. Such a system can change scales without changing the frame in which it exists. Colonial plantations, global distribution, and contemporary business models all adhere to this idea of precision nesting. In contrast, Tsing identifies "nonscalable" systems, like foraging markets or peasant woodlands, in which movement from one scale to another cannot happen without transforming the frame of engagement. While her use of these terms attends to capitalism and global distribution, "nonscalability" is useful here, as well. Just as Tsing remains "alert to the awkward, fuzzy translations and disjunctures inherent in global supply chains" (522), so too does aesthetic expansion from human to lithic space-time involve disjunctions that can't be understood through precision nesting. When dealing with such disparate states of being, the boundary between difference of scale (i.e., the idea that lithic space-time is simply an extended, scalable form of human space-time) and difference of kind (i.e., the idea that lithic space-time offers a completely different planetary vision from human space-time) is fraught. And yet, those variances are just what the works in this study confront.

\section{All Is Lithogenesis: MacDiarmid's “On a Raised Beach”}

The title for Hugh MacDiarmid's “On a Raised Beach” seems simple enough and in line with the expectation of lyrical, landscape poetry: a work reflecting upon a natural setting and using that setting to engage larger questions about nature. While beach setting serves as a site for the poem's planetary visions, 
the text moves quickly beyond that locale to signify unbridgeable gaps between human and lithic space-time. It imagines human existence through supra-human aesthetics: "We must reconcile ourselves to the stones, / Not the stones to us" (428). Rather than T. S. Eliot's fragmented modernity, MacDiarmid's lithic form, published 12 years later in 1934, builds from bedrock. Our "frenzied and chaotic age" is but "a growth of weeds on the site of a demolished building" (429). Grasping the lithic lets us "exercise the loneliness, the independence of stones" (431).

MacDiarmid frames this examination through an overwhelming use of geological and rhetorical jargon. The opening stanza is awash in scientific terminology: "carpolite fruit," "cathoyant pieces," "cyathiform," "foveoles," "slickensides, truité, rugas, foveoles" (146). Readers will surely need a glossary, and in that glossary, they will find two primary scientific fields: geology and biology. This terminological glut serves both formal means and thematic ends. The poem establishes universal opposition between "all" being either "lithogenesis," the formation of stone, or "lochia," afterbirth's discharge, pivoting between lithic and human ontologies. Later in this opening stanza, the speaker asks the beach stones, "What eburnation augments you with men's bones, every energumen an Endymion yet?" In eburnation—or hardening of bone-we see MacDiarmid's reifying project: to think of humans at the scale of the lithic, one must dehumanize-or, to return to Shklovsky, one must defamiliarize-experience: make the human stony, so to speak. MacDiarmid's opening move carves the rhetorical space for nonhuman lyricality.

The poem's conclusion overwhelms in similar ways, though here it does so through rhetorical, rather than scientific, terminology:

Diallage of the world's debate, end of the long auxesis,

Although no ébrillade of Pegasus can here avail,

I prefer your enchorial characters-the futhorc of the future-

To the hieroglyphics of all the other forms of Nature.

Song, your apprentice encrinite, seems to sweep

The heavens with a last entrochal movement;

And, with the same word that began it, closes

Earth's vast epanadiplosis. (156)

The diallage, a form that employs multiple arguments for a single point, becomes a geological structure, as does the hyperbolic growth in "auxesis." Rhetorical and ontological structures merge-structure becomes both linguistic and material. Enclosing the poem within these disorienting technical registers highlights a paradox in ecopoetics: language is both blockade and means by which we experience nature. Terminological specificity, whether scientific or rhetorical, offers conceptual precision while estranging the thing itself-the stoniness of the stones at the center of the poem. In this way, MacDiarmid's text calls for fusion of lithic and human 
in art, reflects upon the impossibility of that fusion, and then enacts that project's failure at the level of form.

"On a Raised Beach" merges rhetorical and ontological, human and lithic. Rather than just revivifying rocks, MacDiarmid lithomorphizes human experience—or, he reanimates modernity's stony "ground" and renders its subject (the human) as one of many actants. By shifting to the nonhuman, "On a Raised Beach" models what Mark McGurl calls "exomodernism," which positions culture "in a time-frame large enough to crack open the carapace of human self-concern, exposing it to the idea, and maybe even the fact, of its external ontological preconditions, its ground" ("New" 380). Beyond T.S. Eliot's fragmented wasteland, MacDiarmid declares "This is no heap of broken images" (150). Whereas Eliot's cultural fragments become epistemological buttresses, MacDiarmid renders the human invisible against larger scales of space and time. MacDiarmid's solution in the face of impotence is aesthetic (and ethical) rigor: for the poet to extend their influence to lithic scales, they must become "more concentrated and determined, / Truer to themselves and with more to be true to, / Than these stones, and as inerrable as they are" (150). If MacDiarmid moves outside Eliot's human scale, he returns through this fusion of art and ethics, which he sees modeled in stone. Escape is not to linguistic origins but to stones, and in them are the means for human transcendence.

\section{The Piling up of Debris: Robert Smithson's "Strata: A Geophotographic History"}

If MacDiarmid leaps from the human to the more permanent scales of stone, so too might lyric render very different scalar movement from lithic to human. One such movement emerges in Robert Smithson's "Strata," published thirty-six years after MacDiarmid's poem in 1970. Originally part of Aspen no. 8, the "Multimedia Magazine in a Box"-edited by Dan Graham and designed by George Maciunas-"Strata" appeared on a sheet of 333/4 x $10^{3 / 4}$-inch paper, folded in fourths. The piece subdivides into ten sections, each affiliated with a geologic epoch or era, beginning in the Cretaceous and ending in the Pre-Cambrian. Moving down the page moves backwards in time, digging deeper into geological history. These subdivisions are separated by cut-out images of fossilized strata spanning the page's width, serving as horizontal barriers separating one geological moment from the next. The page resembles the stratigraphy it renders. Nonetheless, the content of the section troubles smooth movement into the deep past.

Take, for instance, the final, Pre-Cambrian segment, representing the planet's earliest moments (reproduced in all-caps, as it appears in the original pamphlet):

MEMORY AT THE CHTHONIC LEVEL. FLOATING ON SOFT MUDS NEAR THE BLIND RIVER. PINK FOSSILS. OBSCURE 
TRACES OF LIFE. HALF TONE PICTURES OF STRATIFIED ROCKS. RECONSTRUCTIONS OF SANDSTONES IN SQUARE GLASS CASES. HOT WATER. RIDDLE OF THE SEDIMENTS. LOST IN THE ENCYCLOPEDIA BRITANNICA. BEACHED. BOILING, BUBBLING CONTINENTS. PHOTOGRAPH OF BANDED RED CHERT OR JASPER IN THE SOUDAN MINNESOTA (MINNESOTA GEOLOGICAL SURVEY). A GRAFT SHOWING THE CORRELATION OF THE SUCCESSIONS OF ROCK UNITS IN SEVERAL DISTRICTS. IGNEOUS MEANING FIRE. WE LIVE AMID THE WRECK OF FORMER WORLDS (JEROME WYCHOFF, OUR CHANGING EARTH THROUGH THE AGESFULLY ILLUSTRATED WITH PHOTOGRAPHS AND PAINTINGS). THIS PERIOD IS LOSING ITSELF IN SAND AND PAGES. THE REGION BEGINS TO DISSIPATE. AN AERIAL PHOTO SHOWING THE DRIFT OF LAVA. SOME THOUGHTS ARE SINKING INTO THE CONGLOMERATE. LOGAN PASS IN GLACIER NATIONAL PARK IS MADE OF CRUSTAL BLOCKS. THE AGE OF POTASSIUMARGON. GEOLOGICAL GHOSTS ON THE PAGES OF A BOOK ON VIRUSES. ANIMALS WITHOUT BACKBONES TURN INTO STONE. IF ONLY THE GEOLOGISTS WOULD LET ME ALONE, I COULD DO VERY WELL, BUT THOSE DREADFUL HAMMERS (JOHN RUSKIN). GRAPHITE (A CRYSTALLINE TYPE OF CARBON). SLIMY DAYS. STEAMING GEYSER BASINS (NOBODY'S YELLOWSTONE). COUNTERFEIT ALGAE IN THE MUSEUM. BURROWS IN A MOUNTAIN OF CORRUPTION ... THE QUEER FLOATING BASKET-LIKE VARIETY ... (CHARLES R. KNIGHT). HEAPS OF CARBONATE LIME. POURING TONS OF MINERAL MATTER INTO A LAKE. IMITATION GRANITE. LAYERS OF OUTDATED MAPS. XENUSION. PETRIFIED SCUM ON DISPLAY. MAP OF THE MISSING SEA. EXTINCT SPONGE-LIKE THINGS. STEAM. CHARTS SHOWING CLAY FORMATIONS. THE PILING UP OF DEBRIS ... FUTILE AND STUPID STAGNATION ... (HENRY ADAMS). STALE TIME. ONE-CELLED NOTHINGS. ABSENCE OF OXYGEN.

(77; bold, italics, and ellipses in original)

Scientific language mixes with etymological, philosophical, and psychological quotations; titles from classical and early-modern treatises; descriptions of museum exhibitions, charts, illustrations; poetic imagery, etc. Yet only a few intertextual instances are sourced. Most readers must search, or, more likely (even for the cited sources), accept these passages as is, without accessing contextual clarification. In Smithson's words, "THE PILING UP OF DEBRIS" becomes both subject and practice. Smithson's lyrical vision of the Pre-Cambrian is product of human knowledge, whether scientific, religious, philosophical, pedagogical, or otherwise, inaccessible 
through any sense of materiality. Answers to the nature of space and time in the Pre-Cambrian, "MEMORY AT THE CHTHONIC LEVEL," are not found anywhere "outside," in nature. Instead, they are "LOST IN THE ENCYCLOPEDIA BRITANNICA.”

Anthropocentric lyricality is in tension with narrativity here. Geological periods become lyrical segments stacked into a stratigraphic narrative moving backwards in time and down the page. Despite its prosaic appearance, "Strata" uses poetic form to construct this idiosyncratic structure. Clarifying the text's dependence on poetic form despite prosaic appearance requires distinguishing poetic form from lyric mode. Whereas lyricality is best understood in Phelan's terms as a rhetorical mode focused on states of being, poeticity, in Brian McHale's sense, is a formal characteristic dependent on segmentation (14). While lyric is trans-formal, appearing in prose, poetry, music, etc., poetry is trans-modal, capable of lyric, narrative, portrait, and other rhetorical modes. Building on the work of Rachel Blau DuPlessis, McHale distinguishes poetry from other forms through this emphasis on spacing: "segmentivity is the dominant of poetry, in something like Jakobson's sense, just as narrativity is the dominant of narrative, and performativity of performance" (14). Poetry prioritizes spacing (e.g., line breaks, stanzas, sequential sections, or even individual words) and focuses meaning making in negotiation of gaps. Poetic segmentations interact and play off one another to construct constellations of meaning. This interplay between various segmentations countermeasures one level against another. One segmentation creates a particular meaning; another creates a conflicting meaning. But the two coexist and interact, structuring the poem and our sense of it.

Poetic sensibility in "Strata" depends upon its segmentation-reinforced by images of stratigraphic barriers-and exploits gappiness to render geologic spatiotemporality. While its prosaic appearance seems to undermine this gappiness, capitalized text and prosaic form melt together intertextual instances, blurring boundaries between sources to render poetic images of each geological moment. In McHale's sense, the text "semanticizes" prose spacing; its formatting is conspicuous, rather than invisible (15). In this form, sections juxtapose disparate sources to render lyrical representations of geological moments, which are then stacked in a reading of the progression of time implied by ordered layers of rock, creating tension between each section's lyricality and their collective narrativity. Textual collage becomes stabilized event, connected to one another through implied narrative form. Segmentivity constitutes geologic record as product of human-scale spacetime, curating a faulty, fragmented, and ultimately incomplete humanist epistemology. Even if we consider the "geophotographic" attention of the title and consider the text as captions to the photographic barriers, text and photograph render each geological period lyrically. That is, rather than each period represented as a multi-million-year history of transformation and change, they are stabilized and rendered lyrically through textual 
collage and accompanying image. Change and narrativity occur only in the movement from one period to the next and are indicated only in the movement between segments. In that sense, our reading of the text flickers back and forth between a lyrical engagement with the individual segments and a narrative engagement with their arrangement on the page. If these texts are captions, they are captions representing each geological period (and its stratigraphic image) as a lyrical segment, connected to one another through spatial, narrativized ordering of Earth history on the page (i.e., movement backward in time and down the page).

At the same time, the text ironizes and critiques humanist epistemology. For instance, the quote from John Ruskin- "IF ONLY THE GEOLOGISTS WOULD LET ME ALONE, I COULD DO VERY WELL, BUT THOSE DREADFUL HAMMERS"-comes from his lamentation about scientific knowledge and its challenge to his religious worldview. The full quotation, take from an 1851 letter to Henry Acland, is as follows:

You speak of the Flimsiness of your own faith. Mine, which was never strong, is being beaten into mere gold leaf, and flutters in weak rags from the letter of its old forms; but the only letters it can hold by at all are the old Evangelical formulae. If only the Geologists would let me alone, I could do very well, but those dreadful Hammers! I hear the clink of them at the end of every cadence of the Bible verses.

The original quote metaphorizes the challenge that scientific knowledge brings to religious belief through pounding hammers, which beat his faith to the thinness of gold leaf. But, in the collage, this metaphor is removed, and the religious context is transformed: the "me" that laments the pounding of hammers might even be the strata subject to their geological investigation. We flicker back and forth between the two: Ruskin's epistemological crisis and the personified, lithic space from which that crisis arises.

Smithson thus posits an artificial ground for this "natural" narrative and then troubles that ground through collage. That we can articulate history at the geological scale becomes the target of Smithson's critique here, and he works to problematize that possibility through its very construction. Smithson has claimed that "Strata" dealt with geological history as "fiction" (Bear and Sharp 248). But perhaps Smithson's better comparison is to "a jumbled museum:"

Embedded in the sediment is a text that contains limits and boundaries which evade the rational order, and social structures which confine art. In order to read the rocks we must become conscious of geologic time, and of the layers of prehistoric material that is entombed in the Earth's crust. When one scans the ruined sites of pre-history one sees a heap of wrecked maps that upsets our present art historical limits. 
A rubble of logic confronts the viewer as he looks into the levels of the sedimentations. The abstract grids containing the raw matter are observed as something incomplete, broken and shattered.

(Smithson, "Sedimentation" 110)

"Strata" renders this jumbled museum on the page through stratigraphic narrativity and collage. A construct of human knowledge that never fully accesses the scale of lithic space-time, the museum (and the poem) can only be "incomplete, broken, and shattered." In that sense, form in "Strata" is both the thing - the stratigraphic narrative of geological history-and the means by which we access the thing, via fragmentation and approximation.

Jonathan Skinner identifies this poetics as "entropological" and "engaged at the level of material and processes, where entropy, transformation and decay are part of the creative work" (128). He distinguishes it from what he calls "topological" and "tropological" poetics: the first concerned with poetry's referential function to an "outside" nature; the second interested in poems as ecosystems in and of themselves. Skinner borrows his entropic terminology from Smithson, who explicitly connects poetic instabilities to similar instabilities of landscape:

Words and rocks contain a language that follows a syntax of splits and ruptures. Look at any word long enough and you will see it open up into a series of faults, into a terrain of particles each containing its own void. This discomforting language of fragmentation offers no easy gestalt solution; the certainties of didactic discourse are hurled into the erosion of the poetic principle. Poetry being forever lost must submit to its own vacuity; it is somehow a product of exhaustion rather than creation. Poetry is always a dying language but never a dead language.

(Smithson, "Sedimentation" 107)

Smithson recognizes ontological instability in scalar collisions rendered at the level of form, whether poetic or lithic. "Strata" negotiates this collision, representing its effects, imagines its reconciliation, and then represents its impossibility.

\section{Set Down in Strata: Brenda Hillman's “A Geology”}

Page space and stratigraphic form tackle far more disorienting and unstable spatiotemporal structures in Brenda Hillman's “A Geology," published thirty-one years after Smithson's piece and connecting California's geological history to addiction and recovery, transforming humans from subject to object, acted upon by addiction and compared to pressures that transform the landscape. Disjointed juxtaposition troubles the reader's stable engagement with either scale. For instance, the poetic voice compares the Coast Range to "pushing a pile of wet / papers from the left:" a relatively 
simple metaphor that uses the human-scale vehicle of wet paper to describe the shape of a mountain range (7). Yet that comparison breaks down as the line continues: "and finally / they were just in love with each other." Who is the "they" that are in love: two unnamed people or the colliding plates that produced the Coast Range? Soon after, the poem asks readers to "Consider the faultline" and then moves immediately to a moment when the "you" of the poem tried "to quit the drug and broke / in half." The break of the faultline and the breaking of an individual under the pressures of addiction are equated here. But the balance between tenor and vehicle is fraught yet again, as the line continues: "you said ... // And you had to trust it (that is, needing it)." Do the ellipses imply the end of the phrase, or something else? What of the space before the parenthetical phrase? What is the "it" that needed to be trusted? Again, unclear antecedents and ambiguous phrasing disrupt any clear metaphorical movement between human and lithic scales. This unstable relationship between human and geologic scales is reinforced at the end of this opening page:

A geology breaks in half to grow. A person whose drug like a locust jumps across someone's foot, singing-; we disagree with $\mathrm{D}$, who hates similes.

The break that compels growth would seem to reinforce the metaphorical relationship above, establishing the break at the human scale as a site for potential growth or development-a move away from and beyond the stultifying conditions of addiction. But complications arise throughout these lines. Who is D? And how does the locust simile relate to earlier comparisons between rock and human? Is the geologic faultline the vehicle for addiction's tenor? Or is addiction the vehicle for the geologic tenor of Californian landscape?

The poem upsets interpretive stability, keeping open relationships between different scales of being (human, stone, insect). This instability is explicit later, when the text declares, "a poem is // composed of all readings of it" (10). Its openness and instability, its unwillingness to settle metaphorical relationships, its disorienting engagement of scales of being: each frustrating formal aspect of the text positions readers between lithic and human, settled in neither and present in both. The experience of addiction becomes the means for this unsettled co-presence of scales. California is "like the skin of a person about to sit / down" (7); addiction is like "A bunch of fiery / islands [that] floated over and sutured themselves to us // a hundred million years ago" (9). In their similarity to skin, the moving plates leap to the scale of the human, and an addict's experience of time shifts to the lithic scale. Yet, the poem prioritizes neither human nor lithic registers, and readers confront the text as a simultaneous engagement with geological and human space-time.

The poem ends by further conflating and confusing boundaries between addiction and California landscape: 
In the expiation of nature, we are required to experience the dramatic narrative of matter.

The rocks under California are reigning in their little world.

This was set down in strata so you could know what it felt like to have been earth. (14)

In the first two lines, expiation confronts the conditions of the world in which we live, the "dramatic narrative of matter." If the poem engages both human and geologic scales of matter simultaneously, expiation means both confronting the consequences of our actions on an interpersonal, human scale and situating those actions within geological history. Both our lives and the history of the planet are "set down in strata" in this way.

But "This" at the end of the quotation might also means "this poem," this textual object and its unusual form, a human product set down in strata along with all human products of the Anthropocene. Each of its eight pages include four corner words (see Figure 10.1). On most pages, these words also occur within the body text. Jennifer Phelps describes these corners as thematic anchors, securing poem to page, while also troubling that grounding through semantic slippage. So, on the final page, the word "fault," repeated in three corners, is first found in the sentence "Tempting to pun on the world fault." Here, "pun" connects geological "fault" (tectonic pressures, cracks in the earth, etc.) to human addiction and blame. For Jonathan Culler, puns foreground opposition "between accident or meaningless convergence and substance or meaningful relation," producing "meaningful coincidence or convergence that affects meaning" ("Call" 16). Transferring "fault" exploits coincidence and convergence to produce ontological slippage that reifies the human experience of addiction, transforming human from subject to object acted upon by addiction. A break (or fault) reduces pressure and strain, whether we are talking about a faultline or the "break" that opens new possibilities for recovery in the addict. Instability also exists between fault as "blame" and fault as "break" in the phrase "The tendency / to fault relieves the strain." We look unsuccessfully for causality and agency ("fault") at both scales: who or what is responsible for addiction or for earth's transformations? By working on both human and tectonic registers, the poem conflates and confuses scales of space-time. Simultaneously, the third corner "fault," which has no match in the body text, reinforces this instability. For it, we need another sense of "fault," as flaw or defect in the poem. Just when we have identified a formal rule to cohere this disjointed and disorienting text, this "fault" undermines that rule and reflects on its own failure.

Unstable flickering between human and lithic scales undermines any priority between the two. The final line's use of present perfect ("to have been earth") links current experience with the past, implying a past event that has present consequences. Here, metaphor becomes what Timothy Morton calls a "weird loop," in which "two levels that appear utterly separate flip into one another," an uncanny effect that exemplifies the emergence of ecological 
Phyllites, schists, cherts, marbles. Press \# when you are finished. No one knows why the arc of minor islands sewed themselves to us in that way. When I put it

to my mouth I had no ability to stop it.

The sea ate the colors a hundred million years ago.

A geology is not a strategy. When an addict tries to leave the desire to make himself over shifts from what it felt like to have been a subject;

L.A. will dwell beside San Francisco eventually.

Tempting to pun on the word fault. All right, say plot. All right, happens. The tendency to fault relieves the strain. New islands were forming to get the gist of it. We wanted the extraordinary stranger in our veins.

Whether it's better not to have been held by something. The oldest limestone, prevalent between Big Sur and Calaveras, is not "better than," say, any other kind. The suffering wasn't luckier, it wasn't a question of asking.

In the instead hour, the minutes of not recovering from the difference of what we loved; sameness is also true: stone like a spider

sucking the carapace the same color as itself.

In the expiation of nature, we are required to experience the dramatic narrative of matter.

The rocks under California are reigning in their little world.

This was set down in strata so you could know what it felt like to have been earth.

fault

prevalent

Figure 10.1 From Brenda Hillman, "A Geology.” 
awareness (7), or in Hillman's sense, that imagines "what it felt like to have been earth." The ambiguous antecedent for "this" in the final stanza reinforces this co-presence, merging geological and human: expiation requires acknowledgement of and reconciliation with the earth. The poem posits what we might call an Anthropocenic poetics, fusing human to lithic, prioritizing neither while situating the human as collaborator with the geologic landscape.

\section{Conclusion}

Each lyric example I've discussed renders an aesthetic model that reconsiders relationships between lithic and human scales of space-time. In MacDiarmid's "On a Raised Beach," the lithic becomes a model for a human-scale ethical and aesthetic project. It provides new opportunities for artistic potential, stripped of humanity and purified through engagement with expansive scales. It reverses the conventional trajectory of the pathetic fallacy, reifying humanness through lithic juxtaposition and disrupting spatiotemporal stability. In Smithson's "Strata," human space-time ironically supersedes the lithic. Collage form and stratigraphic structure transform lithic spatiotemporality into a problematically human product. In Hillman's "A Geology," lithic and human space-times balance, each reflecting the other on mutually beneficial registers that both clarify and destabilize one another. As these differences attest, no strategy provides the means for articulating relationships between human and ecological. Rather, each lyrical instance produces its own defamiliarizing effects in which this work occurs. Other poems likely produce different spatiotemporal exercises. The point is not that lyric poems produce accurate renderings of "true" relationships between human and lithic spatiotemporality. Instead, each demands adeptness and flexibility that unfixes stable notions of space and time. Building on Matz's sense of time-work, this scalar diversity sharpens the "space-timework" of imaginative possibility in the face of planetary transformation.

Seventy years separate MacDiarmid's poem from Hillman's, and in those seventy years, knowledge of human impact on climate and the consequences of that impact have only increased. The historical positions of these three poems and the ways by which they engage these human-lithic disjunctions reveals how each embodies certain characteristics of their respective moments. MacDiarmid's poem, published in 1934, offers a typically modernist perspective of this disjunction. Writing well before the crisis entered public debates, his concerns are with humans and their capacity to achieve a kind of lithic permanence and stability in art. Where a modernist like Eliot responds to the conditions of modernity through fragmentation and collage or H.D. embraces mysticism and mythology, MacDiarmid radicalizes this impulse to seek continuity outside of the conditions of modernity by turning to the thoroughly nonhuman conditions of the lithic. 
In 1970, Smithson's text appears on the cusp of environmental awareness, when the consequences of human activity on the planet begin to produce political action and popular discussion. Mirroring Margaret Ronda, we might situate his work in a "Great Acceleration poetics" that "replace jeremiads of imminent apocalypse with an uncanny sense of living on amidst accumulating planetary disruption" (6). Human desire and incapacity to render the conditions of lithic space-time ironically critique human practice in light of this vaster scale. Attempts to stabilize and articulate the world only produce its opposite: chaos, wreckage, and "THE PILING UP OF DEBRIS." In light of this budding awareness of ecological crisis, Smithson's observation in "Strata," taken from Jerome Wychoff's Our Changing Earth through the Ages, that "WE LIVE AMID THE WRECK OF FORMER WORLDS" includes not only these ancient worlds but also more recent, human pasts.

Where MacDiarmid's action is centered on the human and Smithson undermines action through irony and failure, Hillman's 2001 poem seeks engagement through the structure of metaphor and the play of language. She responds to the crisis directly, but rather than ironize human capacity to render lithic scales of space and time, her work seeks to explore unstable positions that intertwine human and lithic scales. "A Geology" destabilizes the relationship between tenor and vehicle in order to upend any sense of priority, create a disorienting co-presence of lithic and human ontologies. Her work models a twenty-first-century, Anthropocenic poetics, one different from Smithson's irony in that it renders the relationship between humans and the planet in order to opens sites of engagement between the two. In a later work, Hillman asks the question, "We must do something, but what," and, in that question, seems to identify the central concerns of her poem: before we can take action, we must acknowledge that action can be taken (Practical Water 84).

The point isn't that any lyric instance reconciles human and lithic spatiotemporalities. Instead, each demands adeptness and flexibility that unfixes stable notions of space and time. They can teach us to live in spatiotemporal diversity, moving more comfortably within and between scales. In each instance, defamiliarizing effects transform engagement with temporal disjunction. These works construct radically open and contingent Anthropocenic spatiotemporalities: dependent on form, yet practically limitless within those affordances. Movements between openness and contingency might confront discrepancies between individual and collective responsibility. These lyrical works, and others like them, engage both scales of space and time. If negotiating planetary and human scales has become a political and even existential imperative, perhaps we can turn for guidance to lyric in order to revitalize spatiotemporal politics in service of this imperative. 


\section{Notes}

1 While Phelan's use of lyric as a rhetorical mode, rather than poetic tradition, offers a lens for considering engagements between different aesthetic forms, it breaks with much scholarship on lyric and poetry. For instance, Jonathan Culler sees lyric as an inherently transhistorical poetic form, dependent upon engagement with a particular poetic tradition of recitation for its rhetorical and aesthetic effect. For Culler, lyric "involves a tension between ritualistic and fictional elements" via poetic form (Theory 7).

2 For narrative renderings of deep space-time, see Richard McGuire's graphic narrative Here (2014), which recounts events in a single room over hundreds of thousands of years. Science-fiction narratives engaged with deep time abound: H. G. Well's The Time Machine (1895), Olaf Stapledon's The Last and First Men (1930) and Starmaker (1937), Arthur C. Clarke's The City and the Stars (1956), the six novels in Gregory Benford's Galactic Center Saga (1977-1996), and Stephen Baxter's Ring (1994) and Evolution (2003). In each, duration is compressed and fragmented, distorting extensive spatiotemporalities into anthropocentric frames.

3 See, for instance, Huebener, Szersynski, Davies 15-40, and Bonneuil and Fressoz $3-18$.

4 See also the 2015 special issue of Transatlantica, Hidden in Plain Sight: Deep Time and American Literature edited by Cécile Roudeau.

\section{References}

Bakhtin, M. M. The Dialogic Imagination. Translated by Caryl Emerson and Michael Holquist, University of Texas Press, 1981.

Baxter, Stephen. Evolution. Del Rey, 2003.

Baxter, Stephen. Ring. Harper Voyager, 1994.

Bear, Liza, and Willoughby Sharp. "Discussions with Heizer, Oppenheim, Smithson." Robert Smithson: The Collected Writings, edited by Jack Flam, University of California Press, 1996, pp. 242-252.

Bonneuil, Christophe, and Jean-Baptiste Fressoz. The Shock of the Anthropocene. Translated by David Fernbach, Verso, 2015.

Calvino, Italo. Cosmicomics. Translated by William Weaver, Harcourt Brace, 1968. Chakrabarty, Dipesh. "Climate and Capital: On Conjoined Histories." Critical Inquiry, vol. 41, no. 1, 2014, pp. 1-23.

Cohen, Jeffrey Jerome. Stone: An Ecology of the Inhuman. University of Minnesota Press, 2015.

Clarke, Arthur C. The City and the Stars. Amereon, 1999.

Culler, Jonathan. "The Call of the Phoneme: Introduction." On Puns: The Foundation of Letters, edited by Jonathan Culler, Blackwell, pp. 1-16.

Culler, Jonathan. Theory of the Lyric. Harvard University Press, 2015.

Davies, Jeremy. The Birth of the Anthropocene. University of California Press, 2016.

Dimock, Wai Chee. Through Other Continents: American Literature across Deep Time. Princeton University Press, 2006.

Herman, David. "Limits of Order: Toward a Theory of Polychronic Narration." Narrative, vol. 6, no. 1, 1998, pp. 72-95.

Herman, David. "Modernist Life Writing and Nonhuman Lives: Ecologies of Experience in Virginia Woolf's Flush.” Modern Fiction Studies, vol. 59, no. 3, 2013, pp. 547-568. 
Huebener, Paul. "Timely Ecocriticism: Reading Time Critically in the Environmental Humanities." ISLE: Interdisciplinary Studies in Literature and Environment, vol. 25, no. 2, 2018, pp. 327-344.

Hillman, Brenda. "A Geology." Cascadia. Wesleyan University Press, 2001, pp. 7-14.

Hillman, Brenda. Practical Water. Wesleyan University Press, 2009.

MacDiarmid, Hugh. “On a Raised Beach.” 1934. Complete Poems, vol. 1, edited by Michael Grieve and W. R. Aitken, Carcanet, 1996, pp. 422-33.

Malm, Andreas. The Progress of This Storm: Nature and Society in a Warming World. Verso, 2018.

Matz, Jesse. "Art of Time, Theory to Practice." Narrative, vol. 19, no. 3, 2011, pp. 273-294.

McGuire, Richard. Here. Pantheon Books, 2014.

McGurl, Mark. "The New Cultural Geography." Twentieth-Century Literature, vol. 57, no. 3-4, 2011, pp. 380-90.

McGurl, Mark. "The Posthuman Comedy.” Critical Inquiry, vol. 38, 2012, pp. 533-53.

McHale, Brian. "Beginning to Think about Narrative in Poetry." Narrative, vol. 17, no. 1, 2009, pp. 11-27.

“Media Note: Anthropocene Working Group (AWG).” University of Leicester, 29 August 2016, http://www2.le.ac.uk/offices/press/press-releases/2016/august/med ia-note-anthropocene-working-group-awg.

Moore, Marianne. "An Octopus." New Collected Poems, edited by Heather Cass White, Farrar, Straus, and Giroux, 1924/2017, pp. 72-77.

Morton, Timothy. Dark Ecology: For a Logic of Future Coexistence. Columbia University Press, 2016.

Nelles, William. "Beyond the Bird's Eye: Animal Focalization." Narrative, vol. 9, no. 2, 2001, pp. 188-194.

Phelan, James. Experiencing Fiction: Judgments, Progressions, and the Rhetorical Theory of Narrative. Ohio State University Press, 2007.

Phelps, Jennifer. "Mysticpoetics: Writing the Alchemical Self in Brenda Hillman's Poetry."Jacket2, 12 September 2013, http://jacket2.org/article/mysticpoetics -writing-alchemical-self-brenda-hillmans-poetry.

Ronda, Margaret. Remainders: American Poetry at Nature's End. Stanford University Press, 2018.

Roudeau, Cécile, editor. Hidden in Plain Sight: Deep Time and American Literature, special issue of Transatlantica, vol. 1, 2015.

Ruskin, John. Works of John Ruskin. George Allen, 1909.

Sawyer, Stephen W. "Time after Time: Narratives of the Longue Duree in the Anthropocene." Transatlantica, vol. 1, 2015, pp. 1-17, http://transatlantica .revues.org/7344.

Shklovsky, Victor. "Art as Technique." Literary Theory: An Anthology, edited by Julie Rivkin and Michael Ryan, Blackwell, 1917/2004, pp. 15-21.

Skinner, Jonathan. "Statement for 'New Nature Writing' Panel at 2005 AWP (Vancouver)." Ecopoetics, 4/5, 2004-2005, pp. 127-129.

Smithson, Robert. "A Sedimentation of the Mind: Earth Projects." Robert Smithson: The Collected Writings, edited by Jack Flam, University of California Press, 1968/1996, pp. 100-113. 
Smithson, Robert. "Strata: A Geophotographic Fiction." Robert Smithson: The Collected Writings, edited by Jack Flam, University of California Press, 1968/1996, pp. 75-77.

Stapledon, Olaf. Starmaker. Jovian Press, 1937/2017.

Stapledon, Olaf. The Last and First Men. Penguin, 1930/2014.

Szerszynski, Bronislaw. "The Anthropocene Monument: On Relating Geological and Human Time." European Journal of Social Theory, vol. 20, no. 1, 2017, pp. 111-131.

Tarlo, Harriet. "Introduction." The Ground Aslant: An Anthology of Radical Landscape Poetry, edited by Harriet Tarlo, Shearsman Books, 2011, pp. 7-18.

Tsing, Anna Lowenhaupt. "On Nonscalability: The Living World Is Not Amenable to Precision-Nested Scales." Common Knowledge, vol. 8, no. 3, 2012, pp. 505-524.

Wells, H. G. The Time Machine. Oxford University Press, 1895/2017. 


\title{
11 Narrating the "Great Outdoors"
}

\author{
Ridvan Askin
}

As befits a travel narrative, Margaret Fuller's account of her journey in the Great Lakes region, Summer on the Lakes, in 1843, presents a wide array of geographical, biological, and socio-political observations. ${ }^{1}$ Among other things, the travelogue conveys Fuller's impressions of settler life on the frontier with a particular focus on the exigencies and repercussions for women, provides evocative descriptions of the region's flora and fauna, and extensively discusses the plight of Native Americans. The book thus affords genre-typical explorations of a variety of spaces-physical, mental, and social-promising to be a particularly fruitful source for anyone interested in scrutinizing the relation between narrative and space and the concomitant narrative techniques and strategies employed in the representation and description of such spaces.

My interest in Fuller's text, however, concerns not so much these representations and descriptions themselves but rather how Fuller employs them in order to evoke what French philosopher Quentin Meillassoux has ventured to call "the great outdoors" (After 7). As Meillassoux himself makes clear, the great outdoors is "the absolute outside of precritical thinkers" (7), that is, the notion of the absolute as sustained in the philosophical tradition before Kant. ${ }^{2}$ Indeed, Fuller's explorations of physical, mental, and social space are not self-sufficient. Rather, they serve to unearth what one might call metaphysical space. Note that Meillassoux introduces the absolute in spatial terms. This is quite fitting: not only does the concept's Latin root (absolvere) mean "to loosen away," which is a spatial expression, but the absolute is precisely that which eludes, exceeds, and goes beyond the particular, the concrete, and the relative, opening up another space beyond any and every given space, including the space of reason. It is not just outdoors, it is the great outdoors, absolutely outside and alien, no matter whether one conceives of the "indoors" as the domain of human thought or the whole realm of our lived experiences in the world at large. This is tantamount to saying that the absolute eschews experience and representation, that it is fundamentally inexperienceable and unrepresentable. At the same time, it cannot be a realm just unto itself as that would make it a realm relative to the human realm of experience 
and representation: the absolute has to be both absolutely outside while at the same time permeating and saturating the human experiential and representational world, in which it registers as that alien force of the inexperienceable and unrepresentable. Even though it is all-pervasive, the metaphysical space of the absolute is thus categorically distinct from physical, mental, and social space, which are fundamentally representational and experiential. Meillassoux wants to recuperate the absolute without regressing to a pre-critical, that is, pre-Kantian metaphysics. The reason is that at least since Kant (though Meillassoux actually thinks since Berkeley) ${ }^{3}$, such a straightforward plunge into metaphysics has become indefensible,

because thought cannot get outside itself in order to compare the world as it is "in itself" to the world as it is "for us," and thereby distinguish what is a function of our relation to the world from what belongs to the world alone. Such an enterprise is effectively self-contradictory, for at the moment when we think of a property as belonging to the world in itself, it is precisely the latter that we are thinking, and consequently this property is revealed to be essentially tied to our thinking about the world. We cannot represent the "in itself" without it becoming "for us."

(After 3-4)

If by definition we can never get outside ourselves, can never attain "the world alone" as we invariably turn it into a mere thought, a mere representation, the very moment we think it, how can we ever hope to recuperate the great outdoors? And what has narrative to do with it?

In what follows, I suggest that we, in fact, do not get outside. But we can let the outside seep in. And narrative has a crucial role to play in this letting in. ${ }^{4}$ It is no coincidence that I chose a romantic travel narrative in order to showcase this capacity of narrative. Since the study of Romanticism is such a contested field, let me briefly qualify my use of the term. Against a widespread strain of scholarship going back to Arthur Lovejoy's seminal essay that argues for the inherent plurality of Romanticism and even prefers to speak of Romanticisms in the plural ("Romanticisms"), I take it that there are several fundamental convictions that underwrite a shared romantic project. Roughly, they can be described as the philosophical marriage of Platonic idealism with Spinozist monism and expressionism and the priority of intuitive over discursive reason. Following Plato, the Romantics posited a realm of real Ideas. With Spinoza, they immanentized this realm so that Ideas became thisworldly expressive matrices rather than otherworldly blueprints. ${ }^{5}$ The most explicit statement of this view in Fuller's travelogue comes in a short discussion of fourteenth-century "Flemish hero" Philip van Artevelde as depicted in Henry Taylor's eponymous verse drama, when Fuller casts Taylor's van Artevelde as a role model for America: 
no thin Idealist, no coarse Realist, but a man whose eye reads the heavens while his feet step firmly on the ground, ... a man to whom this world is no mere spectacle, or fleeting shadow, but a great solemn game to be played with good heed, for its stakes are of eternal value.

In other words, against the otherworldliness of Platonic idealism (the world as "fleeting shadow" is an unmistakable reference to Plato's allegory of the cave) Fuller, in true romantic fashion, propagates the thisworldly synthesis of the ideal and the real such that the (transcendental) ideal inheres in (empirical) reality and the (empirical) real is governed by (transcendental) Ideas-otherwise it would not make sense to speak of the eternal value of thisworldly stakes.

Importantly, for the Romantics the realm of Ideas can only be accessed by means of intuitive rather than discursive reason (they were Kantians with respect to the limitations of discursive reason). This intuitive reason is commonly called intellectual intuition (e.g., Schelling, the Schlegel brothers, the Jena Romantics in general) or simply intuition (e.g., Emerson, Fuller, the transcendentalists). Crucially, for the Romantics intuitive reason is at work in acute aesthetic experiences proffered by the beauty and sublimity of nature. But it is most clearly on display in art; works of art are intuition materialized. They are "co-creations" ultimately stemming from the creative powers of nature itself (Deleuze and Guattari, What Is 173). In this way, art becomes the royal road to the realm of Ideas. This is why Schelling at one point even went so far as to claim that art is "at once the only true and eternal organ and document of philosophy" $(231) .{ }^{6}$

The Romantics are precursors to Meillassoux in so far as they, too, hark back to the pre-critical notion of the absolute, and like Meillassoux, they do so in order to solve the riddle Kant bestowed on his successors and that we are still grappling with today: if we are caught in our thoughts, that is, for Kant, the world of representations and appearances, but know that there is an outside to this world-since appearances, after all, must be appearances of something, there must be something that appears-how can we mend this rift between thought and world, between appearances and that which appears, between the "for us" and the "in itself"? While Meillassoux opts for the route of mathematics to solve this problem, the Romantics turned to art. $^{7}$ Where Meillassoux qua rationalist wants to show that rational thought, after all, can bridge this divide, the Romantics proposed to travel down the road of intuition. With my reading of Fuller's travelogue, I attempt to give an exemplary account of this kind of travel. ${ }^{8}$

Fuller's travel narrative about the Great Lakes region comes in handy for such an enterprise precisely because it does not content itself with merely describing the region and relating Fuller's impressions, experiences, and encounters. Rather, these descriptions and representations are but preliminaries in a series of narrative operations that serve to open up to that 


\section{Ridvan Askin}

wholly other realm of the great outdoors. For Fuller, the great outdoors is indeed to be found in nature, specifically American nature, which here means: the American West. She deliberately seeks experiences of beauty and sublimity in the West, which the travelogue is supposed to convey to and, crucially, induce in the reader. This explains why Fuller is less concerned with descriptive accuracy. Rather, her impetus is to render "the poetic impression of the country at large" (42), a country that is "still all new, boundless, limitless" (40). It is this limitlessness she tries to capture, as "what is limitless is alone divine" (40). Descriptive representations necessarily fall short of such divine limitlessness; only poetic evocation can hope to pierce the limits of representation in order to give us a glimpse of the unrepresentable absolute, the limitless great outdoors as intuited in the aesthetic experiences nature affords. ${ }^{9}$

Accordingly, Fuller's narrative deliberately pushes against the limits of representation. It does so by means of performing displacements of experiential space, on at least three levels. First, the many digressions seemingly unrelated to Fuller's actual travel itinerary included in the travelogue, most prominently those on Mariana, Fuller's fictionalized alter ego, and Friederike Hauffe, the so-called Seeress of Prevorst, serve to interrupt and break up Fuller's account of frontier life and the representation of the external space of the American West. Second, the focus on Mariana's and Hauffe's esoteric, spiritual powers and their somnambulism serves to unsettle the internal space of reason and thought, that is, representation per se. Third, these displacements are precisely enacted by means of breaking up the space of narration itself-the travelogue actively works against its own narrative progression. Conjointly, these strategies serve to pierce the limits of representation and to make tangible the otherwise intangible realm of the great outdoors. Such a feat should have repercussions for the narratological apparatus and terminology dealing with the relation of narrative and space. The essay accordingly introduces the notion of pseudo-paraleptic anamorphosis-a particular kind of cognitive distortion or displacement in and through narrative-to account for attempts to narrate the great outdoors.

\section{The Limits of Representation}

Summer on the Lakes, in 1843 presents a particularly disjointed, impressionistic, digressive, polyvocal, and fragmented narrative, even if one takes into account the genre's amenability to such formal extravaganzas. ${ }^{10}$ Fuller's travelogue is interwoven with illustrations, poems, dramatizations, numerous excerpts from other books, a fictionalized autobiographical sketch, and a retelling and part-translation of a German esoteric narrative that is itself the imaginatively embellished story of the life and death of the Seeress of Prevorst, Friederike Hauffe. These formal peculiarities go hand in hand with Fuller's thematic interests. It is evident from the start that Fuller's 
goal is not a faithful and adequate approximation of empirical reality but the rendition and inducement of aesthetic experience facilitating the intuition of the absolute. Summer on the Lakes alludes to the importance of aesthetic experience already in the first of its two epigraphs, both penned by Fuller herself: "But, in fault of wizard spell, / Moderns their tale can only tell / In dull words, with a poor reed / Breaking at each time of need" (1). Lamenting the inadequacy of "dull words" to capture that which can only be adequately invoked by a "wizard spell" (1), the first epigraph wastes no time in setting intuitive over against conceptual reason. That the writing tools are of no use when they are most needed further emphasizes the limitations of representation. But Fuller immediately adds that "those to whom a hint suffices / Mottoes find for all devices" (1), making clear that despite its limitations, representation is at least capable to hint at that which it cannot grasp. This line of thought is continued in the second epigraph, in which Fuller first lists souvenirs such as "dried grass-tufts," a "mussel shell," "antlers," and an "eagle's feather" as poor evocations of the original experience (this holds true of both the words themselves-this is what Fuller actually gives us, after all-and the objects the words represent), only to conclude:

I give you what I can, not what I would, / If my small drinking-cup would hold a flood, / As Scandinavia sung those must contain / With which the giants gods may entertain; / In our dwarf day we drain few drops, and soon must thirst again.

Humans are no giants, and the realm of gods is beyond their reach. Still, they partake in the divine, even if just by means of a few drops. The two epigraphs thus set up the primary challenge for the narrative: how to provide a few of these divine drops, how to forge a wizard spell out of the dull words the narrative needs to content itself with. In other words, how to pen a representational narrative that manages to pierce its representationality so that a glimpse, however small, of the beyond of representation becomes possible.

The narrative proper addresses this conundrum right away as it sets in with an account of the failure to achieve an experience of the sublime. Fuller very much expects such an experience on her visit to Niagara Falls, with which the travelogue begins. But already in the narrative's second sentence she makes clear that initially, she fails to have this experience: "Yet I, like others, have little to say where the spectacle is, for once, great enough to fill the whole life, and supersede thought, giving us only its own presence" (3). Fuller ascribes this failure to the powers of representation:

When I first came I felt nothing but a quiet satisfaction. I found that drawings, the panorama, \&c. had given me a clear notion of the 
position and proportions of all objects here; I knew where to look for everything, and everything looked as I thought it would ... it looks really well enough, I felt, and was inclined, as you suggested, to give my approbation as to the one object in the world that would not disappoint.

But all great expressions [sic] which, on a superficial survey, seems so easy as well as so simple, furnishes, after a while, to the faithful observer its own standard by which to appreciate it. Daily these proportions widened and towered more and more upon my sight, and I got, at last, a proper foreground for these sublime distances. Before coming away, I think I really saw the full wonder of the scene ... The perpetual trampling of the waters seized my senses.

The falls fail to convey their magic at first because they have been captured and represented too often in pictures and drawings; they have become an all-too-familiar, tamed place the perception of which is governed and guided by ready-made representations-representation, "clear notion," cannot get at and even blocks access to the spectacle. Only once Fuller begins to attune herself to the falls, once she becomes a "faithful observer" letting the falls tower on and even seize her senses rather than employing them in the service of representation, does she achieve the kind of experience she was looking for. Faithful observation here indeed means the opposite of concentrated attention to detail, it means letting oneself be inundated, be overcome by the spectacle at hand: "[What] I liked best was to sit on Table Rock, close to the great fall. There all power of observing details, all separate consciousness, was quite lost" (5), Fuller writes. Only once one stops discerning details, that is, distinguishing things, is one able to perceive properly. Only then do "all the lineaments become fluent, and we mould the scene in congenial thought with its genius" (5). Only when we attune our thoughts to the genius of nature, can we expect to experience something like the sublime. In other words, sublimity does not just come by itself, it needs proper attunement, a willingness to forsake the world of representation. ${ }^{11}$

Fuller's account of the sublime as an experience overpowering the senses is in accordance with the Kantian and post-Kantian understanding of sublimity. For it is in the wake of Kant that the sublime has come to name precisely that which exceeds our sensory experience, which outdoes sensibility. But Kant holds that if we cannot process something by means of our senses, reason shows us that we can still conceive of it, we can think it, and that is what is sublime (5:251-257, 5: 260-279). By contrast, for the Romantics, harking back to Baumgarten's understanding of aesthetics as sensual cognition, reason is not limited to rational, conceptual thought but also encompasses sensual, intuitive thought. Reason in this latter sense is more akin to a sensus divinitatis that lets us in on the wonders and secrets of things, and that is what is sublime (Beiser, Romantic 60-63, Coleridge 555-60). For Kant, the feeling of the sublime is essentially an aesthetically 
triggered awareness of our own rational powers. For the Romantics, it is the aesthetic vision or intuition of the absolute. As such, it exceeds the limits of representation. But representation proves hard to overcome.

Fuller emphasizes this latter aspect once more when she tells us that she ultimately managed to experience the sublime where she had not expected it at all precisely because no representation had prepared her for that, namely when she "saw a quarter of a mile of tumbling, rushing rapids" (8). Not the falls themselves, but the comparatively insignificant rapids manage to convey the sublime:

My emotions overpowered me, a choking sensation rose to my throat, a thrill rushed through my veins, 'my blood ran rippling to my finger's ends.' This was the climax of the effect which the falls produced on me-neither the American nor the British fall moved me as did these rapids.

This is the case because the rapids were not previously present in Fuller's thought, they were not yet governed by any representations:

For the magnificence, the sublimity of the latter [the British and American falls] I was prepared by descriptions and paintings. When I arrived in sight of them I merely felt, 'ah, yes, here is the fall, just as I have seen it in picture.' When I arrived at the terrapin bridge, I expected to be overwhelmed, to retire trembling from this giddy eminence, and gaze with unlimited wonder and awe upon the immense mass rolling on and on, but, somehow or other, I thought only of comparing the effect on my mind with what I had read and heard. I looked for a short time, and then with almost a feeling of disappointment, turned to go to the other points of view to see if I was not mistaken in not feeling any surpassing emotion at this sight.

Only once she is able to cast off the rule of representation with the help of the rapids Fuller is able to see "how here mutability and unchangeableness were united" and to feel a "genuine admiration, and a humble adoration of the Being who was the architect of this and of all" (9). The sublime does offer visions of the absolute, but we must work on our sensibility, tune and hone it so that such an experience becomes possible. We must be prepared to let go of representation.

In this way, the first chapter about her visit to the falls, the "prologue" to her travels in the West as Fuller herself calls it (3), introduces the pattern of and the key to the ensuing narrative: we live in a fully representational world; experiences of the sublime provide glimpses into a beyond of this world; but representation is all-encompassing and hard to shake off; 
sublime experiences need to be actively sought out, fostered, and sustained; both nature and art are apt to provide such experiences (but they can and repeatedly do fail to do so); the narrative at hand aims both to represent and provide this kind of experience.

But daily life is not necessarily amenable to such heightened experiences. Quite on the contrary, despite the West's potential to instill experiences of the sublime and thus to provide a glimpse of the great outdoors, most settlers are less concerned with this kind of aesthetic experience that nature affords but much more with the mundane, every-day question of how to exploit its resources in order to secure a living. The settlers' approach to nature is predominantly instrumental and economic. Throughout her travelogue, Fuller decries "an age ... of utility," Americans' general lack of "tenderness of feeling" (25), the settlers' spirit of what she refers to as "calculation" and "accumulation" (12), and their "habit of imitating Europe" (40). These traits keep them from living up to the potential of what Fuller does not hesitate to call "Elysium" (29), "Eden" (75), and "the capital of nature's art" compared to which "Rome and Florence are" mere "suburbs" (33). For Fuller, only women and Native Americans seem to have the sensibility needed to reach beyond calculative thought and intuit the absolute. But the former are locked up in the domestic sphere and the latter are driven away or killed. Women and Native Americans are thus emblematic of this missed opportunity, this untapped potential. ${ }^{12}$ This is why Fuller devotes long stretches of her narrative to the plight of Native Americans (especially chapter six) and inserts the two stories of women with particularly acute sensibilities, Mariana and Hauffe (chapters four and five).

Fuller's "prologue" (3) thus has a double function: the visit to Niagara Falls is the starting point of Fuller's travels-this is the sense in which Fuller employs the term, but it is of course also the entry point to her narrative about her travels. In this vein, her musings on the limits of representation and the power of the sublime need to be understood as programmatic metanarrative comments. Just like Fuller initially only managed to experience the sublime where she did not expect it, we should not expect to have the sublime conveyed to us where we would anticipate it to be conveyed, namely in Fuller's descriptions of and musings on the natural expanse of the American West. Given her awareness of and warnings about the impediments of representation, we should not expect her to actually try to represent the sublime, especially since the sublime by definition exceeds representation. At the same time, since her account cannot but avail itself of "dull words" (1), that is, it cannot but represent, she must do with representation. In other words, in order to evoke the aesthetic vision of the great outdoors provided by the experience of the sublime that both nature and art are apt to offer, Fuller needs to undo representation from within. Fragmentation, disjointedness, digressiveness, polyvocality, the palimpsestic grafting of narrative upon narrative, and generic hybridity are all strategies she musters in the service of this undoing. 
These strategies find their climax in the accounts of Mariana and Hauffe, the Seeress of Prevorst, in the book's two central chapters: not only are the chapters located in the middle of the book (in chapters four and five out of seven), more importantly, they capture what the entire narrative revolves around but cannot express with mere descriptions of nature and life on the frontier. Here, the narrative's form and content converge: as sustained digressions, the accounts of Mariana and the Seeress impede the representation of the travelogue's ostensible object, life in the American West, as they are not in any sense "about" the West. As discursive representations they represent the capacity for intuition as manifested in two young women. Placed at the heart of Fuller's narrative, they are representations that displace representation. Employing representation against representation in this way, the narrative opens up to the realm beyond the limits of representation. In its inherent mutability and malleability, its ability to take on and incorporate any form and genre, narrative is "the form that best captures the experience of colliding forms" (Levine 19) and is thus particularly well-suited to perform this work of displacement.

Displacement is of course a spatial expression, and I have chosen it with care. As is the case with Meillassoux's "great outdoors" and Kant's "in itself," Fuller, too, uses predominantly spatial terms to denote the beyond of representation (which, of course, is yet another spatial expression): to fill, to supersede, to widen, to tower, to surpass, to rise are some of the crucial terms employed in this respect in the excerpts quoted above. But what kind of expression, exactly, are they? If one follows Marie-Laure Ryan, these spatial expressions are mere metaphors, as they "fail to account for physical existence" (n.pag.), fail to index physical space in any way. Indeed, they do not as they quite emphatically wish to account for metaphysical existence. For example, when Fuller writes that the spectacle of the sublime "supersede[s] thought" (8), "supersedes" has no physical referent and does not describe a physical action. Ryan thinks that all uses of spatial expressions that do not refer to actual physical entities or actions are metaphorical uses. One wonders, however, what expressions like "supersedes thought," "beyond representation," and "the great outdoors" would be metaphors for. They seem to be categorically distinct from the metaphors Ryan has in mind such as, for example, the expression "mental spaces," which she paraphrases as a stand-in for "constellations of meanings held together in the mind" (though one cannot fail to note that Ryan's use of "in the mind" seems to be but yet another spatial metaphor-but one can see how this paraphrase might be extended such that it ends with reference to the brain, an actual physical object). Things seem to be different with expressions like superseding thought, the great outdoors, and the absolute: there is no paraphrase indexing physical entities or actions that would capture what these terms presumably stand in for. This is no wonder as they are coinages denoting non-physical existents. Here, one should not forget that in the Kantian and post-Kantian framework physics qua empirical science-like 
all natural sciences-is a science of appearances. It operates well within representation. In fact, representationality is the guarantor of scientificity: only what is empirically observable and testable belongs to the purview of the sciences.

If the metaphoricity of spatial expressions is defined via their relation to physical existence, as Ryan insists, then I would suggest that neither the spatial expressions used to gesture towards the beyond of representation nor the narrative displacement of representation by means of the accounts of Mariana and the Seeress should be understood as mere metaphorical operations. ${ }^{13}$ Rather, they provide the double-vision of anamorphosis-they are the distortive, anamorphic element in the larger picture transforming it (anamorphoein translates as to transform) when viewed accordingly.

It is no wonder that the disjointedness and digressiveness of Fuller's narrative, particularly the inclusion of the seemingly irrelevant stories of Mariana and the Seeress, was immediately criticized upon publication, with later editions sometimes omitting these allegedly egregious and disturbing passages and chapters (Belasco Smith xiii). For if we take these digressions at face value, as further episodes in a series of observations and ruminations about the American West, they seem indeed misplaced. But once we view them differently, as attempts to break up the progression and coherence of the overall narrative in order to twist representation in such a way that it yields a view of the great outdoors, they are spot on.

But narrative anamorphosis does not yet constitute the whole picture. Since such anamorphic narratives profess to provide access to the cognitively inaccessible, they are also what I would propose to call pseudo-paraleptic: paraleptic, because they showcase figures that have direct knowledge about spaces they have no cognitive access to; pseudo, because these figures are not entirely cut-off from the spaces in question as they avail themselves of different, purely aesthetic channels to gain their knowledge. ${ }^{14}$ Let us now zoom in on the travelogue's most significant instance of anamorphosis, the two accounts of Mariana and the Seeress, in order to trace how this anamorphic element helps in yielding a view of the great outdoors and why this yielding warrants to be designated as pseudo-paralepsis.

\section{Beyond the Limits of Representation}

The first of the two stories portrays the very short life of Mariana, introduced as Fuller's former schoolmate, a "provoking nonconformist" (53), "most rich in energy" with "power of excitement" (51), and a "very intellectual being" (59), but who, confined to the domestic sphere, ultimately withers away and dies. The "slight sketch" (51), as Fuller herself calls it, is introduced unceremoniously, with Fuller metaleptically recounting a chance meeting in Chicago with her former schoolmate's aunt, who breaks the news of Mariana's death to her. Like the Seeress, Mariana, too, is a "sleep-walker," her "restlessness" and "excitement" ever "increased by the restraints and 
narrow routine of the boarding school" she attends (52). Due to her unusual nature and comportment, Mariana is soon alienated from everyone else at the school and after several incidents, in which she is alternatively victim and perpetrator resulting in moral self-castigation and affective isolation, her "heart of stone [is] quite broken in her. The fiery life fallen from flame to coal" (57). It is only downhill from there: Mariana returns home and soon marries into a dull, unfulfilling life of domesticity, characterized by "the desolation of solitude" and the "repression of her finer powers" (59) by a husband "with little delicacy of sentiment" (59) and only interested in "business and the world" (59), expecting her to fit in with the superficial and "careless shining dames of society" (60). Living the life of a "solitary and wretched wife" (60), she falls ill and dies.

Fuller thus paints a grim picture of how the resources needed to tap the great outdoors, namely the very aesthetic and intellectual sensibilities displayed by Mariana, the very sensibilities her husband lacks, fully immersed in the world of economy (business) and appearances (shining dames) as he is, are recklessly wasted. By the same token, she emphasizes not only that but also how these resources could be kindled, fostered, and capitalized on: precisely by means of an adequate education focused on training and exercising these sensibilities. Fuller here emphatically employs the romantic discourse of aesthetic education (Beiser, Romantic 88-105), to which her own narrative is designed to contribute. The stories of Mariana and Hauffe constitute both discourses on and, qua instances of narrative anamorphosis, opportunities for the exercise of sensibility or intuitive reason.

Like Mariana, Hauffe, the Seeress of Prevorst, is a figure with acute, heightened sensibility. Wielding prophetic powers, she has direct access to the world of spirits: the "spirit of things, about which we have no perception, was sensible to her," Fuller writes (90). Her account of the Seeress draws on and indeed constitutes part-translation of a voluminous narrative by Justinus Kerner, a German physician specializing in mesmerism with a track record in the successful treatment of somnambulism..$^{15}$ In his report on the case, he tells us how he was called on to cure Hauffe from her bouts of somnambulism and what was then known as mesmeric trance and how he ultimately failed to do so, unable to prevent her premature and gruesome death. ${ }^{16}$ This might all sound rather curious by today's standards, but one should not forget that Kerner was an accomplished and reputed physician and that spiritism and spiritualism were the vogue of the day, so much so that Kerner and Hauffe were visited by a number of famous people hoping to gain insight into the world of spirit, Schleiermacher and Schelling among them. ${ }^{17}$ Fuller inserts the story of the Seeress after having conveyed her impressions of Wisconsin frontier life for several pages, deliberately casting Kerner's "vision of an exalted and sensitive existence" as being "in strong contrast with the [frontier] life around" her (77), which she had just criticized for its excessive instrumentalism and economism. 


\section{Ridvan Askin}

To make this point even more emphatically and in order to put her own thoughts on the issue into relief, she prefaces the translated extracts from Kerner's account with an allegorical dialogue between Good Sense, Old Church, Self-Poise (recognizably Emerson), and her alter ego-Fuller is explicit about this fact (78)-Free Hope. In Good Sense's impatience with Free Hope's interest in somnambulism, mesmeric trance, and the spirit world with which the dialogue begins-the injunction to "be completely natural, before we trouble ourselves with the supernatural" (78)—we can easily recognize the "life around her" (77) with its focus on the empirical here and now and its instrumental and economic attitude that Fuller decries time and again in her narrative. Unsurprisingly, Free Hope's response stresses that being completely natural precisely results in the revelation of the supernatural, something the instrumental empiricist necessarily misses out on: "The meaning of the flower uprooted in the ploughed field" completely eludes "the ploughman who does not look beyond [the field's] boundaries" and can only ever be apprehended by the "poet" and "dreamer" who "looks oftener to the sky than on the ground" (79).

Fuller's commonplace romantic equation of poet and dreamer in this passage helps her to emphasize both the visionary qualities of the poet and the creative aspects of dreaming. More importantly, it establishes a parallel between the figure of the poet and both Mariana and the Seeress, aligning the work of poetry with the two women's somnambulic visionary powers. This is very much in line with Kerner's essentially romantic understanding that "somnambules ... know from direct experience that behind the brutal realities of social and material existence there is a much larger, all-encompassing, and deeply meaningful life," which is expressed "through profound symbols and poetic language" (Hanegraaff, Esotericism 263). Such an understanding is part and parcel of what one could call the Romantics' fundamental existential aestheticism as outlined above and which Hanegraaff, with reference to the esoteric discourse that many of the Romantics including Fuller availed themselves of, describes in the following manner:

When our bodily senses shut down temporarily, and we descend into dream or somnambulic trance, our soul "wakes up" to the larger world whence it has come and where it really belongs. The rationalist, in contrast, is spiritually asleep. He lives in a state of artificial isolation from his own soul and its powers of perception, incapable of understanding the language of symbols and poetry. He naively believes that his brain and his senses show him all there is, never realizing that they are obstacles rather than reliable instruments for discovering the deeper "secrets of nature." Blind as he is to her spiritual dimensions, he can only dismiss belief in occult powers and supra-normal abilities as "superstition." Such abilities are, however, neither miraculous nor supernatural: they are natural human faculties, potentially available to 
us all. Hence, the remarkable feats of somnambules reveal the powers that are latent in humanity.

(Esotericism 263)

I think Hanegraaff draws too stark a contrast between rationalism and romantic aestheticism in this passage-the Romantics did not see themselves as rejecting rationalism but as complementing and completing it (see Beiser, Romantic 43-55). ${ }^{18}$ But it serves us well in pinpointing Fuller's romantic program and in further determining the thematic and structural importance of Mariana's and the Seeress's stories for Fuller's narrative.

That Kerner makes note of Hauffe's inclination to compose little poems in her states of somnambulism, something she is otherwise not prone to do, is an interesting detail in this context (Kerner, Die Seherin 76-78; 58-59), ${ }^{19}$ a fact that Fuller does not fail to mention in her text, even though she is keen to distinguish the Seeress's simple rhymes from true poetry (Fuller 92, 96). The Seeress is not a poet, after all-her creative and visionary powers are expressed in her prophetic states of somnambulic clairvoyance. Fuller's insistence on the much greater force of true poetry compared to "the simplest character" (96) of Hauffe's verse only serves to reinforce the parallel between the powers of poetry and those of prophetic somnambulism. Fuller runs together the creative principles of nature and poetry into one great principle of poiesis. Nature and poetry are presented as expressions of one and the same principle. This is why poetry-and by extension literature and art-is apt to disclose this very principle and why Fuller can hope to evoke the aesthetic vision of this principle in and through her own account.

Ultimately, Fuller casts literature as just as somnambulic as Mariana and the Seeress. In a sense, for Fuller literature is somnambulism, of which her own travelogue is but another instantiation: the inclusion of the stories of Mariana and the Seeress amounts to the travelogue's own somnambulic vision-its anamorphosis-by means of which Fuller wishes to open up her narrative to the realm of the great outdoors or absolute.

Having established her own affirmative stance vis-à-vis Kerner's and the Seeress's spiritualism by means of the brief allegorical exchange with the exemplary positions of empiricism (Good Sense) and dogmatism (Old Church), ${ }^{20}$ Fuller finally gives us a summary of and several pages of translated excerpts from Kerner's book. As with Mariana, Fuller stresses Hauffe's "intellectual nature" and "greater liveliness" compared to her peers in the time before her illness (84). Hauffe suffers severely, plagued by bouts of fever, spasms, prophetic dreams, and an almost continual state of mesmeric trance lasting for several years. Once it becomes clear that Hauffe cannot be cured, Kerner decides "to record ... the mental phenomena of such an almost disembodied life" (Fuller 89; Kerner, Die Seherin 73; 55), among which he lists a "sense of the spirit of metals, plants, animals, and men" (Fuller 90; Kerner, Die Seherin 75; 57), frequent out of body experiences (Fuller 91; Kerner, Die Seherin 76; 58), and "the powers of seeing, healing, 


\section{Ridvan Askin}

and poesy" developed in states of somnambulism (Fuller 93; Kerner, Die Seherin 78; 59).

For Fuller, the most important lesson to draw from Kerner's account of the Seeress is encapsulated in the subtitle of his book, which she translates as "Revelations concerning the inward life of man, and the projection of a world of spirits into ours" (78). Hauffe's peculiar illness serves as a testimony to "spiritual facts of high beauty, ... which cast light on the state of the soul after its separation from the body" (95) and to how the "floating belief of nations, always no doubt shadowing forth in its imperfect fashion the poetic facts with their scientific exposition, is found to grow up anew in a simple, but high-wrought nature" (98). ${ }^{21}$ Fuller thus emphasizes not only the fundamental spiritual nature of nature, but also that this spirituality is often expressed in and through simple minds-all it needs is a certain exalted and appropriately attuned sensibility. Indeed, Kerner wastes no time in formulating this program, directly addressing his readers when he begins his book on the Seeress with the following words:

As must every man who, isolating himself from the hurry and bustle of external life, to contemplate his inner self, you will feel, dear reader, that our inner and outer life are not only different, but often in flat contradiction of each other. What the outer life finds decorous, the inner frequently condemns; and in the midst of the world we are often disquieted by a still small voice that whispers us from within. If you examine further, you will feel that this external life is the dominion of the brain-the intellect which belongs to the world-whilst the inner life dwells in the region of the heart, within the sphere of sensitive life, in the sympathetic and ganglionic system. You will further feel, that by virtue of this inner life, mankind is bound up in an eternal connexion with nature, from which his imperfect external existence can only apparently release him.

$(\text { Seeress, } 5)^{22}$

By placing the stories of Mariana and the Seeress at the heart of the book Fuller manages both to convey what is wrong with settlement on the frontier as it shuts out rather than opens up to the great outdoors (the violent legacy of settler colonialism is a corollary to this shutting out) and what it would actually take to open up, namely the kind of acute sensibility evidenced by Mariana and the Seeress.

Crucially, this opening up is performed by the very narrative at hand as it makes space for the realm of the great outdoors at its very center. Interrupting her descriptions of and musings on the West, Fuller provides textual space for what she thinks is lacking on the frontier. In alignment with her rendition of Kerner's subtitle and program, she lets the spirit world project itself into the world of the narrative. In doing so, Summer on the Lakes emphasizes once more that this spirit world, that the great outdoors 
cannot be accessed rationally—rational thought in its calculations is precisely what impedes the access. Rather, one has to proceed aesthetically, by means of veritable visions. Fuller's travelogue most fully lives up to its professed aim to render "the poetic impression" of the West with the two accounts of Mariana and the Seeress as they provide an apposite rendering of the West's untapped potential even though — or rather, precisely because-they are not in any sense representations of the West.

This twisting and displacement of representation by means of representation is what I suggested to call the narrative's work of anamorphosis. In contrast to metaphor's representational dualism-something standing in for something else-anamorphosis goes hand in hand with expressive monism: one and the same thing is twisted and distorted such that it takes on a new shape. This reshaping, this perspectival distortion of representation, facilitates a new vision, the intuition of the great outdoors. Since in such expressive monism the space of the metaphysical subtends and inheres in the space of the physical, that is, it does not constitute a realm unto its own, expressive monism provides us with an ontologically continuous but epistemologically discontinuous world. Human knowledge is simply restricted to the limitations of the human cognitive apparatus. But this does not mean that the world at large can be reduced and made to shrink to fit these very limitations. On the contrary, the transexperiential great outdoors beyond representation is just as real as and infinitely larger than the space of human experience. If this is indeed the case, then narratives like Fuller's present us with a fourth option besides the "three types of spatial organization within narrative worlds" (552) that Sabine Buchholz and Manfred Jahn distinguish. Next to "texts that contain contiguous subspaces, where characters move freely from one space to the next, ... texts with discontinuous, ontologically distinct spaces that allow communication in exceptional circumstances only," and "texts with ontologically distinct spaces that do not allow communication, except through metalepsis" (552), we need to list texts with ontologically continuous but epistemologically discontinuous spaces that do not allow communication but where access from one space to the other can nevertheless be established by purely aesthetic means.

I take it that in Summer on the Lakes, Mariana and the Seeress personify precisely this kind of relation. They are both the narrative's most salient distortive element of anamorphosis and, by dint of their access to the cognitively inaccessible, its most explicit performance of pseudo-paralepsis. In a further twist, Fuller's travelogue portends to facilitate precisely such a performance for its readers. This, then, is how narratives of the absolute narrate the great outdoors: by means of pseudo-paraleptic anamorphosis.

\section{Coda}

Whatever one thinks about the metaphysical import of narratives such as Fuller's, whether one believes that they achieve what they set out to do 


\section{Ridvan Askin}

or whether one thinks that the entire elaborate metaphysical architecture they offer is but esoteric hocus-pocus, one cannot deny that they profess to perform the kind of work I have outlined throughout this essay, particularly when they contain figures like Mariana and the Seeress who exemplify this kind of performance. While one might very well reject the thought that these narratives themselves constitute cases of intuition by means of what I have called pseudo-paraleptic anamorphosis, that they actually succeed in narrating the great outdoors, it nevertheless remains the case that we need adequate vocabulary to describe such an enterprise. Minimally, this is what I hope to have contributed to.

\section{Notes}

1 I would like to thank Philipp Schweighauser and the editors for their helpful comments on earlier versions of this article.

2 For a resourceful and erudite discussion and renewal of the notion of the absolute, see Gunnar Hindrich's Das Absolute und das Subjekt.

3 While After Finitude might well be read as primarily an attack on transcendental philosophy, Meillassoux has since expanded his initial analysis ("Iteration" 12223, 132-33).

4 Much of what I say in this essay builds on and continues the work begun in my Narrative and Becoming.

5 Spinoza's famous distinction between natura naturans and natura naturata, where the latter is the expression of the former without constituting a realm unto its own is a particularly salient example of his expressionist immanentism: nature expresses itself. For a sustained discussion of Spinoza's expressionism, see Gilles Deleuze's Expressionism in Philosophy: Spinoza.

6 I do not have the space here to defend this view of Romanticism in any detail. But much of what I say on Romanticism's Platonism cum Spinozism, its prioritization of intuitive over discursive reason, and its efforts to synthesize idealism with realism is indebted to Frederick Beiser's invaluable work in his seminal monographs German Idealism and The Romantic Imperative. In a similar vein, see also Dalia Nassar's The Romantic Absolute. For discussions of the transcendentalists' transatlantic connections-they were all avid readers of English, German, and French romantic literature and philosophy, and Fuller was a pivotal figure in the dissemination of these ideas, whether as translator or the editor of the most important transcendentalist journal, The Dial-see, for example, the works by David Greenham, Samantha Harvey, and Charles Capper.

7 In the last two chapters of After Finitude, Meillassoux suggests that Cantorian transfinites provide the solution to this problem (see particularly 101-111). For a detailed discussion of Meillassoux's argument see Sergey Sistiaga's Das Prinzip vom Grund bei Kant und Meillassoux.

8 The reading of Summer on the Lakes presented here expands and elaborates on my brief discussion of Fuller's text in an essay for The Cambridge Companion to Literature and the Posthuman (Askin, "Objects").

9 Stephen Adams was one of the first to point out that Fuller's travelogue is deliberately designed to elude "conventional objective description." However, unlike Adams, I do not think that Fuller's strategy serves to recalibrate the focus "on the perceiver more than the objects perceived" (249). Fuller is not more interested in the subjective over the objective side of perception. Rather, her 
travelogue aims at the great outdoors beyond the representational subject-object dyad.

10 Adams (248), Susan Belasco Smith (xii), Casey Blanton (1), Michael Meyer (239), and Carl Thompson (11-12) all emphasize travel literature's essential looseness and malleability and what one might call its generic hybridity. Meyer also gives a short and informative overview of the genre's history (239-42).

11 Such at times laborious attunement to the powers of poiesis or creationlaborious precisely because it demands an unconditional letting-go-is a precondition of aesthetic experience in general, as Fuller makes clear in another passage:

But it was not so soon that I learned to appreciate the lake scenery; it was only after a daily and careless familiarity that I entered into its beauty, for nature always refuses to be seen by being stared at. Like Bonaparte, she discharges her face of all expression when she catches the eye of impertinent curiosity fixed on her. But he who has gone to sleep in childish ease on her lap, or leaned an aching brow upon her breast, seeking there comfort with full trust as from a mother, will see all a mother's beauty in the look she bends upon him.

12 Fuller deliberately contrasts Native Americans' aesthetic sensibility in attunement with the powers of nature with the settlers' destructive coarseness:

Seeing the traces of the Indians, who chose the most beautiful sites for their dwellings, and whose habits do not break in on that aspect of nature under which they were born, we feel as if they were the rightful lords of a beauty they forbore to deform. But most of these settlers do not see it at all; it breathes, it speaks in vain to those who are rushing into its sphere. Their progress is Gothic, not Roman, and their mode of cultivation will, in the course of twenty, perhaps ten, years, obliterate the natural expression of the country.

13 Of course, metaphors are also intrinsically representational: in a metaphor, something stands in for something else, at least if one follows traditional theories of metaphor, what Max Black in his seminal essay referred to as the "substitution view” (279). But cognitive and interactionist theories (like Black's) are equally based on relations of similarity and analogy and thus do not do away with representationalism. Seen this way, metaphors are not the best means to test the limits of representation anyway. In this context, it is also worth remembering that Jacques Lacan famously equated displacement-the term I have been using to designate the work performed by the narrative strategies in questionwith metonymy, precisely in contradistinction to the condensation of metaphor (Lacan, "The Instance"). As will become clear later on, the contiguity inherent in metonymy is indeed crucial for the kind of narrative performance I am delineating here.

14 In his typology of paraleptic narrators, Rüdiger Heinze glosses paralepsis as narrators' display of knowledge that "is temporally, spatially, or cognitively undisclosed to them" (279). Unsurprisingly, the term paralepsis ultimately derives from discussions of narratorial omniscience (280-82).

15 When he was asked to treat Hauffe in late 1826, Kerner was already well-known and an established expert on somnambulism, having published his widely read Geschichte zweyer Somnambülen: Nebst einigen andern Denkwürdigkeiten aus dem Gebiete der magischen Heilkunde und der Psychologie two years earlier. 


\section{Ridvan Askin}

16 Kerner's account of Hauffe's somnambulic and magnetic states and visions and his attempts to cure her-Hauffe even moved in with the Kerner householdfirmly established her as the spiritist $d u$ jour, creating the myth of and turning Hauffe into the infamous Seeress of Prevorst. Wouter Hanegraaff discusses this mythographic aspect of Kerner's narrative extensively in an essay on the topic ("A Woman Alone")-I would like to thank Susannah Crockford for alerting me to Hanegraaff's work.

17 A brief portrait of Kerner in the Deutsches Ärzteblatt, the official organ of the German Medical Association (Bundesärztekammer) and the National Association of Statutory Health Insurance Physicians (Kassenärztliche Bundesvereinigung), stresses his professional merits and conduct (Schott), something that Hanegraaff also emphasizes in his essay.

18 When in Fuller's travelogue Old Church decries "wild speculation and intemperate curiosity" (80) because it violates the limits of human finitude as imposed by God, Free Hope refutes this charge by replying that nothing violates this supposed imposition more than the dogmatic, unexamined, and ultimately rationally unfounded doctrines of the church, thus testifying to Fuller's adherence to the principles of rational thought. Like all Romantics, Fuller is not interested in doing away with rational, conceptual thought. Rather, she thinks it needs to be complemented by aesthetic, intuitive thought.

19 Here and throughout, references to Kerner's book are first to the German original, then to Catherine Crowe's abridged translation published in 1845 (in this passage, for example, Hauffe's poems are not reproduced in the English version)-in Summer on the Lakes, Fuller still thinks that Kerner's book "has not, probably, and may not be translated into other languages" (78), underestimating its appeal. Crowe is an interesting figure herself, bestknown for her 1848 bestseller The Night Side of Nature Or, Ghosts and Ghost Seers.

20 Self-Poise's injunction to seek spirit in one's own soul rather than in the world at large only serves as an occasion to distinguish her own, more expansive brand of transcendentalism from Emerson's, which Fuller thinks is too imposing and stifling in its unrelenting insistence on self-reliance (80-83).

21 While these passages might sound like they advocate a dualist world view, one should not forget that the Romantics immanentized the realm of spirit such that it inheres in matter. The Romantics' Spinozist monism holds that while there are different aspects to the world, there is just one world. Analytic philosophers accordingly call such a Spinoza-derived ontology dual-aspect monism (Atmanspacher 4.6, Stubenberg 5.4, 8.3).

22 In the original German, the passage reads as follows:

Wie jeder Mensch, der entfernt vom Treiben des äußern Lebens nur etwas in seinem Innern einkehrt, wirst auch du, lieber Leser, fühlen, daß in diesem ein ganz andres, dem Äußern meist widersprechendes Leben ist. Was das äußere Leben für geziemend findet, tadelt oft das innere, und oft geht bei Thaten des äußern ein stilles, beunruhigendes Gefühl, das nur aus dem innern Leben kommt, auf das äußere über. Fühlst du dann weiter nach, so fühlst du, daß dieses äußere Leben besonders mit den mechanischen Einrichtungen des Gehirnes, dem für die Welt berechnenden Verstande, zu thun hat, das innere Leben aber, in der Region des Herzens, dem sympathetischen und Gangliensysteme, in den Kreisen des Gefühllebens, seinen Sitz fand.

Noch weiter fühlst du, daß vermöge dieses innern Lebens der Mensch in einer alten ewigen Verbindung mit der Natur steht, von der ihn die einseitige Ausbildung des Gehirnlebens nur scheinbar freistellen kann.

(Kerner, Die Seherin 27) 


\section{References}

Adams, Stephen. “That Tidiness We Always Look for in Woman': Fuller's Summer on the Lakes and Romantic Aesthetics." Studies in the American Renaissance, 1987, pp. 247-264.

Askin, Ridvan. "Objects." The Cambridge Companion to Literature and the Posthuman, edited by Bruce Clarke and Manuela Rossini, Cambridge University Press, 2017, pp. 170-181.

Askin, Ridvan. Narrative and Becoming. Edinburgh University Press, 2016.

Atmanspacher, Harald. "Quantum Approaches to Consciousness." The Stanford Encyclopedia of Philosophy, edited by Edward N. Zalta, CSLI, 2015, https://pl ato.stanford.edu/entries/qt-consciousness/.

Beiser, Frederick C. German Idealism: The Struggle Against Subjectivism, 17811801. Harvard University Press, 2002.

Beiser, Frederick C. The Romantic Imperative: The Concept of Early German Romanticism. Harvard University Press, 2003.

Belasco Smith, Susan. "Introduction." Summer on the Lakes, in 1843, edited by Margaret Fuller, University of Illinois Press, 1991, pp. vii-xxii.

Black, Max. "Metaphor." Proceedings of the Aristotelian Society, vol. 55, 19541955, pp. 273-294.

Blanton, Casey. Travel Writing: The Self and the World. Routledge, 2002.

Buchholz, Sabine, and Manfred Jahn. "Space in Narrative." Routledge Encyclopedia of Narrative Theory, edited by David Herman, Manfred Jahn, and Marie-Laure Ryan, Routledge, 2010, pp. 551-554.

Capper, Charles. Margaret Fuller: An American Romantic Life. Oxford University Press, 1992, 2007.

Coleridge, Samuel Taylor. Coleridge's Poetry and Prose: Authoritative Texts, Criticism, edited by Nicholas Halmi, Paul Magnuson, and Raimonda Modiano, Norton, 2004.

Crowe, Catherine. The Night Side of Nature Or, Ghosts and Ghost Seers. Cambridge University Press, 2011.

Deleuze, Gilles, and Félix Guattari. What Is Philosophy? Translated by Graham Burchell and Hugh Tomlinson, Columbia University Press, 1994.

Deleuze, Gilles. Expressionism in Philosophy: Spinoza. Translated by Martin Joughin, Zone Books, 1992.

Fuller, Margaret. Summer on the Lakes, in 1843. University of Illinois Press, 1991.

Greenham, David. Emerson's Transatlantic Romanticism. Palgrave Macmillan, 2012.

Hanegraaff, Wouter J. “A Woman Alone: The Beatification of Friederike Hauffe née Wanner (1801-1829)." Women and Miracle Stories: A Multidisciplinary Exploration, edited by Anne-Marie Korte, Brill, 2001, pp. 211-247.

Hanegraaff, Wouter J. Esotericism and the Academy: Rejected Knowledge in Western Culture. Cambridge University Press, 2012.

Harvey, Samantha. Transatlantic Transcendentalism: Coleridge, Emerson, and Nature. Edinburgh University Press, 2013.

Heinze, Rüdiger. "Violations of Mimetic Epistemology in First-Person Narrative Fiction."Narrative, vol. 16, no. 3, 2008, pp. 279-297.

Hindrichs, Gunnar. Das Absolute und das Subjekt: Untersuchungen zum Verhältnis von Metaphysik und Nachmetaphysik. Klostermann, 2011. 


\section{Ridvan Askin}

Kant, Immanuel. Critique of the Power of Judgment. The Cambridge Works of Immanuel Kant. Translated by Paul Guyer and Eric Matthews, Cambridge University Press, 2002.

Kerner, Justinus. Die Seherin von Prevorst: Eröffnungen über das innere Leben des Menschen und über das Hereinragen einer Geisterwelt in die unsere. Reclam, 1938.

Kerner, Justinus. Geschichte zweyer Somnambülen: Nebst einigen andern Denkwürdigkeiten aus dem Gebiete der magischen Heilkunde und der Psychologie. G. Braun, 1824.

Kerner, Justinus. The Seeress of Prevorst: Being Revelations Concerning the Inner Life of Man, And the Inter-Diffusion of a World of Spirits in the One We Inhabit. Translated by Catherine Crowe, J. C. Moore, 1845.

Lacan, Jacques. "The Instance of the Letter in the Unconscious, or Reason since Freud." Ecrits: The First Complete Edition in English. Translated by Bruce Fink, Norton, 2002, pp. 412-444.

Levine, Caroline. Forms: Whole, Rhythm, Hierarchy, Network. Princeton University Press, 2015.

Lovejoy, Arthur O. "On the Discrimination of Romanticisms." PMLA, vol. 39, no. 2, 1924, pp. 229-253.

Meillassoux, Quentin. "Iteration, Reiteration, Repetition: A Speculative Analysis of the Sign Devoid of Meaning." Genealogies of Speculation: Materialism and Subjectivity since Poststructuralism, edited by Armen Avanessian and Suhail Malik. Translated by Robin Mackay and Moritz Gansen, Bloomsbury, 2016, pp. 117-197.

Meillassoux, Quentin. After Finitude: An Essay on the Necessity of Contingency. Translated by Ray Brassier, Continuum, 2009.

Meyer, Michael. "Romantic Travel Books." Handbook of British Romanticism, edited by Ralf Haekel, De Gruyter, 2017, pp. 237-255.

Nassar, Dalia. The Romantic Absolute: Being and Knowing in Early German Romantic Philosophy, 1795-1804. The University of Chicago Press, 2013.

Ryan, Marie-Laure. "Space." The Living Handbook of Narratology, edited by Hühn Peter, Hamburg University Press, 2014, https://www.lhn.uni-hamburg.de/ node/55/revisions/282/view.html.

Schelling, F. W. J. System of Transcendental Idealism. Translated by Peter Heath, University Press of Virginia, 1978.

Schott, Heinz. "Medizin und Magie im Geiste der Romantik." Deutsches Ärzteblatt, vol. 100, no. 4, 2003, pp. 173-176.

Sistiaga, Sergey David. Das Prinzip vom Grund bei Kant und Meillassoux: Über Anfangs- und Ungründe des nachmetaphysischen Denkens. Fink, 2018.

Stubenberg, Leopold. "Neutral Monism." The Stanford Encyclopedia of Philosophy, edited by Edward N. Zalta, CSLI, 2016, https://plato.stanford.edu/entries/neutr al-monism/.

Thompson, Carl. Travel Writing. Routledge, 2011. 


\title{
12 Inside the Great Outdoors
}

\section{A Complete and Unabridged Guide: With Travelogue, Bestiary, Judgement}

\author{
Line Henriksen
}

\section{DEDICATION}

This is a guide for those who have:

1. Secrets that eat them up from inside

2. Unrealistic expectations to the spacetime continuum

3. Unfinished business

4. A broken heart

If you have none of the above, this guide will provide them for you.

\section{FOREWORDS}

"Here! I'm in here!"

\section{INRODUCING YOU AND ME}

I know you think of space. You think of empty space a lot. This is understandable, of course. I don't judge. No, I don't write guides in order to judge people. I mean, if I did, where would I be work-wise, right? My guides on How to Travel with Umbrellas, A Vade Mecum to the Void and To Hell in a Handbasket never would have done as well as they did were I busy belittling my readers, now, would they? No no, call me old-fashioned, but I save my judgement for the right one.

So you think of space. You think of empty space a lot, and I watch you and don't judge, because you have Your Reasons, you have your longings for the Great Outdoors, you have your plans, you have your moods that stir the weather, that draw in large grey clouds like a blanket around the shoulders of the city. Your mood makes mist hiss in the alleyways and snow sprout in-between floorboards, and one day you find your coffee mug hovering. Not much, just enough to draw a perfectly round shadow, a small black hole underneath it. With two fingers on the handle, you carefully 


\section{Line Henriksen}

maneuver the mug back down. When next you look up, it has sunk halfway into the table. I don't think it's necessary for anyone to know more about you than this, and since words can never contain me, let's begin.

\section{BESTIARY}

You: Fictional body. A read body.

$M e$ : Beyond words. A reading cosmos. Weirdly realistic.

\section{CHAPTER 1}

\section{NEVER RECEIVED A CARD}

You're welcome, by the way. For all that I did, and all that I'm about to do. I don't expect gratitude. Words cannot contain my magnanimity anyway. Magnanimity. Now there's a word.

\section{CHAPTER 2}

\section{STEP ONE: A REPRESSED MEMORY}

"Here! In here!"

\section{CHAPTER 3 STEP TWO: AN ITCH}

Whenever you close a door, space presses in on you. It itches, like a woolly sweater, or that yellow dress you once loved but that is now too small, too snug, too old-fashioned.

\section{BESTIARY}

Yellow dress, possibly silk.

Long skirt, high sleeves.

Idiotically old-fashioned.

Dangerous when approached. Impossible to remove.

You pick at the sleeves, absentmindedly, until a thread comes undone, and you wind it around your finger-one time, two times, three times-and you have to tug at it to make it move.

Nothing.

You tug again, harder.

Nothing, nothing.

You tug again.

Something comes undone.

Something gives way.

Something's at the door. 
CHAPTER 4

STEP THREE: OPEN THE DOOR

There's nothing at the door. You linger a while and nothing changes. You don't see that, because you're a little dim. I say that lovingly.

CHAPTER 5

STEP FOUR: BEGIN AT ANY STEP YOU LIKE. THERE IS NO SPECIFIC ORDER TO THESE EVENTS

\section{CHAPTER 6}

\section{STEP FIVE: KNOCK KNOCK KNOCK}

You lock the bathroom door and sit on the toilet seat, lid down, legs up. You listen to the steady knock knock knock of nothing at the front door all night.

\section{CHAPTER 7}

\section{STEP SIX: THINKING OF YOU}

Space thinks of you. Empty space thinks of you a lot. I watch you both and don't judge, because you have Your Reasons, you have your longings for the Great Outdoors and the Vast Inside. You have your plans, you have your moods that stir the weather, that draw in nebulas like pearls around a lover's neck. You should talk more often. You should communicate better.

You don't even realize that there's another knocking, small and delicate. Coming from inside the bathroom. Coming from inside the toilet bowl.

\section{CHAPTER 8}

STEP SEVEN: REPEAT STEP ONE

"Here here!"

\section{CHAPTER 9}

\section{STEP EIGHT: SPIRITS}

Spirits communicate by knocking-once for yes, twice for no. This one is saying "maybe."

\section{CHAPTER 10}

\section{STEP NINE: FOLDINGS}

The city folds. Time to the right, space to the left, meet in the middle. Tug in the ends. 


\section{Line Henriksen}

\section{CHAPTER 11}

\section{STEP TEN: TAKE THE FLIPPER}

Feet down, breath held, lid up.

There's a tiny bird moving through the water in the toilet bowl.

"There's not much space!" it says. "Take my flipper!"

It's a penguin, you think, but you're wrong.

There's a live penguin in my loo! you think, but you're wrong.

I don't mean to keep pointing out your flaws, you just have so many.

\section{BESTIARY}

Great auk, not a penguin.

wonderful, incredibly beautiful

watches you with a curious expression.

A ghost.

\section{CHAPTER 12}

\section{STEP ELEVEN: FOLDINGS}

The kitchen folds. Pots to the left, kettle to the right, sink sinks. Ends like gossamer tentacles squirming from the flowerpots.

\section{CHAPTER 13}

\section{STEP TWELVE: A REPRESSED MEMORY}

You are flushed out, legs in the air, a swarm of water twirling around your kicking feet.

Gone.

\section{CHAPTER 14}

\section{STEP THIRTEEN: FOLDINGS}

The door folds. Right corner left; left corner center. Floor opening in the middle for a maelstrom the size of continents to peep through. The ends are here.

\section{BESTIARY}

The dead.

\section{CHAPTER 15 STEP FOURTEEN: INSIDE OUTDOORS}

You think of space. You think of empty space a lot, and the Great Auk watches you curiously and doesn't judge. It knows the Great Outdoors as well as the Vast Inside, because they're all the same thing, really, or so a philosopher Great Auk might say. Something dramatic, like: 
"It seeps."

or

"All of us are dead, flowing over the bridge."

or

"You should send more postcards. Writing opens the mind to the Great Outdoors."

That last one was me, I admit. Not the Great Auk.

\section{BESTIARY}

Text.

Empty spaces in between non-empty spaces.

A séance held by the dead calling the living.

\section{CHAPTER 16}

\section{STEP FIFTEEN: YOU HAVE ARRIVED}

The door unfolds. Right corner right; left corner left. Floor closing like the eyelid of a maelstrom the size of continents.

The kitchen unfolds. Pots back in the cupboards, kettle plugged in, sink pops back up. Gossamer tentacles withdraw from the flowerpots.

The city unfolds. The ends are undone.

You are where you want to be.

I wish you'd write more often. 


\section{Index}

Individual works referenced in-text can be found under the author's name.

absolute 201-205, 207-209, 213, 215 abstraction 166-167, 172, $174-175,178$

absurd 169

Acland, Henry 191

the actant 7, 169, 188

actor-network theory 6, 169

Adamson, Joni 4

addiction and recovery 192-194

aeonic insistence 183

aesthetic experience see experience aesthetics: and cognition 206; and database aesthetic 158 ; and description 54, 64; as dimension 8 ; and education 211 ; and existentialism 212-213; and expansion 186; as form 4, 12, 55 ; and geology 182 ; and literary styles 128; and the lithic 197; and materiality 65 ; and matter 36 ; and meaning-making 162; and models 14, 196; and ontologies 54, 57, 65; and rigor 188; romantic aestheticism 213; and sensibilities 211; and space 215 ; and spatiotemporality 185 ; and structures 134-135; as supra-human 187; tendency to aestheticize 79-81, 85 ; and using aesthetic channels to gain knowledge 210; and vision 207-208

affect: and affective states 21, 23, 30; and clothes 30,32; and cognition 31, 89-91; and description 95-96, 98; and empathy 27 ; and encounters of human and nonhuman 19, 23-24, $32,89-90,92$; and engagement 31, 89-90; and environmental affect 95; and the experience of the sublime 159; and human experience 166-167; and literary forms 19-20; and material affectivity 97 ; and mood 92-93, 96; as part of the literary form 19-20; and patterning 178; and reading 94-96, 100, 134; and relationality 93 ; and response 89-90, 92-95, 97-99; and short story structures 23-24, 26-28; and sympathy 21 ; and "things" 21,23 , 36; see also emotion

Affect Theory 6

affordances 19, 22, 31, 129, 170, 197 agency $45,48,54-55,166,169$ air $37,42-44,46-48$

Alaimo, Stacy 177

Alber, Jan 11

alchemy 176

alienation 22

Ameel, Lieven 4, 13, 71-72, 76;

"Reading Signs" 76

amplification 90, 92, 99-100

analepses/flashback 105, 117-118, 120

anamorphosis 210-211, 213, 215-216

anomaly, physical 168, 172

Anthropocene: and climate change 183-184; as concept 5, 14, 104, 125-127, 133-134, 182, 185; and the edge 129-131; and enumeration 162 ; as era $1-3,182$; and extinction 158; as indeterminate space 130-131; as lens for re-evaluation 37 ; as metanarrative 5 ; and narrative 48 , 127 ; and narrative theory 12 ; as organizing perspective 14,143 ; and poetics 196, 197; as point of view 


\section{Index}

125-127, 130, 134; and space 8; and time 184

anthropocentrism: and bias 10; in description 39; and disruption of 127,139 ; and experientiality 134 ; as focus 20; and frames 185; and lyricality 190; and narrative space 38 ; and narratology 36 ; and naturalism 59; and objects 54; as perspective $3,11,37-38,48,168$; and realisticanthropocentric fiction 52; and sexuality $171-172$

anthropomorphism 37, 44-46, 63, 108, $112,168,178-179$

anxiety and anxiousness 92, 96, 128-129, 136

art: and cognition 104; and ethics 188 ; and fusion of lithic and human 187-188; and intuition 203; and materiality 138; and mood 93; and poiesis 213; and the purpose of 182; and the sublime 208; and "true art" 60

Artevelde, Philip van 202

Askin, Ridvan 4, 9, 14-15

atmosphere 93

attractor (Latour) 127

attunement 206, 214

Atwood, Margaret 14, 105, 108-120; MaddAddam trilogy 108; Oryx and Crake 14, 105, 108-120

Auerbach, Eric 40-41, 47; Mimesis 40; and "namenlosen Geister" 47

auk see great auk (garefowl) autofiction 129

Azaryahu, Maoz 11, 38, 167-168

Bachelard, Gaston 9, 26, 128-131, 184; Air and Dreams 128-131; Poetics of Space 26

Bacigalupi, Paolo 13, 89, 92, 94-100; The Windup Girl 13, 89, 92, 94-100

Back to the Future 77-78, 137

Bakhtin, Mikhail 9, 184

Banfield, Ann 43; "Describing the Unobserved" 43

Barad, Karen 6, 91, 169; Meeting the Universe Halfway 169

Baroni, Raphaël 108, 120

baroque $73,80,83,86,152$

Barthes, Roland 39, 158

Baudelaire, Charles 75, 80, 84; Les Fleurs du mal 80; Le Spleen de Paris 80
Baumgarten, Alexander Gottlieb 206

Bear, Liza 191

Beiser, Frederick C. 206, 211, 213

Belasco Smith, Susan 210

Belknap, Robert 158

Bennett, Arnold 40

Bennett, Jane 3, 6-7, 13, 20-21, 27, 29, 36-38, 42, 44, 46, 53-56, 61, 64, 111; Influx and Efflux 7, 21, 27; "System and Things" 7, 36; Vibrant Matter 6-7, 36, 38, 44, 46, 54-55; Whitman's Sympathies 29

Berkeley, Bishop (George) 83

Bernaerts, Lars 171

bias 178

biology 187

black hole 168, 171

blending 173, 176, 179

blindness and insight 76, 86; see also vision

bodily feelings and experiences see feelings

Boscagli, Maurizia 37-38, 41; Stuff Theory 37-38

Bouton, Katherine 169

bracket: as a narrative operation (bracketing) 36-39, 42, 135; as a punctuation mark 41-42, 47

Bradbury, Malcolm 75

Bronk, William 135

Brooks, Peter 178; Reading for the Plot 178

Buchholz, Sabine 215

Buell, Lawrence 63; The Environmental Imagination 63

Bunting, Basil 185

Burke, Edmund 159; A Philosophical Enquiry into the Sublime and Beautiful 159

calamity form 136

call of the inorganic 154, 160

Calvino, Italo 184; Cosmicomics (Calvino) 184

campus novel 169

Caracciolo, Marco 4, 9-10, 14, 74, 91-94, 97, 105, 107-108, 117, 119; Experientiality 105, 108, 117; "Narrative Space" 107; "Perspectives" 92-94, 97; "The Reader's Virtual Body" 91

Carson, Rachel 128; Silent Spring 128

Casey, Edward S. 125

Cave, Terence 19-20 
caves 153-158, 160-162, 203

chains 168, 173-176, 179

Chakrabarty, Dipesh 2, 184

character 14, 167-169, 172-176, 179

Chernobyl 128, 141

Christianity, Protestant 152-153

chronotope 184

cities 79-80

Clark, Thomas A. 185

Clark, Timothy 2, 5, 130, 132, 139-140, 170; "Enlightenment Faith" (Clark) 140

Clarke, Michael Tavel 158-159; Scale in Literature and Culture (Clarke and Wittenberg) 151-152

climate: climate fiction 89-90, 94-95, 126, 129; and climate futures 125; and climate science 94 ; and humanity 2, 104, 196

climate change: as anthropogenic 104, 185; climate change fiction 76 , 104, 118-120; and the fold 13; and images 170-171; in narrative 85, 94, 109-110; and poetry 183; and scale 170; and time 183-184

clothes 20, 23-24, 28

coexisting worlds see fold

cognitive mapping 10

Cohen, Jeffrey 183

Cohen, Tom 2

Cole, Teju 13, 71-72, 74-77, 81-82, 85-86; Open City 13, 71, 74-77, 81-82, 85-86

Colebrook, Claire 6, 145

Coleridge, Samuel Taylor 206

collage 190-192, 196

Colombetti, Giovanna 21, 23, 90-92

Connor, Steven 46-47; The Matter of Air 46-47

Conrad, Joseph 95, 155; Heart of Darkness 95, 155

containers: and clothes as 20, 23-24, 32 ; and contemporary culture 126 ; as material spaces $20,22-23,28$, 33 ; and movement between 23; and narrative 32 ; and people as $26-27$, 29-30, 33

containment 12, 19-20, 25-26, 30-33

contemporary fiction 4, 13-14, 126, 129,158

continuity 7,42

Coole, Diana 91

Cornwall, Susannah 171

correspondence technique 75 cosmos 176,178

Cretaceous 188

Crist, Eileen 2, 5, 125, 127

criticism: ecocriticism 3-4, 45, 62-63, 91-92, 110-111, 125, 169; literary criticism 3, 8-9, 94, 104; as poststructuralist 155

Crutzen, Paul 1

Cthulhu 56

Culler, Jonathan 194; "Call” 194

culture 152-153, 161, 185

cupboards 22-23, 26

Danielewski, Mark 1-3, 5, 11; House of Leaves 1-3, 5, 11

Dante Alighieri 80; Divina Commedia 80

darkness 90, 100

death drive 154

De Bruyn, Ben 79-80

defamiliarization: and art 135, 182; and the lithic 187 ; and poetry 186 , 197-198; and scales of space-time 185; and sexuality 171, 173; and space 11 ; and spatial form 14

Defoe, Daniel 140; Robinson Crusoe 140

Deleuze, Gilles 13, 71-74, 77, 85-86, 203; The Fold: Leibniz and the Baroque 73-74; What Is 203

De Man, Paul 76, 84, 86

Dennerlein, Katrin 20

depression 92-93

description: and the affective experience 90, 99; and descriptive realism 40 (see also realism); the descriptive turn 53, 59,66; and dynamic descriptions 117,119 ; and ekphrastic description 135, 137; and enumeration 158; horizontal 64-65; horizontal and vertical 53, 56-58, 61-63, 65; and internal focalization 105,114 ; as literary 65 ; and materiality 49, 90; and narrativized description $13,25,45$; of nature 209; and New Naturalism 59-61; and the nonhuman 39, 47, 52-54, 58, 66; and opening up the great outdoors 203-204; and the "particular assemblage" of objects 54; and scale 157; and space 201 ; and spatiality $13,40-42,119$; and sustainable models 12; and the theory of description 3, 39, 53, 65; and weather phenomena 95 
desire 14, 168-169, 171, 173-174, 178-179

determinacy see indeterminacy

Didion, Joan 127

Dimock, Wai Chee 186

displacement 209-210, 215

Döblin, Alfred 13, 53, 58-61, 65-66; Berge Meere und Giganten (Mountain Seas and Giants) 53, 61-62, 66; "Berlin Program" 59-61;

"Committment to Naturalism"

("Bekenntnis zum Naturalismus")

60; "Futuristische Worttechnik"

60; Neue Naturalismus (New

Naturalism) 58-61, 65

dogmatism 213

Doležel, Lubomír 140

Downing, Lisa 83

DuPlessis, Rachel Blau 190

dynamic description see description dystopia 13, 94

Easterlin, Nancy 107

ecocriticism 3-4, 45, 62-63, 91-92, 110-111, 125, 169

ecology: and boundaries 185-186; and culture 140; and ecological awareness 194, 196-197; and ecological changes $2,13,182-183$

ecosickness (Houser) 79, 85

edge 129-132, 134, 137

Eichendorff, J. F. von 59; The Memoirs of a Good-for-Nothing (Aus dem Leben eines Taugenichts) 59

Einstein, Albert 184

Eliot, T.S. 46, 80, 187-188; The Waste Land 80, 188

ellipsis 82, 86; see also vision

embodiment: and cognition 93; and the embodied mind 31, 91; and empathy 20; as experience $33,90,99-100$, 157, 163, 170-172, 174-175, 177-178; and metaphors 25; and $\operatorname{mood} 99$; and the nonhuman 27, 172; and self-understanding 157; as space $5,92,168$

Emerson, Ralph Waldo 203, 212 emotion 21-22, 29-30, 91-94, 97, 156-157, 159, 169; see also affect empathy 12, 19-22, 24-28, 31-33

empiricism 59-61, 203, 205, 212-213

enactivism 90-92, 94, 99-100

enumeration 14, 152-153, 157-159, 162 environmental propping 92, 95-96, 99-100

environments: as actual 91, 95-96, 117, 129; and cognition 91; as experience 92-94, 117; as imaginary or imaginative $91,95-96,105,110$, 116; and interactions between human and environment 99-100, 110-111; and mood 91-92; and nonhuman environments 153; and the physical environment 90-91, 93-95, 100; as posthuman 104, 110, 113, 118; and sense-making 100, 160

Esquirol, Jean-Étienne Dominique 154 ethics 188, 196

exomodernism (McGurl) 188; see also modernism

expansion 186

experience: and the absolute 201-202; as aesthetic $91,135,137-138,143$, 157, 159, 203-205, 208, 215; as affective 15, 23, 25, 27; as afforded 32 ; as embodied 20; as everyday 152 , 178; and experiential traces 98; as human 15, 151, 157, 166, 201-202, 215; and hyperobjects 169-170; as lived 27; as spatial 3-5, 28-31, 151, 168, 174; as story-driven 105, 119 experientiality 96, 108, 117, 119, 134, 178, 204

expiation 194, 196

expressionism 202

extinction 141, 158

Faflak, Joel 161

fantastic-ecocentric fiction 52

fantasy and fantastic literature 52, 66

Fauconnier, Gilles 173, 176

feelings 89, 91-96, 98-100; see also emotion

feeling with 20, 23

feminism 177

fictionality 10, 138, 141

film theory 94

Finch, Jason 71

Finlay, Ian Hamilton 185

flora and fauna 201

Fludernik, Monika 108, 114, 116-117, 179, 184; "Description" 114; "Naturalizing" 116; Towards 108, 117 focalization: and affect 24, 26, 97-98; ambient 127; Anthropocenic 14, 125, 127-128, 131-132, 134, 136-140, 142, 144; and dehumanization 24; 
and internal focalizations $22,24,26$, 28-29, 32, 105, 114, 116, 120

fold $13,71-74,77,79-80,82-83$, $85-86$

folklore 153

Foote, Kenneth 11, 38, 167-168

form: as aesthetic 4, 12, 140; as cultural

152; as literary 4, 19-20, 131,

152-153, 158; in literary studies

178-179; as lithic 187; and narrative

1, 3-5; and New Formalism 4; as

spatial 3-4, 14, 28, 127, 167, 172,

175,184 ; as temporal 26

formalism 105, 167-168

fragmentation and approximation 192

frames and frameworks 10-12, 38, 82, 84, 170, 178-179, 183-185

Frank, Joseph 4, 9, 13, 167, 184

Freud, Sigmund 154, 160; Beyond the Pleasure Principle 154

frontier life 201, 204, 208-209, 211,214

Frost, Samantha 91

Fry, Roger 46

Fuller, Margaret 14-15, 201-215; Summer on the Lakes, in 1843 15, 201-202, 204-211, 213-215

future 13, 71-72, 75-77, 79-80, 85,185

gaps 55-56, 64, 190; see also hiccups Garrard, Greg 76

Gebauer, Carolin 4, 13-14, 115-116

Genette, Gérard 9, 38

genre: climate change fiction 76,104 , 118-120; contemporary fiction 4, 13-14, 126, 129, 158; and contemporary literature 136 ; and extinction fiction 158; and fantasy and fantastic 52, 66; and genre labels 126; horror fiction 52, 95; and "lab lit" 169, 172; narrative fiction 119; realistic fiction 52, 80; regional fiction 52; science fiction 13, 52-53, 57, 136, 169

geography $11,38,115$

geology: and description 62; and diallage 187 ; and eras $1,36,182$, 188, 190-191; and history 185, 188, 191-192; and humanity 1-2, 5, 127,182 ; and lyric 183 ; and modern geology 161; and narrative 184; and phenomena 14 ; and poetry 62 , 190-194, 196; and scale 184-185,
191, 194; and space-time 193; and spatiotemporality 190

geometry: and anthropomorphization 166; and character-systems 168 ; and patterns 172; and shapes 166-168, 179; and space-time 184; and spatiality 132-133, 171, 173; and structure 176

Gibbons, Alison 80

golden spike 125

Goodbody, Axel 63

Goulet, Andrea 84

Grady, Joseph E. 168

Graham, Dan 188

Great Acceleration 197

great auk (garefowl) 154, 156-157, 160, 162

the great outdoors (Meillassoux)

14-15, 201, 204, 208-211, 213-216

Greek chorus 47

Grusin, Richard 5-6, 169

Guattari, Félix 203; What Is 203 gut 177

Hammond, Meghan Marie 20-22, 27

Hamon, Philippe 39, 41, 47

Hampe, Beate 168

Hanegraaff, Wouter J. 212-213; Esotericism 212-213

Haraway, Donna 110

Harley, J. B. 155

Harman, Graham 8, 13, 53-56, 61, 64; Immaterialism: Objects and Social Theory 54; Weird Realism: Lovecraft and Philosophy 8, 54-56, 61; "The Well-Wrought Broken Hammer" 8, 55

Harrington, Ellen Burton 22

Hebel, Johann Peter 161

Heidegger, Martin 55-56

Heider, Fritz 166-168, 179

Heise, Ursula 71, 133, 136, 152, 158, 170-171; Imagining Extinction 152, 158; Sense of Place and Sense of Planet 170-171

Henriksen, Line 3-4, 15

Herman, David 10-11, 21-22, 107-108, 115, 183-184; Basic 107; Limits 183; "Modernist" 184; Narratology Beyond the Human 11; "Spatial Reference" 10; Story 107, 115

Herman, Luc 119

Hesse, Hermann 59; Peter Camenzind 59 
heterocosm 73

hiccups 84-86; see also gaps

Hillman, Brenda 14, 183, 185, 192-197; “A Geology” 183, 192-197; Practical Water 197

Hoffmann, E.T.A. 161-162; The Mines of Falun 162

Holocene 182

horizontal materialism see materialism

horror fiction 52, 95

Houser, Heather 79, 85

Hrushovski, Benjamin 74

Hühn, Peter 42; Event and Eventfulness 42

Hulme, T.E. 46

Hume, Kathryn 178

Husserl, Edmund 56

hyperobject (Morton) 125, 134, 169

hypotaxis 42

ice cream 170-171

idealism 83-85, 202-203

image: as change agent 140-141; and edge 129, 134; and possibility 143 ;

and reality 128, 131, 137-141, 144; as visual metaphor $170-171,173$

imagery 4, 58-60, 95, 97

image schemata 168

imagination: and the Anthropocene 125,127 ; as autonomous 130; and human 158; and imaginative environments 4; and imaginative possibility 196; and immersion 115-116; and limitations 186; and literary forms 131, 152; and the nonhuman 15, 159-160; and possible worlds 136; and reality 128, 131-132; and scale 158, 186; and spatiality 3,143 ; and spatiotemporality 158 ; and time 183

immaterialism 13, 54-58, 61, 64-66 immersion 105, 115-117, 134, 138 impermanence see permanence impossibility 11, 138, 141

indeterminacy 127, 129-131, 133, $135-136,139,141$

inertia 154

Ingarden, Roman 74, 86

inhuman 135

inorganic 154, 160-162

insight see blindness and insight intention 132, 138 interiority 27

intersubjectivity: and affectivity 22 , 33; as connection or engagement 27-30, 32; as constellation 179; as embodied 172-173, 176; and empathy 20 ; and models and metaphors for 168,175

intuition 202-209, 211, 215-216; see also sensibility

Iovino, Serenella 7-8, 44, 91-92, 100,111

irony $191,196-197$

isolation 19, 22, 26

itselfpomorphism (Morton) 45-46, 48

Jahn, Manfred 215

Jakobson, Roman 190

James, Erin 9, 115

Jameson, Fredric 184

Jamieson, Dale 2

Janet, Pierre 154

Jena Romantics 203

Johnson, Mark 20, 116, 170; Metaphors We Live By 170

Johns-Putra, Adeline 3

Joyce, James 7, 40; Finnegans Wake 7

Judd, Donald 135; "100 untitled works in mill aluminum" 135

Judd boxes 135-136, 138, 142

Jünger, Ernst 58, 66; Atlantische Fabrt 66; Myrdun 66

Kafka, Franz 7

Kalevala 152-153

Kankkunen, Sarianna 4, 10, 14

Kant, Immanuel 158-159, 201-203, 206, 209

Karlsson Pedersen, Michael see Pedersen, Michael Karlsson

Kästner, Erich 58; Fabian: The Story of a Moralist (Fabian. Die Geschichte eines Moralisten) 58

Kerner, Justinus 211-214; Die Seherin 213-214

Keunen, Bart 75

Kimmel, Michael 168

Kingsolver, Barbara 169; Flight Behavior 169

Kisch, Egon Erwin 58; The Wild Reporter (Der rasende Reporter) 58

Kittay, Jeffrey 9

knowledge 19, 25, 155, 189-191, 215

Kokot, Joanna 22 
Kortekallio, Kaisa 4, 13, 95-96

Kukkonen, Karin 91

Kuzmičová, Anežka 90-92, 95, 100; "Does It Matter" 90-92, 95; "Presence" 91

labyrinths $1,3,5,81,160$

Lakoff, George 20, 116, 170; Metaphors We Live By (Lakoff and Johnson) 170

landscapes 39-40, 52-54, 170, 192

larger-than-human 133

Lassila, Pertti 152-153

Latour, Bruno 3, 7, 126-127, 169

Lawrence, D.H. 21

Lee, Hermione 47

Lee, Vernon 21, 25; Beautiful 21; Laurus Nobilis 25

Lefebvre, Henri 184

Le Guin, Ursula K. 52, 66; "The Critics, the Monsters, and the Fantasists" 52

Lehmann, Wilhelm 13, 53, 58, 63-66; Bukolisches Tagebuch (Bucolic Diary) 53, 63-66

Lehto, Silene 152

Leibniz, Gottfried Wilhelm 71, 73, 83

Leopold, Aldo 63

Lerner, Ben 13-14, 71, 77-82, 85-86, 127-140, 142-144; 10:04 13-14, 71, 77-82, 85-86, 127-140, 142-144; Leaving the Atocha Station 143

Lessing, Gotthold 9

Lethem, Jonathan 13-14, 71, 81-86, 168-169, 171-176, 178-179; As She Climbed Across the Table 14, 168-169, 171-176, 178-179; Chronic City 13, 71, 81-86

Levine, Caroline 4, 11-12, 19-20, 26, 131, 178-179, 209; “The Enormity Effect" 12; Forms 4; "Model Thinking” 11; “Three Unresolved Debates" 11

Levinson, Marjorie 4, 178

lights 142-143

limitations: and human imagination 186; and knowledge 19, 25, 155; and overcoming 160; and representation 204-205, 207-209; and self 159

lists see enumeration

literary history 57, 59, 66

literature: as agent of change 6; and container forms 22; and Finnish literature 152; and literary genre 13, $52,57,65-66$; and literary history $57,59,66$; and literary studies 5, 151, 178; as medium 36; and the nonhuman 7 ; and objects 8 ; and planetary futures 71 ; and space 9-11

lithic 14, 182-184, 186-188, 191-194, 196-197

Loos, Adolf 58-59; "Ornament and Crime" ("Ornament und Verbrechen") 58

Lotman, Yuri M. 14, 105-108, 111, 113, 118-119; The Structure of the Artistic Text 105-107

Lovecraft, H-P. 8, 53-58, 62, 66; At the Mountains of Madness 53, 56-57, 62, 66

Lovejoy, Arthur 202

Lyotard, Jean-François 5

lyric 182, 186-188, 190-191, 196-197

MacDiarmid, Hugh 14, 183, 185-188, 196-197; “On A Raised Beach” 183, 186-188, 196

Maciunas, George 188

magical realism 169; see also realism

Mailer, Norman 127

Majander, Antti 152

Malm, Andreas 183-184

Mann, Thomas 40

Manovich, Lev 152

Mansfield, Katherine 12, 19, 20, 22-28, 31-33; "Miss Brill” 19, 22-28, 31-33

maps and mapping 115-116, 151, 155-156, 160-162

Marclay, Christian 137; The Clock 137

Marcussen, Marlene Karlsson 4, 11-13, 20

Mariana, alter ego for Margaret Fuller 204, 208-216

Marinetti, Filippo Tommaso 60

Marran, Christine 140

Martin, Kirsty 21, 25, 27

Martínez, Matías 107

materialism 13, 53-58, 61, 64-66, 177-178; see also New Materialism materiality: and affect 97-98; of art 138, 203; as challenge 157; and conceptions of the material 37-38, 42, 82, 91, 97, 99-100, 104, 117, 125; in container-spaces 20, 22; and description 49, 98; and embodiment 
90-91; and itselfpomorphizing 45-46, 48; and knowledge 190; and the little airs (Woolf) 13, 46-48; and modernism 46; and ontological contradictions 178; and perception 28, 30; and space 109-110

Matrix (movie) 83

Matz, Jesse 183, 196

McAllister, Brian J. 4, 11, 14

McEwan, Ian 169; Solar 169

McGrath, S. J. 160

McGurl, Mark 186, 188; "New” 188; "Posthuman" 186

McHale, Brian 72-74, 81, 86, 104, 120, 126, 190; Postmodernist Fiction 72, 81, 126

McKibben, Bill 132

meaning-making see sense-making measurements and measuring 156-157

Meillassoux, Quentin 15, 201-203, 209; After 201-202

melancholia and melancholy 154

memory 138

Menely, Tobias 126

mesmerism 211-213

metanarrative (Lyotard) 5, 208

metaphor: and anamorphosis 215; as anthropomorphic 13, 41, 44-46; as bridge strategy 179; of caves 162 ; of character-space and charactersystem 168; as cognitive tool 170 , 173; and container metaphors 32-33; and ellipsis 82; as embodied 25, 32; and engagement 197; of fictional and actual worlds 72-74; as frame 178-179; and immersion 90-91; and inner and outer worlds 77, 86; and intersubjectivity 175; and knowledge 191; of mines 160; and reading 134, 136-137; and the sensorium 92; and sexuality 177 ; and space 33, 73-74, 105, 130, 172, 209; and transportation 90-91, 137; as visual 170-171, 173; as a weird loop 194

metaphysics 201-202, 215-216; see also physics

mind-body 93

mineralogy 160-161

mines 160-161

miniaturization 130-132, 134

minimum departure principle 117

Minkowski, Hermann 184

mirrors 72-73, 135 modernism: as concept $19,21-22,40$, 46, 75, 196; and emotion 94; and exomodernism 188; in fiction and writing 22, 37, 40-41, 72, 81, 167; and Georgian modernism 40; and high modernism 80 ; in narrative 40 monadology 83

Monani, Salma 4

monism 84, 202, 215

Monk, Geraldine 185

monomania and monomaniacs 14 , 153-154, 156-157, 159, 161-162 mood 90, 92-96, 98-100

Morel, Eric 9

more-than-human: and affectivity 92, 98; as atmospheric forces 21, 27; and communicative transfers 27 ; and realities $13,36,38,48$; and realms of 92; and scale 171

Moretti, Franco 152

Morton, Timothy 3, 8, 36, 38, 45-46, 79, 82, 110, 125, 140, 169, 171, 185, 194; Dark Ecology 79, 82; Ecological Thought 110, 169; Ecology without Nature 38, 140; Humankind 171; Hyperobjects 169; "An Object-Oriented Defense of Poetry" 8, 36, 45

mourning 76

Muir, John 63

Müller-Salget, Klaus 61

music 24-25

narration: and affect 98; and description 41,53 ; as desire 178 ; as form 152; and ontological stability 71 ; as present-tense 115 ; and punctuation 42,48 ; and space 37 , 41-42, 44, 48, 132, 204; as temporal 13,42

narrative: abstraction 166; and affect 93, 95; and animal narratives 184; and catastrophe 13; and chronological markers 44; as concept $37,106,113$; and containment 20; of culture 138; and description 9, 38-39; and episodic tales 112, 119; and events 44, 90; and form 1, 3-5, 12, 36, 45, 48, 94, 104; fragmentation and approximation 192; and frames 10,12; and limits 15 ; and literary narrative 131; and materiality 97, 99; as modernist 13 ; 
and narratemes 108, 113; narrative in space 11; and narrative text 41 ; and narrative theory $5,8-9,11-12$, 37-38, 48, 184; and narrativity 107-108, 111, 120, 190-191; and representation 205; and scale 128 ; and space 10-11, 13-14, 38, 42, 71, 107, 118-119, 201, 204; and spatiality $10,12,125,168$; and structure $95,105,110,112$, 118-119, 127; and sustainability 12 ; as tool 36; and Western narrative 4 narratology: and aesthetics 158; and climate-change fiction 104-105; as cognitive 89-90; and description 39, 41; as feminist 94; and focalization 127; and narrative and description 36-39; and the nonhuman 40, 47; and possible worlds 134, 136; and space $9,11,13,107,204$; and time 13

Native Americans 201, 208

naturalism 13, 53, 58-62, 65-66 nature: and aesthetic experience 204; as autonomous 104, 110-113; as creative 203; and culture 172; and description of 209; and Finnish literature 152-153; and the great outdoors 204; and humanity 110-111, 153; and human nature 176; and landscape poetry 185 ; and natural history 63; and natural theology 152-153; and nature writing 52-53, 57, 63, 66, 153; as personified 109; and philosophy 160 ; and poetry 213 ; and the self 159 ; as spiritual 214; and the sublime 206, 208; as threat 109-110; and time and space 184

negation 139, 142-143

Neimanis, Astrida 90-92, 100

Nelles, William 184

Nersessian, Anahid 127, 136

nescience 127,136

nesting see precision nesting

Neue Naturalismus (New Naturalism) 58-61, 65

Neue Sachlichkeit (New Objectivity) 13, 52-53, 58-59, 61, 63, 65-66

New, William H. 26

New Formalism 4, 11, 131, 178

New Materialism 6-8, 21, 54-58, 8992, 99-100, 111; see also materialism
New York City 72, 74-77, 79-81, 84, 86

Niagara Falls 205-206, 208

Niedecker, Lorine 185

nineteenth century literature 84, 167

Noë, Alva 91

nonhuman: as active $5,7,13,37,42$; and agency 44, 91; and brackets 42; and environments $1,3,7,48,53,58$, $63,84,86$; as force $36-37,39,89$, 97, 100; and the human 39, 72; and the nonhuman turn 5-7, 169; and the nonhuman world 4, 7, 20-21, $27,53,58,62-63,84,134,156$; as perspectives 138-139

nonscalability 186

nothingness $172,175,178$

numerical sublime 152, 158

Nünning, Ansgar 119; "Towards a Typology, Poetics and History of Description in Fiction" 119

object-oriented ontology (OOO) see ontology

objects: as active 40, 49; and agency 12 ; and assemblages 64; and description 53-54; as negative or autonomous 55-57, 61, 64, 66; and New Naturalism 60; as nonhuman 38, 61, 64; and object and space 8, 37-38; and objectivity 61; and object-object connections 55, 57, 64-66; world of objects 53; as worlds apart 63-66; see also things

obsession 153-155, 157, 159-162

O'Gorman, Daniel 85

one-person world 140-141

ontology: and aesthetics 65; and biocentrism 63; and boundaries 182; as continuous 215; and contradictions 178; of edges 130; and empathy 33; of gaps 55-56; and the human 182, 197; and landscape poetry 187-188; and the lithic 197; and materialism 91; and the nonhuman 13, 54-56, 65,182 ; and object-oriented ontology (OOO) 6, 8, 36, 53-55, 65; and ontological instability $23,71-73$, 75-78, 81, 84-86, 192; and ontological slippage 194; and ontological status 83-84, 215

Oppermann, Serpil 7-8, 91-92, 100,111 


\section{Index}

O’Sullivan, Maggie 185

O'Sullivan, Simon 83

Oulanne, Laura 4, 10, 12

Paracelsus 176

parataxis $37,42-43,48$

Parisi, Luciana 172

Park, Robert 79

pastoralism and wilderness 153

patterns 167,178

Pedersen, Michael Karlsson 4, 10, 13

perception: and affectivity 31,92 , 100; and art 182; and dissolution of boundaries 79; and dynamic descriptions 119; and empathy 28; and focalization 135-136; and hyperobjects 169 ; and image 171 ; and imagination 127; and limits to 158-159; and materialism 56; and ontology 71 ; and route perspective 114, 116; and scale 169, 186

Perec, Georges 3, 49; La Vie mode d'emploi 49

permanence 154

personification 23-24, 109-110, 191 perspective: and affect 134; alien 135;

Anthropocene 126; and determinacy

127, 130; and ecology 183; and enumeration 158; as human 127 , 131-132, 138, 140, 142; as nonhuman 138-139; and shifts in 127

Phelan, James 182, 190

Phelps, Jennifer 194

phenomenology: and analyses 89 ; and approaches 20-21, 23, 27, 32, 99; and being 45; and enactive theory 91 , 99; and experience 185; of mood 96, 99; and narratives 183; of reading 90; and space $2-3,184$

philosophy 160

photography and photographs 77-79, 86

physics $168-169,171-172,174-178$, 209-210

Plato 202-203

plot: and affect 32; as bracketed 37, 41; and character 37-38; and charactersystems 174; and description 39, 47; and desire 178; and enumeration 158; and geometry 167, 179; as narrative element 106-107, 112-113, 119; plotless and plotted texts 106-108; and space 105, 107-108, $111,113,167-169$ poeticity 190

poetry: in 10:04 (Lerner) 142-143;

and calamity form 136; and defamiliarization 186; and ecopoetics 187; as form 190; and intertextual references 80 ; and landscape poetry 14, 182-183, 185-187, 192; and nature 152, 213; and the nonhuman 7,36 ; and the poetic image 128-129, 190-191; and poetic language 46; and poetics $26,187,192,196-197$; and scalar engagements 183 ; and segmentation 190; and sensibility 190; and somnambulism 213; and space 106; and stabilization 190-191, 196; as trans-modal 190; and travel writing 204; and visionary powers 212

poiesis 213

Polvinen, Merja 91, 94

polychronic frameworks 183

Pope, Alexander 52

possibility 142-143, 196

possible worlds $13,71-73,127,132$, 134, 136-138

post-anthropocentric theory 5-6, 8-9, 36-37, 40, 44-46, 48, 63

post-expressionism 58; see also Neue Sachlichkeit (New Objectivity)

posthuman: and climate change fiction 118, 120; as experience 100; posthuman comedy 186 ; and posthuman space $14,105,109-110$, 114, 117-119; and sensibilities 91; as world 110-111

postmodernism 72-73, 84, 126, 184

Pound, Ezra 46

Pre-Cambrian 188-190

precision nesting 186

presence of the reader 91; see also immersion

present tense 115

Prince, Gerald 11

probable 141

projection 115-116, 129, 132

proleptic mourning 76

pronominal reference 127-128, 138-139

Proust, Marcel 40

provisionally inaccessible frames 10-11; see also frames and frameworks pseudo-paraleptic anamorphosis 15 , 204, 210, 215-216

punctuation $13,37,41-44,48$ 
puns 194

Pynchon, Thomas 84

quest motif 117-118

Ratcliffe, Matthew 90, 92-93, 99-100 rationalism 160, 203, 206-207, 213 reading 90, 94-96, 100, 134, 136-138 realism: agential realism 6; descriptive realism 40; magical realism 169; and realistic fiction 52, 80 (see also genre); and speculative realism 6,8 ; weird realism 53, 56, 61 realities: and humanization of reality 37; human-nonhuman 179; and human realities 12 ; and mathematical realities 173; and more-thanhuman realities 13; and nonhuman realities $12,45,48,60,63,66$, 171-172; and physical reality 169 ; and physical structure of 176; and planetary realities 5, 80, 170; and post-anthropocentric reality 63 ; and realistic representations of 40 ; of things 55; and understanding reality through spatial relations 105-106 reality effect 158 reason 206-207

reciprocal amplification 90, 100; see also amplification regional fiction 52; see also genre relationality $46,48,55-57,63-65$ relations and relationships: and affect 21 ; of bodies in space 29,31 ; of culture and nature 185; of figure and ground 182; and hierarchy 73 , 111; of human and nonhuman 14, 21, 23-24, 140-142, 155, 158, 182, 185-186; humans and Anthropocene 144; of space and things 46; and spatial relations 167; and subjectobject 38-39, 52-53, 59-60, 156, 159, 162-163, 169, 182, 192, 194; of worlds 73-74, 86, 137

relativity 184

religion 154,184

representation 201-207, 209-210, 215

rhetoric 75, 138, 157, 182, 187, 190

Rhys, Jean 48; Good Morning, Midnight 48

Rich, Nathaniel 13; Odds Against Tomorrow 13

Richardson, Brian 111

Rigby, Kate 3
Robertson, Ritchie 62

Rochat, Philippe 20, 30

Rodriguez, David 4, 11, 14

Rohan, Kelly 93

Rohn, Jennifer 169

Rohrer, Tim 3, 170

romanticism 84, 160-161, 202-203, 206-207, 211-212

Ronda, Margaret 197

Ronen, Ruth 10-11, 38, 40, 53-54

Rough, Jennifer N. 93

route perspective 114-115

Ruskin, John 191

Ryan, Marie-Laure 11, 38-39, 71, 73, 86, 107, 112, 114-117, 134, 136-138, 167-168, 184, 209-210;

"Cognitive Maps" 114, 116; "Impossible Worlds" 71; Narrating Space/Spatializing Narrative 38, 167-168; Narrative 115; "On the Theoretical Foundations” 107; Possible Worlds 73, 117; "Toward a Definition of Narrative" 39

Ryan, Vanessa L. 159-160; The Physiological Sublime 159

Salmela, Markku 72

Sander, Gabriele 58

Sarraute, Nathalie 48; Tropismes 48

Sawyer, Stephen S. 185

scale: beyond the human 178 ; difference in scale and difference in kind 186; and ecocriticism 125; of events 48; and everyday events 40-41; and human-nonhuman 125, 128, 131-134, 153, 169-171, 174, 182, 184-185, 192-193; and human scale $5,128,140,151,171$, 179, 184, 188, 190, 194, 196-197; and interconnectedness 72, 80; and mismatches 151-152, 157-158; and models 14; and narrative 29; and nonhuman scale 14, 158, 160-162, 169, 171; and perception 169 , 186; and planetary scale 171,184 ; and representation 12; and scalar collisions 192; and scalar differences 13, 156-157; and scalar expansion 186, 196; and scale effects 130-131; and scale framing 170; and scaling $131,133,172,186$; and shifts in 159; and space-time 182-183, 188, 194, 196; as spatial 2-3; as temporal 135,184 
Schäfer, Hans Dieter 58;

"Naturdichtung und Neue

Sachlichkeit" 58; Wilhelm

Lehmann 58

Scheffel, Michael 107

Schelling, F. W. J. von 160, 203, 211

Schlegel brothers 203

Schleirmacher, F. 211

Schneider, Ralf 116

Schopenhauer, Arthur 130-131

science: and alchemy 176; climate science 94 ; cognitive science 10 ; and enumeration 158; and fiction's engagement with 178-179; and "lab lit" 169; and metaphor 171, 173; and nescience 127, 136; physics 168-169, 171-172, 174-178, 209-210; science of semiotics 136; and science writing 127; and scientists 169,172

science fiction 13, 52-53, 57, 136, 169 seasonal affective disorder 90, 93, 95 segmentation or segmentivity 190-191 semantics 105-108, 113, 119, 167, 190, 194

Semino, Elena 173

sense-making 100, 132, 160, 162, 170,190

sensibility 190, 206-208, 211, 214; see also intuition

sensorium 92; see also feelings

separation and alienation 22

setting 10, 38-42, 47-48, 107, 110, 186-187

settlers and settler life 201, 208-209, 211,214

Severs, Jeffrey 85

sexuality 171, 174, 176-177, 179

Sharp, Willoughby 191

Sheehan, Paul 47

Shklovsky, Viktor 182, 185, 187; “Art as Technique" 182

short story 12, 22-23, 33

similes 13, 41, 44-45, 193

Simmel, Marianne 166-168, 179

Simonetti, Paolo 84

simulation 83-84

Skinner, Jonathan 192

sleep-walking see somnambulism

Smith, Robert Rowland 154

Smithson, Robert 14, 183, 185 , 188-192, 196-197; "Sedimentation"

191-192; "Strata” 183, 188-192, 197 social sciences 5 solipsism 20, 27, 32

Solon, Olivia 83

somnambulism 204, 210-214

soullessness (Seellosigkeit) and soul carrier (Seelenträger) 60-61

space: as active or dynamic 40-41, 44, 47-49; and aesthetics 143; and the Anthropocene 126-127; and anthropocentrism 14, 138; and anxiety 136 ; and character 14,41 ; and clothes 19,23; and cupboards 22-23, 26; and description 9, 42; as diegetic 107, 113, 116-117; as experiential 204; and fold 82-83; and form 4-5; and geometry 132-133, 171; and imaginative space 173 ; as indeterminate 130 , 139; and intention 132, 138; and literature 7, 9-10; as material 19, 33; and metaphysical space 201202; as models 20,106, 137; and movement 23, 27-28, 37, 43, 48; and narration $37,41,42,44,46$, 48; and narrative 11, 13-14, 38-39, $105,108,168$; and narrative theory 9-10; and objects 7, 29, 38, 46; and organization 215; and orientation 116, 119; and patterns 166-168, 172, 179; and phenomenology 2, 5 ; as physical and imagined 1 ; and possibility 90,96 ; as posthuman 104; probable and possible spaces 127-128, 132, 140; and reason 204; and representation 115; and scale 3 ; and semantics 116; semantics of space $105-108,113,119$; as setting 37, 48; and structure 105, 107-108, 110-111, 113, 116-119; as symbolic 105, 108, 110-111, 113, 118-119; and symmetry 176 ; and text $10-11$; and time 14, 104, 169, 184-185, 188, 190, 197

space shuttles 137

space-time 183-187, 190, 192-194, 196-197

spacing in poetry 190; see also segmentation or segmentivity spatial expressions 209-210 spatial forms see form spatiality see space spatial metaphor see metaphor spatiotemporality 158, 183-186, 196-197 
species extinction 158

speculative realism 6,8

speleologists 151,162

spelunca aevi 161-162

Spinoza 202

spiritism and spiritualism 211, 213-214

spirituality 47, 59-61

spirit world 212, 214-215

storms 13; see also weather

storyworld: of climate-change fiction

104; and connection 33; and

containers 32 ; and the edge of fiction

129; and embodiment 27; and the

fold 73-75, 77, 79-80, 86; and

material features 26 ; and narrative

10, 108; and ontology 71, 76; and

possible worlds approach 136 ; as

posthuman 105, 110-111, 113-114,

117; and route perspective 114-115;

shared storyworlds 32 ; and spaces

$38,72,105,108,118,174$; and

stability $14,71,76,78$

stratigraphy 188, 190-193, 196

structuralism 107

subject: as anthropocentric 171; and

consciousness 40; and experience 93,

158-159; as externalized 60; and

indeterminacy 41 ; and subjectivism

59; and subject-object relationship

38-39, 52-53, 59-60, 156, 159,

162-163, 169, 182, 192, 194

subjectivity 36-37, 58, 61, 158-159, 177-178

sublime 152-153, 158-160, 163, 203-209

supernatural 10-11

symmetry $176-178$

sympathy 19-21, 26-27, 29, 33, 159

Tarkiainen, Viljo 152

Tarlo, Harriet 185

tatsachenphantasie (factual imagination) 59

Taylor, Henry 202-203

Taylor, Jesse Oak 126

Taylor, Matthew A. 139

teleology 112-113, 119

tellability 105, 108, 119-120, 178

temporality: and Anthropocene as epoch 125, 130; and co-existence 77,80 ; as human 185 ; and the lithic 184; and logic 108, 112; in narration 40, 42; and narrative 44, 107-108,
112, 137; and narratology 36; and nonhuman 71; and planes of meaning $77,80,85-86$; and poetry 183 ;

as prehuman or inhuman 57; and structure 48, 112, 141-142; and time 14, 104, 169, 171, 183-184; and underground temporality 161

things: and thing-assemblages

54-55; and thing-dialogue 44; and thing-power 7, 37-38; and thingrelationality 54-55; see also objects

Thompson, Evan 90-91

Thoreau, H. D. 7, 63

thought experiment 129

time see under temporality

time and space $171,182-184$

time-work 183, 196

Titchener, Edward B. 21

Tolkien, J. R. R. 66; Lord of the Rings

(Tolkien) 66

topoi 106, 137

topology 105-107, 110, 115-116, 119

transcendentalists 203

transcorporeality 177

transhumanism 92

travel narrative 14-15, 201, 203-204, 208-209

travel writing 4, 201, 204

Trexler, Adam 3, 104

triangles $168,175,177-179$

truth value 158

Tsing, Anna 186

Turner, Mark 173, 176

typography 1,3

uncanny 13, 162, 194, 197

unheimlich 1

unnatural 11

unreal city 80

Updike, John 166-168; "Problems"

(Updike) 166-168

urbanization 153

urban spaces $58,71-72,75-77,79,81$, 85,138

urban studies 13, 71

Varela, Fransisco 91

Vermeulen, Pieter 5

Verronen, Marrit 14, 151-162;

Keihäslintu (The Spearbird)

153-154, 156, 160-162;

Luolavuodet ("The Cave Years")

151, 153-155, 157-158, 160-162; 
Sukupuutto ("Extinction") in

Keibäslintu (The Spearbird) 153; Villi lintu ("Wild bird") in Keihäslintu

(The Spearbird) 153

vertical and horizontal gaps 55-56, 64

vertical immaterialism see

immaterialism

Vervaeck, Bart 119

vision 71, 75-79, 81-86, 186, 212-213,

215; see also blindness and insight

Warhol, Robyn 92, 94, 99

weather: and affect 96, 98; as catastrophic 13; and descriptions of 95; and feelings 89, 93-94; and fog 81, 84; and heat 97-98; and moods 92-93, 96, 99-100; as seasonal 97; and sensibility 79; and Southern Finland 89-90, 94-95, 100; as threat 71, 76-78

Weatherill, Rob 154

weird realism 53, 56, 61

Weisman, Alan 14, 127-129, 132-134, 136-144; "Art Beyond Us" (in The World Without Us) 138; The World Without Us 14, 127-129, 132-134, 136-144

Westphal, Bertrand 73; Geocriticism 73

Whitman, Walt 7, 20, 80, 143; Specimen Days 143

wilderness 110-111, 152-153

Wilson, Elizabeth 177

winter 90, 92

Winterson, Jeanette 14, 168-169, 171, 175-179; Gut Symmetries 14, 168-169, 171, 175-179 withdrawnness 8

Wittenberg, David 151-152, 158-159; Scale in Literature and Culture 151-152

Woelert, Peter 3-4, 170

Wolf, Werner 107-108, 112, 117, 119; "Description" 112, 117, 119; "Narrative" 107

Wölfflin, Heinrich 86

Woloch, Alex 14, 167-168, 179; The

One Vs. the Many 167

women 201, 208

Woolf, Virginia 12-13, 20-21, 27-29, 31-33, 37, 40-48; Between the Acts 41; Jacob's Room 41; "The Lighthouse" (in To the Lighthouse) 40; "Modern Fiction" 40; Mrs. Dalloway 27, 29, 32, 41; "The New Dress" 19, 27-29, 31-33; "Time Passes" (in To the Lighthouse) 13, 37, 40-48; To the Lighthouse 13, 37, 40-41; The Waves 40-41, 43, 48; "The Window" (in To the Lighthouse) 40

world of objects 53

Wychoff, Jerome 197; Our Changing Earth through the Ages 197

Yale French Studies 3, 9, 39

Yusoff, Kathryn 127

Zahavi, Dan 20, 30

Ziolkowski, Theodore 160-162

Zola, Émile 59

Zoran, Gabriel 9-10

Zuylen, Marina van 154 